\title{
Transformações Geométricas na formação inicial e continuada de professores de Matemática: atividades investigativas envolvendo reflexões por retas e GeoGebra
}

\author{
Herbert Wesley Azevedo
}

Dissertação apresentada ao

Instituto de Matemática e Estatística

da Universidade de São Paulo

para a obtenção do título de

Mestre em Ciências

Programa: Mestrado Profissional em Ensino de Matemática

Orientadora: Prof. ${ }^{\underline{a}}$ Dr. ${ }^{\underline{a}}$ Rosa Maria dos Santos Barreiro Chaves 
Transformações Geométricas na formação

inicial e continuada de

professores de Matemática:

atividades investigativas envolvendo

reflexões por retas e GeoGebra

Herbert Wesley Azevedo

São Paulo, novembro de 2016 


\section{Transformações Geométricas na formação \\ inicial e continuada de \\ professores de Matemática: \\ atividades investigativas envolvendo \\ reflexões por retas e GeoGebra}

Esta é a versão corrigida da dissertação elaborada pelo candidato Herbert Wesley Azevedo, tal como submetida à Comissão Julgadora.

Comissão Julgadora:

- Prof. ${ }^{a}$. Dr. ${ }^{\text {a }}$ Rosa Maria dos Santos Barreiro Chaves (Presidente) - IME - USP

- Prof. Dr. Márcio Fabiano da Silva - UFABC

- Prof.. . Dr. ${ }^{a}$ Ana Paula Jahn - IME - USP 


\section{Agradecimentos}

\section{Agradeço ao Senhor Deus:}

Por ter me concedido cada dia e a oportunidade de realizar mais um trabalho. Agradeço a Ele por ter dado paciência aos meus pais Hermínio e lleide, por serem verdadeiras referências de sabedoria.

Por meus irmãos Hely e Hernani e também a Amanda e ao Carlos pelas alegrias, ideias, ajudas e companhia em todo tempo. Por meu grande amigo Otavio Ushida, pela preocupação, pela amizade e lealdade, por mostrar novas perspectivas e sempre arranjar tempo para boas conversas.

Pela professora Rosa Chaves, minha orientadora, por sua imensa paciência, por suas orientações e correções, por não desistir de mim e sempre estar ao meu lado nessa caminhada. Ela é um presente do Senhor, uma orientadora, uma professora e uma amiga.

Pela professora lole Druck, que já na graduação, sem saber, me ajudou com uma simples frase antes de eu começar a fazer uma prova, palavras que nunca vou esquecer. Já no mestrado, percebi seu esforço, carinho e dedicação por cada aluno do MPEM.

Pela professora Ana e pelo professor Márcio, por suas correções e sugestões, que contribuem sempre para aperfeiçoar todos os seus alunos.

Pelas professoras Marta Salermo, Cristina Cerri, Cláudia Cueva e pelo professor Francisco Rui, sem eles e suas recomendações este trabalho não existiria.

Pelo professor Marcos Magalhães, por sua preocupação com os alunos de Licenciatura em Matemática. Em uma simples conversa, chegando ao IME USP pela manhã, sem saber, me incentivou a continuar.

Pelas professoras Cristina Bonomi e Barbara Corominas que me mostraram, através de suas condutas, a dedicação, a paciência e o compromisso com seus alunos.

Pelos participantes que contribuíram para esse trabalho e pelos professores e funcionários do CAEM e do ENEM.

Pelos colegas do Mestrado, em especial Caio Moura, Caio Cesar, Wanessa Trevisan, Fabiana, Débora Cona, Marcos Alves, Carlos Henrique e Oswaldo, verdadeiros gigantes que desde a Graduação me ajudaram com suas brilhantes ideias. Agradeço pelos colegas do MPEM que também contribuíram para a realização deste trabalho.

Pelos irmãos da Igreja Batista em Jardim Jaraguá, que sempre me apoiaram nessa caminhada. Pelo amigo Eliel Leão, por também me ajudar em momentos difíceis.

Pela Viviane Maia, que já na reta final, confiou em mim e esteve ao meu lado nesta conquista. 
Buscai ao Senhor enquanto se pode achar, invocai-o enquanto está perto.

Deixe o perverso o seu caminho, o iníquo seus pensamentos;

converta-se ao Senhor, que se compadecerá dele, e volte-se para o nosso Deus, porque é rico em perdoar.

Bíblia Sagrada: Livro de Isaías, capítulo 55, versículos 6 e 7. 


\section{Resumo}

AZEVEDO, H. W. Transformações Geométricas na formação inicial e continuada de professores de Matemática: atividades investigativas envolvendo reflexões por retas e GeoGebra. 2016. 177 f. Dissertação (Mestrado) - Instituto de Matemática e Estatística, Universidade de São Paulo, São Paulo, 2016.

O estudo das Transformações Geométricas do plano, mais particularmente das reflexões por retas, é recomendado em documentos oficiais que direcionam o ensino em nosso no país. Seu estudo é recomendado, dentre outros motivos, pelo seu grande auxílio na resolução de problemas e também pelas possibilidades de associação com outros assuntos de fundamental importância em Matemática como, por exemplo, a congruência de triângulos. Nestes documentos oficiais que balizam a Educação Básica, também é recomendada a implementação de outras metodologias em sala de aula. Na presente pesquisa, associamos essas duas recomendações ao trabalharmos o tópico reflexão por retas por meio de uma sequência de atividades, baseadas na metodologia da Investigação Matemática. Aplicamos essa sequência a dois grupos de professores de Matemática e a um grupo de estudantes de Licenciatura em Matemática. As produções feitas, por eles, nos cadernos de respostas e no software GeoGebra foram analisadas de acordo com a Teoria das Representações Semióticas, de Raymond Duval. Os resultados apontaram que as atividades investigativas em conjunto com o software auxiliaram na resolução dos problemas propostos. Este trabalho indica mais uma alternativa para os professores abordarem o tema reflexão por retas em suas aulas e esperamos estar, também, contribuindo para a formação inicial e continuada de docentes em Matemática.

Palavras-chave: Reflexões por retas. Investigação matemática. GeoGebra. Formação inicial e continuada de professores de Matemática. 


\section{Abstract}

AZEVEDO, H. W. Geometric Transformations in initial and continuing education of mathematics teachers: investigative activities involving reflections in a line and GeoGebra. 2016. $177 \mathrm{f}$. Thesis (MA) - Institute of Mathematics and Statistics, University of São Paulo, São Paulo, 2016.

The study of Geometric Transformations of the plane and, more particularly, reflections in a line, is recommended in official documents of the education in our country. It is recommended, among other reasons, due to its great help in solving problems and also by the possibilities of association with other matters of fundamental importance in mathematics like, as an example, the congruence of triangles. In those official documents that guide the Basic Education, is also recommended the implementation of other methods in classrooms. In this research, we associate these two recommendations in order to work with reflections in a line through a sequence of activities based on the methodology called Mathematics Investigation. We applied the sequence of activities in two groups of mathematics teachers and a group of undergraduate students in Mathematics. The productions made by them in the notebook answers and in the GeoGebra software were analyzed according to the Theory of Semiotic Representations, developed by Raymond Duval. The results showed that the investigative activities, together with the software, helped partially to solve the proposed problems. This work indicates one more alternative for teachers to address the topic reflections in a line in their classes and we hope to be also contributing to the initial and continued education of mathematics teachers.

Keywords: Reflections in a line. Mathematics investigation. GeoGebra. Initial and continuing education of mathematics teachers. 


\section{Sumário}

Lista de Figuras ................................................................................ vii

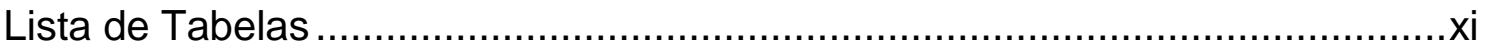

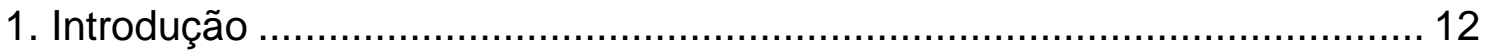

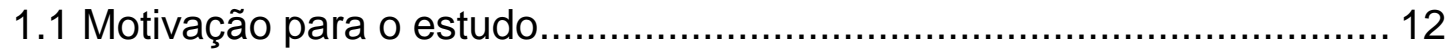

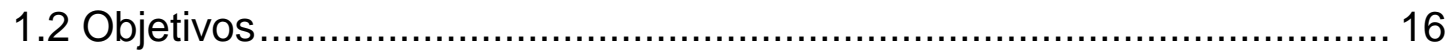

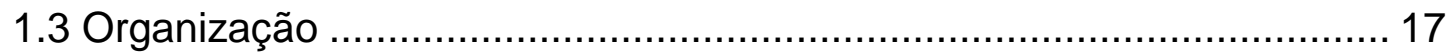

2. O estudo das Transformações Geométricas nos PCN, PNLD e no Ensino

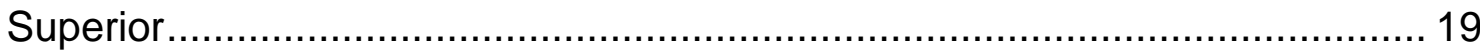

2.1 Parâmetros Curriculares Nacionais do Terceiro e Quarto ciclos do Ensino

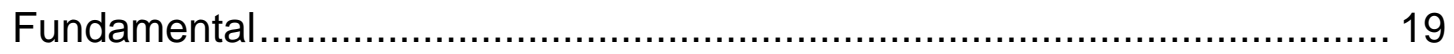

2.2 Parâmetros Curriculares Nacionais do Ensino Médio.............................. 24

2.3 Reflexões por Retas: conceitos básicos .............................................. 27

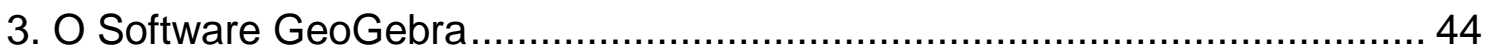

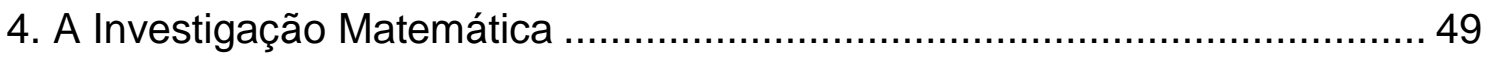

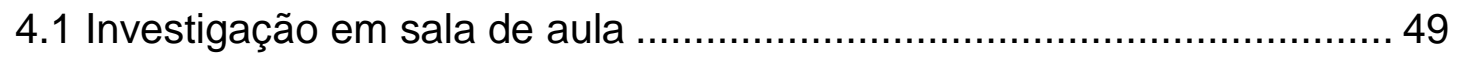

4.2 Características das Investigações Matemáticas .................................... 53

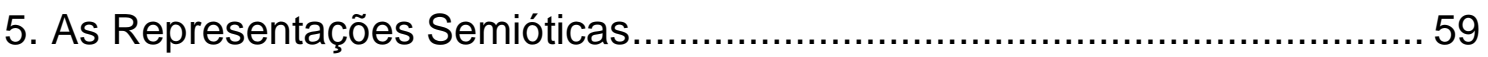

6. Detalhamento das atividades e análise dos resultados............................... 71

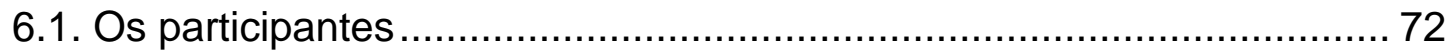

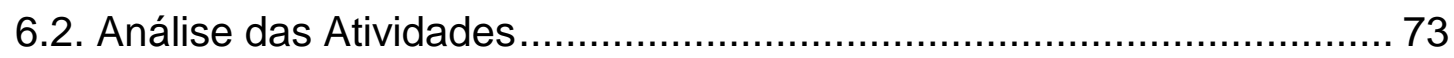

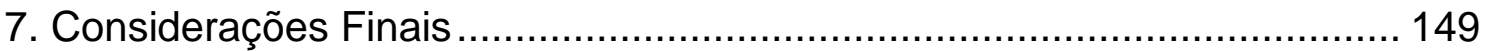

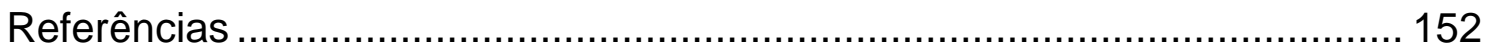

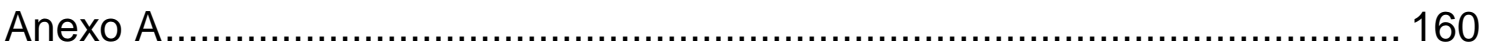

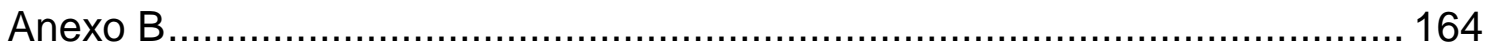

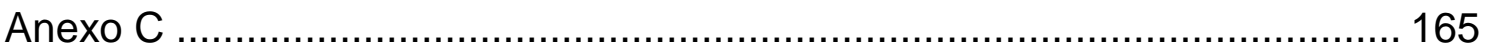




\section{Lista de Figuras}

Figura 1: Solução Atividade 6 ....................................................... 14

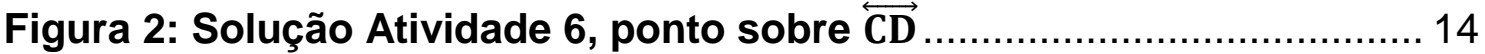

Figura 3: Reflexão do ponto $\mathrm{P}$ pela reta $\mathrm{m}$........................................... 30

Figura 4: Reflexão dos pontos $\mathbf{P}$ e $\mathbf{Q}$ pela reta $\mathbf{m}$.................................... 31

Figura 5: Translação de um ponto por um vetor ..................................... 32

Figura 6: Exemplo de reflexão por duas retas paralelas ......................... 32

Figura 7: Reflexão por duas retas paralelas dos pontos A e C .................. 33

Figura 8: Reflexão por duas retas paralelas do ponto B ......................... 33

Figura 9: Exemplo de reflexão do ponto $P$ por duas retas paralelas......... 34

Figura 10: Existência de duas retas paralelas à uma reta $\mathrm{m}$ dada............. 34

Figura 11: Composta de reflexões por três retas paralelas....................... 35

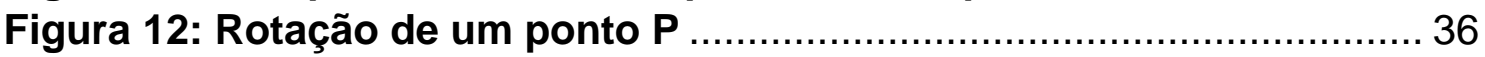

Figura 13: Reflexão por duas retas concorrentes .................................. 36

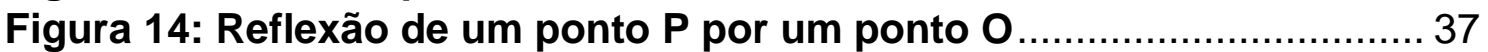

Figura 15: Existência das retas $r$ e s concorrentes com $\mathbf{m}$ no ponto 0 .... 38

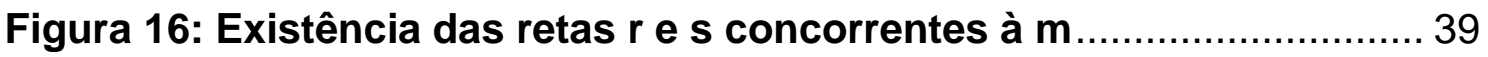

Figura 17: Reflexão compostas por três retas concorrentes ..................... 39

Figura 18: Resultado da composta de três reflexões ............................. 40

Figura 19: Composta de reflexões de três retas concorrentes ................. 41

Figura 20: Intersecção entre as retas t e m no ponto $A$........................... 41

Figura 21: Reflexão transladada ..................................................... 42

Figura 22: Reflexão por reta e ponto .................................................... 42

Figura 23: Reflexão transladada dados reta e ponto ............................. 43

Figura 24: Tela principal do GeoGebra ......................................... 45

Figura 25: Janelas do GeoGebra .................................................... 46

Figura 26: Ícones na janela principal do GeoGebra .............................. 46

Figura 27: Exemplo de tratamento..................................................... 61

Figura 28: Diferença entre figura e desenho..................................... 65

Figura 29: Desconstrução dimensional ............................................ 66

Figura 30: Lei do fechamento......................................................... 68

Figura 31: Operação mereológica homogênea................................... 69

Figura 32: Operação mereológica estritamente homogênea ....................69

Figura 33: Operação mereológica heterogênea ..................................... 69

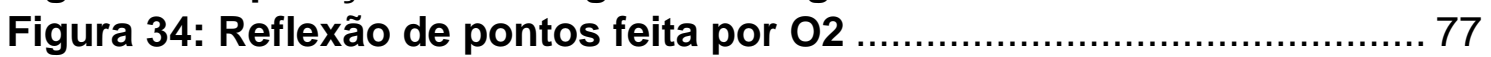

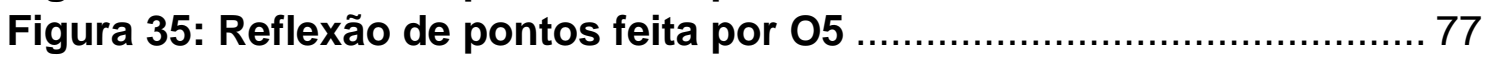

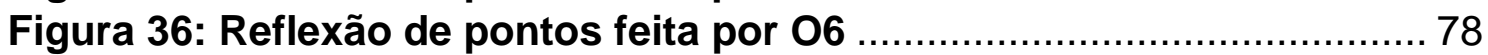

Figura 37: Reflexão de pontos feita por M2 …....................................... 78

Figura 38: Reflexão de pontos feita por M3 ...................................... 79

Figura 39: Reflexão de pontos feita por M5 ...................................... 79

Figura 40: Reflexão de pontos feita por L4 …........................................ 80

Figura 41: Referência horizontal ................................................... 80

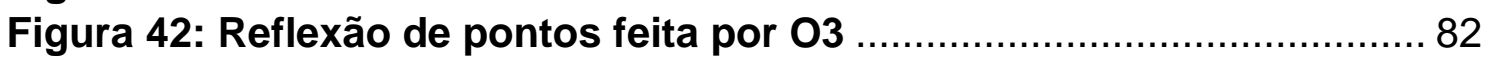

Figura 43: Reflexão de pontos feita por M1 e M4 …............................ 83

Figura 44: Solução de M1 na Atividade 2 ............................................. 83

Figura 45: Solução de M3 na Atividade 2 ................................................. 84 
Figura 46: Solução de M4 na Atividade 2 …………............................. 84

Figura 47: Solução de L4 na Atividade 2 .............................................. 84

Figura 48: Solução de L15 na Atividade 2 ............................................. 85

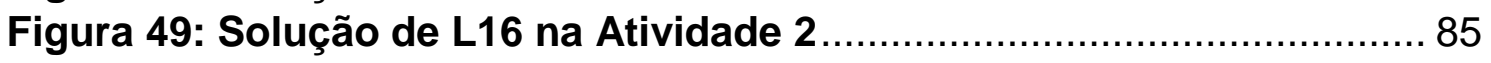

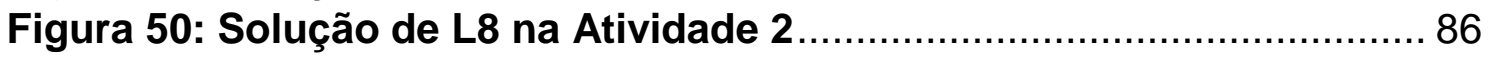

Figura 51: Solução de L13 na Atividade 2 .............................................. 87

Figura 52: Solução de L10 na Atividade 2 ............................................ 87

Figura 53: Solução de L11 na Atividade 2 .......................................... 87

Figura 54: Uso da ferramenta polígono por M4 …….............................. 89

Figura 55: Representações na Atividade 2 ……................................... 90

Figura 56: Solução de 01 na Atividade 3 ……….................................... 94

Figura 57: Solução de 02 na Atividade 3 ……....................................... 94

Figura 58: Soluções de M4 e M5 na Atividade 3 .................................... 95

Figura 59: Solução de L18 na Atividade 3........................................... 96

Figura 60: Solução de L8 na Atividade 3............................................. 96

Figura 61: Solução de L7 na Atividade 3........................................... 97

Figura 62: Solução de L4 na Atividade 3........................................... 97

Figura 63: Resposta de M2 na Atividade 3 ……................................ 100

Figura 64: Resposta de M4 na Atividade 3........................................ 100

Figura 65: Solução de L11 na Atividade 3 …….................................. 101

Figura 66: Solução de L17 na Atividade 3 ......................................... 102

Figura 67: Representação figural de M1 na Atividade 3 ......................... 104

Figura 68: Representação figural de M3 na Atividade 3 ......................... 105

Figura 69: Representação figural de L5 na Atividade 3 …..................... 105

Figura 70: Representação figural de L17 na Atividade 3 ….................... 105

Figura 71: Solução de L13 na Atividade 3........................................... 106

Figura 72: Solução de L9 na Atividade 3......................................... 107

Figura 73: Construção de M3 no GeoGebra........................................... 109

Figura 74: Construção de L4 na Atividade 3 ……................................ 109

Figura 75: Intersecções de uma circunferência com uma reta. .............. 110

Figura 76: Representação figural de 04 na Atividade 4 ......................... 112

Figura 77: Representação figural de M4 na Atividade 4 ….................... 112

Figura 78: Representação figural de L14 na Atividade 4 ….................... 113

Figura 79: Representação figural de L9 na Atividade 4 ......................... 114

Figura 80: Representação discursiva de L10 na Atividade 4 ................. 116

Figura 81: Representação figural de L11 na Atividade 4 ….................. 118

Figura 82: Circunferência tangente visualmente.................................. 120

Figura 83: Ponto C e E na circunferência S2 ....................................... 121

Figura 84: Ponto A na circunferência S1 ................................................ 121

Figura 85: Pontos B e D em m......................................................... 122

Figura 86: Supondo o problema resolvido........................................... 123

Figura 87: Solução de 04 sobre o número de intersecções .................... 124

Figura 88: Representação figural de 02 no item 5 b) .............................. 124

Figura 89: Representação figural de 04 no item 5 b) ............................. 125

Figura 90: Representação figural de 01 no item 5 b) ........................... 125

Figura 91: Representação figural de 06 na Atividade 5 ........................ 126

Figura 92: Resposta de M3 no item 5 a) ........................................... 126 
Figura 93: Resposta de M4 no item 5 a) ............................................ 126

Figura 94: Representação figural de L15 no item 5 b) ......................... 128

Figura 95: Resposta de 02 no item 5 a) ............................................ 129

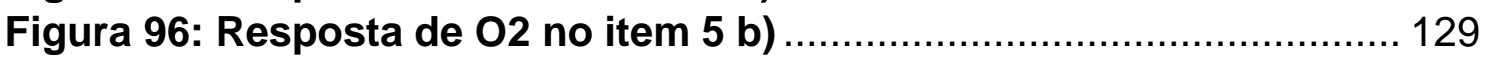

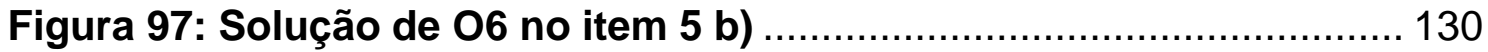

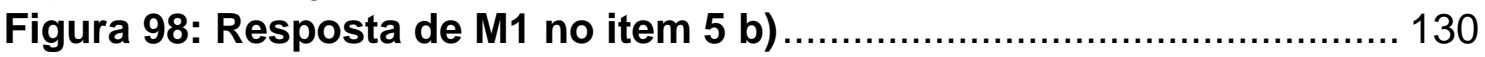

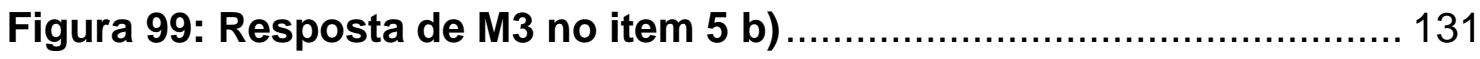

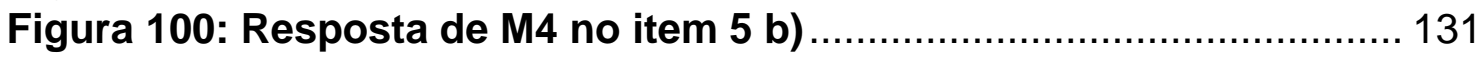

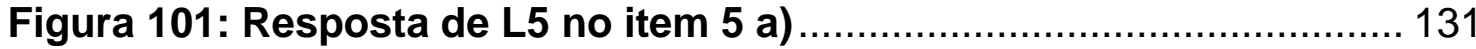

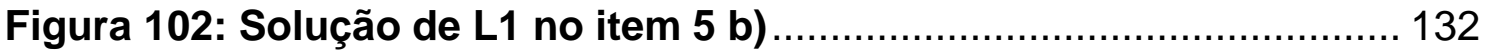

Figura 103: Representação figural de M1 no item 5 b) ........................... 134

Figura 104: Representação figural de M2 no item 5 b) ......................... 134

Figura 105: Representação figural de M3 no item 5 b) .......................... 134

Figura 106: Representação figural de M4 no item 5 b) .......................... 135

Figura 107: Representação figural de M5 no item 5 b) .......................... 135

Figura 108: Solução de L4 no item 5 b) ........................................... 136

Figura 109: Descrição da construção feita por M2 na Atividade 5 b) ...... 137

Figura 110: Construção de M6 na Atividade 5 b) ................................ 138

Figura 111: Descrição da construção feita por L3 …….......................... 138

Figura 112: Descrição da construção feita por L8 …........................... 138

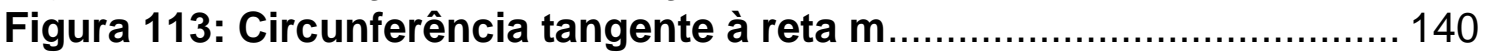

Figura 114: Construção de retas tangentes a uma circunferência .......... 140

Figura 115: Resolução da Atividade 6 c) ........................................... 141

Figura 116: Resolução completa da Atividade 6 c) ............................. 141

Figura 117: Representação figural de L1 no item 6 b) .......................... 142

Figura 118: Representação figural de L15 no item 6 c) ......................... 143

Figura 119: Representação figural de L11 no item 6 c) …..................... 143

Figura 120: Resposta de L11 no item 6 a) ......................................... 144

Figura 121: Resposta de L11 no item 6 b) ........................................ 144

Figura 122: Representação figural de L13 no item 6 a) ......................... 145

Figura 123: Representação figural de L2 no item 6 a) .......................... 145

Figura 124: Representação figural de L11 no item 6 b) ………............. 146

Figura 125: Representação figural de L11 no item 6 c) ……….............. 146

Figura 126: Resposta de L15 no GeoGebra no item 6 c) …................... 147

Figura 127: Resposta de L18 no GeoGebra no item 6 c) …................... 147

Figura 128: Ilustração do Teorema A2 ………….............................. 162 


\section{Lista de Tabelas}

Tabela 1: Ferramentas do GeoGebra utilizadas

Tabela 2: Momentos na Investigação Matemática.................................. 57

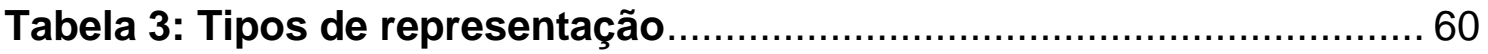

Tabela 4: Unidades figurais. 


\section{Introdução}

\subsection{Motivação para o estudo}

Sabemos que os alunos demonstram dificuldades com o aprendizado de Geometria em todos os níveis de ensino. Soares (2009) apresenta dificuldades que os alunos têm com o conteúdo de Geometria Analítica. Aponta, em seu trabalho, que essa falha no conhecimento geométrico pode estar relacionada com a didática dos professores (SOARES, 2009, p. 45).

Pereira (2010) mostra que alunos, no curso de Educação de Jovens e Adultos (EJA), têm dificuldades com resolução de problemas envolvendo o cálculo de áreas, volumes e sistema de unidades de medida. Este trabalho salienta que um dos grandes obstáculos do aprendizado é negligenciar os aspectos conceituais dos objetos geométricos, uma vez que o aluno tende a limitar-se à figura visualizada no problema.

No trabalho de Nascimento (2008) é ressaltado que alunos do curso de Licenciatura em Matemática apresentam dificuldades na compreensão de conceitos básicos de Geometria relacionados à perímetro, área de polígonos, congruência e semelhança de triângulos. Nessa pesquisa, o autor evidencia que os alunos de Licenciatura em Matemática "não possuem habilidades lógicodedutivas" (NASCIMENTO, 2008, p. 152) e, independente da turma e em que ano estejam, os pesquisados não se sentem cômodos para realizar demonstrações, ou seja, fazer demonstrações geométricas é mais um dos obstáculos apresentados por esses alunos de Licenciatura em Matemática.

Segundo Nascimento (2008), alguns alunos dos cursos de Licenciatura em Matemática têm dificuldades com os conteúdos de Geometria tratados nas disciplinas do curso de formação de professores, podendo gerar um problema cíclico na visão do autor: uma má formação básica acarreta dificuldades nos cursos de Licenciatura em Matemática o que pode influenciar, eventualmente, quando estes atuarem nas aulas do Ensino Fundamental e Médio.

O trabalho de Tempera, Serrazina e Loureiro (2013) mostra que alguns professores do Ensino Básico, em Portugal, têm dificuldades conceituais em geometria. Os autores apontam que, na verdade, há vários trabalhos identificando que os professores apresentam as mesmas dificuldades, em Geometria, que seus próprios alunos. Apesar dessa pesquisa ser realizada em 
outro país, reforça a ideia de que conceitos errados em Geometria, muitas vezes são repassados do professor para os próprios alunos (TEMPERA; SARRAZINA; LOUREIRO, 2013, p. 111), concordando com o trabalho de Nascimento (2008).

Esses trabalhos confirmam que as dificuldades na aprendizagem de Geometria se revelam em todos os níveis de ensino. Os alunos do Ensino Fundamental, Médio e Superior apresentam dificuldades na resolução de problemas envolvendo vários tópicos de Geometria e também na compreensão de conceitos em demonstrações de propriedades geométricas.

No Ensino Superior, mais precisamente, nos cursos de Licenciatura em Matemática, nem sempre os estudantes têm contato com conteúdos de Geometria, tais como o estudo das isometrias do plano, que contempla, dentre outras transformações geométricas, as reflexões por retas. Em particular, no curso de Licenciatura do Instituto de Matemática e Estatística da Universidade de São Paulo, este tópico faz parte do conteúdo da disciplina intitulada Geometria III, que utiliza como ferramenta as construções geométricas com régua e compasso e a estrutura algébrica de grupo.

Ao estudar reflexões por retas, o estudante deve resolver problemas interessantes, como por exemplo: dados dois pontos distintos $A$ e $B$ em um mesmo lado de uma reta $\overleftrightarrow{C D}$, encontrar um ponto $X \in \overleftrightarrow{C D}$, de modo que a medida de $A \hat{X} C$ seja o dobro da medida de $B \hat{X} D$. Como veremos mais adiante, este é um dos problemas propostos em nossa pesquisa, como Atividade 6 (veja a Parte 1 do Anexo C).

Devemos observar que para se resolver um problema como este é necessário, além da manipulação de instrumentos como régua e compasso, o conhecimento das propriedades das reflexões por retas, o conhecimento de várias propriedades dos objetos matemáticos envolvidos, a incorporação de elementos que não aparecem explicitamente no enunciado, o conhecimento das propriedades desses novos elementos inseridos na resolução.

Busca-se comumente nesses problemas encontrar o lugar geométrico dos pontos do plano com determinada característica. Assim, os alunos devem encontrar, no mínimo, dois objetos matemáticos tais que a intersecção deles gere os pontos que contemplam a característica desejada. Nesse tipo de 
problema é recomendado ainda usar um método de resolução que poucos alunos estão acostumados a utilizar, que é supor o problema resolvido e, então, observar as propriedades dos objetos matemáticos envolvidos, fazendo uma espécie de construção da solução a partir do resultado que se deseja atingir. Em outras palavras, se qualquer resolução possui a ordem "começo, meio e fim", os problemas, como aquele mostrado acima, devem ser resolvidos, primeiramente em um rascunho, na ordem "fim, meio e começo". Esta estratégia pode ajudar muito na busca da solução.

No problema mencionado é necessário criar elementos para tentar encontrar a solução. Nele, é necessária a construção de uma reta $t$ diferente de $\overleftrightarrow{\mathrm{CD}}$, tal que $t$ seja tangente à circunferência com centro em $\mathrm{B}$, sendo que essa mesma circunferência deve ser também tangente à $\overleftrightarrow{\mathrm{CD}}$.

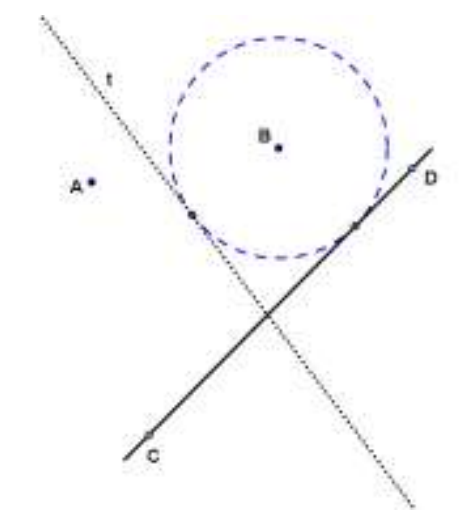

Figura 1: Solução Atividade 6

Fonte: Autor.

A intersecção entre as retas $t \mathrm{e} \overleftrightarrow{\mathrm{CD}}$ gera um ponto $\mathrm{X}$ que resolve o problema. Somente depois dessas considerações é que se pode efetivamente realizar a reflexão da reta t e da circunferência criada pela reta $\overleftrightarrow{\mathrm{CD}}$.

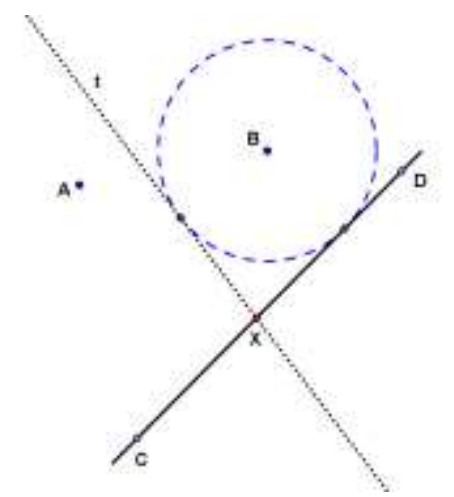

Figura 2: Solução Atividade 6, ponto sobre $\overleftrightarrow{\mathrm{CD}}$ Fonte: Autor. 
Neste tipo de problema, nota-se a necessidade de noções básicas em Geometria. Além dos conhecimentos sobre construções de retas perpendiculares, retas tangentes às circunferências, translações de pontos, entre outros, percebe-se ainda que os alunos devem dominar esses conhecimentos para resolver os problemas que envolvem essas construções com régua e compasso. Os alunos precisam ter uma postura inventiva, pois, devem criar elementos para a resolução ser possível. Porém, os elementos a serem criados não são aleatórios, estes contêm propriedades que, quando associadas aos objetos matemáticos presentes no próprio problema, produzem um ou mais elementos com características específicas. Isso aumenta o número de informações que devem ser trabalhadas em conjunto, dificultando assim, o encontro das possíveis soluções. Alguns estudantes informam que têm dificuldades para encontrar a solução de tais problemas.

Diante disso, surgiram algumas questões:

- Por que eles não conseguem resolvê-los?

- Por que alguns alunos apresentam dificuldades em resolver esses tipos de problemas de construção envolvendo transformações geométricas?

- Existe algum modo de amenizá-las?

- Como ajudar o aluno a compreender os conteúdos e métodos vistos na disciplina Geometria III?

Neste trabalho, procuramos responder a essas perguntas por meio de uma sequência de atividades relacionadas à Investigação Matemática na perspectiva de Ponte e seus colaboradores (PONTE; BROCARDO; OLIVEIRA, 2003), metodologia esta que será caracterizada no capítulo 4. Aplicamos uma atividade piloto, sobre propriedades das reflexões por retas, a uma turma de 13 alunos do curso de Licenciatura em Matemática do IME-USP, na disciplina de Geometria III. Os alunos foram favoráveis às atividades e sugeriram mudanças em algumas delas. Tais atividades serviram de base para a elaboração das atividades apresentadas nesta dissertação.

Apesar das atividades contemplarem apenas a reflexão por retas, acreditamos que, por meio da Investigação Matemática, elas possam ajudar no 
progresso dos alunos em outras atividades que envolvam Transformações Geométricas.

Destacamos, assim, que há um grande benefício do trabalho com Investigação Matemática em um curso de formação de professores. Uma vez que os professores procuram ensinar da mesma maneira que aprenderam (CURY, 1999), estes futuros professores entrariam em contato com outra metodologia, diferente da convencional (lousa e giz), pois a Investigação Matemática muda o foco da aula, do professor para o aluno (PONTE; BROCARDO; OLIVEIRA, 2003a). Além disso, por meio da Investigação Matemática, esses futuros professores estão sendo incentivados a abordarem o tema das reflexões por retas em suas aulas.

\subsection{Objetivos}

O objetivo do nosso estudo é auxiliar o estudante na apreensão de propriedades das reflexões por retas de modo que consiga aplicá-las na resolução de problemas.

Com apoio na Teoria das Representações Semióticas de Raymond Duval, buscamos nesse trabalho averiguar:

- Como as atividades propostas auxiliam na resolução dos problemas apresentados;

- Como as representações via o software GeoGebra auxiliam na resolução dos problemas.

Para isto, realizamos uma pesquisa com os seguintes participantes: professores em uma oficina promovida pelo $\mathrm{CAEM}^{1}$, professores em um minicurso no ENEM ${ }^{2}$ e alunos de Licenciatura em Matemática.

A proposta aos participantes da pesquisa foi que investigassem e conjecturassem algumas propriedades das reflexões por retas, através de uma

${ }^{1}$ Centro de Aperfeiçoamento do Ensino da Matemática

2 Encontro Nacional de Educação Matemática 
sequência de atividades. Eles tinham à disposição o software de geometria dinâmica GeoGebra.

No final do processo, apresentamos dois problemas mais elaborados de construção geométrica. Dessa forma, procuramos observar se a sequência de atividades incentivou a produção heurística nos dois problemas finais.

\subsection{Organização}

No primeiro capítulo vamos abordar as motivações que nos fizeram ter interesse pelo o tema e sua relevância para o ensino de Matemática. Apresentamos, ainda, os objetivos desta pesquisa que envolvem atividades ligadas à Investigação Matemática e ao software de geometria dinâmica GeoGebra.

O segundo capítulo é dedicado ao estudo das Transformações Geométricas, da forma como seu ensino é recomendado nos Parâmetros Curriculares Nacionais, nos anos finais do Ensino Fundamental e Médio. Fazemos algumas considerações, de acordo com o Programa Nacional do Livro Didático, sobre a presença desse tema em coleções de livros didáticos destinados ao Ensino Fundamental II e Ensino Médio. Neste capítulo, apresentamos ainda o tópico Reflexões por Retas, como é apresentado nos livros utilizados em cursos de formação de professores.

No terceiro capítulo, destacamos as principais características do GeoGebra. Apresentamos algumas das ferramentas presentes neste software e que foram usadas pelos participantes desta pesquisa.

Destacamos, no quarto capítulo, a importância da implementação de outras metodologias em salas de aula, apresentamos também considerações sobre a Investigação Matemática, suas semelhanças e diferenças com a Resolução de Problemas.

O quinto capítulo é destinado à Teoria das Representações Semióticas e sua importância para o professor de Matemática. Neste capítulo, ressaltamos a relevância da teoria na classificação das representações em problemas matemáticos. Apresentamos, de maneira sucinta, os quatro tipos de apreensão 
figural: perceptiva, discursiva, operatória e sequencial, que são fundamentais para a análise de representações figurais.

Detalhamos, no sexto capítulo, a metodologia de pesquisa e o perfil dos participantes. Destacamos as atividades propostas, suas características e como elas estão ligadas à Investigação Matemática. As análises das produções feitas pelos participantes são abordadas também neste capítulo.

O último capítulo é reservado às considerações finais sobre a pesquisa. 


\section{O estudo das Transformações Geométricas nos PCN, PNLD ${ }^{3}$ e no Ensino Superior}

Neste capítulo, ressaltamos como as Transformações Geométricas são tratadas em alguns livros utilizados no Ensino Superior. Acreditamos que observar como é abordado o tema no Ensino Superior torna-se importante para entendermos como é seu tratamento no Ensino Fundamental e Médio.

As recomendações sobre Transformações Geométricas, em especial sobre as isometrias do plano encontradas nos PCN, nos revelam o grau de importância que esse documento empreende em relação ao tema. A seguir, elencamos essas recomendações.

\subsection{Parâmetros Curriculares Nacionais do Terceiro e Quarto ciclos do Ensino Fundamental}

As considerações sobre Transformações Geométricas presentes nos Parâmetros Curriculares Nacionais (PCN) aparecem mais explicitamente citadas nos PCN para o Terceiro e Quarto Ciclos do Ensino Fundamental do que nos Parâmetros Curriculares Nacionais do Ensino Médio.

Para o Terceiro Ciclo do Ensino Fundamental, este documento recomenda a abordagem de Transformações Geométricas no conteúdo referente ao bloco Espaço e Forma:

Este bloco de conteúdos contempla não apenas o estudo das formas, mas também as noções relativas a posição, localização de figuras e deslocamentos no plano e sistemas de coordenadas.

Deve destacar-se também nesse trabalho a importância das transformações geométricas (isometrias, homotetias), de modo que permita o desenvolvimento de habilidades de percepção espacial e como recurso para induzir de forma experimental a descoberta, por exemplo, das condições para que duas figuras sejam congruentes ou semelhantes. (BRASIL, 1998, p. 51)

\footnotetext{
${ }^{3}$ Programa Nacional do Livro Didático
} 
Percebe-se, assim, a presença das Transformações Geométricas no currículo prescrito. É recomendado aos professores que trabalhem as construções geométricas com seus alunos, utilizando régua e compasso. Reconhece-se, ainda, a importância de se trabalhar com isometrias para desenvolver habilidades de percepção, de um modo geral.

$O$ documento destaca que o professor pode resolver problemas envolvendo figuras no plano utilizando-se transformações, homotetias e recomposição de figuras (BRASIL, 1998, p. 65). Assim, vemos que as transformações aparecem como ferramenta para resolução de problemas. Outras características das aplicações dessas transformações são ressaltadas no documento. Por exemplo, no tópico Conceitos e Procedimentos, é comentado sobre reflexões, translações e rotações:

Transformação de uma figura no plano por meio de reflexões, translações e rotações e identificação de medidas que permanecem invariantes nessas transformações (medidas dos lados, dos ângulos, da superfície). (BRASIL, 1998, p. 73)

Na citação acima, aparece a preocupação com o tema Transformações Geométricas, inserido nesse documento, de forma a conduzir o professor para sua abordagem em sala através da resolução de problemas, devido à importância que o tema traz em si.

De maneira semelhante ao Terceiro Ciclo, é citado nos Objetivos para o Quarto Ciclo:

Produzir e analisar transformações e ampliações/reduções de figuras geométricas planas, identificando seus elementos variantes e invariantes, desenvolvendo o conceito de congruência e semelhança. (BRASIL, 1998, p. 82)

Os PCN afirmam que a produção e análise de situações que envolvem Transformações Geométricas, observando a ocorrência de invariâncias, auxilia na identificação de congruências e semelhanças na Geometria plana. Isso reforça a ideia de que cabe ao docente trazer para a sala de aula essas situações, fazendo com que os alunos utilizem várias ferramentas para a 
apreensão do conteúdo em foco. Percebe-se isso também nos Conteúdos Propostos, onde o documento ressalta:

Construindo figuras a partir da reflexão, por translação, por rotação de uma outra figura, os alunos vão percebendo que as medidas dos lados e dos ângulos, da figura dada e da figura transformada são as mesmas. (BRASIL, 1998, p. 86)

No tópico Espaço e Forma é recomendado trabalhar com as Transformações Geométricas com o fim de desenvolver o conceito de congruência (BRASIL, 1998, p. 89). Explorar o tema de outros modos, fazendo com que o aluno reconheça figuras congruentes por meio das transformações no plano, é outro aspecto que o documento ressalta (BRASIL, 1998, p. 93).

Apresenta-se, nas Orientações Didáticas para o Terceiro e Quarto Ciclos, a proposta para serem trabalhados os conceitos de congruência de figuras planas apoiados nos estudos das rotações, translações e reflexões por reta e ponto (BRASIL, 1998, p. 124), ajudando no aprendizado das propriedades destas figuras.

Devemos notar que, nos PCN, o professor é incentivado a reconhecer a importância das transformações geométricas isométricas do plano devido à sua relação com congruências no plano. $O$ documento considera que as relações do cotidiano do aluno com os conteúdos de Matemática, que são vistos em sala de aula, devem sempre ser propostas pelo docente, quando for possível.

À primeira vista as transformações podem parecer um assunto que não tem relação com o dia-a-dia, mas, refletindo e observando um pouco, nota-se, por exemplo, que as simetrias estão muito presentes no cotidiano. Em inúmeros objetos físicos ocorrem aproximações de planos de simetria de reflexão. Em representações planas desses objetos, tais planos de simetria reduzem-se a eixos de simetria. No corpo humano pode-se observar (aproximadamente) um plano de simetria. Assim, também a imagem de um objeto no espelho é simétrica a ele. Há eixos de simetria em diversas criações do homem, como desenhos de aeronaves, edifícios e móveis. (BRASIL, 1998, p. 124) 
Observa-se que no Quarto Ciclo há uma continuidade do aprendizado sobre o assunto Transformações Geométricas iniciado no Terceiro Ciclo. As reflexões por retas e outras isometrias são indicadas como ferramentas que podem auxiliar o aluno no aprendizado de outros assuntos tanto em Matemática, como em outros ramos do conhecimento.

Todo esse incentivo dos PCN para o professor trabalhar com Transformações Geométricas também se reflete nos livros didáticos destinados aos alunos dos quatro últimos anos do Ensino Fundamental. Há evidências disso nos Guias de Livros Didáticos do PNLD (BRASIL, 2013), para os anos finais do Ensino Fundamental. Não apresentaremos aqui uma análise minuciosa das obras contidas nesses documentos, pois, a utilização delas é de apenas três anos, o que torna frequente a mudança de obras presentes nas escolas de Ensino Fundamental. Também em nosso trabalho, não especificaremos nenhumas das obras ou seus autores, uma vez que, estas informações, e mesmo os próprios Guias de Livros Didáticos aqui mencionados, estão disponíveis na internet ${ }^{4}$.

Analisando o PNLD para anos finais do Ensino Fundamental, referente aos anos de 2008, 2011 e 2014, percebemos como algumas coleções destacam já no índice das obras o tema isometrias e homotetias. Em algumas delas aparecem conteúdos sobre simetria de reflexão ou simetria axial, que estão ligados às reflexões por retas no plano, indicando uma possível introdução desse conceito.

No PNLD 2008 vemos que a maioria das coleções de livros indicados aborda o conceito de simetria, porém, isso não implica que o tema reflexão por reta seja mencionado em algum momento nas obras. Infelizmente, há obras que indicam de maneira equivocada conceitos de plano ou eixo de simetria (BRASIL, 2008 , p. 47). O documento ressalta que poucas obras se dedicam ao tema Transformações Geométricas e que a articulação destas com o conceito de simetria também não é feita.

O PNLD 2008 traz comentários especificando, para cada coleção de livros, como são abordados os conteúdos: Números e operações; Álgebra; Geometria; Grandezas e Medidas (incluindo as grandezas geométricas) e

\footnotetext{
${ }^{4}$ http://www.fnde.gov.br/programas/livro-didatico/guias-do-pnld
} 
Tratamento da Informação (estatística, probabilidade e combinatória). Neste documento dezesseis coleções foram analisadas, onde cada coleção contemplava os quatro anos finais do Ensino Fundamental. Algumas dessas obras são elogiadas por tratarem das Transformações Geométricas de forma satisfatória. Para três dessas coleções é comentado que o estudo das transformações do plano, nessa faixa de escolaridade, é pouco comum. Nesse aspecto, se considerarmos apenas o conteúdo sobre Transformações do Plano, essas considerações destacam essas obras mais que as outras.

Ainda com relação ao documento acima citado, chama-nos a atenção o fato de que poucas obras fizeram uma boa articulação entre as Transformações Geométricas e outros assuntos como, por exemplo, congruências. Menciona-se que uma das coleções apresenta mosaicos, o que foi considerado no documento como uma boa articulação (BRASIL, 2008, p.111).

No PNLD 2011, também para os anos finais do Ensino Fundamental, foram analisadas dez coleções. Na segunda coleção, as Transformações Geométricas são tratadas em textos complementares. Nesta obra não se separa um capítulo para abordar o tema simetrias, onde poderia ser feita uma boa introdução sobre reflexão por retas. De maneira semelhante se apresenta a sexta coleção, porém não há comentários, no documento, sobre como é a abordagem das Transformações do Plano, no tópico sobre Geometria. O documento de 2011 traz comentários satisfatórios para cinco coleções. Sobre a terceira delas é citado, por exemplo, que isometrias do plano são estudadas articulando-as de maneira inovadora com o conceito de simetria. Mas no caso da nona coleção houve falta de conceitos e propriedades das reflexões, rotações e translações, na visão dos avaliadores.

Assim como nos documentos de 2008 e 2011, o PNLD de 2014 traz informações relevantes sobre as obras indicadas, para auxiliar na escolha dos professores. Nesse documento são apresentadas dez coleções, dentre elas, apenas uma não traz nos índices, do sexto ao nono ano, algum tópico ligado às isometrias do plano.

No PNLD 2014, há comentários significativos para quatro coleções envolvendo assuntos ligados às reflexões por retas. A terceira obra apresentada 
define bem simetrias e isometrias, porém, não há articulação entre elas. Já na quarta obra, o documento ressalta que não existe clareza na distinção entre eixo e plano de simetria, podendo causar equívocos. Por sua vez, a nona coleção traz a noção de congruência apoiada às Transformações Geométricas, o mesmo ocorrendo com simetrias de figuras planas. Por fim, a décima obra traz isometrias de rotação e translação, mas, articulando pouco com simetria.

Observando os três últimos guias do Livro Didático, para os anos finais do Ensino Fundamental, consideramos que houve uma preocupação crescente com o tema Transformações Geométricas, através da abordagem dos conceitos de simetria axial e outras isometrias do plano. Inclusive, a simetria axial, que é abordada em boa parte das obras presentes no PNLD, pode ser um bom assunto introdutório para apresentação das propriedades das reflexões por retas.

\subsection{Parâmetros Curriculares Nacionais do Ensino Médio}

Nos Parâmetros Curriculares Nacionais do Ensino Médio não é citado em momento algum, reflexões por reta, simetrias, isometrias ou homotetias.

Porém, este documento cita o artigo 35 da Lei de Diretrizes e Bases

Art. 35 "O Ensino Médio, etapa final da Educação Básica, com duração mínima de três anos, terá como finalidade :

I - a consolidação e aprofundamento dos conhecimentos adquiridos no ensino fundamental, possibilitando o prosseguimento de estudos;

Il - a preparação básica para o trabalho e a cidadania do educando como pessoa humana, incluindo a formação ética e o desenvolvimento da autonomia intelectual e do pensamento crítico;

III - a compreensão dos fundamentos científico-tecnológicos dos processos produtivos, relacionando a teoria com a prática, no ensino de cada disciplina." (BRASIL, 2000, p. 18)

Apesar de não estarem explicitamente citadas as Transformações Geométricas, no parágrafo primeiro do artigo acima há um cuidado em assegurar 
o aprofundamento dos conhecimentos adquiridos pelo aluno até então, de modo que este, ao final do Ensino Médio, trabalhe esse e outros conceitos, aprofundando assim os conteúdos já trabalhados nos anos anteriores.

Entretanto, nas Orientações Curriculares para o Ensino Médio, que é um documento mais recente, as Transformações Geométricas são citadas no tópico Temas Complementares

Uma introdução à geometria vetorial e às transformações geométricas no plano e no espaço - isometria e homotetia - é também mais uma oportunidade de trabalhar conceitos matemáticos sob os pontos de vista algébrico e geométrico. (BRASIL, 2006, p. 93)

Pode parecer assim que o tema Transformações Geométricas não está tão presente nas salas de aula no Ensino Médio, uma vez que são pouco mencionadas nos documentos citados acima. Porém, nestes é recomendado ao professor encontrar meios de trabalhar com o tema, utilizando isometrias e homotetias como ferramentas para abordagem de outros conteúdos. Alguns dos meios para o professor articular este e outros temas podem ser encontrados também nos livros didáticos destinados aos alunos do Ensino Médio.

O Guia de Livros Didáticos de Matemática para o Ensino Médio, assim como o PNLD para os anos finais do Ensino Fundamental apresentado anteriormente, tem como objetivo orientar os professores na escolha dos livros que serão utilizados, para a escola que os adotou, durante os três anos seguintes. Percebemos que, ao longo dos últimos anos, as Transformações Geométricas têm feito parte dos assuntos tratados nesses livros. Podemos notar isso através das coleções apresentadas nos Guias de Livros Didáticos de Matemática para o Ensino Médio de 2009, 2012 e 2015.

O Guia de Livros Didáticos de 2009 apresenta oito obras, sendo que cada uma se destina aos três anos do Ensino Médio. Cinco delas possuem três volumes, enquanto que as últimas três obras são volumes únicos. Curiosamente, em nenhuma das obras há menção sobre Transformações do Plano (nenhuma obra apresenta tópicos em seus índices relacionados ao tema). Nem mesmo o documento faz referências ou comentários sobre o assunto Transformações Geométricas. 
O PNLD 2012 apresenta sete coleções e de maneira semelhante ao PNLD anterior, nenhuma delas traz em seus índices alguma referência aos assuntos ligados às transformações no plano. Porém, nesse documento, os professores são encaminhados a trabalhar com Transformações Geométricas articulando-as com o plano cartesiano. O professor também é incentivado a trabalhar com funções de modo que sejam abordadas as transformações do plano (BRASIL, 2011, p. 30).

O Guia explicita que, das obras listadas, apenas quatro delas fazem a associação das transformações geométricas com matrizes, somente sobre a quarta coleção apresentada, são feitos comentários ressaltando essa abordagem. Esse documento lembra aos professores que poucas das obras fazem a conexão entre Geometria Analítica e Transformações Geométricas (BRASIL, 2011, p. 44), assim, além de ajudar os professores de Matemática a fazerem suas escolhas quanto às obras adotadas, o guia também revela possíveis formas dos docentes trazerem para a sala de aula determinados conteúdos.

Por sua vez, o PNLD 2015 traz em sua composição a análise de seis coleções. Assim como nos guias anteriores, nenhuma das coleções trazem em seus índices alguma referência ao tema Transformações Geométricas. Mas, o documento deixa explícito que três obras exploram conexões entre matrizes e as transformações do plano.

Encontramos no PNLD 2015 uma preocupação maior com o ensino das transformações do plano. Isto é claramente visto através da quantidade de vezes que o tema é citado, principalmente se compararmos com os dois guias anteriores voltados para o Ensino Médio. O Guia de 2015 comenta, por exemplo, que as transformações geométricas do plano podem ser exploradas analisandose as funções $y=a+f(x)$ e $y=f(x+a)$, onde $f$ é uma função, $f: \mathbb{R} \rightarrow \mathbb{R}$, com a sendo um número real (BRASIL, 2014, p. 96). Apesar dessa consideração, o documento ressalta que é pouco comum aparecer em livros didáticos a conexão entre matrizes e transformações geométricas, assim como a articulação entre Geometria Analítica e as transformações do plano. 
Observando os três últimos Guias de livros didáticos para o Ensino Médio, consideramos que houve uma maior preocupação com a incorporação e 0 desenvolvimento das Transformações Geométricas entre as obras indicadas, visto que no PNLD 2009 o guia nem faz menção sobre o tema e posteriormente, nos Guias seguintes, existe certo incentivo para que os professores trabalhem com elas em sala de aula.

De maneira semelhante ao exposto sobre o PNLD do Ensino Fundamental, não fizemos a análise detalhada de cada uma das coleções de livros.

\subsection{Reflexões por Retas: conceitos básicos}

Apresentamos a base teórica para o estudo da reflexão por retas. Tomamos como referência o livro de ALVES e GALVÃO (1996). Escolhemos este livro por estar presente na bibliografia do Curso de Geometria III, do Instituto de Matemática e Estatística da USP e por ser amplamente usado pelos professores que ministram esta disciplina no Instituto.

Vamos utilizar as notações usuais da Geometria Euclidiana. Assim, pontos do plano serão denotados por letras maiúsculas $A, B, C, D, \ldots$, enquanto que as retas serão denotadas pelas letras minúsculas $m, n, r, s, \ldots$ Indicamos por $\mathrm{AB}$ a medida do segmento que tem por extremos os pontos $A$ e $B$. A notação $\overrightarrow{\mathrm{AB}}$, poderá indicar um vetor ou uma semirreta, entretanto, para não haver ambiguidade, será escrito anteriormente que se trata de um vetor ou de uma semirreta.

Sabemos que para um estudante de Matemática, é fundamental conhecer o conceito de funções ou aplicações. Tal conceito depende do domínio que estamos considerando. No caso das aplicações da geometria Euclideana, o domínio e o contradomínio são, naturalmente, o plano.

O conceito de reflexão por reta é bastante intuitivo, porém, para utilizarmos essa isometria como ferramenta e entendermos suas propriedades como um assunto por si só, faz-se necessário fundamentarmos outros conceitos, munindo-nos de definições e propriedades para assim chegarmos às reflexões por retas. Alguns teoremas, proposições e demonstrações deixamos no Anexo 
A para o leitor que quiser se aprofundar em conceitos necessários para a fundamentação teórica.

Intuitivamente, a reflexão por reta nos remete à reflexão por um espelho, apesar da reta ter dimensão um e o espelho, que tem dimensão três, se aproxima de um plano, que possui apenas dimensão dois, pois, comumente desprezamos sua espessura. Assim, o processo de reflexão por um espelho ou reta pode ser associado a uma aplicação. Devemos, primeiramente, definir essas aplicações.

Definição 1: Seja $\wp$ o conjunto dos pontos do plano. Uma aplicação F: $\wp \rightarrow \wp$ é uma lei que associa cada ponto $\mathrm{P} \in \wp$, um único ponto $\mathrm{F}(\mathrm{P})$ do plano.

Definição 2: Diremos que a imagem de $F$ é o conjunto $F(\wp)=\{F(P)$, tal que $P$ $\in \wp\}$.

Em geral, em Matemática, temos interesse em classificar as aplicações com propriedades especiais. Poderia ocorrer que uma aplicação do plano associasse a dois pontos distintos do plano um mesmo ponto. Mas, se a dois pontos distintos são associadas imagens distintas, temos uma aplicação especial.

Definição 3: Diremos que uma aplicação $F: \wp \rightarrow \wp$ é injetora se, para dois pontos distintos $\mathrm{P}$ e $\mathrm{Q}$, com $\mathrm{P}, \mathrm{Q} \in \wp$, tem-se que $F(\mathrm{P}) \neq F(\mathrm{Q})$.

Há uma outra aplicação especial que merece destaque. São as aplicações em que o contradomínio é igual à imagem.

Definição 4: Diremos que uma aplicação $F: \wp \rightarrow \wp$ é sobrejetora se, para todo ponto $\mathrm{Q} \in \wp$, existir um ponto $\mathrm{P} \in \wp$ tal que $F(\mathrm{P})=\mathrm{Q}$.

Existem aplicações que possuem as características apresentadas nas definições 3 e 4 acima. Elas são de especial interesse, pois, são ao mesmo tempo, injetoras e sobrejetoras.

Definição 5: Uma aplicação que é injetora e sobrejetora simultaneamente é chamada bijetora.

Estamos agora em condições de trabalhar com aplicações bijetoras do plano no plano. Elas também recebem uma denominação especial, como segue. 
Definição 6: Uma transformação do plano é uma aplicação T: $\wp \rightarrow \wp$ bijetora, do conjunto dos pontos do plano sobre si mesmo.

Note que, em particular, a reflexão por reta contempla a última definição, veja também os resultados apresentados no Anexo A. Novamente, de maneira intuitiva é fácil perceber que para pontos diferentes em um semi-plano determinado pela reta, a reflexão pela reta dada vai gerar imagens no semi-plano oposto. Para cada uma dessas imagens há sempre pontos que as geraram, através da reflexão pela reta.

Notação: Denotaremos por $\mathcal{F}$ o conjunto de todas as transformações do plano.

Uma forma de obter, eventualmente, novos exemplos de transformações é utilizar a composição de transformações. Se $F: \wp \rightarrow \wp$ e G: $\wp \rightarrow \wp$ são duas transformações do plano tais que a imagem da $F$ está contida no domínio da $G$, então a aplicação composta $G \circ F$ é definida por: $(G \circ F)(P)=G(F(P))$.

A aplicação composta satisfaz as seguintes propriedades:

a) se $F, G \in \mathcal{F}$ então $G \circ F \in \mathcal{F}$;

b) se $F, G, H \in \mathcal{F}$ então $(H \circ G) \circ F=H \circ(G \circ F)$;

c) $l d \in \mathcal{F}$, onde $l d$ é o elemento que satisfaz a seguinte condição: $I d \circ F=F=F \circ l d$, para todo $F \in \mathcal{F}$;

d) Para todo $F \in \mathcal{F}$ existe a aplicação inversa $F^{-1} \in \mathcal{F}$, que satisfaz a seguinte condição $F^{\circ} F^{-1}=l d=F^{-1} \circ F$.

Observe que, apesar de não especificarmos o que as aplicações $F, G$ e $H$ fazem, podemos perceber pelas propriedades a), b), c) e d), que a composição entre as aplicações é também uma transformação do plano.

Mais adiante, veremos que a composta de reflexões por retas gera outras transformações do plano.

Definição 7: Seja $F$ uma transformação do plano. $F$ é uma isometria se, para dois pontos distintos $P$ e $Q$ do plano e sendo $\mathrm{P}^{\prime}=F(\mathrm{P})$ e $\mathrm{Q}^{\prime}=F(\mathrm{Q})$, tivermos $P Q=P^{\prime} Q$ ', ou seja, a distância entre $P$ e $Q$ é a mesma de que a distância entre $P^{\prime}$ e $Q^{\prime}$. 
Na definição anterior estamos apenas classificando as transformações do plano que têm a propriedade de preservar distâncias. Estamos assim evidenciando certas transformações que conservam as distâncias entre pontos do plano.

Em Geometria, podemos estudar alguns tipos de isometrias. Dentre elas vamos destacar a reflexão por uma reta, que é o objeto principal deste trabalho.

Definição 8: A reflexão em relação a uma reta $m$ é uma aplicação que associa a cada ponto $\mathrm{P}$ do plano, $\mathrm{P}$ não pertencente a $m$, o ponto $\mathrm{P}^{\prime}$, tal que $m$ é a reta mediatriz do segmento $\overline{\mathrm{PP}^{\prime}}$ e que fixa os pontos de $m$. Notação: $R_{m}(\mathrm{P})=\mathrm{P}^{\prime}$.

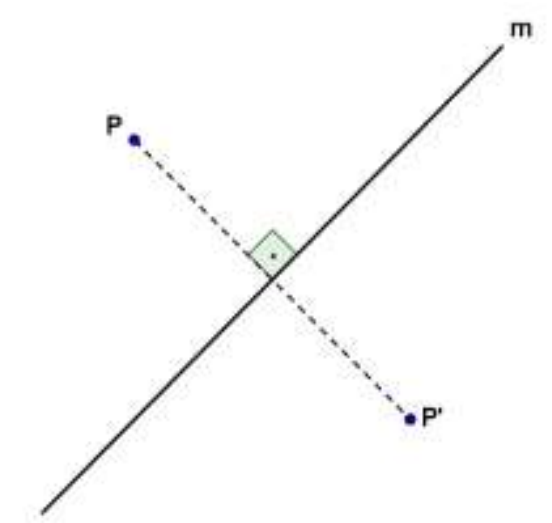

Figura 3: Reflexão do ponto $P$ pela reta $m$ Fonte: Autor.

A definição anterior está relacionada com as primeiras duas atividades que aparecem na Parte 1 do Anexo $C$. Vale ressaltar que, mesmo representando a reflexão por uma reta com uma figura, alguns alunos podem apresentar dificuldades para se apropriar do conceito, até mesmo professores. Para confirmar isto, veja as figuras 34 e 35 na seção 6.2. Uma possibilidade para amenizar isso seria observando, em um software de geometria dinâmica, as reflexões dos pontos, após a movimentação da reta de reflexão, ou apresentando uma maior quantidade de exemplos variando a posição da reta, na folha de respostas. Em nossa pesquisa, discutimos as respostas das atividades, com os participantes, após o período que eles tiveram para realizálas.

Definimos, há pouco, o que são aplicações isométricas. De maneira intuitiva, é natural supormos que as reflexões por retas preservam distâncias. Provaremos, a seguir, que toda reflexão por reta é uma isometria. Aliás, 
propusemos essa demonstração como atividade, aos participantes de nossa pesquisa, como pode ser confirmado na Atividade 3, na Parte 1 do Anexo C.

Proposição 1: Toda reflexão em relação a uma reta é uma isometria.

Demonstração: Dada a reta $\mathrm{m}$, sejam $\mathrm{P}$ e $\mathrm{Q}$ dois pontos distintos do plano, tais que $P$ e $Q$ não pertençam à reta $m$. Suponha ainda que $\overleftrightarrow{P Q}$ não seja perpendicular à reta $\mathrm{m}$. Considere $R_{\mathrm{m}}(\mathrm{P})=\mathrm{P}^{\prime}$ e $R_{\mathrm{m}}(\mathrm{Q})=\mathrm{Q}$ ' as reflexões dos pontos $\mathrm{P}$ e $\mathrm{Q}$, respectivamente, pela reta $\mathrm{m}$. Sejam $\mathrm{A}$ e $\mathrm{B}$ pontos médios de $\overline{\mathrm{PP}^{\prime}}$ e $\overline{\mathrm{QQ}^{\prime}}$, respectivamente.

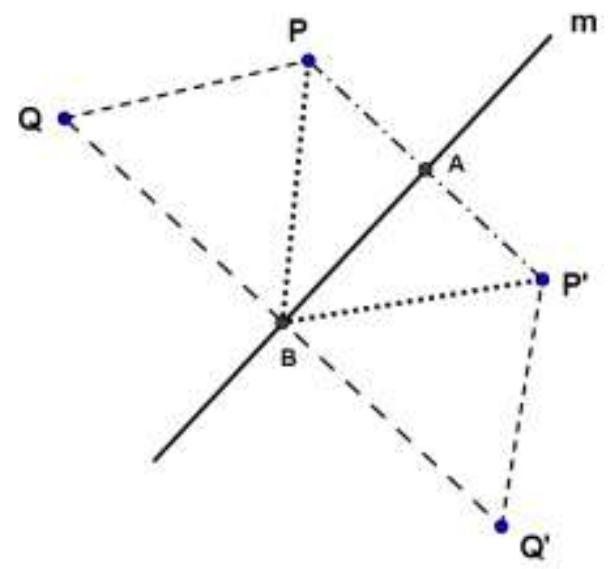

Figura 4: Reflexão dos pontos $P$ e $Q$ pela reta $m$ Fonte: Autor

Pelo critério $L A L$ de congruência de triângulos temos:

$\triangle P A B \cong \triangle P^{\prime} A B$, pois $P A=P^{\prime} A ; \Varangle P A B \cong \Varangle P^{\prime} A B$ e $\overline{A B}$ é lado comum.

Como $\triangle P A B \cong \triangle P^{\prime} A B$ temos que $P B=P^{\prime} B$. Novamente, pelo mesmo critério $L A L$ temos $\triangle P B Q \cong \triangle P^{\prime} B Q^{\prime}$. De fato: $\Varangle P B Q \cong \Varangle P^{\prime} B Q^{\prime}$, pois

$\Varangle A B Q \cong \Varangle A B Q^{\prime} \cong \frac{\pi}{2}$. Como $\Varangle A B Q \cong \Varangle A B P+\Varangle P B Q$ e $\Varangle A B Q^{\prime} \cong \Varangle A B P^{\prime}+\Varangle P^{\prime} B Q^{\prime}$ podemos escrever $\Varangle A B P+\Varangle P B Q \cong \Varangle A B P^{\prime}+\Varangle P^{\prime} B Q^{\prime}$. Como $\triangle P A B \cong \triangle P^{\prime} A B$, temos que $\Varangle A B P \cong \Varangle A B P^{\prime}$. Então pela lei do cancelamento, $\Varangle P B Q \cong \Varangle P^{\prime} B Q^{\prime}$. Como $Q B=Q Q^{\prime} B ; \Varangle P B Q \cong \Varangle P^{\prime} B Q^{\prime}$ e $P B=P^{\prime} B$, os dois triângulos $\triangle P B Q$ e $\triangle P^{\prime} B Q^{\prime}$ são congruentes, portanto $P Q=P^{\prime} Q$ '.

Este resultado ainda se mantém para os casos em que um dos pontos $P$ e $Q$ ou ambos pertencerem à reta $\mathrm{m}$ ou quando $\overleftrightarrow{\mathrm{PQ}}$ é perpendicular à $\mathrm{m}$. Nestes casos, a prova segue da definição de reflexão por retas e da relação de estar-entre. 
A seguir, definimos uma outra transformação interessante, a translação, pois ela também será utilizada em um resultado a seguir.

Definição 9: $A$ translação na direção de um vetor $\overrightarrow{\mathrm{v}}$ é uma aplicação $T: \wp \rightarrow \wp$ tal que, para todo ponto $P$ do plano, é associado o ponto $\mathrm{P}+\overrightarrow{\mathrm{v}}$.

Notação: $\mathrm{T}_{\overrightarrow{\mathrm{v}}}(\mathrm{P})=\mathrm{P}+\overrightarrow{\mathrm{v}}$.

Devemos lembrar que a soma de um ponto com um vetor é sempre um ponto, assim, considerando o vetor $\vec{v}$, diferente do vetor nulo, podemos escrever:

$$
\mathrm{T}_{\overrightarrow{\mathrm{v}}}(\mathrm{P})=\mathrm{P}+\overrightarrow{\mathrm{v}}=\mathrm{P}^{\prime}
$$

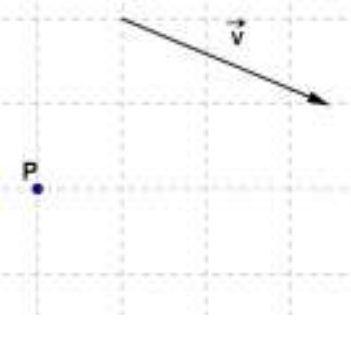

a

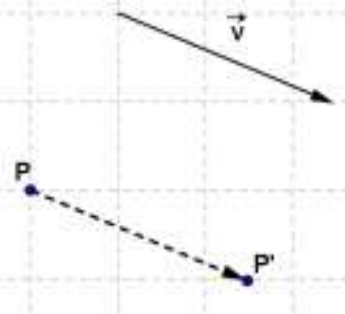

b

Figura 5: Translação de um ponto por um vetor Fonte: Autor.

Na Figura $5 a$, temos apenas um ponto e um vetor $\vec{v}$; na Figura $5 b$ temos também o ponto $P^{\prime}$ que é a translação do ponto $P$ pelo vetor $\vec{v}$.

Teorema 1: Sejam m e n retas paralelas distintas do plano. Considere os pontos $A$ e $B$, tais que $A$ pertence à reta $m$ e $B$ pertence à reta $n$ de modo que $\overleftrightarrow{A B}$ seja uma perpendicular comum às retas $m$ e $n$. Então $R_{n} \circ R_{m}=T_{2 \overrightarrow{A B}}$.

Antes de fazermos a demonstração, observe a ilustração a seguir. Nela apresentamos a composta de reflexões do ponto $P$ por duas retas $m$ e $n$.

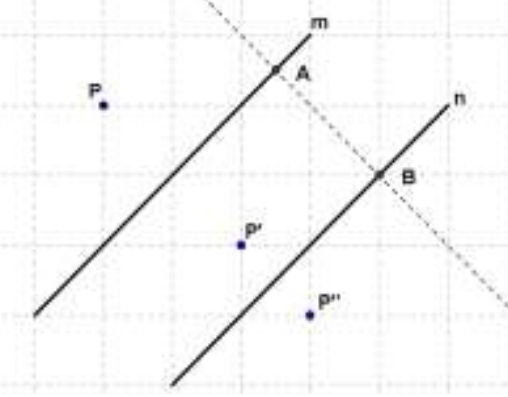

Figura 6: Exemplo de reflexão por duas retas paralelas Fonte: Autor. 
Demonstração: Considere $\mathrm{A}^{\prime}=R_{\mathrm{n}}(\mathrm{A})$. É fácil perceber que $\overrightarrow{\mathrm{AA}^{\prime}}=2 \overrightarrow{\mathrm{AB}}$ (Figura 7a). Logo, podemos escrever: $T_{2 \overrightarrow{\mathrm{AB}}}(A)=A^{\prime}$. Considerando $C$ um ponto da reta $m$, com C diferente de $A$, seja $C^{\prime}=R_{n}(C)$. Pelo Corolário A1 (veja o Anexo $A$ ), teremos assim que ACC'A' é um retângulo, tal que, $\overrightarrow{\mathrm{AA}^{\prime}}=\overrightarrow{\mathrm{CC}^{\prime}}=2 \overrightarrow{\mathrm{AB}}$ (Figura $7 \mathrm{~b}$ ). Temos: $\mathrm{T}_{2 \overrightarrow{\mathrm{AB}}}(\mathrm{C})=\mathrm{C}+2 \overrightarrow{\mathrm{AB}}=\mathrm{C}+\overrightarrow{\mathrm{CC}^{\prime}}=\mathrm{C}^{\prime}$.

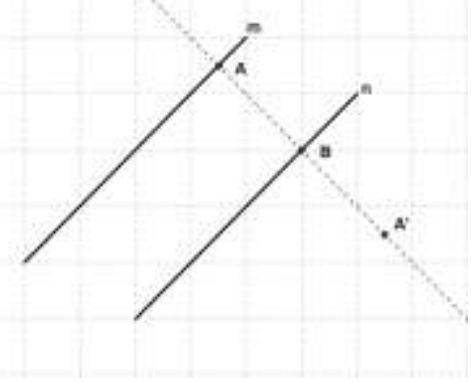

a

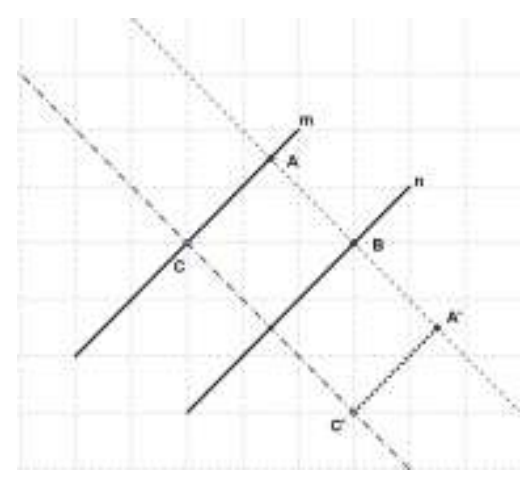

b

Figura 7: Reflexão por duas retas paralelas dos pontos A e C Fonte: Autor.

Podemos também escrever: $R_{m}(B)=B^{\prime}$ e $\overrightarrow{B^{\prime} \mathrm{B}}=2 \overrightarrow{A B}$, ou seja $T_{2} \overrightarrow{A B}(B)=B^{\prime}$.

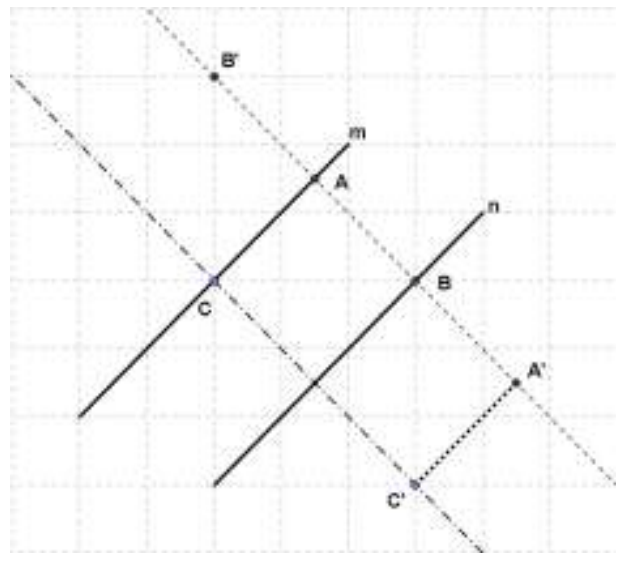

Figura 8: Reflexão por duas retas paralelas do ponto B Fonte: Autor.

Temos então: $\left(R_{n} \circ R_{m}\right)(A)=R_{n}(A)=A^{\prime}=T_{2} \overrightarrow{A B}(A)$

Do mesmo modo temos:

$$
\begin{aligned}
& \left(\mathrm{R}_{\mathrm{n}} \circ \mathrm{R}_{\mathrm{m}}\right)(\mathrm{C})=R_{\mathrm{n}}(\mathrm{C})=\mathrm{C}^{\prime}=\mathrm{T}_{2 \overrightarrow{\mathrm{AB}}}(\mathrm{C}) \\
& \left(\mathrm{R}_{\mathrm{n}} \circ \mathrm{R}_{\mathrm{m}}\right)\left(\mathrm{B}^{\prime}\right)=R_{\mathrm{n}}(\mathrm{B})=\mathrm{B}=\mathrm{T}_{2 \overrightarrow{\mathrm{AB}}}\left(\mathrm{B}^{\prime}\right)
\end{aligned}
$$

Pelos teorema A1 e A3 (veja o Anexo A), segue que $R_{n} \circ R_{m}=T_{2 \overrightarrow{A B}}$. 
Apresentamos as retas $\mathrm{m}$ e $\mathrm{n}$ inclinadas na Figura 9 abaixo. Note que, desse modo é mais difícil perceber que a distância entre os pontos $\mathrm{P}$ e P" tem alguma relação com a distância entre as retas paralelas. Tem-se que PP" = $2\|\overrightarrow{A B}\|$, com os pontos $\mathrm{A}$ e $\mathrm{B}$ sendo as intersecções, respectivamente, das retas $\mathrm{m}$ e $\mathrm{n}$ com uma reta perpendicular comum às duas.

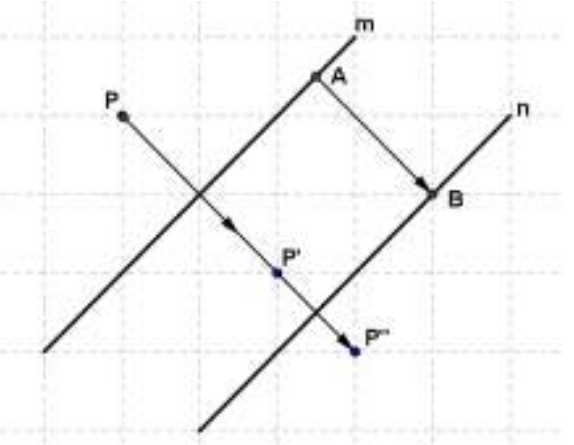

Figura 9: Exemplo de reflexão do ponto $P$ por duas retas paralelas Fonte: Autor.

O próximo resultado será utilizado numa demonstração a seguir.

Proposição 2: Sejam $\vec{v}$ um vetor não nulo e $m$ uma reta do plano perpendicular à direção de $\overrightarrow{\mathrm{v}}$. Então, existem somente duas retas $r$ e $s$ tais que $T_{\vec{v}}=R_{m} \circ R_{r}=R_{s} \circ R_{m}$. Além disso, as retas $r$, s e $m$ são paralelas distintas.

Demonstração: Sejam $t$ uma reta paralela à direção de $\vec{v}$ e $\{A\}=m \cap t$. Considere ainda $\mathrm{B}$ e $\mathrm{C}$ pontos pertencentes à $\mathrm{t}$ tais que $2 \overrightarrow{\mathrm{BA}}=2 \overrightarrow{\mathrm{AC}}=\overrightarrow{\mathrm{v}}$. Assim, $\overleftrightarrow{\mathrm{BA}}$ é uma perpendicular comum à $r$ e $m$ enquanto que $\overleftrightarrow{\mathrm{AC}}$ é uma perpendicular comum a $\mathrm{m}$ e s.

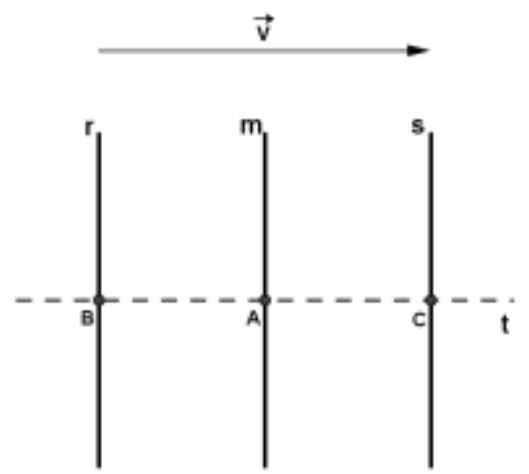

Figura 10: Existência de duas retas paralelas à uma reta $\mathrm{m}$ dada Fonte: Autor.

Pelo Teorema 1 temos que $R m \circ R r=T_{2 \overrightarrow{B A}}=T_{\vec{v}}$ e $R_{s} \circ R_{m}=T_{2 \overrightarrow{A C}}=T_{\vec{v}}$. 
Como o teorema diz que há somente duas retas, é necessário demonstrar a unicidade. Assim, suponha que exista uma reta $n$ paralela à reta $r$ tal que:

$T_{\vec{v}}=R_{m} \circ R_{r}=R_{m} \circ R_{n}$, desse modo, considerando a segunda igualdade $\mathrm{e}$ aplicando $R_{m}$ nos dois membros, temos:

$$
\begin{aligned}
R_{m} \circ R_{r} & =R_{m} \circ R_{n} \\
R_{m} \circ R_{m} \circ R_{r} & =R_{m} \circ R_{m} \circ R_{n} \\
l d \circ R_{r} & =l d \circ R_{n} \\
R_{r} & =R_{n}
\end{aligned}
$$

Logo, $r=n$.

De maneira análoga podemos mostrar a unicidade para reta $s$.

No próximo resultado caracterizamos a composta de três retas paralelas.

Teorema 2: Sejam $r$, s e t três retas paralelas do plano. Então $R_{t} \circ R_{s} \circ R_{r}=R_{n}$ onde $n$ é uma reta paralela às retas $r$, s e $t$.

Representamos esse resultado em duas ilustrações a seguir:

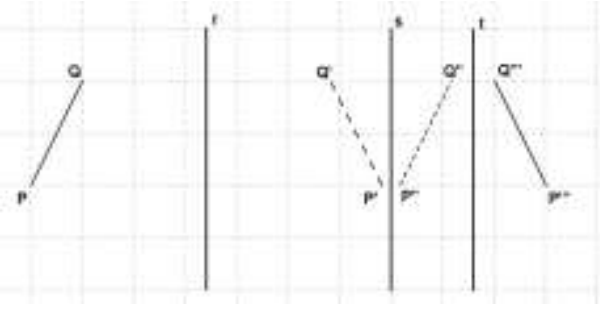

a

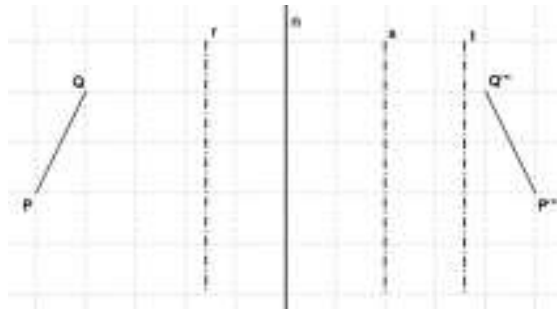

b

Figura 11: Composta de reflexões por três retas paralelas Fonte: Autor.

Demonstração: Pelo Teorema 1, sabemos que $R_{s} \circ R_{r}=T_{2 \overrightarrow{A B}}$, onde $A \in r, B \in$ $s$ e $\overrightarrow{A B}$ é perpendicular à $r$. Mas, fazendo $t=m$ na proposição anterior, encontramos

$T_{2 \overrightarrow{A B}}=R_{t} \circ R_{n}$ onde $n$ é uma reta paralela a t. Portanto,

$$
R_{t} \circ R_{s} \circ R_{r}=R_{t} \circ T_{2 \overrightarrow{A B}}=R_{t} \circ R_{t} \circ R_{n}=l d \circ R_{n}=R_{n} .
$$

A definição a seguir nos ajudará a compreender resultados posteriores. Definimos a rotação de centro $O$ e ângulo $\alpha$. 
Definição 10: Dados um ponto $O$ e um número real $\alpha,-\pi<\alpha \leq \pi$, a rotação de centro $\mathrm{O}$ e ângulo $\alpha$ é a aplicação que fixa o ponto $\mathrm{O}$ e associa a cada ponto $\mathrm{P}$ do plano, $\mathrm{P}$ diferente de $\mathrm{O}$, o ponto $\mathrm{P}$ ' pertencente à circunferência de centro $O$ e raio OP e tal que a medida do ângulo orientado $\Varangle \mathrm{POP}^{\prime}$ é igual a $\alpha$.

Notação: $R_{\mathrm{O}, \alpha}(\mathrm{P})=\mathrm{P}^{\prime}$ denota a rotação de centro $\mathrm{O}$ e ângulo $\alpha$ de um ponto $\mathrm{P}$.

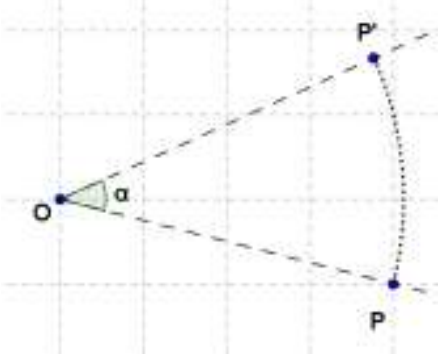

Figura 12: Rotação de um ponto $P$ Fonte: Autor.

Os próximos resultados são relativos à composta de reflexões por retas, concorrentes em um único ponto. Observe que esse é um caminho natural a seguir, pois, a partir do momento que definimos a reflexão por uma reta, podemos fazer a composta de reflexões por duas ou mais retas. Porém, as retas poderão ser paralelas ou concorrentes. Para duas retas concorrentes teremos 0 resultado a seguir.

Teorema 3: Sejam $r$ e $s$ duas retas concorrentes distintas do plano se interceptando em um único ponto $O$ e seja $\alpha$ a medida de um dos ângulos orientados da reta r para a reta s. Então $R_{s} \circ R_{r}=R_{0,2 \alpha}$.

Demonstração: Seja A um ponto qualquer de $r$, A distinto de O. Considere B, um ponto pertencente à reta $\mathrm{s}, \mathrm{com} \mathrm{B} \neq \mathrm{O}$.

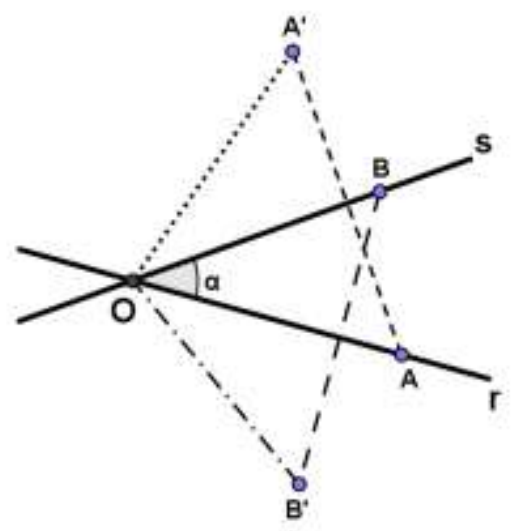

Figura 13: Reflexão por duas retas concorrentes

Fonte: Autor. 
Sendo $R_{s}(A)=A^{\prime}$, então s é a reta mediatriz de $\overline{\mathrm{AA}^{\prime}}$ e como $O$ também pertence à s temos: $O A=O A^{\prime}$. Além disso, desde que s contém a bissetriz do ângulo orientado $\Varangle A O A^{\prime}$, segue que este ângulo tem medida igual a $2 \alpha$, ou seja, $\mathrm{R}_{0,2 \alpha}$ $(A)=A^{\prime}$. De modo análogo, se $\operatorname{Rr}(B)=B^{\prime}$ então $O B=O B^{\prime}$ e o ângulo orientado $\Varangle B^{\prime} O B$ tem medida igual a $2 \alpha$, ou seja, $R_{0,2 \alpha}\left(B^{\prime}\right)=B$. Então

$$
\begin{aligned}
& \left(R_{s} \circ R_{r}\right)(O)=R_{s}(O)=O=R_{0,2 \alpha}(O) ; \\
& \left(R_{s} \circ R_{r}\right)(A)=R_{s}(A)=A^{\prime}=R_{0,2 \alpha}(A) ; \\
& \left(R_{s} \circ R_{r}\right)\left(B^{\prime}\right)=R_{s}(B)=B=R_{0,2 \alpha}\left(B^{\prime}\right) .
\end{aligned}
$$

Como O, A e B' são pontos não colineares temos, pelo Teorema A4 (veja o Anexo $A$ ), a seguinte igualdade: $R_{s} \circ R_{r}=R_{0,2 \alpha}$.

Note que, o Teorema A1 (veja o Anexo A) garante a última igualdade, pois ele nos mostra que a composta de aplicações isométricas é também uma isometria.

A definição seguinte refere-se à reflexão por um ponto. Veremos adiante que esta transformação do plano está ligada à composta de reflexões por duas retas.

Definição 11: Dado um ponto $O$ do plano, a reflexão em relação a $\mathrm{O}$ é a aplicação que fixa o ponto $\mathrm{O}$ e associa a cada ponto $\mathrm{P}$ do plano, $\mathrm{P}$ diferente de $\mathrm{O}$, o ponto $\mathrm{P}^{\prime}$ tal que $\mathrm{O}$ é o ponto médio do segmento $\overline{\mathrm{PP}^{\prime}}$. Notação: $R_{O}(\mathrm{P})=\mathrm{P}^{\prime}$ denota a reflexão de um ponto $\mathrm{P}$ pelo ponto $\mathrm{O}$.

A seguir, a Figura 14 ilustra a definição:

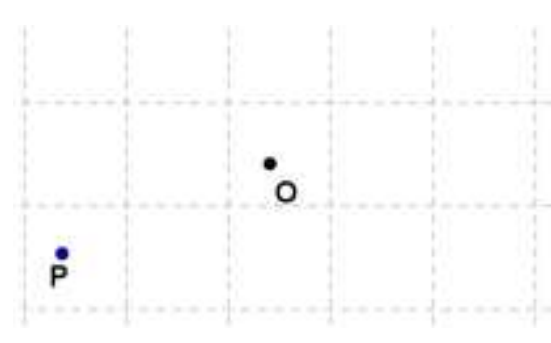

a

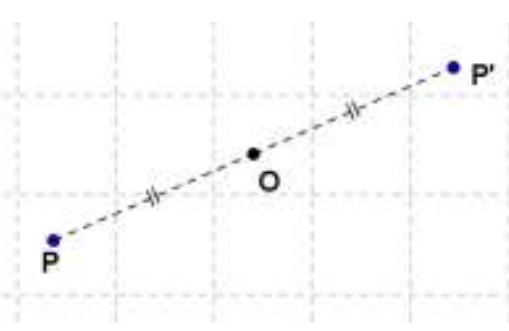

b

Figura 14: Reflexão de um ponto $\mathrm{P}$ por um ponto $\mathrm{O}$ Fonte: Autor

Observação: Em uma rotação, quando $\alpha=\pi$ teremos $\mathrm{R}_{0, \pi}=R_{O}$ pois, pela definição de rotação, se $R_{0, \pi}(P)=P^{\prime}$ os pontos $P$ e $P^{\prime}$ estão em uma mesma 
circunferência de centro $\mathrm{O}$ e raio $\mathrm{OP}$, sendo $\mathrm{m}\left(\Varangle \mathrm{POP}^{\prime}\right)=\pi$. Dessa forma, $\mathrm{O}$ é ponto médio de $\overline{\mathrm{PP}^{\prime}}$. De acordo com a Definição 11 (veja a Figura $\left.14 \mathrm{~b}\right), R_{O}(\mathrm{P})=$ $\mathrm{P}^{\prime}$. Logo, $\mathrm{R}_{\mathrm{O}, \pi}=R_{\mathrm{O}}$.

Devemos observar que a última igualdade pode ser encontrada através da composta da reflexão por duas retas, desde que o ângulo formado por elas seja congruente à $\frac{\pi}{2}$. Temos então o seguinte resultado:

Corolário 1: Sejam r e s retas perpendiculares se interceptando em um ponto O. Então $R_{s} \circ R_{r}=R_{r} \circ R_{S}=R_{0}$.

Demonstração: Seja $\alpha=\frac{\pi}{2}$ o ângulo orientado formado entre $r$ e s. Pelo Teorema 3 temos que $R_{s} \circ R_{r}=\mathrm{R}_{0,2 \alpha}$ e $R_{r} \circ R_{s}=\mathrm{R}_{0,2 \alpha}$, logo,

$R_{S} \circ R_{r}=R_{r} \circ R_{S}=\mathrm{R}_{0,2 \alpha}$, mas $\alpha=\frac{\pi}{2}$, portanto,

$R_{s} \circ R_{r}=R_{r} \circ R_{S}=\mathrm{R}_{0,2 \alpha}=\mathrm{R}_{0, \frac{2 \pi}{2}}=\mathrm{R}_{0, \pi}=R_{O}$.

Podemos entender a próxima proposição como um complemento do Corolário 1 que nos ajuda na demonstração do Teorema 4 a seguir.

Proposição 3: Dadas uma rotação $R_{O, 2 \alpha}$, tal que, $0<|\alpha|<\frac{\pi}{2}$ e uma reta $m$ do plano que passa por $O$, então existem somente duas retas $r$ e $s$, passando por $O$, tais que $R_{O, 2 \alpha}=R_{m} \circ R_{r}=R_{s} \circ R_{m}$.

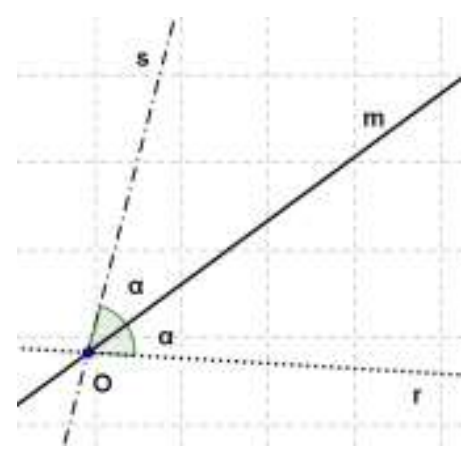

Figura 15: Existência das retas $r$ e s concorrentes com $\mathrm{m}$ no ponto 0 Fonte: Autor.

Demonstração: Seja $A$ um ponto arbitrário de $m$, com $A$ diferente de $O$, considere os pontos $B$ e $C$ tais que $R_{0,-\alpha}(A)=B ; R_{0, \alpha}(A)=C$. 


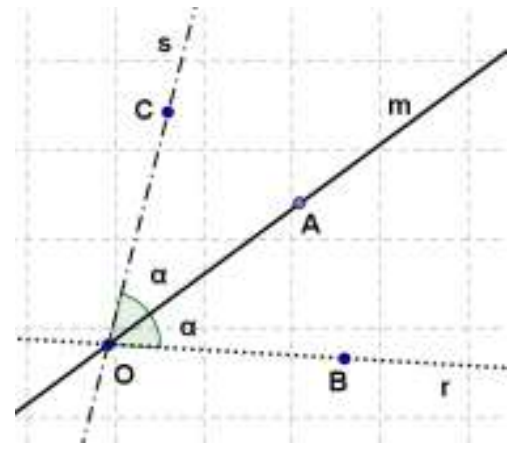

Figura 16: Existência das retas $r$ e s concorrentes à $m$ Fonte: Autor.

Sejam $r$ e $s$ duas retas que passam por $O$, tais que a medida de um ângulo orientado de $r$ para $m$ e de $m$ para s é $\alpha$. Pelo Teorema 3 segue que

$$
R_{m} \circ R_{r}=R_{0,2 \alpha} \text { e } R_{s} \circ R_{m}=R_{0,2 \alpha} .
$$

A unicidade de $r$ e s segue das leis de cancelamento. Para a reta $r$, suponha por absurdo que exista outra reta t distinta de $r$ tal que $R_{0,2 \alpha}=R_{m} \circ R_{t}$, assim, podemos escrever $R_{m} \circ R_{r}=R_{m} \circ R_{t}$, fazendo a composição como $R_{m}$ nos dois membros dessa igualdade, temos:

$$
R_{m} \circ R_{m} \circ R_{r}=R_{m} \circ R_{m} \circ R_{t}
$$

Portanto,

$$
I d \circ R_{r}=I d \circ R_{t} \text {, logo } R_{r}=R_{t}
$$

ou seja $r=t$. Mas isso é um absurdo, uma vez que consideramos $r$ e t distintas. Para a reta s é análogo.

Para três retas concorrentes em um único ponto a reflexão composta resulta em outra reflexão por reta. Acompanhe na figura abaixo que o ponto $P$, após as reflexões pelas retas $r, s$ e $t$, respectivamente, gera o ponto $P$ '”.

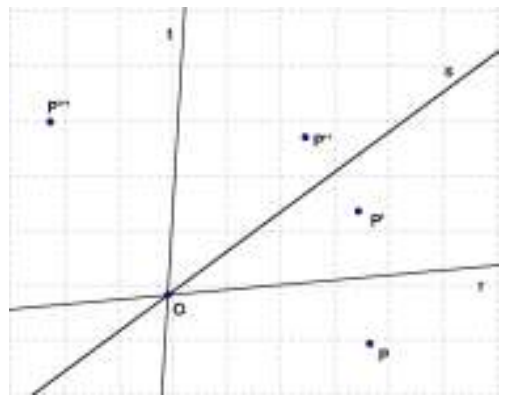

Figura 17: Reflexão compostas por três retas concorrentes Fonte: Autor.

No teorema a seguir mostraremos que essa composição é igual à outra reflexão por uma reta. 
Teorema 4: Sejam r, s e três retas concorrentes em um único ponto O. Então $R_{t} \circ R_{s} \circ R_{r}=R_{n}$, onde $n$ é uma reta que passa por $O$.

Demonstração: Se r coincide com s, o resultado é imediato, ou seja, basta tomar $\mathrm{n}=\mathrm{t}$. Caso contrário, sendo $\alpha$ a medida de um dos ângulos orientados da reta $r$ para a reta $\mathrm{s}$, podemos supor $0<|\alpha|<\frac{\pi}{2}$. Pelo Teorema 3 temos a seguinte igualdade $\mathrm{R}_{\mathrm{s}} \circ \mathrm{R}_{\mathrm{r}}=\mathrm{R}_{\mathrm{O}, 2 \alpha}$. Fazendo $\mathrm{m}=\mathrm{t}$ na proposição anterior, obtemos:

$\mathrm{R}_{0,2 \alpha}=\mathrm{R}_{\mathrm{t}} \circ \mathrm{R}_{\mathrm{n}}$, onde $\mathrm{n}$ é uma reta que passa por $\mathrm{O}$. Portanto, $\mathrm{R}_{\mathrm{t}} \circ \mathrm{R}_{\mathrm{s}} \circ \mathrm{R}_{\mathrm{r}}=\mathrm{R}_{\mathrm{t}} \circ \mathrm{R}_{0,2 \alpha}=\mathrm{R}_{\mathrm{t}} \circ \mathrm{R}_{\mathrm{t}} \circ \mathrm{R}_{\mathrm{n}}=l d \circ \mathrm{R}_{\mathrm{n}}=\mathrm{R}_{\mathrm{n}}$.

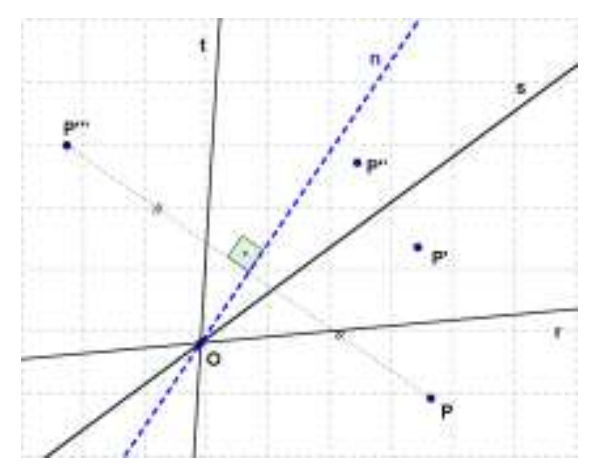

Figura 18: Resultado da composta de três reflexões Fonte: Autor.

Para o caso em que $\alpha=\frac{\pi}{2}$, temos $R_{s} \circ R_{r}=R_{0, \pi}=R_{\circ}$. Logo,

$$
R_{t} \circ R_{s} \circ R_{r}=R_{t} \circ R_{0, \pi}=R_{t} \circ R_{0} .
$$

Nas proposições 4 e 5 a seguir, apresentaremos o resultado da composta da reflexão por três retas, duas a duas concorrentes e o resultado da composta de uma reflexão por ponto com uma reflexão por reta, que está relacionado com o último resultado mostrado no Teorema 4. Para esses dois resultados temos um nome especial, descrito na Definição 12 a seguir.

Proposição 4: Sejam $r, s$ e $t$ retas distintas do plano, tais que, $r, s$ e $t$ se interceptam duas a duas em três pontos distintos do plano, então $R_{t} \circ R_{S} \circ R_{r}=R_{A} \circ R_{n}$, onde $A$ é um ponto pertencente a $t$.

Demonstração: Seja $O$ o ponto de intersecção entre $r$ e s, de modo que,

$$
\mathrm{R}_{\mathrm{s}} \circ \mathrm{R}_{\mathrm{r}}=\mathrm{R}_{0,2 \alpha} \text {, com } 0<|\alpha|<\frac{\pi}{2},
$$


sendo $\alpha$ a medida do ângulo orientado de $r$ para s. Note que, $O$ não pertence a $\mathrm{t}$, pois $\mathrm{r}$, $\mathrm{s}$ e t não são concorrentes em um único ponto. Considere agora uma reta $\mathrm{m}$ perpendicular a t e que passa por $\mathrm{O}$.

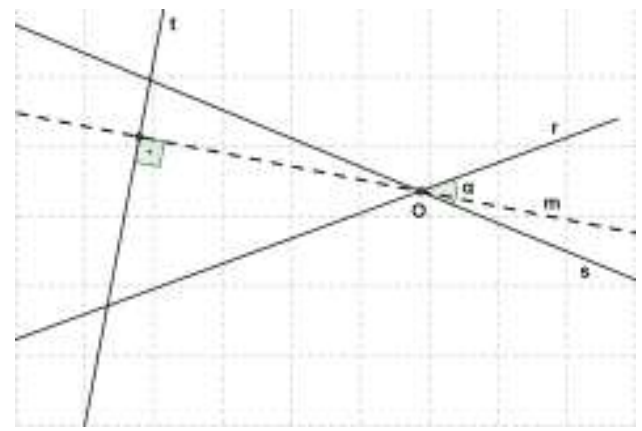

Figura 19: Composta de reflexões de três retas concorrentes

Fonte: Autor.

Pela Proposição 3, existe uma reta $n$, passando por $\mathrm{O}$, tal que $\mathrm{R}_{0,2 \alpha}=\mathrm{R}_{\mathrm{m}} \circ \mathrm{R}_{\mathrm{n}}$. Considere $\{A\}=m \cap t$, então pelo Corolário 1 temos $R_{t} \circ R_{m}=R_{A}$, logo, $R_{t} \circ R_{s} \circ R_{r}=R_{t} \circ R_{0,2 \alpha}=R_{t} \circ R_{m} \circ R_{n}=R_{A} \circ R_{n}$.

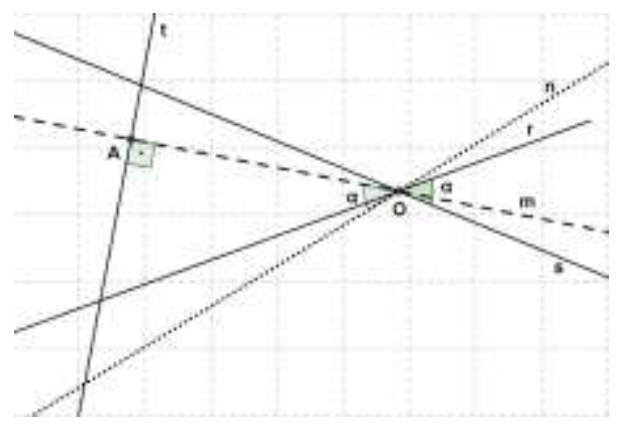

Figura 20: Intersecção entre as retas t e $\mathrm{m}$ no ponto $\mathrm{A}$ Fonte: Autor.

Temos a seguir a definição de uma nova isometria.

Definição 12: Sejam r e s retas distintas do plano, ambas perpendiculares à uma reta t. A isometria $R_{t} \circ R_{s} \circ R_{r}$ é chamada uma reflexão transladada ou translação refletida de eixo $t$.

Na Figura 21 a seguir ilustramos essa definição: 


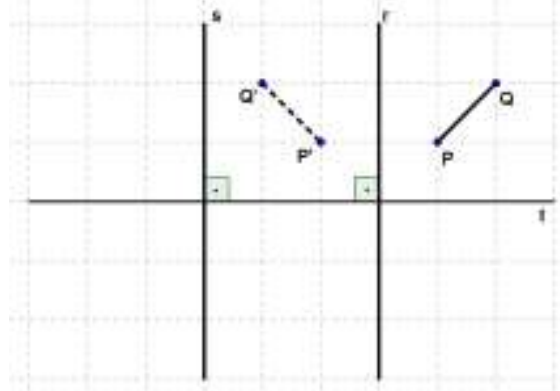

a

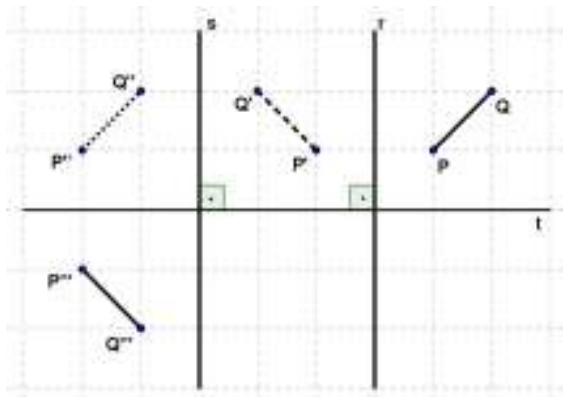

C

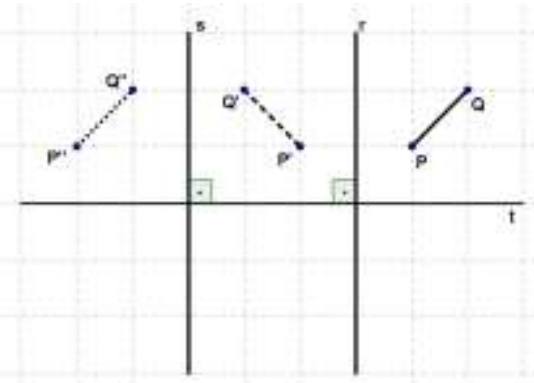

b

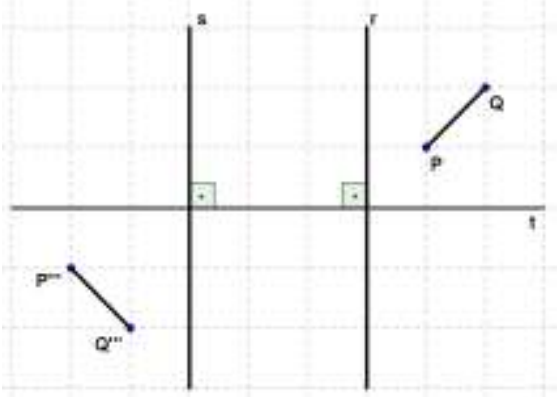

d

Figura 21: Reflexão transladada Fonte: Autor.

A próxima proposição mostra como podemos obter uma reflexão transladada apenas com uma reta e um ponto fora dela.

Proposição 5: Dados uma reta $n$ do plano e um ponto $A$ não pertencente à $n$, então $R_{A} \circ R_{n}$ e $R_{n} \circ R_{A}$ são reflexões transladadas de eixo $t$, onde $t$ é a reta perpendicular à $n$ passando por $A$.

$\mathrm{Na}$ ilustração a seguir refletimos dois pontos $\mathrm{P}$ e $\mathrm{Q}$ pela reta $\mathrm{n}$ e depois fizemos a reflexão pelo ponto $A$.

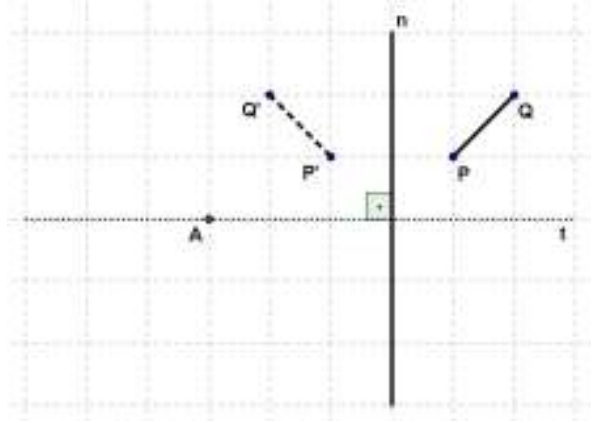

a

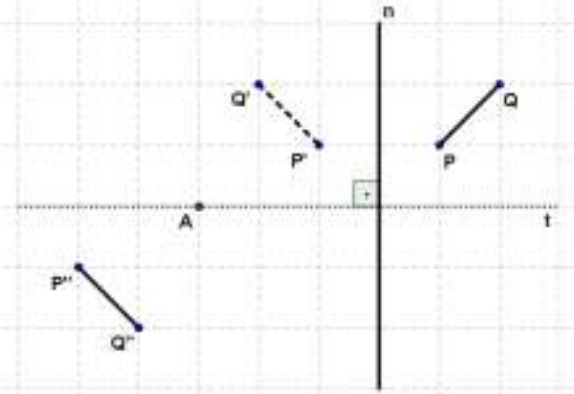

b

Figura 22: Reflexão por reta e ponto

Fonte: Autor 
Antes de fazermos a demonstração da Proposição 5, perceba que ela tem resultado igual ao obtido na Proposição 4 e também da Definição 12.

Demonstração: Se $m$ é a reta perpendicular à t passando por $A$, temos que $n$ e $\mathrm{m}$ são retas paralelas distintas, ambas perpendiculares à t. Pelo Corolário 1, temos $R_{A} \circ R_{n}=R_{t} \circ R_{m} \circ R_{n}$ e $R_{n} \circ R_{A}=R_{n} \circ R_{t} \circ R_{m}=R_{t} \circ R_{n} \circ R_{m}$.

Note que na última igualdade estamos utilizando a propriedade comutativa, uma vez que as retas $n$ e t são perpendiculares.

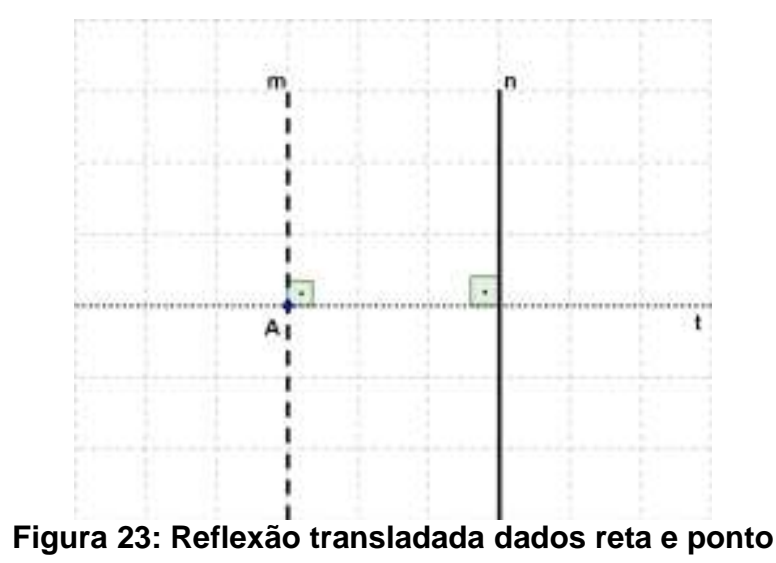

Fonte: Autor

Todas as figuras desta seção foram feitas no GeoGebra. A seguir, descrevermos algumas das características deste software de geometria dinâmica e quais ferramentas presentes nele foram utilizadas durante as atividades. 


\section{O Software GeoGebra}

As contribuições do software de geometria dinâmica GeoGebra têm sido amplamente verificadas em aulas de Matemática em todos os níveis de ensino, como vemos no trabalho de Cyrino e Baldini (2012). As pesquisas que abordam a utilização desse software não se limitam às disciplinas de Cálculo, Geometria Euclideana e Geometria Analítica. Há alguns trabalhos relatando experiências com o ensino de Estatística associados ao software (COUTINHO, ALMOULOUD e SILVA, 2012; DUARTE, 2010).

Várias pesquisas ao longo dos últimos anos mostram que o software GeoGebra traz benefícios no ensino-aprendizagem das transformações do plano e outros assuntos relacionados com esse tema (EVANGELISTA, 2012; FRANCO, 2015; MEDEIROS, 2012). Nessas pesquisas, são apresentadas também outras vantagens de se trabalhar com ele. A grande maioria cita, como um diferencial, o fato de o software estar disponível gratuitamente na internet ${ }^{5}$ em mais de sessenta e cinco línguas. O software está ainda disponível para ser instalado em computadores, tablets e smartphones, diferentemente de outros softwares de geometria dinâmica.

A página na internet, onde ० GeoGebra está disponível para instalação, oferece aos usuários vídeos onde são indicadas construções geométricas de gráficos de funções, objetos geométricos como cubos, pirâmides, entre outros. Dessa forma, é proporcionado ao usuário, sendo ele professor ou não, uma gama de exemplos para utilização dos recursos presentes no GeoGebra.

Além dos fatores mencionados acima, é indiscutível a enorme contribuição que o uso do computador pode trazer para as aulas de Matemática como é evidenciado em vários trabalhos: GRAVINA (2001); BORBA e PENTEADO (2007); KENSKI (2007); OLIVEIRA (2009). Os softwares, em especial o GeoGebra, enriquecem a aprendizagem pois trazem novas experiências com os objetos matemáticos, potencializando o aprendizado também por meio da visualização.

O trabalho utilizando os softwares matemáticos pode proporcionar representações interativas e versáteis de objetos matemáticos. Através

\footnotetext{
${ }^{5}$ Disponível em http://www.geogebra.org/
} 
de um diálogo inteligente dos alunos com a máquina, que pode facilitar a exploração visual e numérica de temas relativos a diferentes campos da matemática, são favorecidas as diversas formas de pensamento matemático. (LAGE; FROTA, p. 77, 2011).

No quesito visualização, o GeoGebra proporciona ao usuário esse diálogo inteligente como menciona as autoras Lage e Frota. Logo na tela inicial do software há três campos principais destinados ao acompanhamento visual por parte de quem o manipula, a Janela de Visualização (campo geométrico), Janela de Álgebra (campo que relaciona cada objeto geométrico da Janela de Visualização com sua escrita algébrica) e a Entrada (campo destinado à escrita de comandos computacionais). Indicamos na figura abaixo esses três campos por (I), (II), e (III) respectivamente:

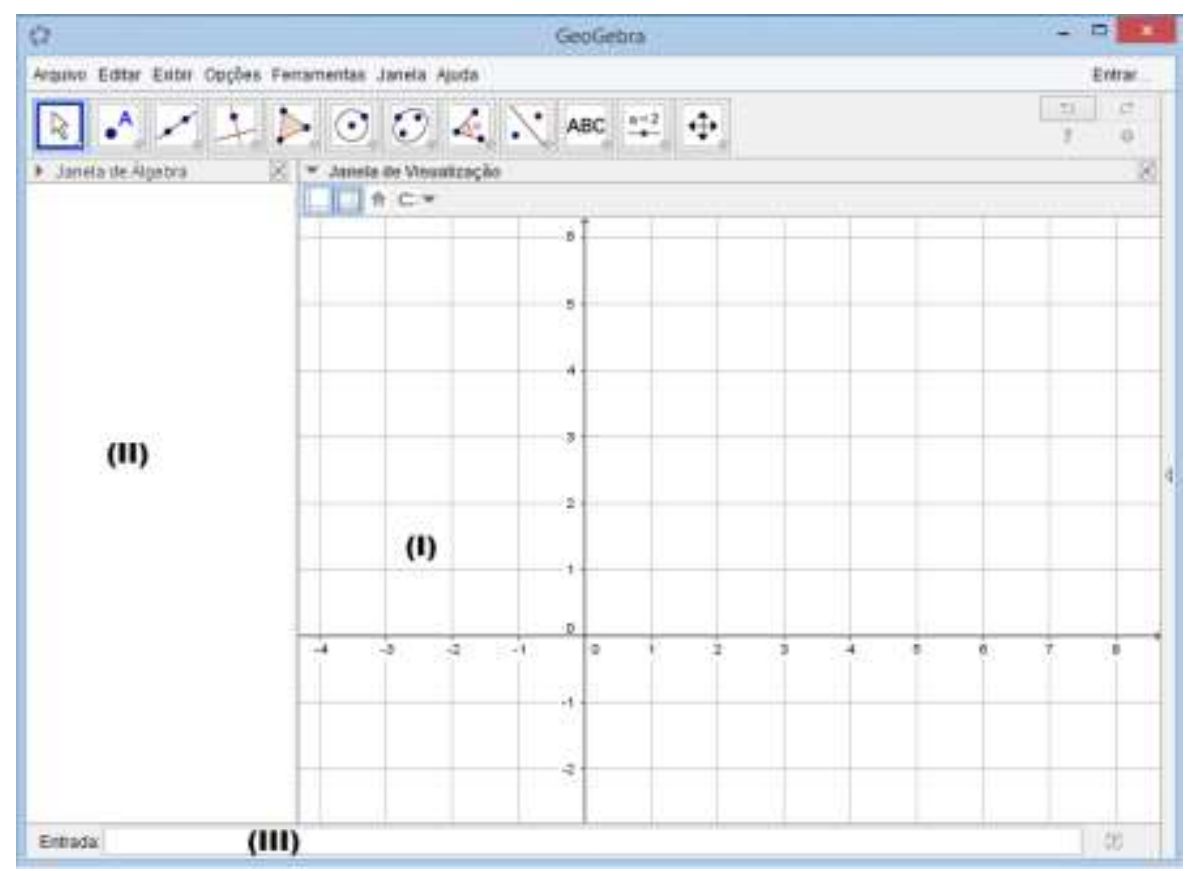

Figura 24: Tela principal do GeoGebra Fonte: Autor.

Como exemplo, apresentamos na figura a seguir o gráfico da função $f(x)$ $=\mathrm{x}^{2}$; os pontos $\mathrm{A}$, B e C; uma reta passando pelos pontos $\mathrm{B}$ e $\mathrm{C}$. Observe que cada objeto geométrico no campo (I) tem sua representação algébrica no campo (II). Note que, no campo Entrada (III), a função $f(x)$ é escrita utilizando um comando específico, a saber, $f(x)=x^{\wedge} 2$. 


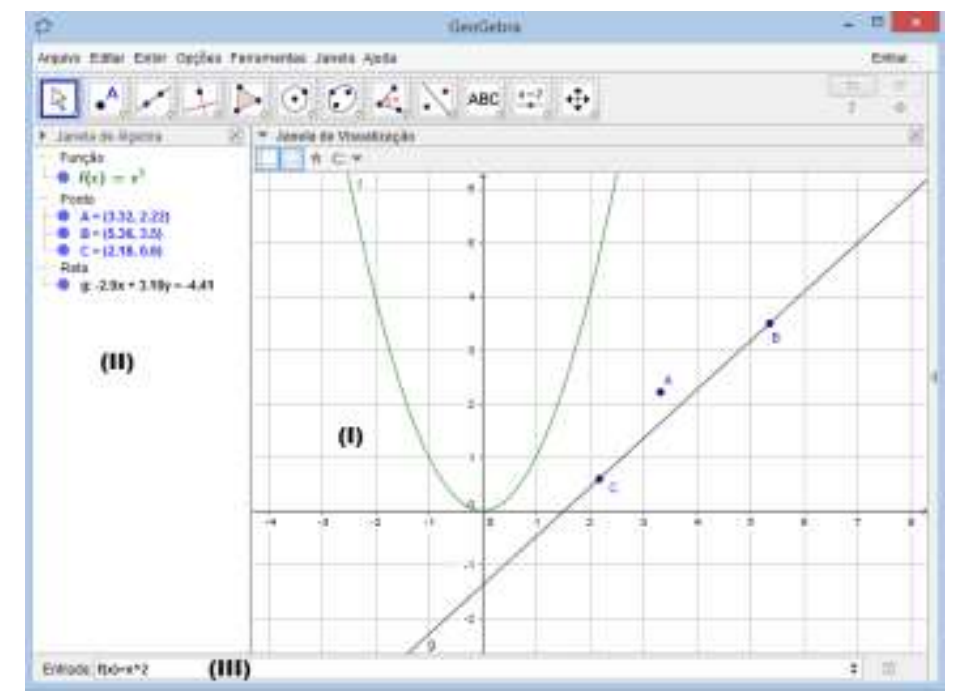

Figura 25: Janelas do GeoGebra

Fonte: Autor.

Essa visualização, por sua vez, auxilia na formação de imagens mentais (AMANCIO, 2013) possibilitando uma maior apreensão dos conceitos matemáticos envolvidos nas respectivas atividades, ajudando em atividades futuras.

Os ambientes de geometria dinâmica ainda oferecem a vantagem de arrastar ou mover as figuras e objetos geométricos com o cursor, possibilitando assim a percepção de características que foram alteradas ou mantidas após esse mover. Isso representa "um grande potencial para que atividades investigativas sejam elaboradas" (SILVA, p. 9, 2013), ajudando o aluno em suas conjecturas através da experimentação. Observa-se assim que, esse software ajuda em atividades investigativas. Inclusive, o fato de podermos modificar os objetos e acompanhar a mudança na representação algébrica e na representação figural estimula a aprendizagem. Veremos, no Capítulo 5 deste trabalho, que essa variedade de registros é essencial para a apreensão dos objetos matemáticos.

O GeoGebra, em sua tela principal, disponibiliza ícones revelando algumas das várias ferramentas contidas nele. Isso é vantajoso, pois facilita seu uso, incentivando a intuição do usuário.

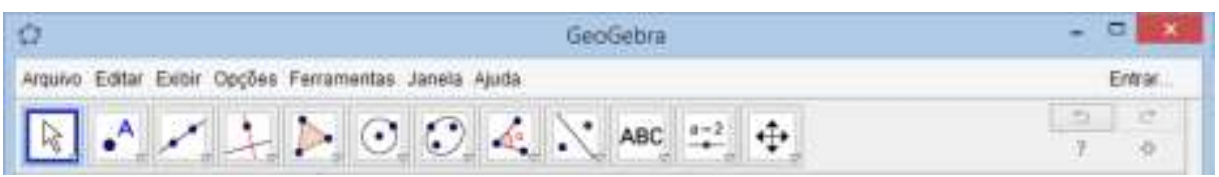

Figura 26: Ícones na janela principal do GeoGebra Fonte: Autor. 
Por conta dos aspectos mencionados acima, por sua versatilidade e funcionalidade; pelo amplo número de trabalhos relacionados ao uso do software, o GeoGebra se tornou uma interessante opção e uma excelente ferramenta para este trabalho. A seguir, apresentamos as ferramentas que 0 software disponibiliza. Não mostraremos todas, apenas as que podem ser usadas para a realização das atividades que estão presentes no Anexo $C$ deste trabalho.

\begin{tabular}{|c|c|}
\hline$v_{v}$ & Mover, arrastar e marcar objetos \\
\hline${ }^{A}{ }_{\nabla}$ & Criar pontos \\
\hline$\gamma_{0}$ & Marcar a intersecção entre duas ou mais linhas \\
\hline$\therefore$ & Criar ponto médio \\
\hline$\rho_{0}^{\circ}$ & Criar reta \\
\hline$\therefore$ & Criar segmento de reta \\
\hline$\dot{t}_{0}$ & Criar reta perpendicular à uma reta dada \\
\hline 6 & Criar retas tangentes à uma circunferência, passando por um ponto \\
\hline$\bigodot_{\nabla}$ & Criar circunferências a partir de seu centro \\
\hline$\odot_{\nabla}$ & Criar circunferência a partir de seu centro e seu raio \\
\hline 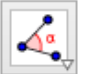 & Calcular, mostrar ângulos \\
\hline$\stackrel{\bullet}{\bullet}$ & Refletir um objeto por uma reta dada \\
\hline$\bullet^{\bullet}$ & Refletir um objeto por um ponto dado \\
\hline$\leftrightarrow_{\nabla}$ & Mover a janela de visualização \\
\hline Q & Ampliar a janela de visualização \\
\hline Q. & Reduzir a janela de visualização \\
\hline
\end{tabular}

Tabela 1: Ferramentas do GeoGebra utilizadas

Fonte: Autor. 
Devemos notar que o próprio GeoGebra oferece aos usuários algumas das transformações geométricas do plano através dos ícones apresentados em sua tela principal. Optamos por utilizá-las em nosso trabalho apenas para otimizar o tempo na realização das atividades, porém, o software também oferece todas as condições para que realizemos, por completo, todos os procedimentos na obtenção de determinados resultados, como se estivéssemos trabalhando com régua não graduada e compasso.

A utilização do GeoGebra nas aulas de Matemática se torna um excelente incentivo para os alunos em todos os níveis de ensino, por oferecer várias ferramentas e por ser de fácil utilização. Segundo Cyrino e Baldini (2012), o uso do GeoGebra favorece a superação de dificuldades conceituais em matemática. Por meio da interação com esse software, o aluno é levado a interagir com os colegas, quando mostra o resultado encontrado e quando comunica sua descoberta. $O$ aluno também se torna possivelmente mais ativo, porque 0 software o incentiva a investigar. Segundo Gravina (1996)

\footnotetext{
Quanto às atitudes dos alunos frente ao processo de aprender: experimentam; criam estratégias; fazem conjecturas; argumentam e deduzem propriedades matemáticas. A partir da manipulação concreta, "o desenho em movimento", passam para a manipulação abstrata atingindo níveis mentais superiores da dedução e rigor, e desta forma entendem a natureza do raciocínio matemático. (GRAVINA, 1996, p.13)
}

Dissemos que o GeoGebra tem a vantagem de estimular a investigação Matemática. No capítulo seguinte, veremos quais as características dessa investigação em sala de aula e veremos que ela é uma metodologia que deveria estar mais presente nos vários níveis de ensino. 


\section{A Investigação Matemática}

No segundo capítulo, vimos como os PCN recomendam o estudo das isometrias no Ensino Básico e como o tema é abordado em um dos livros destinados aos cursos de formação de professores.

A seguir, apresentamos como a Investigação Matemática está inserida em documentos oficiais que regem a Educação no Brasil e como é recomendada sua inserção em sala de aula. Veremos suas principais características segundo Ponte, Brocardo e Oliveira (2003a) e em que aspectos ela se diferencia da Resolução de Problemas.

\subsection{Investigação em sala de aula}

A Lei de Diretrizes e Bases da Educação Nacional apresenta na seção IV o seguinte artigo:

Art. 36. O currículo do ensino médio observará o disposto na Seção I deste Capítulo e as seguintes diretrizes:

II - adotará metodologias de ensino e de avaliação que estimulem a iniciativa dos estudantes (...)

Vemos, assim, que na LDB há um incentivo ao professor para que em suas aulas utilize metodologias que façam com que os alunos sejam participativos e estimulados a aprender.

Nos Parâmetros Curriculares Nacionais (BRASIL, 2000, p. 74) os professores também são direcionados a procurar novas posturas em sala de aula:

adotar estratégias de ensino diversificadas, que mobilizem menos a memória e mais o raciocínio e outras competências cognitivas superiores, bem como potencializem a interação entre aluno-professor e aluno-aluno para a permanente negociação dos significados dos conteúdos curriculares, de forma a propiciar formas coletivas de construção do conhecimento; 
estimular todos os procedimentos e atividades que permitam ao aluno reconstruir ou "reinventar" o conhecimento didaticamente transposto para a sala de aula, entre eles a experimentação, a execução de projetos, o protagonismo em situações sociais.

Desta forma, percebemos que, cabe ao professor buscar outras maneiras de ensinar, procurando novas metodologias, fazendo com que seus alunos se interessem em aprender cada vez mais, pois as escolhas que o professor faz também influenciam na aprendizagem dos alunos (BRASIL, 2000, p.83).

Entretanto, as recomendações acima não estão voltadas somente ao Ensino Médio. Na LDB, também é proposto semelhante postura aos professores no Ensino Superior:

Art. 43. A educação superior tem por finalidade:

I - estimular a criação cultural e o desenvolvimento do espírito científico e do pensamento reflexivo;

Se queremos ver mudanças nas atuações dos professores em sala de aula, esses estímulos às mudanças devem ser visíveis nos cursos de formação de professores, uma vez que os professores "procuram ensinar do mesmo modo que aprenderam", pois,

\footnotetext{
Normalmente, seus referenciais de prática, são as lembranças que têm dos procedimentos de seus próprios professores, sem clareza de uma escolha pedagógica, que irá interferir diretamente na interação necessária entre professor, aluno e conteúdo a ser ensinado. (BURATTO, 2006, p. 45)
}

Outros autores também comentam sobre a postura que alunos e exalunos têm em relação aos seus cursos. Parte deles têm a concepção de ensino como transmissão de conhecimento (D'AMBRÓSIO, 1989 apud BURATTO, 2006, p. 41), sendo que o professor deve apresentar o maior conteúdo de matéria aos alunos.

Dessa forma, não é difícil perceber que os professores ministram suas aulas de acordo com as experiências que tiveram como alunos. Suas 
concepções e o modo como aprenderam os conteúdos em Matemática serão, em parte, transmitidos aos seus futuros alunos. Segundo Cury (1999), as influências sócio culturais também interferem na maneira que alunos e professores percebem a Matemática.

Segundo Mabuchi, até mesmo o modo como o professor construiu o próprio conhecimento acaba influenciando seus alunos. Ela concorda com os outros autores ao dizer que

O professor desenvolve nos seus alunos aquilo que teve oportunidade de desenvolver nele mesmo, a aprendizagem de conteúdo, a construção de conhecimento, a independência e autonomia próprias. [...]. As concepções de aprendizagem, de conteúdo, de avaliação, entre outras competências que o futuro professor construir durante seu processo de formação, marcarão sua atuação profissional. (MABUCHI, 2000, p. 196)

A maneira como os professores ensinam na sala de aula é, em parte, um reflexo de como eles aprenderam. Ou seja, se ainda vemos professores ensinando da "maneira tradicional" é porque nos cursos onde foram formados também haviam professores ensinando através do "método tradicional". E mais,

Um livro-texto, não importa o quão completo e bem projetado ele seja, nunca pode orientar completamente o ensino, mesmo que o professor o siga ao pé da letra. (PUTNAN, 1992 apud. ONUCHIC, 1999, p. 213).

[...] um ensino apoiado inteiramente em técnicas operatórias, repetitivas, e sem significado, não deveria ser o caminho escolhido. (ONUCHIC, 1999, p. 215).

O professor tem papel fundamental, em qualquer nível de ensino que lecione. Assim, para que haja efetiva aprendizagem dos alunos é necessário a implementação de estratégias diferenciadas em relação ao ensino "tradicional". Sabendo disso, Ortigão (2009) reforça as considerações de Carvalho (1994):

[...] a Educação Matemática no Brasil precisa ter como meta central a melhoria da atuação do professor no processo de ensino-aprendizagem. Para ele, o problema básico da Educação Matemática em nosso país é a formação inicial e continuada do professor, que deve almejar, 
prioritariamente, a mudança da prática pedagógica do professor em sala de aula. (ORTIGÃO, 2009, p. 193)

Faz-se necessária, na formação de professores, a implementação de metodologias que incentivem os futuros professores a serem menos passivos em relação ao conteúdo que estão vendo, para que no futuro, influenciem seus próprios alunos a serem também mais ativos em seus aprendizados. Concordamos com Buratto ao afirmar:

Os alunos (seja qual for o nível de ensino) têm um papel passivo nas aulas de Matemática, pois normalmente não trabalham com questões que admitam diferentes respostas, nem levantam contradições para serem analisadas e discutidas e, que os desafiem a obter diferentes soluções para um problema. (BURATTO, 2006, p. 46)

Segundo Lima (2009), atividades investigativas não devem ser vistas como atividades adicionais. Devem ser mais exploradas em salas de aula, pois permitem a atuação dos alunos em sua própria aprendizagem.

Temos na Investigação Matemática uma ferramenta para fazer com que os alunos deixem o "papel passivo nas aulas", pois, os alunos são levados a construir o aprendizado. Para Frota (2004), além de um poderoso recurso na Educação Matemática, as atividades investigativas auxiliam na reeducação matemática de nossos professores (FROTA, 2004, p.9).

Onuchic vai ainda além ao afirmar que ensinar Matemática através da resolução de problemas está condizente com os PCN e conceitos e habilidades matemáticas são aprendidos no contexto de resolução de problemas (ONUCHIC, 1999, p. 207). A autora comenta ser necessário haver mudanças também no Ensino Superior para que ocorra efetiva contribuição à aprendizagem. Ela afirma

De acordo com os PCN, entre os obstáculos que o Brasil tem enfrentado em relação ao ensino de Matemática, encontram-se a falta de uma formação profissional qualificada, as restrições ligadas às condições de trabalho, a ausência de políticas educacionais efetivas e interpretações equivocadas de concepções pedagógicas. 
Um problema sério enfrentado por uma reforma de ensino como a pretendida reside na formação dos professores e em seu trabalho de sala de aula. (ONUCHIC, 1999, p. 211)

Frota (2004) ressalta ainda a importância de um ensino baseado na Investigação Matemática, de modo que este não seja simplificado em uma lista de problemas apresenta aos alunos.

Lamonato e Passos (2011) também apontam para a mesma necessidade de implementar essa metodologia em todos os níveis de ensino, em especial, na formação de professores:

Consideramos a resolução de problemas e a exploração-investigação matemática nos diversos níveis de escolaridade, inclusive na Educação Infantil, pois, mesmo os alunos não tendo condições de elaborar processos complexos de raciocínio, podem posicionar-se, justificar e argumentar seus feitos, com posturas investigativas perante situações matemáticas ou não, tomando decisões e não apenas dando respostas esperadas. Para tanto, cabe ao professor questionar suas próprias afirmações e a dos estudantes e não encerrar a conversa na primeira afirmação, mesmo que esta esteja correta. Cabe à formação do professor proporcionar tais vivências. (LAMONATO; PASSOS, 2011, p. $19)$.

Sendo a Investigação Matemática uma ferramenta poderosa e mesmo adequada para os professores, como exposto acima, devemos compreender 0 que se caracteriza como Investigação Matemática.

\subsection{Características das Investigações Matemáticas}

Acima comentamos que a Investigação Matemática como metodologia é adequada e está de acordo com os PCN, entretanto, não a caracterizamos.

A estratégia para trabalhar em sala de aula com investigação matemática é semelhante à adotada em Resolução de Problemas proposta por Polya (1995). Esse autor apresenta em seu conhecido livro "A Arte de Resolver Problemas" os seguintes passos: 
1ำ passo: Compreender do problema

- É preciso compreender o problema;

$2^{\circ}$ passo: Estabelecer um plano

- Encontrar conexões entre os dados e a incógnita

- Considerar problemas auxiliares se não puder encontrar uma conexão imediata;

- Chegar a um plano para a resolução;

3ำ passo: Executar o plano

- Verificar se cada estratégia está sendo executada corretamente, observando se é possível demonstrar;

4ำ passo: Retrospecto

- Verificar os resultados e argumentos;

- Verificar sua utilização em outro problema.

Outros autores defendem a abordagem por Resolução de Problemas: Dante (2000), Pozo (1998), Cavalcanti (2001), Onuchic (1999). Também foi ressaltado em alguns desses trabalhos o papel do professor de acordo com essa metodologia. Romanatto (2012), por exemplo, cita Carvalho e Gil-Perez (2000), indicando que o professor deve:

a) conhecer os grandes problemas que originaram a construção de determinado assunto;

b) conhecer as orientações metodológicas empregadas na construção de determinada parte da Matemática;

c) conhecer os obstáculos epistemológicos ou didáticos relacionados aos mais diversos conteúdos da Matemática;

d) saber selecionar conteúdos adequados e que sejam acessíveis aos estudantes e suscetíveis de interesse;

e) ter algum conhecimento dos assuntos matemáticos atuais; 
f) estar preparado para aprofundar conhecimentos assim como adquirir outros e

g) ter conhecimentos de pesquisas em educação matemática. (CARVALHO; GIL-PEREZ, apud. ROMANATTO, p. 304, 2012).

Obviamente, as considerações dos autores acima se relacionam com a Investigação Matemática e também com outras metodologias. De acordo com os itens acima, o professor precisar ter uma visão ampla do assunto que for tratar em sala de aula, se preocupando com assuntos atuais tanto em Matemática quanto em Educação Matemática. Na visão destes autores, o professor deve problematizar os conteúdos, fazendo com que partam dos alunos as respostas, conduzindo os alunos à descoberta.

Onuchic (2004) salienta que, dentro da Resolução de Problemas, o professor também necessita fazer questionamentos antes de levar quaisquer problemas para a sala de aula. A autora reforça a ideia que esta metodologia não significa fazer uma lista de exercícios e distribuir aos alunos.

Entretanto, estando presente nas orientações curriculares das décadas de 80 e 90, observou-se que há vários tipos de problemas que podem ser propostos com diferentes finalidades.

(...) acabou por se constatar que os problemas a propor podem ser de muitos tipos, estando longe de terem todos o mesmo interesse educacional (Abrantes, 1988). Uma análise das potencialidades dos diferentes tipos de problemas levou a um interesse cada vez maior pelas questões abertas, susceptíveis de dar origem a atividades de investigação matemática por parte dos alunos. (PONTE; BROCARDO; OLIVEIRA, 2003, p. 14)

Com o avanço tecnológico, o acesso às calculadoras e computadores em sala de aula, foi favorecido o caráter experimental e investigativo. Isso provocou uma "nova perspectiva" na Metodologia proposta por George Polya.

Para D’Ambrosio (1989), a Resolução de Problemas foi baseada, inicialmente, em heurísticas e passos, muitas vezes essa abordagem gerava um ensino visando o ocasional envolvimento com a resolução de problemas (D’AMBROSIO, 1989, p.17). Segundo ele, a proposta atual é caracterizada pela 
investigação e construção de conceitos matemáticos pelo próprio aluno. Essa investigação se dá por meio de situações que estimulem a curiosidade. D’Ambrosio diz que ainda há espaço para a Resolução de Problemas segundo o modelo de Polya, mas sua abordagem tem sido menos enfatizada diante da nova visão do conceito.

Na visão de Ponte, Brocardo e Oliveira (2003), a Investigação Matemática propõe atividades mais abertas, a questão não está completamente definida (PONTE, 2003, p. 101). Com isso, o desenvolvimento cognitivo do aluno é favorecido através da participação ativa do mesmo, pois, mobiliza os seus recursos cognitivos e afetivos com vista a atingir um objetivo (PONTE; BROCARDO; OLIVEIRA, 2003, p. 23), além de fazer com que o discente atue como um matemático:

O conceito de tarefa de investigação pretende assim trazer para a sala de aula o espírito da atividade matemática genuína, constituindo, por isso, uma poderosa metáfora educativa. $O$ aluno é chamado a agir como um matemático, não só na formulação de questões e conjecturas e na realização de provas e refutações, mas também na apresentação dos seus resultados e na sua discussão e argumentação com os colegas e o professor. (PONTE; BROCARDO; OLIVEIRA, 2003, p. 23)

Segundo os autores, o que caracteriza uma Investigação Matemática são os seguintes "momentos":

O primeiro abrange o reconhecimento da situação, a exploração preliminar e a formulação de questões. O segundo momento refere-se ao processo de formulação de conjecturas. $O$ terceiro inclui a realização de testes e o eventual refinamento das conjecturas. E, finalmente, o último diz respeito à argumentação, à demonstração e avaliação do trabalho realizado. (PONTE; BROCARDO; OLIVEIRA, 2003, p. 20)

Eles ainda apresentam atividades que estão ligadas a cada um desses momentos (PONTE; BROCARDO; OLIVEIRA et al., 2003): 


\begin{tabular}{|c|l|}
\hline Momentos & \multicolumn{1}{c|}{ Atividades } \\
\hline \multirow{2}{*}{$\begin{array}{c}\text { Exploração e formulação de } \\
\text { questões }\end{array}$} & - Reconhecer uma situação \\
& problemática; \\
& - Explorar a situação problemática; \\
& - Formular questões \\
\hline Conjecturas & - Organizar dados; \\
& - Formular conjecturas (e fazer \\
& afirmações sobre a conjectura) \\
\hline Testes e reformulação & - Realizar testes; \\
& - Refinar uma conjectura \\
\hline \multirow{2}{*}{ Justificação e avaliação } & - Justificar uma conjectura; \\
& - Avaliar o raciocínio ou o resultado \\
& do raciocínio \\
\hline
\end{tabular}

Tabela 2: Momentos na Investigação Matemática

Fonte: Autor, baseado em PONTE; BROCARDO; OLIVEIRA et al., 2003.

Trabalhar com essa metodologia em sala de aula produz alguns benefícios, como cita Lamonato e Passos (2011)

(a) proporcionar momentos de trabalho em grupo que apostam na organização e na troca de experiências e conhecimentos;

(b) oportunizar o registro, a negociação de significados e a comunicação de processos e resultados;

(c) estimular a aprendizagem e a articulação de conhecimentos aprendidos anteriormente;

(d) contribuir para o desenvolvimento da percepção, de observações, da exploração e para o estabelecimento de relações entre fenômenos, objetos ou situações;

(e) colaborar para que as crenças e concepções dos alunos a respeito da Matemática e seu ensino estejam mais próximas da natureza desta disciplina, valorizando o caráter científico da Matemática, com influências diretas em sua posição perante esta ciência;

(f) possibilitar ao professor momentos de partilha de informações e melhor conhecimento dos processos de aprendizagem de seus alunos, 
com consequências para suas crenças e concepções a respeito do ensino, da aprendizagem da Matemática e das aulas propriamente ditas. (LAMONATO; PASSOS, 2011, p.70)

Lamonato e Passos (ibid.), no item (f), demonstram que as vantagens de se trabalhar com essa metodologia não se restringem aos alunos, mas também, atendem ao professor em sua prática. As duas autoras concordam com Ponte e seus colaboradores, pois, estes afirmam que o próprio professor pode criar uma postura investigativa ao preparar suas aulas de Matemática, para depois desenvolver as ideias com seus alunos (PONTE; BROCARDO; OLIVEIRA, 2003, p. 142).

A Investigação Matemática se apresenta como um caminho a mais para a Educação Matemática. A sua introdução no Ensino Básico, assim como a Resolução de Problemas, precisa estar presente em sala de aula (LIMA; MIRANDA, 2009), inclusive em cursos de formação de professores, tanto inicial como continuada (LAMONATO; PASSOS, 2011). 


\section{As Representações Semióticas}

A análise da sequência de atividades foi feita segundo a Teoria das Representações Semióticas de Raymond Duval, uma vez que, as representações feitas pelos participantes, se tornam uma rica fonte para os docentes aperfeiçoarem suas práticas.

Podemos pensar na utilização da teoria de Duval como uma maneira didático/metodológica que o professor e/ ou o pesquisador devem utilizar se o objeto é a aquisição de conhecimento. (DAMM, 2012, p.168)

As Representações Semióticas têm um papel fundamental não somente no desenvolvimento cognitivo, mas também, para a evolução do pensamento matemático (DUVAL, 2012b).

Segundo Duval, cada objeto matemático (retas, número, função, vetores, entre outros) tem representantes, que podem ser, por exemplo, notações, figuras ou símbolos. Dessa forma, é importante perceber primeiramente que, não se deve confundir o objeto matemático com a sua representação (DUVAL, 2013).

(...) em matemática, as representações semióticas não são somente indispensáveis para fins de comunicação, elas são necessárias ao desenvolvimento da atividade matemática. (DUVAL, 2009, p. 15)

Devemos notar que a comunicação de qualquer resultado matemático necessita de representações semióticas. Damm (2012) afirma que o conhecimento matemático sempre é mobilizado pelas pessoas com o auxílio de representações. Dessa forma, é imprescindível a consideração sobre as diferentes formas de representação dos objetos matemáticos para o ensino.

A utilização de representações semióticas aparece primordialmente pela atividade matemática e lhe parece ser intrínseca.

De maneira mais global, podemos constatar que o progresso do conhecimento vem acompanhado sempre da criação e do desenvolvimento de sistemas semióticos novos e específicos que coexistem mais ou menos com o primeiro dentre eles, aquele da língua natural. Assim, a formação do pensamento cientifico é inseparável do 
desenvolvimento de simbolismos específicos para representar os objetos e suas relações. (DUVAL, 2009, p.16)

As Representações Semióticas, para Duval, podem ser classificadas de acordo com a tabela a seguir:

\begin{tabular}{|c|c|c|}
\hline & \multicolumn{2}{|c|}{ Representação } \\
\hline Registros & Discursiva & Não discursiva \\
\hline Multifuncionais & $\begin{array}{l}\text { Língua natural } \\
\text { Associações verbais } \\
\text { Forma de raciocinar: } \\
\text { - Argumentação a partir de } \\
\text { observações } \\
\text { - Dedução válida a partir de } \\
\text { definição ou de teoremas. }\end{array}$ & $\begin{array}{l}\text { Figuras geométricas planas } \\
\text { ou em perspectiva (em } \\
\text { dimensão } 0,1,2 \text { ou } 3 \text { ) } \\
\text { - Apreensão operatória e não } \\
\text { somente perceptiva } \\
\text { - Construção com instrumentos }\end{array}$ \\
\hline Monofuncionais & $\begin{array}{l}\text { Sistemas de escritas: } \\
\text { - Numéricas (binárias, decimal, ...) } \\
\text { - Algébricas } \\
\text { - Simbólicas (línguas formais) } \\
\text { Cálculo }\end{array}$ & Gráficos cartesianos \\
\hline
\end{tabular}

Tabela 3: Tipos de representação

Fonte: Duval (2013, p. 14).

De acordo com a tabela acima, qualquer representação utilizando régua e compasso, por exemplo, é uma representação multifuncional não discursiva. Além disso, Duval afirma que as representações permitem analisar as produções matemáticas, sobretudo as que são construídas com objetivos de ensino e aprendizagem. (DUVAL, 2011, p. 104).

Entretanto, para resolução de um problema, Duval comenta:

(...) em uma resolução de problema, um registro pode aparecer explicitamente privilegiado, mas deve existir sempre a possibilidade de passar de um registro ao outro. (...) a compreensão matemática supõe a coordenação de ao menos dois registros de representação semiótica. (DUVAL, 2013, p. 15)

A passagem ou a transformação de um registro para outro mencionada acima pode ocorrer de duas maneiras distintas: através de conversões ou através de tratamentos. As conversões são mudanças totais do sistema, 
procurando a conservação das referências aos mesmos objetos. Já os tratamentos são mudanças de representações permanecendo no mesmo sistema. Como exemplo de uma conversão, Duval cita a passagem da escrita algébrica de uma equação para a sua representação gráfica, já como exemplo de tratamento, completar uma figura segundo critérios de conexidade e de simetria (DUVAL, 2013), como segue:

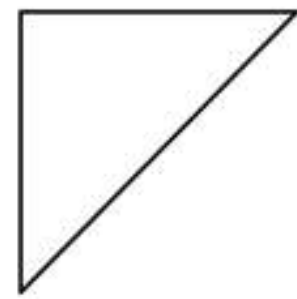

a

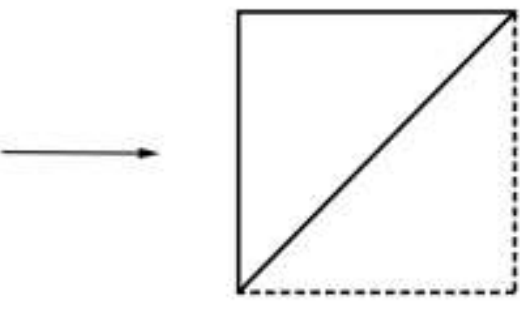

b

Figura 27: Exemplo de tratamento Fonte: Autor.

Note que, o tratamento exemplificado é figural. Neste tipo de tratamento, a divisão em subfiguras, criação de objetos como pontos e segmentos são comuns.

O autor ainda esclarece o papel das representações semióticas dentre outros tipos de representações. Para ele, além da comunicação que se estabelece por meio delas, as representações são igualmente essenciais à atividade cognitiva do pensamento. (DUVAL, 2012b, p. 269). Com isto,

Não é possível, portanto, fingir como se as representações semióticas fossem simplesmente subordinadas às representações mentais, pois o desenvolvimento da segunda depende de uma interiorização da primeira e somente as representações semióticas permitem preencher algumas funções cognitivas essenciais como a de tratamento. O funcionamento cognitivo do pensamento humano se revela inseparável da existência de uma diversidade de registros semióticos de representação. Se é chamada "semiose" a apreensão ou produção de uma representação semiótica, e "noesis" a apreensão conceitual de um objeto, é preciso afirmar que a noesis é inseparável da semiose. (DUVAL, 2012b, p. 270)

Segundo Duval, as Representações Semióticas realizam funções das Representações Mentais e ainda vão além (DUVAL, 2009). 
A compreensão conceitual, a diferenciação e o domínio das diferentes formas de raciocínio, as interpretações hermenêutica e heurística dos enunciados são intimamente ligados à mobilização e à articulação quase imediatas de muitos registros de representação semiótica. (DUVAL, 2009, p. 20)

Isso nos leva a concluir que a mobilização de vários registros é fundamental para o domínio de conceitos em Matemática por parte dos alunos, pois estes, diante de vários registros sobre um mesmo objeto matemático, adquirem diferentes formas de raciocínio devido à articulação dos distintos registros.

Pinheiro e Barreto (2013) afirmam que, Duval, defende assim uma abordagem cognitiva junto aos alunos.

Tal abordagem procura inicialmente descrever o funcionamento cognitivo que possibilita a um aluno compreender, efetuar e controlar, ele próprio, a diversidade dos processos matemáticos que lhe são propostos em situação de ensino. (PINHEIRO; BARRETO, 2013, p. 3)

Para as duas autoras, as Representações Semióticas apresentam recursos que podem contribuir nas metodologias de ensino, pois a teoria oferece ferramentas que auxiliam na compreensão dos modelos de conhecimento. Por meio dela, é possível refletir sobre as teorias de aprendizagem e seus usos em atividades de formação nos ambientes educacionais (PINHEIRO; BARRETO, 2013, p. 4).

Uma vez que a utilização de vários registros se torna imprescindível para a compreensão dos objetos matemáticos (DUVAL apud. PINHEIRO; BARRETO, 2013), o uso de programas de geometria dinâmica como o GeoGebra torna-se mais um auxílio, tanto aos alunos quanto aos professores, pois, são mais uma forma de representar os objetos matemáticos.

Barroso e Franco (2012) consideram que o uso de novas tecnologias estimula os alunos para novas descobertas. Devido aos recursos disponíveis em softwares de Geometria Dinâmica, estes têm se tornado de grande auxílio para o aprendizado. 
Segundo Duval (2012b), para um sistema semiótico ser um registro de representação é preciso satisfazer três atividades cognitivas:

\section{- A formação de uma representação identificável como uma representação}

de um registro dado: que respeita regras de utilização, de modo que haja condições de identificação e de reconhecimento da representação;

- O tratamento: que é a transformação de uma representação no mesmo registro onde foi formada;

- A conversão: que é a transformação de uma representação em outro registro, conservando ou não o conteúdo da representação original.

Levando em consideração estes três aspectos, em nossa pesquisa consideramos os objetos construídos, por meio do software GeoGebra, como um sistema de representações semióticas.

A Teoria das Representações Semióticas não se limita à simples classificação dos registros. Ainda há os conceitos de congruência e nãocongruência entre as unidades de sentido.

Para analisar a atividade de conversão, é suficiente comparar a representação no registro de partida com a representação terminal no registro de chegada. Esquematicamente, duas situações podem ocorrer. Ou a representação terminal transparece na representação de saída e a conversão está próxima de uma situação de simples codificação - dizse então que há congruência -, ou ela não transparece absolutamente e se dirá que ocorre a não congruência. (DUVAL, 2013, p. 19)

Segundo Duval (2013), três condições são necessárias para que haja congruência entre dois registros:

- Correspondência semântica entre os elementos nos registros;

- Unicidade semântica terminal;

- Mesma ordem nas unidades de representação. 
Para Duval, o grau de não congruência entre os registros de partida e de chegada está ligado à dificuldade da conversão de uma representação em outra (DUVAL, 2009) e isso interfere no aprendizado.

A variação de congruência e não congruência é uma das maiores causas da incompreensão ou dos erros de interpretação dos enunciados do problema para os alunos. (DUVAL, 2011, p. 121)

Duval revela que a importância da conversão é que os tratamentos podem ser totalmente diferentes em cada registro, e um exemplo disso são as figuras em Geometria. Dessa forma, vemos que as mudanças de registro são importantes para o aprendizado, pois é uma variável cognitiva que facilita consideravelmente a aprendizagem ou ela oferece procedimentos de interpretação (DUVAL, 2009, p. 81).

As figuras, seja qual for a área de conhecimento, transmitem algum conceito ou pensamento. Em Geometria, elas têm um papel fundamental para o ensino e o aprendizado. Porém, mesmo com o auxílio de uma figura, podemos ainda assim ter dificuldades para compreender o assunto em questão ou perceber as propriedades e conceitos próprios da figura. Nesse sentido, as figuras desempenham mais que a simples função de ilustração de um objeto matemático.

As figuras possuem três caraterísticas segundo Duval (2011):

- Permitem um reconhecimento imediato;

- Possuem valor intuitivo;

- Podem ser construídas com instrumentos (régua, compasso, softwares, entre outros).

As figuras, em Geometria, podem ter significados diferentes para cada observador, como nos esclarece Torregrosa e Quesada:

Se visualizamos um desenho podemos obter um objeto mental que não tem porquê ser o mesmo para todos os observadores, já que o desenho está unido a propriedades matemáticas que a figura não possui, se não 
as que são atribuídas pelo observador. ${ }^{6}$ (TORREGROSA; QUESADA, 2007, p. 279)

Duval (2009), assim como Bishop e Fischbein (apud. Torregrosa e Quesada, 2007), faz a diferenciação entre os conceitos de desenho e figura. Para o autor, desenho é um caso particular, enquanto que figura é a classe de todos os desenhos que representam determinado objeto. Nesse sentido, podemos inferir o que representamos a seguir:
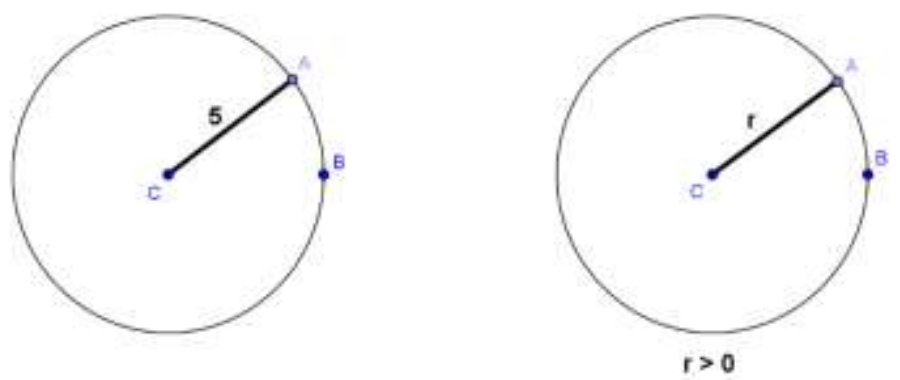

Figura 28: Diferença entre figura e desenho Fonte: Autor.

O círculo da esquerda seria um desenho, pois, é um caso particular já que determinamos que seu raio vale 5 , enquanto que o círculo à direita é uma figura, já que seu raio é variável.

Em Geometria, as operações figurais podem ser de duas naturezas segundo Duval (2011): as mereológicas e as de desconstrução dimensional.

A operação mereológica é aquela que modifica a figura mantendo-a na mesma dimensão, que veremos mais adiante.

As operações de desconstrução dimensional, que segundo Duval é onipresente em todo raciocínio e em toda explicação em relação às figuras em geometria (DUVAL, 2011, p. 90), envolvem a análise das transformações que uma figura pode sofrer através do prolongamento de suas unidades figurais que estão em um nível imediatamente inferior. A dimensão da figura é mantida após a transformação realizada, porém poderá ficar completamente diferente em relação à figura original, mas ainda na mesma dimensão, como no exemplo a seguir:

\footnotetext{
6 Tradução do autor.
} 


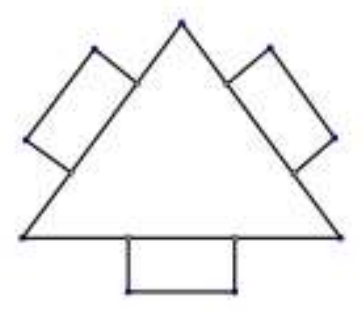

a

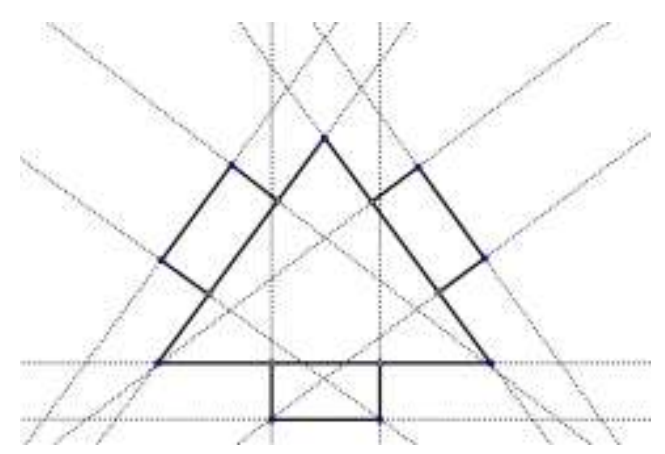

b

Figura 29: Desconstrução dimensional Fonte: Autor.

Na figura 29b apresentamos todas as retas que estão ocultas na parte a. Note que, apesar de tratar-se de uma figura de dimensão dois, fizemos os prolongamentos de seus segmentos e estes são de dimensão um, perceba que as unidades figurais que foram prolongadas estão em um nível imediatamente inferior em relação à figura inicial, como dito anteriormente. Para o caso de figuras ou desenhos em dimensão três estaríamos observando os planos que os compõem, por exemplo.

Duval ressalta que a operação de construção das figuras tem relevância menor em relação à operação de desconstrução dimensional (DUVAL, 2011, p. 89), pois esta última produz novos elementos: segmentos, pontos de intersecção, entre outros.

As operações mereológicas de reconfiguração e de desconstrução dimensional são de fundamental importância no ensino de Geometria, qualquer atividade em Geometria está ligada a essas operações. Segundo Duval,

Toda utilização heurística das figuras na resolução de problemas, toda explicação de uma propriedade geométrica com a ajuda de figuras ou mesmo, para algumas, com a manipulação de um material, toda articulação do enunciado de propriedades com uma figura para justificar ou demonstrar uma conjectura dependem inteira e exclusivamente dessas duas operações. (DUVAL, 2011, p. 90)

Isso nos revela o quão importante é para os professores a Teoria das Representações Semióticas, pois eles são incentivados a evidenciar os aspectos destas duas operações para os alunos, por meio de exemplos e problemas que as destacam. Como docentes, devemos esclarecer aos educandos essas 
transformações figurais, como diz Duval, sem real consciência dessas duas operações, os alunos e os adultos educados podem ficar cegos diante das representações geométricas (DUVAL, 2011, p. 90).

Diante destas duas operações, faz-se necessário apresentar as unidades figurais que comumente aparecem nas representações geométricas:

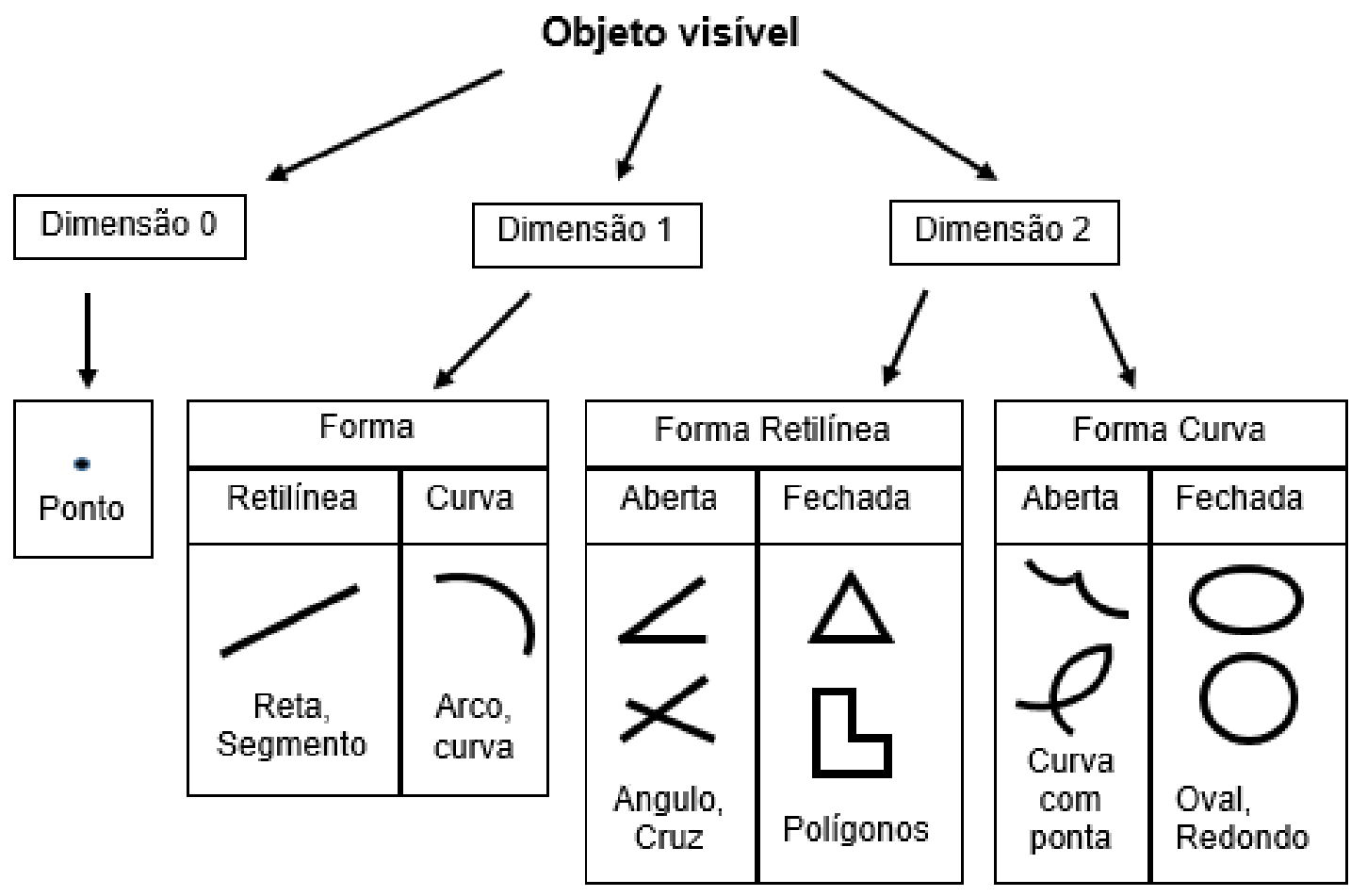

Tabela 4: Unidades figurais

Fonte: Autor, baseado em (DUVAL, 1995, p. 117, apud MORAN, 2015, p.31).

Enxergar essas unidades figurais é muito importante para o processo heurístico em Geometria. Devemos ter a facilidade de passar de uma dimensão para outra, reconhecendo as unidades figurais que podem ser encontradas nas imagens. No entanto, Duval alerta que a unidade figural da dimensão superior se impõe imediatamente à percepção (DUVAL, 2011, p. 87), prejudicando, muitas vezes, o reconhecimento de todas as unidades das figuras de dimensão inferior. A figura seguinte ilustra isso, pois mostra a superposição de dois quadrados, enquanto não ficam tão evidentes os pontos formados pelas intersecções dos lados dos quadrados ou o octógono, por exemplo. 


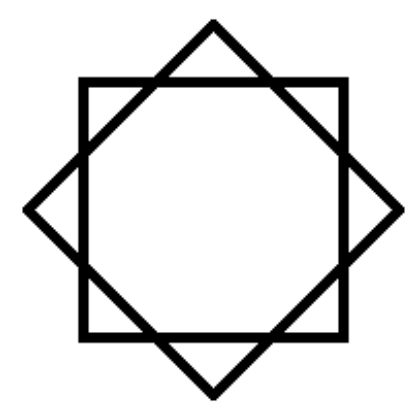

Figura 30: Lei do fechamento Fonte: Autor

O próprio Duval esclarece que existe uma lei que acaba direcionando a percepção da imagem de acordo com a continuidade e fechamento do traçado, os contornos simples e fechados se destacam como uma figura sobre um fundo (DUVAL, 2012a, p. 121).

O modo como interpretamos uma figura, para Duval (2012a), é chamado de apreensões. Elas são de quatro tipos: perceptiva, discursiva, operatória e sequencial.

A apreensão perceptiva está relacionada com as informações imediatas que conseguimos extrair de uma figura, ou seja, quando visualizamos as figuras, de maneira automática percebemos algumas de suas características, como, por exemplo, o seu formato. Ela envolve também a interpretação dos elementos que compõem a figura. Moran diz que a apreensão perceptiva se identifica como uma "maneira natural de ver" as figuras (MORAN, 2015, p. 35).

A apreensão discursiva envolve uma articulação entre a interpretação do enunciado do problema e as figuras relacionadas a ele. Essa apreensão torna-se subordinada à apreensão perceptiva em alguns casos, como revela Duval (2012a).

As modificações possíveis em uma figura estão ligadas à apreensão operatória. Essas modificações que uma figura pode sofrer são de naturezas diferentes. Segundo Duval (2012b), existem três tipos de modificações: Modificação mereológica: consiste em repartir uma figura em subfiguras. Estas podem ser de três tipos:

- Homogênea: as subfiguras são iguais entre si, mas diferentes da figura inicial, como na figura abaixo: 


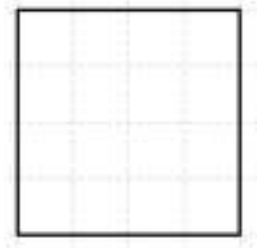

a

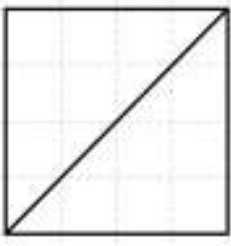

b

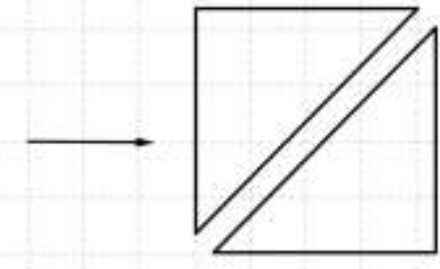

c

Figura 31: Operação mereológica homogênea Fonte: Autor, baseado em Moran (2015).

- Estritamente Homogênea: as subfiguras são iguais entre si e semelhantes à figura inicial. Observe a Figura 32, a seguir,

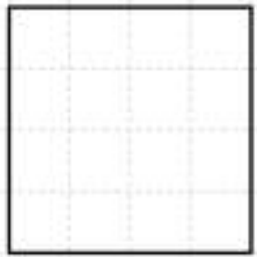

a

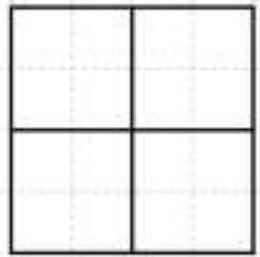

b

Figura 32: Operação mereológica estritamente homogênea Fonte: Autor, baseado em Moran (2015).

Na figura 32b podemos perceber que a divisão do quadrado inicial gerou quadrados menores, mas semelhantes à Figura 32a.

- Heterogênea: as subfiguras são diferentes entre si e diferentes da figura inicial, como no exemplo a seguir:

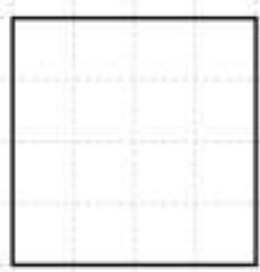

a

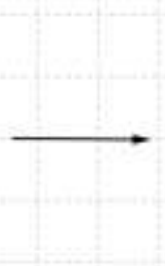

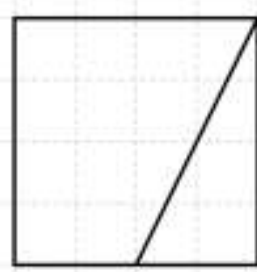

b

Figura 33: Operação mereológica heterogênea Fonte: Autor, baseado em Moran (2015).

Note que, nestes exemplos valem também os processos inversos, que recebem as respectivas classificações. Percebemos que a operação mereológica nada mais é que a decomposição de uma figura em subfiguras. Exemplificamos uma decomposição em dimensão dois, porém podem ocorrer também em dimensão um ou dimensão três. 
As outras duas modificações são:

Modificação ótica: consiste em aumentar, diminuir ou deformar uma figura; Modificação posicional: consiste em mudar uma figura com relação à sua posição inicial. Rotacioná-la ou transladá-la são dois exemplos de modificação posicional.

A apreensão sequencial está ligada a construções de figuras. Quando descrevemos ou produzimos uma figura estamos fazendo uso dessa apreensão.

Utilizamos essas quatro apreensões em nossa pesquisa, devido à natureza de nossas atividades. A seguir apresentamos, em detalhes, cada uma das atividades desenvolvidas e suas correspondências com alguns momentos da Investigação Matemática, os perfis dos grupos que participaram deste trabalho e a análise de suas produções nos cadernos de respostas e no GeoGebra, de acordo com a Teoria das Representações Semióticas de Duval. 


\section{Detalhamento das atividades e análise dos resultados}

Na presente seção, mostraremos os percursos tomados na elaboração da sequência de atividades que foram aplicadas aos três grupos que fizeram parte de nossa pesquisa: professores do Ensino Fundamental II e Ensino Médio; alunos do curso de Licenciatura em Matemática.

A análise é de cunho qualitativo, seguindo características de investigações descritas por Bogdam \& Biklen (1994). Em cada uma das atividades, consideramos as representações semióticas feitas nos cadernos de respostas e também as representações feitas no software GeoGebra.

Estamos chamando de atividade cada um dos problemas propostos no caderno de respostas. Por acreditarmos que uma atividade prepara 0 participante para a atividade seguinte, entendemos que nossa proposta está formando uma sequência problemas, ainda que para o participante não esteja explícita tal ligação. Nesse sentido, estamos considerando os problemas propostos como uma sequência de atividades, sem entrarmos no mérito de alguns autores que fazem diferenciação entre atividades e problemas.

No anexo $\mathrm{C}$, apresentamos a sequência de atividades sobre reflexões por retas. Para melhor acompanhamento por parte do leitor, dividimos esse anexo em parte 1 e 2. Cada uma das atividades foi identificada, entre parênteses, com o respectivo teorema, proposição ou definição, presente na Seção 2.3, ao qual está relacionada. Obviamente, estas identificações não estavam nos cadernos de respostas, entregues aos participantes.

Dentre as atividades que propusemos aos participantes, apenas a Atividade 4 (veja a Parte 1 do Anexo C) está mais próxima de problemas abertos, como recomendados pela metodologia da Investigação Matemática. No entanto, com o uso do software, acreditamos que os momentos da Investigação Matemática podem ser observados nas outras atividades da sequência. Vale lembrar que para Ponte e seus colaboradores, o uso de computadores pode auxiliar na resolução de problemas, incluindo realçar o caráter investigativo (veja a página 55). 


\subsection{Os participantes}

Os dados foram coletados em três grupos distintos: em uma oficina com o apoio do Centro de Aperfeiçoamento de Ensino de Matemática (CAEM) do Instituto de Matemática e Estatística da Universidade de São Paulo para professores de Ensino Fundamental II, professores do Ensino Médio e alunos de Licenciatura em Matemática; em um minicurso durante o Encontro Nacional de Educação Matemática (ENEM) e em uma turma do curso de Licenciatura em Matemática do IME-USP

Dos seis professores que estiveram na oficina do CAEM, quatro eram do Ensino Fundamental II e dois do Ensino Médio, sendo um destes ainda cursando a Licenciatura em Matemática.

Apesar das trinta e seis inscrições que recebemos, apenas seis professores participaram do minicurso no ENEM. Destes, dois lecionam no Ensino Fundamental II e no Ensino Médio, enquanto que os outros quatro dão aulas, atualmente, só no Ensino Médio.

Os professores desses dois grupos não informaram se ministravam aulas em escolas da rede pública, particular ou profissionalizante.

$\mathrm{Na}$ turma de Licenciatura em Matemática, não sabemos ao certo quantos já estão nas salas de aula. Por se tratar de uma turma do período noturno, sabemos que sua maioria já está atuando profissionalmente, não necessariamente no ramo da Educação. Estes alunos estão entre o $5^{\circ}$ e o $9^{\circ}$ semestres do curso de Licenciatura em Matemática.

A oficina do CAEM foi ministrada em dois sábados, totalizando seis horas. No minicurso no ENEM ocorreu apenas um encontro, totalizando duas horas e trinta minutos. Com os alunos da Licenciatura ministramos duas aulas, de uma hora e quarenta minutos cada.

Aos professores que estiveram conosco na Oficina do CAEM, disponibilizamos régua e compasso. Para os demais participantes da pesquisa não fornecemos tais materiais. Neste caso, não acreditamos que tenha havido algum tipo de prejuízo, em termos de realização das resoluções dos problemas, pois não havia a necessidade de precisão no formato das figuras para que se encontrasse as soluções dos problemas. 
Em todos os grupos, para cada uma das atividades da sequência, informávamos aos participantes o tempo disponível para a resolução, que era de cinco a vinte minutos. Ao final do período estipulado, além de darmos oportunidade para os participantes exporem seus resultados, mostrávamos as construções possíveis. Estávamos disponíveis para prestar qualquer tipo de esclarecimento sobre a atividade ou sobre o software, caso os participantes tivessem dúvidas.

Como nessa pesquisa trabalhamos com três grupos distintos, preferimos fazer a seguinte caracterização: chamamos de Grupo I os participantes da Oficina do CAEM. Como foram seis professores, os descreveremos por O1, O2, O3, ..., O6. O Grupo II é formado pelos professores participantes do minicurso no ENEM e os designamos M1, M2, M3, ..., M6. Já a turma de Licenciatura, chamamos de Grupo III e cada participante de L1, L2, ..., L19.

As transcrições das respostas dos participantes, neste trabalho, foram feitas, integralmente, respeitando a escrita que eles fizeram em seus cadernos de respostas.

De acordo com as normas éticas estabelecidas, o Termo de Consentimento Livre e Esclarecido, apresentado no Anexo B, foi assinado por cada um dos participantes.

A seguir, apresentamos as análises das produções desses participantes segundo a Teoria das Representações Semióticas de Duval.

\subsection{Análise das Atividades}

$\mathrm{Na}$ análise das atividades, foram considerados as representações figurais e discursivas feitas nos cadernos de respostas e as representações no GeoGebra. Alguns dos participantes deixaram objetos ocultos no software, mesmo assim os consideramos.

Baseado no trabalho de Moran (2015), para cada uma das atividades, observamos as seguintes apreensões:

\section{Apreensão perceptiva}

Como anteriormente citado, ao observarmos uma figura, já extraímos informações relevantes. Isso também pode ser percebido nas representações 
feitas pelos participantes, uma vez que, suas produções estão atreladas às interpretações e percepções do enunciado.

Dessa forma, analisamos se:

- Ocorreu a lei do fechamento;

- Aspectos importantes e unidades figurais foram evidenciados;

- Recorreram a medidas (mediram comprimentos, utilizaram malha

quadriculada para medir distâncias);

- Houve reações imediatas diante do problema.

\section{Apreensão discursiva}

A apreensão discursiva de uma figura, segundo Moran (2015), está também presente nas atividades que envolvem demonstrações, pois faz-se necessário a articulação entre o enunciado do problema e as propriedades da figura ou do objeto matemático, estando ligada diretamente à interpretação.

Para Duval (2012a), uma mesma figura em um problema de Geometria, de acordo com o que percebemos dela, pode ser uma figura geometricamente diferente se modificarmos o enunciado. Isso revela uma subordinação das apreensões.

Procuramos identificar se:

- Ocorreu interação entre a representação figural e a representação discursiva (articulação entre as respostas em linguagem natural ou simbólica de uso especializado e as figuras feitas pelos participantes);

- Interpretação correta do enunciado;

- Houve subordinação da apreensão perceptiva à discursiva (se a apreensão discursiva inibiu a apreensão perceptiva).

\section{Apreensão operatória de posição ou mereológica}

A resolução de problemas em Geometria envolve, frequentemente, modificações figurais. Essas modificações estão associadas às interpretações que se faz do enunciado e ao processo heurístico.

Nas produções dos participantes, quisemos verificar principalmente as seguintes características:

- Correspondência entre os tratamentos e o raciocínio dedutivo; 
- Foram realizadas modificações (operatórias mereológicas ou de posição, veja a página 68) no software ou no caderno de respostas;

- Houve possibilidade de exploração heurística.

\section{Apreensão Sequencial}

A apreensão sequencial é mobilizada quando construímos uma figura, por exemplo, em uma folha de papel ou com o auxílio de instrumentos (software, régua e compasso, entre outros). Também a mobilizamos quando estamos descrevendo a figura. Para Duval, em uma atividade de construção, a figura é, de certa maneira, independente de todo enunciado (DUVAL, 2012a, p. 134).

Procuramos identificar se as construções feitas no GeoGebra são robustas ou moles segundo Laborde (2005). Essa autora define da seguinte maneira estes tipos de construções:

\footnotetext{
Construções robustas são aquelas em que o modo de arrasto preserva suas propriedades. Elas devem ser feitas usando os objetos geométricos e as relações que caracterizam a construção que desejamos obter. Nestas construções a variação é usada como um meio de verificação. Em construções moles, a variação é parte da própria construção e uma propriedade torna-se visível somente quando outra é satisfeita. ${ }^{7}$ (LABORDE, 2005, p.22)
}

Segundo a autora, as construções moles não preservam as propriedades dos objetos encontrados. As propriedades desejadas só são satisfeitas visualmente, sob determinas condições dos objetos construídos. Se movimentarmos esses objetos, as propriedades encontradas não se mantêm. Como exemplo, veja as figuras 62 e 74 .

Dessa forma, observamos nas representações os seguintes aspectos:

- Se houve descrição correta da construção;

- Houve construção robusta no software.

Para cada um dos três grupos citados anteriormente, fizemos a análise de acordo com essas quatro apreensões em todas as atividades.

A seguir estão as análises das respostas obtidas nas seis atividades.

\footnotetext{
7 Tradução do autor.
} 


\section{Atividades 1 e 2}

\section{Comentários sobre as atividades}

$\mathrm{Na}$ Atividade 1, bastava refletir os pontos e os segmentos ${ }^{8}$ pela reta $\mathrm{m}$ segundo a definição de reflexão por uma reta apresentada na primeira página do caderno de respostas (veja as atividades 1 e 2 , na Parte 1 do Anexo C).

A Atividade 2 é um complemento da atividade anterior, uma vez que faz menção desta. Para o participante da pesquisa respondê-la, deveria fazer as devidas reflexões na Atividade 1.

A segunda atividade era diferente para os grupos. Para os grupos II e III houve o acréscimo da Definição 2 e pede-se que o participante justifique suas considerações referentes ao conceito de "estar entre" (veja a Definição 2 na Parte 1 do Anexo C).

Nestas duas atividades, alcançamos, ao menos, três momentos presentes na Investigação Matemática. Essas duas atividades levam o participante a formular hipóteses. Na realização da Atividade 1, ele já está fazendo testes e na Atividade 2, procura justificar, ainda que utilizando somente a língua natural, suas percepções ou hipóteses.

Com essas duas atividades buscamos mobilizar duas representações distintas: a figural e a discursiva (resposta usando linguagem natural ou simbólica), uma vez que, de acordo com Duval, é a articulação dos registros que constitui uma condição de acesso à compreensão matemática (DUVAL, 2013, p 22).

É natural que, nestas duas atividades, os participantes se apoiem na apreensão perceptiva, presente em todas as nossas atividades. No entanto, na Atividade 2 é esperado que mobilizem a apreensão discursiva por meio, obviamente, das representações em linguagem natural ou simbólica.

$\mathrm{Na}$ Atividade 1, a ocorrência de modificações operatórias de posição é esperada nas representações dos participantes, pois a ferramenta de reflexão, que o software disponibiliza, facilita tal procedimento. Já sobre a apreensão sequencial, apesar de não ser requisitada a descrição das construções, é possível perceber quais passos o participante fez em suas representações, principalmente através do GeoGebra.

\footnotetext{
${ }^{8}$ Para o Grupo I, essa atividade apresentava pontos e segmentos que deviam ser refletidos. Para os grupos II e III haviam somente pontos.
} 
Vamos, a seguir, avaliar os tipos de apreensões que podem ser percebidos nas atividades 1 e 2 , em cada grupo de trabalho.

\section{Apreensão Perceptiva}

\section{Grupo I (Oficina CAEM)}

Os professores não fizeram representações no software, apesar dele estar acessível desde o início da oficina. Todos eles reconheceram as unidades figurais presentes na Atividade 1, pois fizeram uso da nomenclatura usual para pontos, identificando-os por meio de letras maiúsculas. A maioria dos professores representou suas reflexões de maneira correta. Devemos ressaltar que a malha quadriculada é um grande auxílio para essa atividade, em especial. Este talvez seja um dos motivos pelos quais não houve representação de ângulos retos e segmentos, unindo os pontos dados e suas respectivas reflexões nas representações feitas.

A seguir, pode-se observar três soluções feitas pelos participantes $\mathrm{O} 2, \mathrm{O} 5$ e 06: nos dois primeiros, os participantes fizeram marcações equivocadas nos cadernos de respostas, que estão indicadas por setas nas figuras 34 e 35:

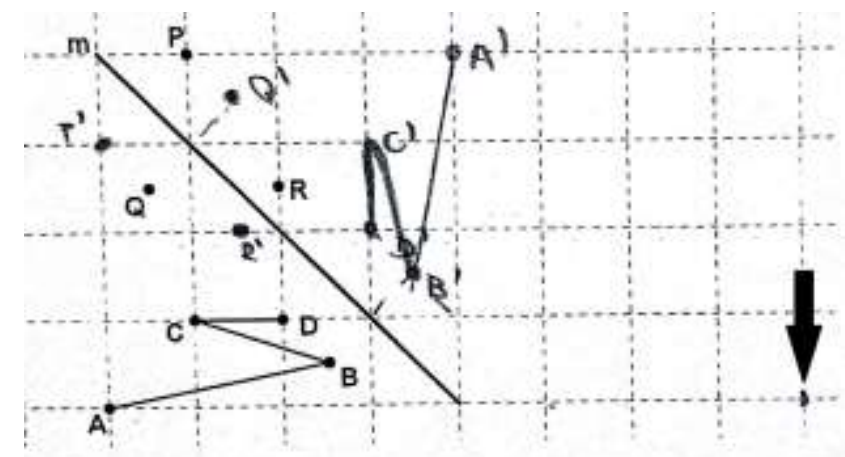

Figura 34: Reflexão de pontos feita por 02 Fonte: Autor.

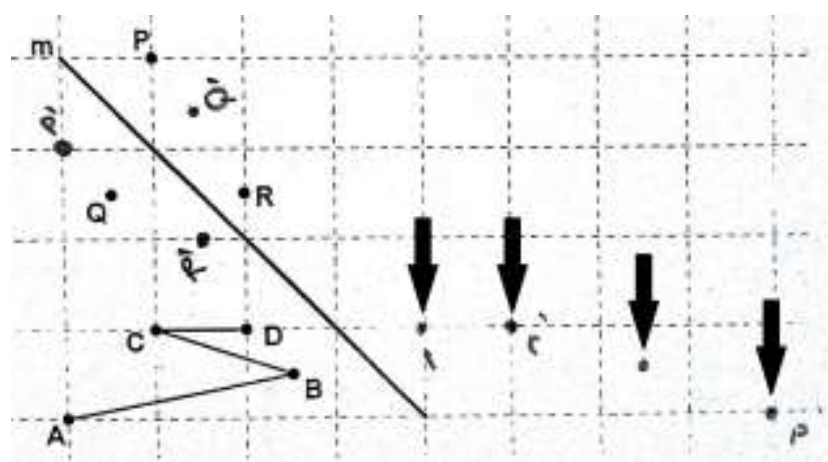

Figura 35: Reflexão de pontos feita por 05 Fonte: Autor. 
Percebendo o erro, O2 refez a primeira marcação identificando-a por A'. Mas O5, apesar de refletir corretamente os pontos $P, Q$ e $R$, fez e apagou as reflexões dos pontos $\mathrm{A}, \mathrm{B}, \mathrm{C}$ e D, como vemos acima. É curioso notar que $\mathrm{O} 5$ não refez as reflexões desses quatro pontos. As reflexões corretas e também as incorretas, feitas por este professor, podem ter relação com a proximidade entre os pontos.

O professor 06 escreveu no canto superior direito do caderno de respostas a seguinte consideração: $P$ e $D$ são simétricos em relação à reta $m$. $O$ que não é verdade, pois a simetria entre $\mathrm{P}$ e $\mathrm{D}$ é em relação a um ponto. $\mathrm{Na}$ Figura 36 é possível notar na resposta de 06 , a seguir, a indicação pontilhada de $\overline{\mathrm{PD}}$,

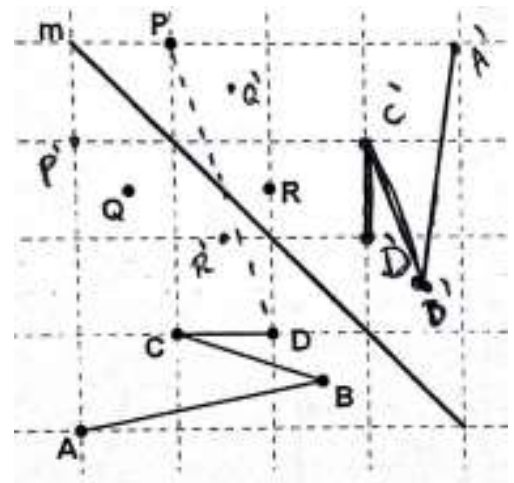

Figura 36: Reflexão de pontos feita por 06 Fonte: Autor.

\section{Grupo II (Minicurso ENEM)}

Os professores participantes do Minicurso, com exceção de M6, utilizaram o espaço reservado para a Atividade 1 no caderno de respostas. Todos os colaboradores fizeram as reflexões dos pontos através da ferramenta que 0 próprio software disponibiliza, como é possível perceber pela indicação da figura no GeoGebra:

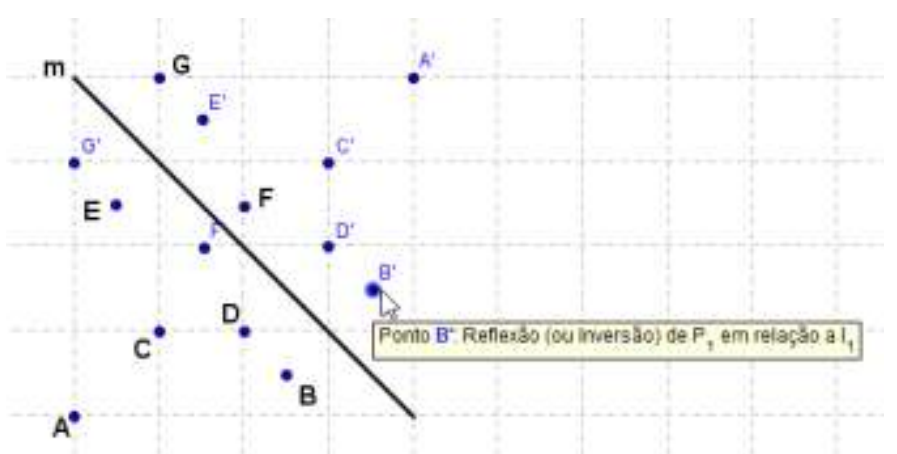

Figura 37: Reflexão de pontos feita por M2

Fonte: Autor. 
Os participantes M1, M3 e M4 realizaram tratamentos semelhantes, representando cada um dos segmentos, unindo os pontos e suas respectivas reflexões, como mostramos na figura a seguir:

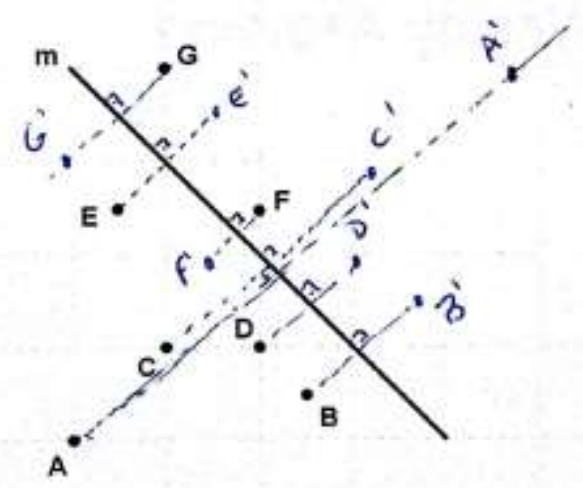

Figura 38: Reflexão de pontos feita por M3 Fonte: Autor.

Na resposta de M5, a seguir, vê-se que, através da ferramenta de cálculo de distâncias fornecida pelo software, o participante tentou responder a Atividade 2, utilizando a representação numérica.

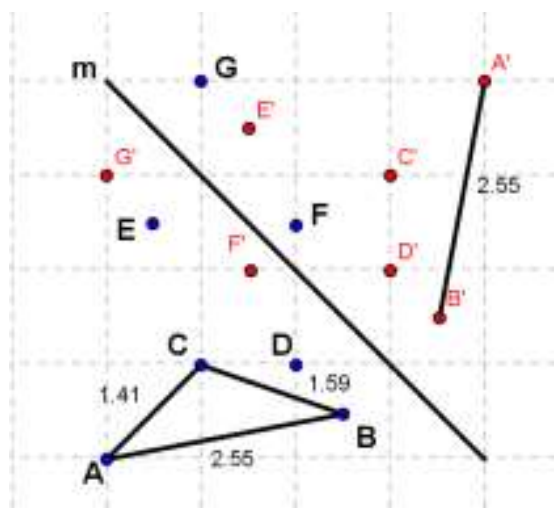

Figura 39: Reflexão de pontos feita por M5

\section{Grupo III (Licenciatura em Matemática)}

Fonte: Autor.

Os alunos L1, L2, L3 e L12 não realizaram as reflexões em seus cadernos de respostas, nem no arquivo do GeoGebra. Os alunos L4 e L17 fizeram a Atividade 1, somente no software. As reflexões dos pontos feitas pelo aluno L17 foram realizadas através da ferramenta disponível no GeoGebra, do mesmo modo que L11, L13, L14, L15 e L18. Mas L4 não utilizou a mesma ferramenta, como é possível observar na Figura 40: 


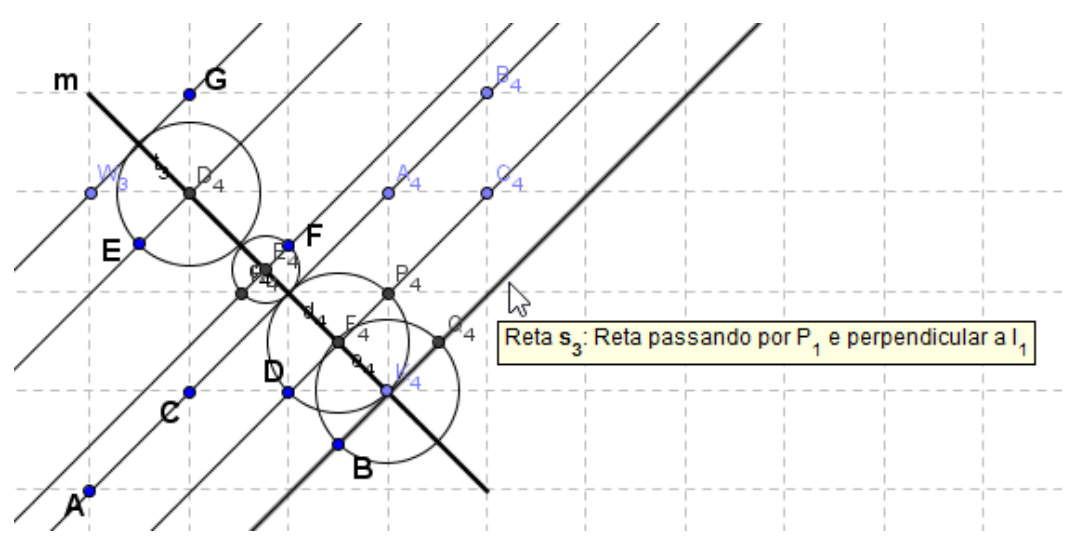

Figura 40: Reflexão de pontos feita por L4

Fonte: Autor.

Note que o software indica a construção feita, quando se coloca o cursor sobre o objeto construído, no caso, a reta $\mathrm{S}_{3}$ é uma reta perpendicular à reta $\mathrm{m}$ dada. Vemos que L4 usou as ferramentas que criam retas perpendiculares e círculos, para encontrar as reflexões de alguns dos pontos.

\section{Considerações}

Note que, nas respostas desta atividade, não houve preocupação em realizar uma demonstração, porém, a própria questão não sugere tal rigor.

Identificamos nas respostas de $\mathrm{O} 2$ e O5, no Grupo I, o que Mabuchi chama de referência horizontal (MABUCHI, 2000, p. 116), como no exemplo abaixo:

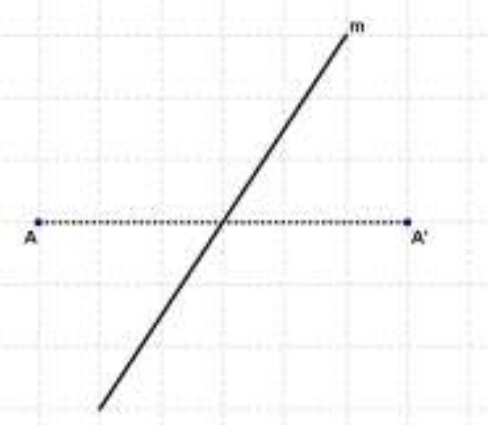

Figura 41: Referência horizontal

Fonte: Autor, baseado em (MABUCHI, 2000).

Antes dos professores fazerem a Atividade 1, foi apresentada a definição de reflexão por reta onde, no exemplo utilizado, a mediatriz também era inclinada (veja a Definição 1, na Parte 1 do Anexo C).

Apesar dos participantes não recorrerem, explicitamente, a medidas para fazer as reflexões, eles contaram os quadrados da malha quadriculada para 
fazer algumas delas. Isto indica que a malha quadriculada estimula respostas imediatas em algumas atividades, o que era esperado.

Diferentemente do Grupo I, estes professores do Grupo II não apresentaram reflexões equivocadas. Isso é justificado pois estes professores preferiram fazer, primeiramente, as respostas da Atividade 1 no GeoGebra.

Foram percebidas reações imediatas, como a identificação de ângulos retos e recorrência a medidas, em algumas respostas. É claro que essas reações imediatas estão atreladas às respostas da Atividade 2.

Os alunos, no Grupo III, procuraram destacar as unidades figurais presentes na atividade. Não houve recorrência a medidas, pois talvez foram influenciados pela malha quadriculada.

Como esperado, reconhecemos a apreensão perceptiva nas respostas destes alunos, uma vez que apresentaram de maneira imediata seus resultados (somente dois deles utilizaram a régua como auxílio nas representações nos cadernos de respostas). Percebemos que o enunciado do problema reforça a apreensão perceptiva da figura (DUVAL, 2012a). Destaca-se a representação de L4 (Figura 40), pois vemos que propriedades da reflexão por reta foram utilizadas, para encontrar as reflexões dos pontos dados, através das intersecções entre retas perpendiculares e circunferências.

\section{Apreensão Discursiva}

\section{Grupo I (Oficina CAEM)}

Todos os participantes desta oficina reconheceram as unidades figurais presentes na Atividade 1 (pontos, segmentos e reta mediatriz). Nenhum deles utilizou o software como apoio para suas respostas.

Os seis professores participantes responderam nos cadernos de respostas a Atividade 1. Aos colaboradores foram fornecidos réguas e compassos, no entanto, somente O2 (veja a Figura 34) e O3 procuraram fazer as reflexões dos pontos e segmentos com instrumentos. Eles utilizaram régua para identificar a localização dos pontos refletidos de acordo com a malha quadriculada, indicando assim um tratamento figural, como exemplo, segue a representação figural de O3: 


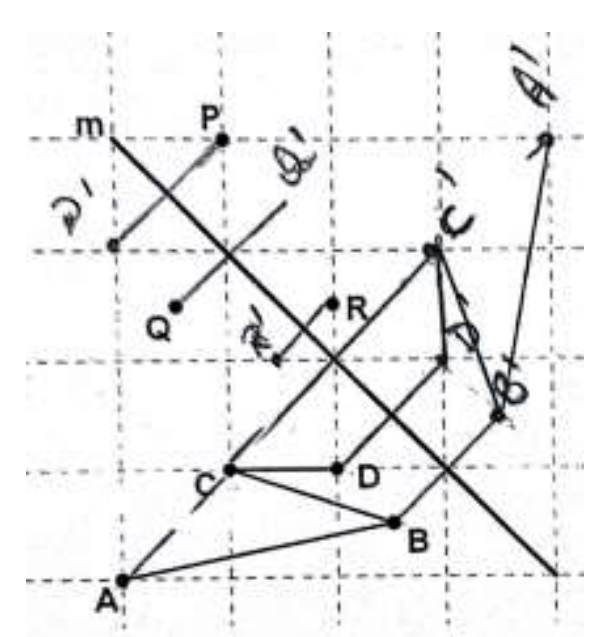

Figura 42: Reflexão de pontos feita por 03 Fonte: Autor.

Os demais professores, embora não tenham apresentado de forma precisa a maioria de suas reflexões, se valeram da apreensão perceptiva para fazerem suas representações, beneficiados pela malha quadriculada presente na atividade.

A realização da Atividade 2 dependia das respostas obtidas na atividade anterior. Abaixo estão as respostas dadas:

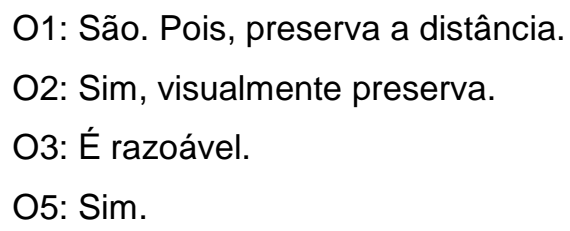

Os professores 04 e 06 não fizeram representações discursivas nessa atividade, talvez por conta da interação com os outros participantes da oficina. Todos eles reconheceram as unidades figurais presentes na Atividade 1, pois fizeram uso da nomenclatura usual para pontos, identificando-os por meio de letras maiúsculas.

\section{Grupo II (Minicurso ENEM)}

Para a realização desta Atividade, M1 e M4 (Figura 43) fizeram tratamentos diferentes dos demais professores no GeoGebra, pois representaram alguns segmentos ou polígonos. 


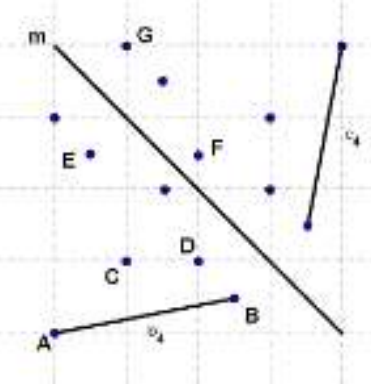

M1

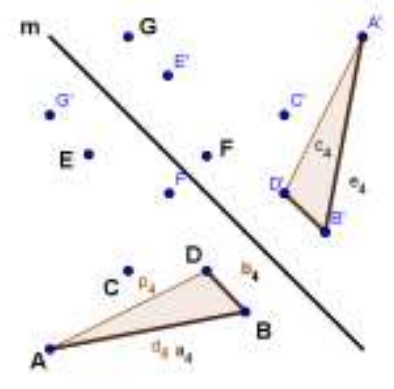

M4

Figura 43: Reflexão de pontos feita por M1 e M4 Fonte: Autor.

Os tratamentos realizados por M1 e M4 indicam uma possível investigação, na tentativa de encontrar propriedades geométricas. Os professores M2 e M6 responderam em linguagem formal e natural, respectivamente, como segue:

\footnotetext{
M2: Sim, pois se $A-C-B$ então $A C+C B=A B$. Como a distância entre dois pontos é preservada na reflexão então $A^{\prime} C^{\prime}$ + $C^{\prime} B^{\prime}=A^{\prime} B^{\prime}$ para $A^{\prime}, B^{\prime}$ e $C^{\prime}$ reflexões de $A$, B e $C$ respectivamente. Logo $A^{\prime}-C^{\prime}-B^{\prime}$.
}

M6: Sim porque a reflexão prevalece para todos os pontos.

A seguir, apresentamos as soluções dos participantes M1, M3 e M4. Note que eles buscaram argumentar através de conversões, representações discursivas e tratamentos figurais, no caderno de respostas:
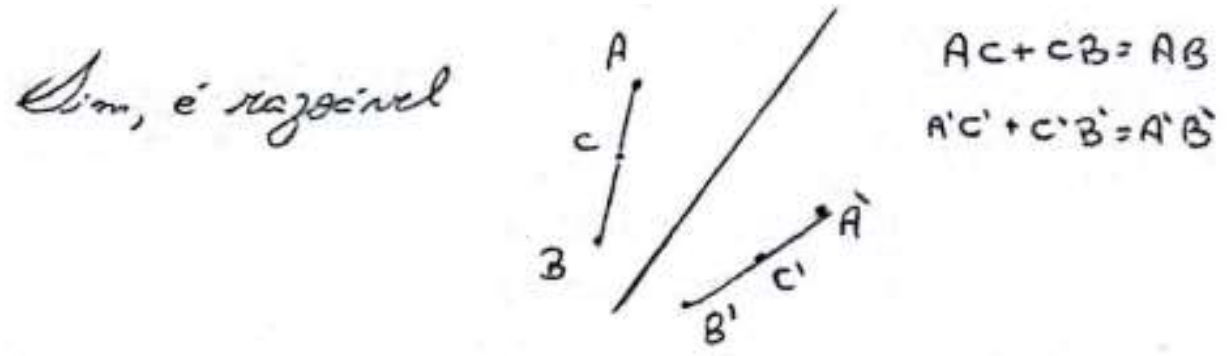

Figura 44: Solução de M1 na Atividade 2

Fonte: Autor. 


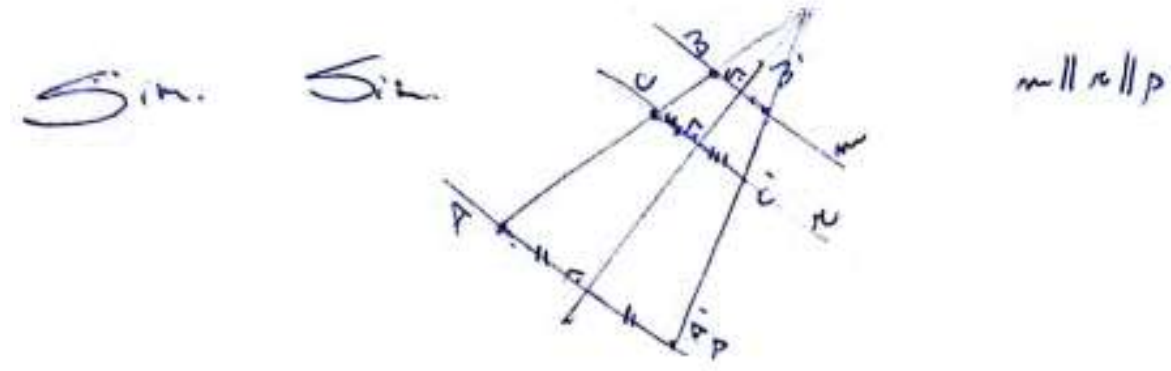

Figura 45: Solução de M3 na Atividade 2 Fonte: Autor.

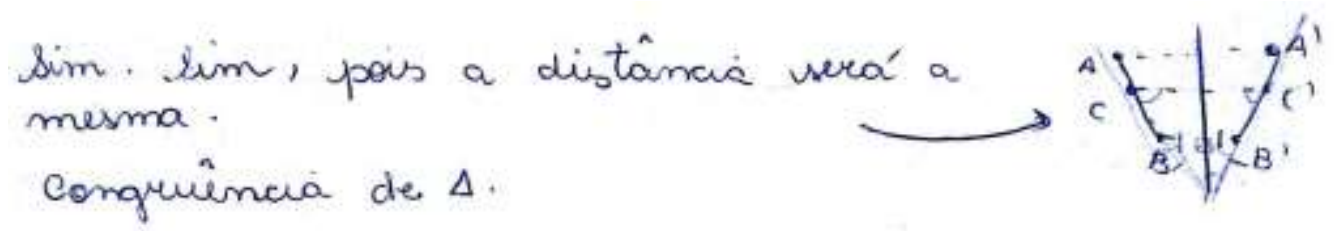

Figura 46: Solução de M4 na Atividade 2 Fonte: Autor.

O colaborador M5, apesar de ter feito as reflexões dos pontos no software, não respondeu à questão.

\section{Grupo III (Licenciatura em Matemática)}

As resoluções da Atividade 2 que L4, L15 e L16 realizaram no caderno de respostas, indicaram mais uma vez o caráter heurístico que as representações figurais proporcionam:

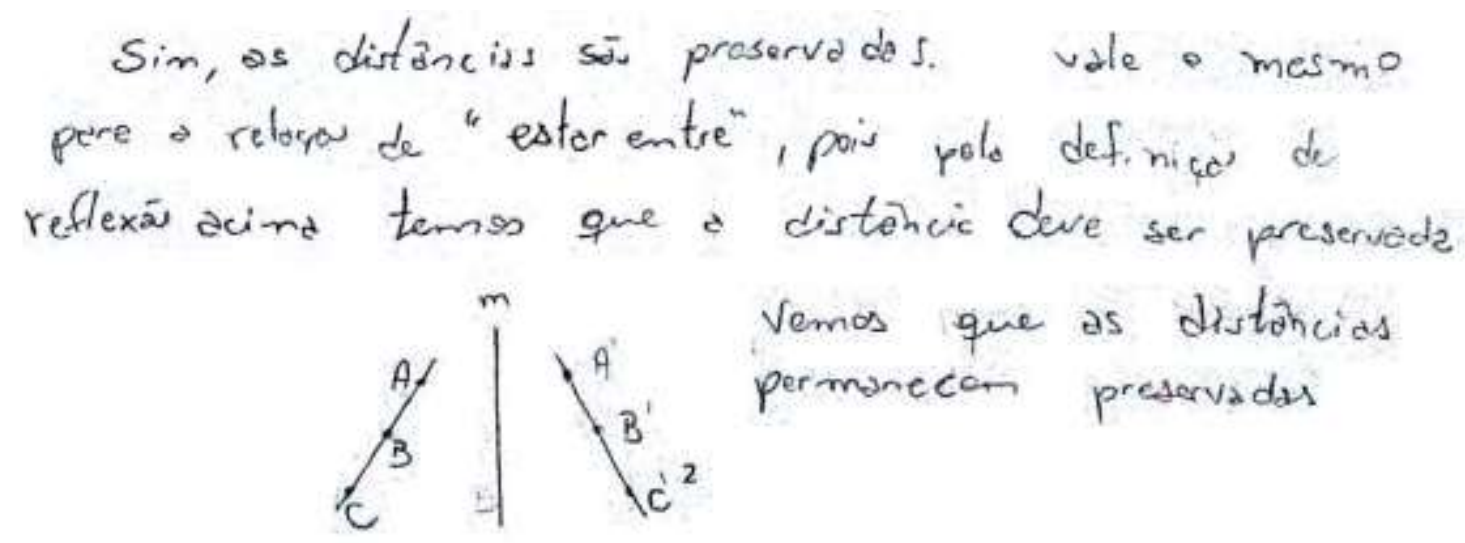

Figura 47: Solução de L4 na Atividade 2

Fonte: Autor. 


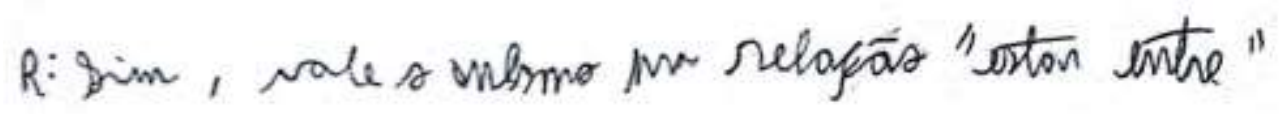

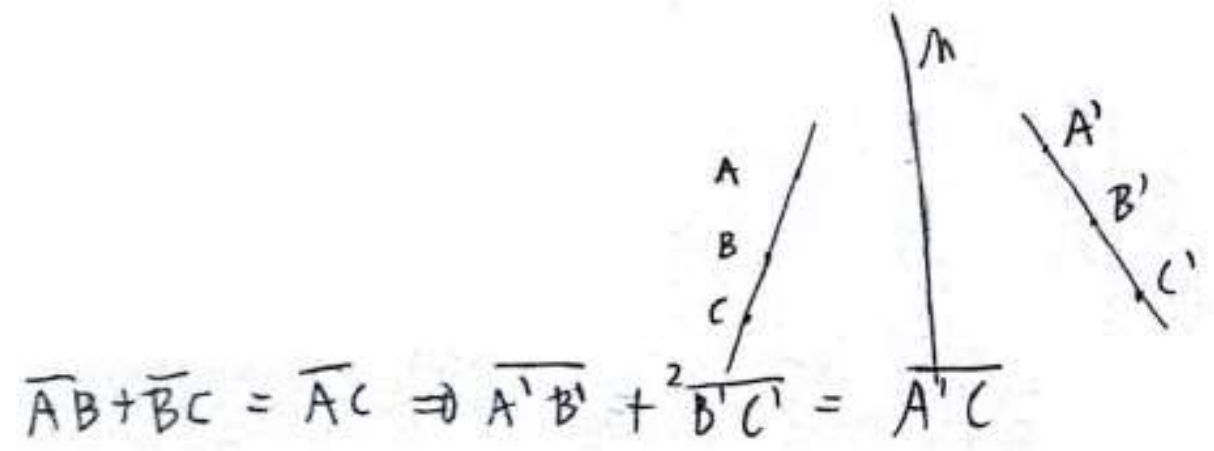

Figura 48: Solução de L15 na Atividade 2 Fonte: Autor.
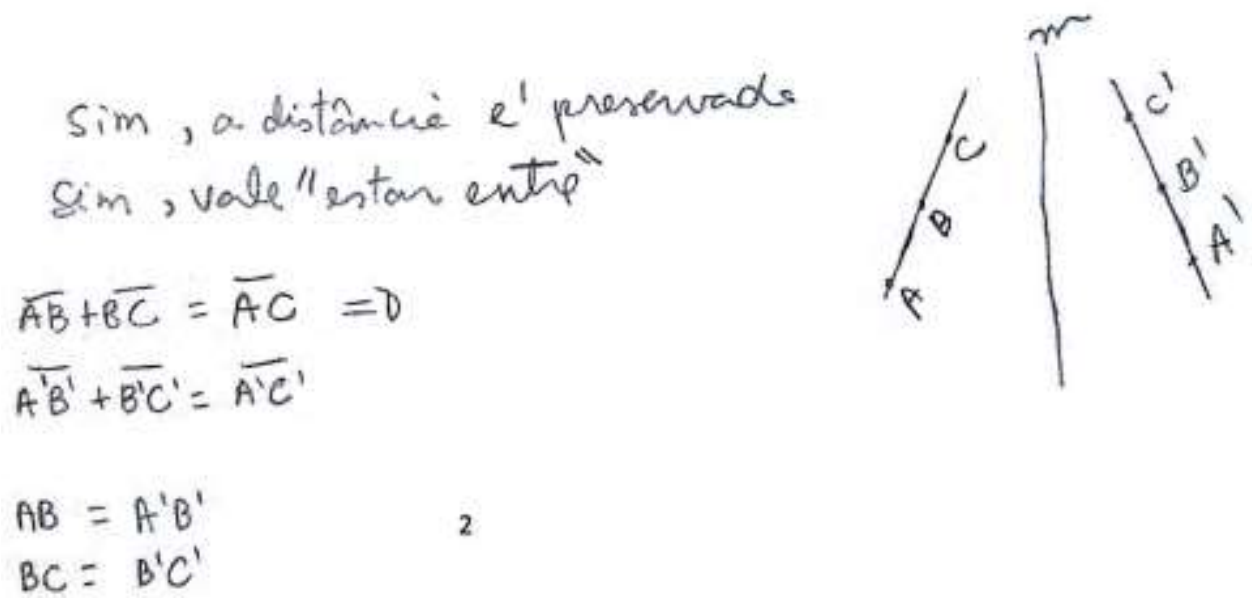

Figura 49: Solução de L16 na Atividade 2 Fonte: Autor.

Observe que os alunos L15 e L16 apresentaram de maneira equivocada a notação para a medida de segmento, Por exemplo, na resposta de L15 o correto seria escrever: $A B+B C=A C \Rightarrow A^{\prime} B^{\prime}+B^{\prime} C^{\prime}=A^{\prime} C^{\prime}$, ou seja, deveria ter escrito cada medida sem a "barra".

Os alunos L7 e L18 registraram, em língua natural, considerações semelhantes, como segue:

L7: Sim. Não. Pois a reflexão é colineação e nem toda colineação é isometria.

L18: Sim, são preservadas. Não vale a relação estar entre, pois entre a reta $\mathrm{m}$ e por exemplo o ponto $\mathrm{G}$ está o ponto $\mathrm{A}$. 
Para eles, as reflexões por retas preservam distâncias, porém não intuíram que elas preservam colinearidade. Enquanto L9 não fez representação discursiva na Atividade 2, os outros participantes responderam através da linguagem natural suas aferições:

L5: Sim. A reflexão por uma reta é uma isometria, e, portanto, preserva distâncias e a relação "estar entre".

L17: Sim porque é uma isometria, preserva distância, estar entre e medida angular.

Os dois últimos alunos afirmam que a reflexão por reta é uma isometria. Devemos lembrar que esta turma já teve contato com outras isometrias, como translações e rotações, ao longo do curso, porém, vale ressaltar que este resultado é apresentado somente na Atividade 3 (veja a Parte 1 do Anexo C).

Os participantes L6 e L14 também responderam em língua natural:

L6: Creio que seja natural sim que tais relações sejam preservadas, uma vez que a própria definição de reflexão leva a este entendimento.

L14: Sim, a distância entre os pontos é mantida.

Nas respostas de L8 e L13 destacam-se referências às unidades figurais da Atividade 1 e como os participantes se apoiaram na representação figural para argumentar sobre a relação estar entre:

Sion, poia pela difinicpor a ruta m é mediatriz do ponto dado e do refutido; intäo $m$ é perpenducular no ponto midis de $A A^{\prime}$ (por evemplo), logo an distâncias lías presenadas.

"Estar entre" tambern épreservado, observando as M. Plex̃as firtar ma atividade 1. Os pontos $E_{1} D_{\text {e }} B$ lao colineares, sendo que $D$ estā entre E eB. Nota-se que ar respotivas ruflisars tamberm estar alintradas e D' permanece entre E'e B'.

Figura 50: Solução de L8 na Atividade 2

Fonte: Autor. 


\section{Lim, érazoivel. be fato, peservar}

tantém a relay or de estar entru olservanto or pontor $\beta, D, E$ moex (1)

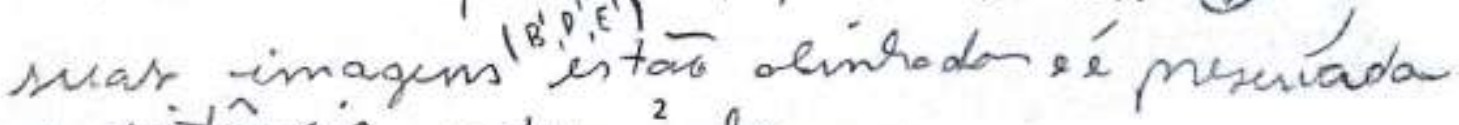
on dirtancia entre eles,

Figura 51: Solução de L13 na Atividade 2 Fonte: Autor.

Já L10 e L11 fizeram uso da linguagem simbólica em suas representações discursivas:

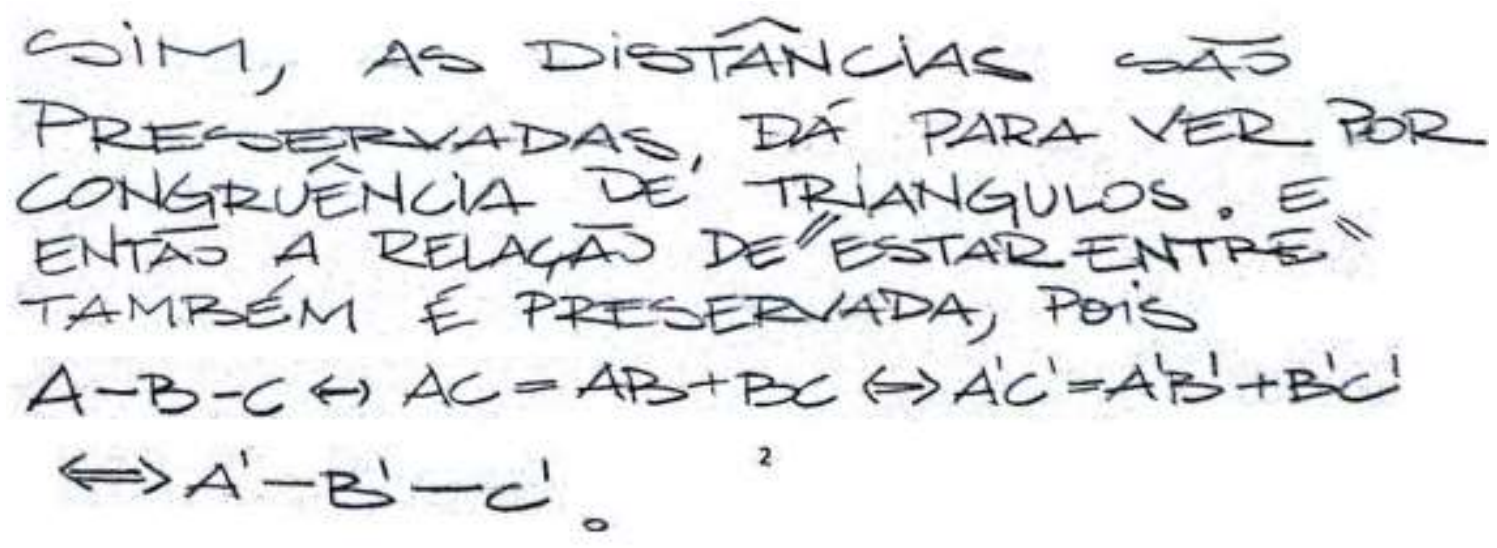

Figura 52: Solução de L10 na Atividade 2 Fonte: Autor.

Sim. Tome, por exemplo, na figura 2, os pontes Be D. Sabemos que, por rufercāo, $d(B, m)=d\left(B^{\prime}, m\right)$; o unermo ecorle para $D$ e $D^{\prime}\left(d(D, m)=d\left(D^{\prime}, m\right)\right.$. Meste caso, usando congruência de tiângulo vere nos que $B D=B^{\prime} D^{\prime}$, ou sega, a uflentäs em vilacąo a neta preserva destäncia. da velacãos "estar enhe" pedemes tomar como no caso da velací pentes $B, D$ LE. Como afuna anterionexcemplos o alinhamento distáncia, enztäo $d\left(B^{\prime}, D^{\prime}\right)+d\left(D^{\prime}, E^{\prime}\right)=d\left(B^{\prime}, E^{\prime}\right)$. $L_{0} p_{1} c^{\prime}$ está entre $B^{\prime}, e$ '

Figura 53: Solução de L11 na Atividade 2

Fonte: Autor. 


\section{Considerações}

Acreditamos que, no primeiro grupo, a Atividade 1 contribuiu para a realização da Atividade $2 \mathrm{e}$ isto levou os professores a um condicionamento em suas respostas. Neste caso, a apreensão discursiva está subordinada à apreensão perceptiva. Nenhum deles levantou a possibilidade da aplicação não preservar distâncias.

Segundo Duval (2012b), os tratamentos de uma representação são as transformações desta representação no mesmo registro onde ela foi formada. Dentro desse aspecto, as produções dos professores do Grupo II revelam tratamentos figurais para a percepção de propriedades matemáticas, o que auxilia uma possível justificativa na Atividade 2, indicando variação cognitiva.

A solução de M4 (Figura 46) nos revela a apreensão discursiva, pois o professor, mesmo sem descrever formalmente sua justificativa, indica que por meio de congruência de triângulos que é possível comprovar alguns resultados. Isto revela uma interação entre a representação figural produzida e sua justificativa na representação discursiva. Nas figuras 43 e 44, vemos que estes participantes do minicurso não ficaram limitados à análise de um segmento refletido por uma reta, mas prolongaram segmentos e construíram triângulos.

Entendemos que houve variação cognitiva por parte de vários alunos no Grupo III, uma vez que a percepção visual foi mobilizada para a realização da Atividade 2, sendo que alguns deles fizeram outras representações, explorando resultados, não se limitando à intuição. Estes alunos procuraram encontrar propriedades através de suas representações figurais. Isto reforça a ideia que as figuras permitem explorar possibilidades, antecipar resultados, mas nem sempre facilitam a percepção de relações ou propriedades (DUVAL, 1995, apud ALMOULOUD, 2013, p.130).

\section{Apreensão Operatória}

\section{Grupo I (Oficina CAEM)}

Todos os participantes da oficina fizeram modificações posicionais de reflexão em seus cadernos de respostas. Acreditamos que a malha quadriculada favoreceu a realização da Atividade 1, pois a maioria dos professores fizeram as reflexões dos pontos localizando suas respectivas posições visualmente, não se preocupando com o rigor em suas respostas. De maneira semelhante, 
observamos que, na Atividade 2, seguiram o mesmo padrão, uma vez que nelas não eram pedidas justificativas.

Curiosamente, apesar do software estar sempre à disposição dos professores, nenhum deles o utilizou. Isso pode ter ocorrido devido às características da atividade não serem complexas.

\section{Grupo II (Minicurso ENEM)}

Neste grupo três respostas se destacaram, pois, incentivados pelo pedido de justificativa na Atividade 2, realizaram modificações figurais no GeoGebra. Exploraram heuristicamente a Atividade 1, ainda que de maneira sutil, buscando perceber características e propriedades presentes.

Esses três professores construíram segmentos, sendo que nas respostas de dois deles há triângulos, mostrados anteriormente nas figuras 45 e 46 . Os professores M1 e M5 construíram segmentos nos dois semi-planos, determinados pela reta $\mathrm{m}$ com a ferramenta que o software disponibiliza, ou seja, não utilizaram a ferramenta de reflexão do GeoGebra. Mas M4, além de construir segmentos, utilizou a ferramenta polígono, construindo um triângulo. O professor M4 refletiu este triângulo e também pontos, utilizando a ferramenta que faz reflexões por retas, como é possível perceber em sua resposta abaixo:

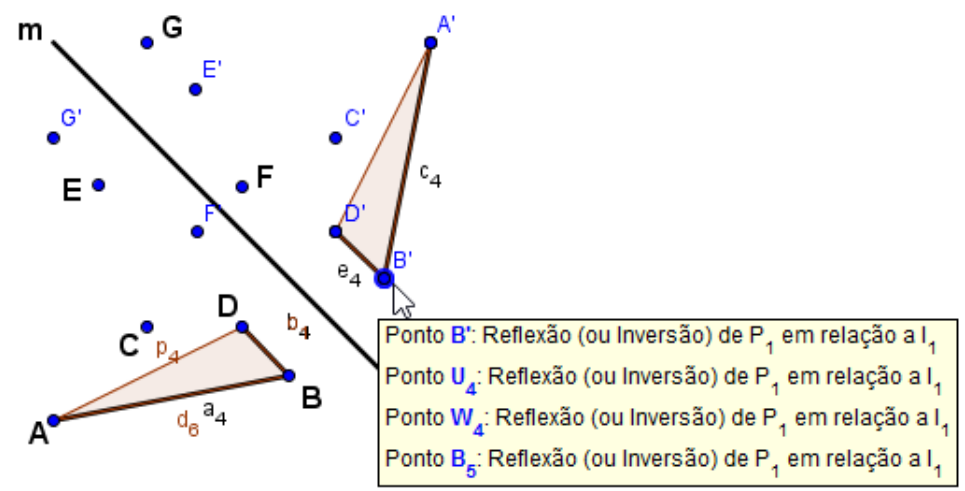

Figura 54: Uso da ferramenta polígono por M4 Fonte: Autor.

Note que, na Figura 54, o GeoGebra indica que o ponto B', onde está o cursor, foi obtido por quatro procedimentos diferentes, sendo todos eles reflexões feitas através da ferramenta disponibilizada pelo software, como vemos na caixa de diálogo. A saber, pode-se obter o ponto B' refletindo-se 
apenas o ponto $B$, como pode-se obter $U_{4}$, refletindo-se o segmento $\overline{\mathrm{DB}}$, ou $\overline{\mathrm{AB}}$, ou o triângulo $\triangle \mathrm{ABD}$.

Vale ressaltar que outras respostas também foram observadas na tentativa de justificar se a relação de "estar entre" (veja a Definição 2, na Parte 1 do Anexo C), é preservada, na reflexão por uma reta, veja as figuras 44, 45 e 46.

\section{Grupo III (Licenciatura em Matemática)}

Os alunos fizeram modificações posicionais de reflexão, semelhantemente aos grupos anteriores. Todos os alunos que apresentaram respostas no GeoGebra apenas realizaram as reflexões através da ferramenta do software, sem mostrar outros objetos matemáticos, como segmentos ou polígonos. Porém, quatro alunos responderam explorando heuristicamente as figuras que fizeram em seus cadernos de respostas. A seguir, na Figura 55, apresentamos as repostas dos alunos L4, L10:

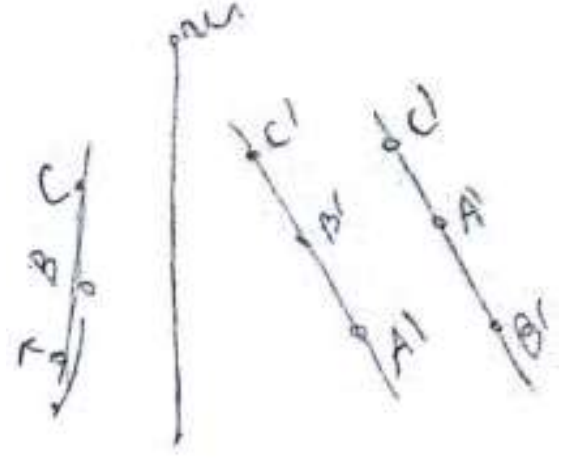

L4

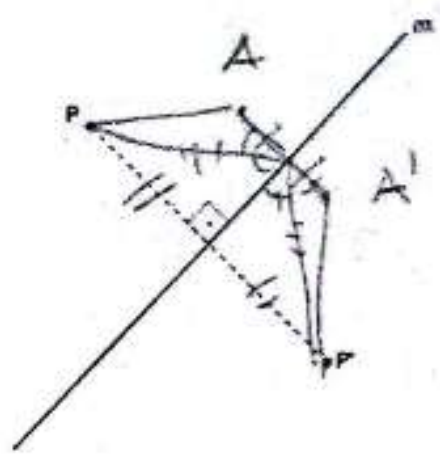

L10

Figura 55: Representações na Atividade 2 Fonte: Autor.

A representação figural de $L 4$ revela que ele investigou a possibilidade da relação de estar entre não ser preservada nas reflexões por retas. Note que $L 4$ apresenta, no mesmo semi-plano determinado pela reta $\mathrm{m}$, as seguintes marcações de estar entre: C' - B' - A' e C' - A' - B'. Já a figura feita por L10, mostra que este encontrou segmentos de mesma medida, buscando comprovar que as reflexões também preservam distâncias. 


\section{Considerações}

Nos três grupos as figuras feitas foram semelhantes, em especial, na Atividade 1. Porém, a exploração heurística das figuras foi mais visível nos grupos II e III, devido à necessidade de justificativa presente na Atividade 2. Tratamentos figurais foram vistos nas respostas dos participantes destes dois grupos, inclusive representações discursivas utilizando linguagem simbólica.

A ocorrência da chamada referência horizontal, nas respostas do primeiro grupo, nos chama a atenção. Para Duval, grande parte dos alunos não se dão conta de que uma figura deve ser olhada não mais do que através ou em função de suas propriedades (DUVAL, 2012a, p.124). Porém, com o uso do software, essa ocorrência diminuiu, como observamos nas respostas do Grupo II.

Devemos lembrar que o Grupo III teve contato anteriormente com outras isometrias, o que possivelmente influenciou nas representações discursivas mais completas dos alunos.

\section{Apreensão Sequencial \\ Grupo I (Oficina CAEM)}

A atividade não pedia a descrição da construção, mesmo assim foi possível perceber que alguns dos professores utilizaram a malha quadriculada em suas representações, como anteriormente descrito. Alguns professores utilizaram réguas, veja as figuras 34 e 42 . Vimos também que eles começavam suas reflexões a partir do ponto $A$, em seguida, do ponto $B$ e assim sucessivamente, o que era esperado.

\section{Grupo II (Minicurso ENEM)}

Neste grupo, observamos procedimentos semelhantes ao do Grupo I, porém, como mostramos anteriormente, todos os professores utilizaram o software. Estes participantes também não descreveram suas construções, obviamente influenciados pelos enunciados das atividades 1 e 2 .

\section{Grupo III (Licenciatura em Matemática)}

A maioria dos alunos não utilizou régua em suas construções, como é possível perceber nas figuras 47, 48, 49 e 55 . 
Na resposta de L4 (Figura 40), podemos perceber se a construção é robusta ou não, por meio da movimentação de alguns objetos, no caso, as circunferências, pontos e retas. Em sua resposta, L4 construiu corretamente alguns pontos: $\mathrm{P}_{4}$ e $\mathrm{Q}_{4}$, por exemplo. Já outros pontos não foram feitos de maneira correta: não há a reflexão do ponto $E$, nem mesmo uma de suas circunferências foi construída de maneira robusta.

\section{Considerações}

O fato dos participantes não descreverem suas construções ocorreu por conta dos enunciados das atividades.

As construções feitas pelos participantes foram, em sua maioria, no GeoGebra. Este software oferece ao usuário, na guia Exibir, o Protocolo de Construção, que é a lista ordenada de todas as construções feitas. Esta lista pode também ser utilizada para verificar se as construções são robustas.

Segundo Moretti (2013), baseado em Duval (2005), para resolver atividades em Geometria, são necessários os seguintes olhares:

- Olhar do botanista: é aquele que reconhece contornos e formas, como exemplo, diferenciar um triângulo de um quadrado exige esse olhar;

- Olhar do agrimensor: é aquele que faz medidas e consegue transferir essas informações para outras escalas;

- Olhar do construtor: é mobilizado no uso de instrumentos, régua não graduada e compasso, por exemplo;

- Olhar do inventor: é aquele que adiciona traços na figura dada para resolver o problema, modificando-a para encontrar a solução.

Esses olhares são requisitados de acordo com a mobilização das apreensões em Geometria, como exemplo, no olhar do botanista a apreensão perceptiva é essencial, enquanto que no olhar do inventor todas as apreensões são requisitadas (MORETTI, 2013). De acordo com essas características dos olhares requisitados para a resolução de problemas, na Atividade 1 reconhecemos os dois primeiros olhares citados. No entanto, na Figura 40, percebemos que L4 mobilizou também o olhar do construtor. 


\section{Atividade 3}

\section{Comentários sobre a atividade}

Na Atividade 3 (veja a Parte 1, do Anexo C), bastava refletir $\overline{\mathrm{PQ}}$ pela reta $\mathrm{m}$, construir alguns segmentos e observar a congruência de triângulos para demonstrar o resultado, veja a Proposição 1 na Seção 2.3, deste trabalho.

A formulação de hipóteses se revela na possibilidade de construções de segmentos, que por sua vez são auxiliadas pela malha quadriculada. Note que, esta atividade não envolve a Exploração e Formulação de Questões que é um dos momentos da Investigação Matemática. Porém, os outros momentos podem ser percebidos: devemos fazer conjecturas, fazer testes e justificar por meio da demonstração.

A apreensão perceptiva é necessária para a identificação dos triângulos que serão comparados na demonstração. Notam-se ainda as apreensões operatória mereológica homogênea e de posição na Atividade 3: na decomposição da figura em triângulos e na reflexão de $\overline{\mathrm{PQ}}$, respectivamente. $\mathrm{A}$ apreensão discursiva está presente nessa atividade, pois se faz necessária a língua natural ou simbólica para a demonstração. Além disso, entendemos que há uma articulação entre os tratamentos utilizados e o raciocínio dedutivo.

Nesta atividade, a apreensão sequencial está presente obviamente devido às construções necessárias, principalmente de triângulos congruentes, para a demonstração. Assim como nas duas atividades anteriores, não requisitamos no enunciado que os participantes mostrassem as instruções, passo a passo, de suas construções.

Espera-se que os participantes identifiquem, por meio da mobilização das apreensões perceptiva e discursiva principalmente, as unidades figurais como pontos, segmentos de mesma medida e ângulos congruentes, de modo que reconheçam a congruência de triângulos em suas representações.

\section{Apreensão Perceptiva}

\section{Grupo 1 (Oficina CAEM)}

Dos seis professores deste grupo, apenas quatro refletiram $\overline{\mathrm{PQ}}$, o que influenciou em suas respectivas tentativas de demonstração. Não houve recorrência a medidas, a não ser visualmente, o que é facilitado pela malha quadriculada. Somente $\mathrm{O} 1 \mathrm{fez}$ representações no software, para esta atividade. 
Todos reconheceram ou representaram as unidades figurais presentes na Atividade 3. Duas respostas se destacaram: $\mathrm{O} 1$ na tentativa de demonstração, criou segmentos e pontos, sendo que um segmento e dois pontos ficaram ocultos em sua solução, ver Figuras 56a e 56b, a seguir. Isto prejudicou a percepção de outras características necessárias para a resolução, como mostramos abaixo:

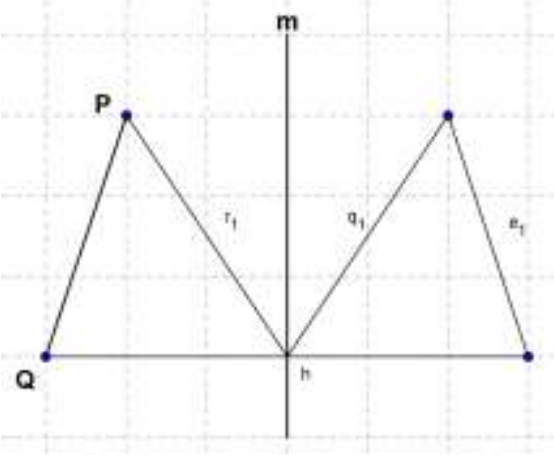

a

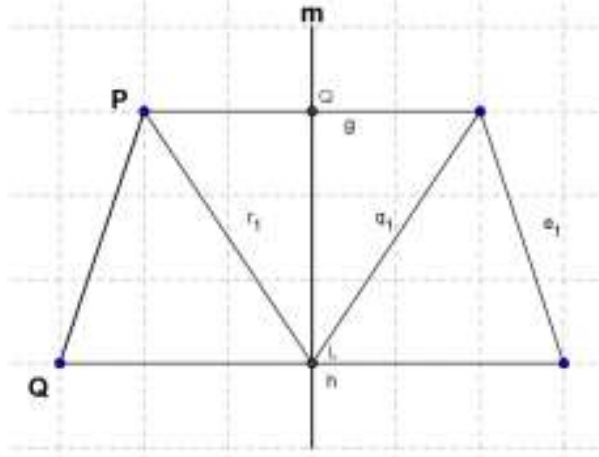

b

Figura 56: Solução de 01 na Atividade 3 Fonte: Autor.

Note que na Figura 56a, não há o segmento $g$ e os pontos $L$ e $Q$ sobre a mediatriz $\mathrm{m}$, como na figura à direita. Por algum motivo, $\mathrm{O} 1$ preferiu ocultar estes objetos, não havendo avanços na demonstração.

Já o professor $\mathrm{O} 2$ fez representações semelhantes ao professor 01 , em seu caderno de respostas, porém com dois segmentos paralelos à reta $\mathrm{m}$, como vemos a seguir:

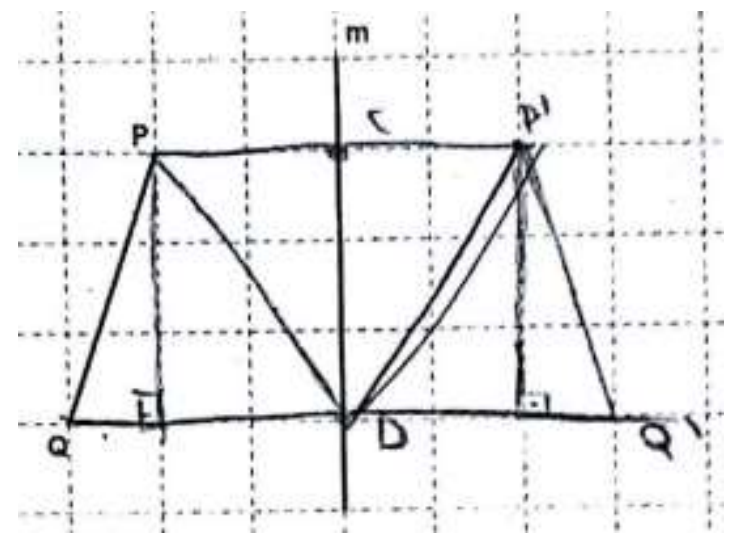

Figura 57: Solução de 02 na Atividade 3 Fonte: Autor.

A malha quadriculada parece ter sido usada como recurso pelo professor O2. As representações de ângulos retos indicam esse reconhecimento imediato sobre a figura. Este professor indicou elementos importantes como os pontos $\mathrm{C}$ e $\mathrm{D}$, bem como as intersecções da reta $\mathrm{m}$ com os segmentos $\overline{\mathrm{PP}^{\prime}}$ e $\overline{\mathrm{QQ}^{\prime}}$, 
respectivamente. No entanto, $\mathrm{O} 2$ não demonstrou em língua natural, ou formal, que a reflexão por reta é uma isometria, assim como os outros participantes da oficina.

\section{Grupo II (Minicurso ENEM)}

Neste grupo, todos os professores responderam em seus cadernos de respostas. Com exceção de $\mathrm{M} 6$, que apenas refletiu o segmento $\overline{\mathrm{PQ}}$, todos reconheceram aspectos importantes das reflexões por retas, como ângulos retos, e segmentos com a mesma medida.

Os professores utilizaram bem o software para esta atividade. Em geral, as figuras no GeoGebra foram semelhantes aos que apresentaram no caderno de respostas. Apenas M2 não repetiu a representação.

A recorrência a medidas surgiu nas respostas de M4 e M5 como vemos na Figura 58, a seguir:

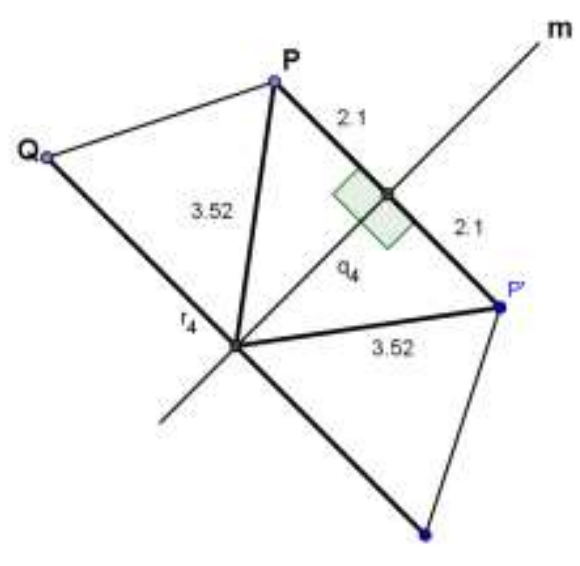

M4

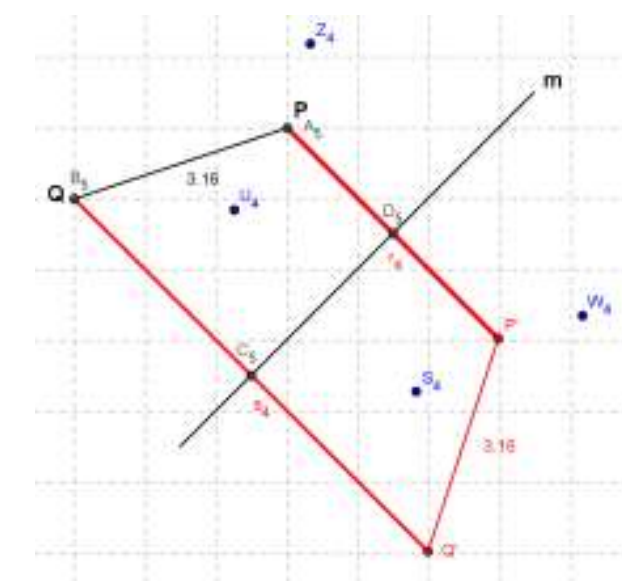

M5

Figura 58: Soluções de M4 e M5 na Atividade 3

Fonte: Autor.

O professor M5 (Figura 58 a direita), durante esta atividade, apresentou de maneira espontânea sua resposta ao pesquisador, afirmando que bastava medir os dois segmentos $\overline{\mathrm{PQ}}$ e $\overline{\mathrm{P}^{\prime} \mathrm{Q}^{\prime}}$ para demonstrar que a reflexão por reta é uma isometria.

\section{Grupo III (Licenciatura em Matemática)}

O aluno L7 fez as mesmas figuras, tanto no GeoGebra como em seu caderno de respostas. Já L14 fez tratamentos, para esta atividade, somente no 
software. Os alunos L11 e L18 fizeram tratamentos diferentes no caderno de respostas e no GeoGebra, como na figura abaixo:
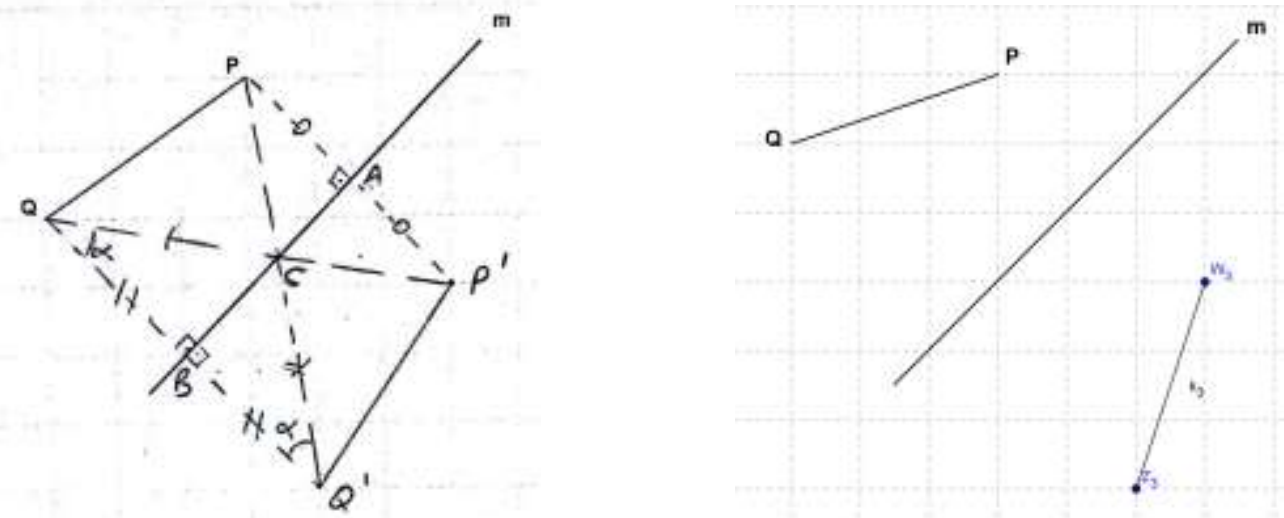

Figura 59: Solução de L18 na Atividade 3

Fonte: Autor.

Houve o reconhecimento de unidades figurais por parte da maioria dos alunos. Destacam-se as respostas de L4, L7, L8, L11, L13, L15, L16 e L18 por indicarem não somente segmentos de mesma medida, mas também ângulos congruentes. A seguir temos uma dessas respostas como exemplo:

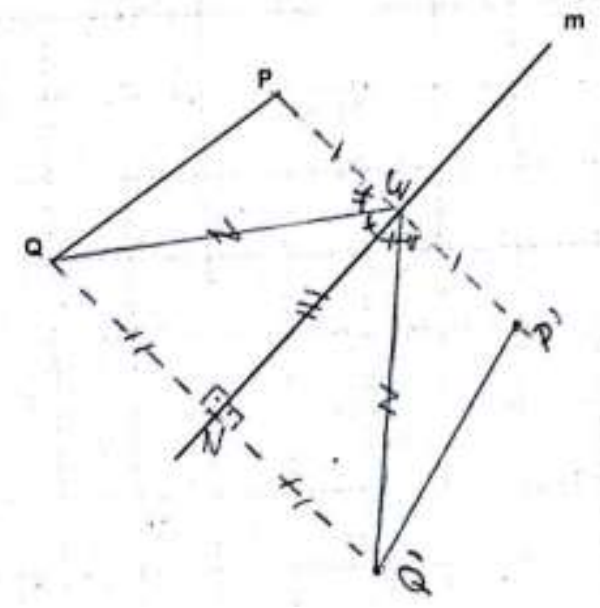

Figura 60: Solução de L8 na Atividade 3 Fonte: Autor.

A ferramenta polígono, presente no GeoGebra, também foi utilizada nesta atividade pelos alunos L7 e L14. 


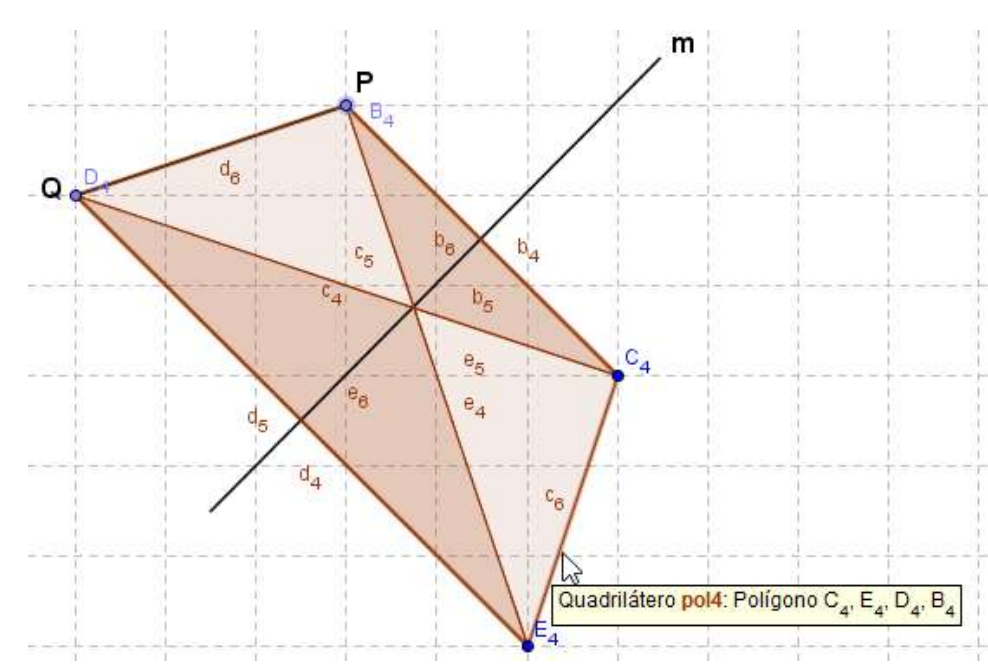

Figura 61: Solução de L7 na Atividade 3

Fonte: Autor.

O aluno L4 optou por não utilizar a ferramenta de reflexão do software, preferindo uma construção como se estivesse usando régua e compasso:

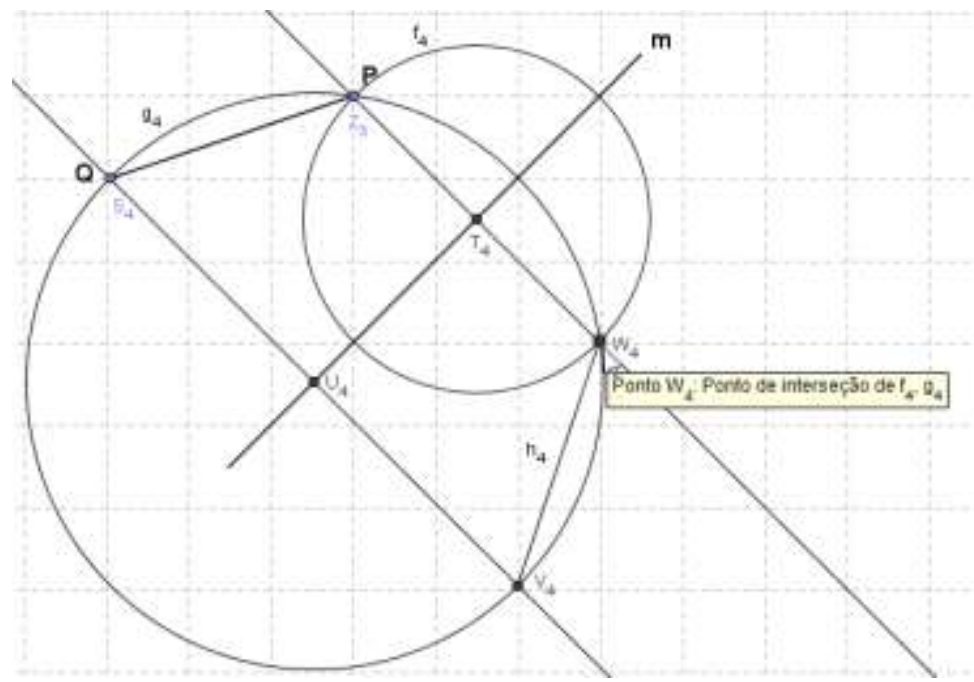

Figura 62: Solução de L4 na Atividade 3 Fonte: Autor.

Observe que o ponto $W_{4}$ é a intersecção das circunferências $\mathrm{f}_{4}$ e $\mathrm{g}_{4}$. $\mathrm{A}$ representação feita no GeoGebra indica que o aluno não construiu este ponto através da ferramenta de reflexão por reta.

Os alunos L1, L2, L3 e L12 não apresentaram nenhuma construção, tanto no caderno de respostas como no GeoGebra.

\section{Considerações}

Em todos os grupos os participantes reconheceram as unidades figurais presentes na atividade, incluindo segmentos e pontos de intersecção. 
Observamos que no Grupo I houve somente dois professores que construíram triângulos em suas respostas. A construção destes objetos matemáticos era primordial nesta atividade, mas algo inibiu a percepção dos demais professores, o que fica evidente pela falta de soluções nos cadernos de respostas e no software.

De acordo com as respostas de alguns participantes ocorreu, predominantemente, a apreensão perceptiva influenciando nas modificações figurais, o que prejudicou a exploração em alguns casos. Vale ressaltar que os tratamentos que constituem a produtividade heurística das figuras geométricas combinam operações que não se mostram ser nem do tipo de apreensão puramente perceptiva, nem do tipo conceitual (DUVAL, 2012b, p.287). Isso mostra que a apreensão perceptiva, apesar de estar presente em todas as atividades, não é suficiente para a resolução de alguns problemas.

Alguns professores do Grupo II, por meio da ferramenta de medição de segmentos, acreditaram demonstrar seus resultados, uma vez que o software confirmava que os segmentos $\overline{\mathrm{PQ}}$ e $\overline{\mathrm{P}^{\prime} \mathrm{Q}^{\prime}}$ apresentavam a mesma medida.

Os alunos de Licenciatura apresentaram mais elementos ou aspectos importantes através de suas respostas em comparação com os outros grupos, indicando ângulos e triângulos congruentes, enquanto que os demais professores não destacaram tanto a congruência de triângulos.

A seguir, veremos como essas respostas influenciaram suas demonstrações.

\section{Apreensão Discursiva}

\section{Grupo I (Oficina CAEM)}

Houve interação entre os tratamentos figurais e as representações discursivas utilizadas pelos professores na Atividade 3, apesar de não terem respondido de maneira satisfatória. A seguir, transcrevemos suas respostas:

01: preserva a distância em relação a reta $m$, formando um segmento P' e Q', portanto $P Q=P^{\prime} Q$ '.

Em seu caderno de respostas, $\mathrm{O} 1$ apenas refletiu $\overline{\mathrm{PQ}}$ por $\mathrm{m}$. Vemos nesta resposta também a subordinação da apreensão discursiva à perceptiva. $O$ fato 
de $\mathrm{O} 1$ ter argumentado de maneira coerente com a figura que fez revela também a apreensão discursiva. Já o professor $\mathrm{O} 2$ utilizou a linguagem simbólica apoiado na figura que fez no caderno de respostas (veja a Figura 57), respondendo da seguinte forma:

O2: Seja $P^{\prime}=F(P)$, onde $F$ é uma transformação isométrica, desta forma temos que, pela definição de isometria em relação a reta $\mathrm{m} P C=C P^{\prime}$, onde $\mathrm{C} \in \mathrm{m}$ e $\mathrm{PP}^{\prime} \perp \mathrm{m}$. Analogamente, para $Q^{\prime}=F(Q)$ teremos $Q D=D Q^{\prime}$, onde $D \in m$ e $Q Q^{\prime} \perp \mathrm{m}$. Pela definição de simetria temos que $P Q=P^{\prime} Q$ '.

As respostas de 03 e 06 estão mais próximas da resposta dada por 01 , pois este também utilizou mais a língua natural, não fazendo uma demonstração formal:

O3: Pois preservam a mesma distância em relação ao eixo de simetria, no caso, à reta $\mathrm{m}$, consequentemente a congruência do segmento $\left(\overline{\mathrm{PQ}} \cong \overline{\mathrm{P}^{\prime} \mathrm{Q}^{\prime}}\right)$.

O6: Sim pois o ponto $\mathrm{P}^{\prime}$ e $\mathrm{P}$ tem a mesma distância em relação a reta $m$, assim como $Q$ e $Q$ ' também e os segmentos $\overline{\mathrm{PQ}}$ e $\overline{\mathrm{P}^{\prime} \mathrm{Q}^{\prime}}$ Também possui o mesmo tamanho.

Nesta atividade, $\mathrm{O} 3$ e $\mathrm{O} 6$ só refletiram $\overline{\mathrm{PQ}}$ por m. Os professores $\mathrm{O} 4$ e $\mathrm{O} 5$ não apresentaram respostas nesta atividade.

\section{Grupo II (Minicurso ENEM)}

Dos professores participantes do minicurso, M2 foi o único que procurou apresentar uma demonstração completa. Na Figura 63, a seguir, temos a solução apresentada por este professor: 


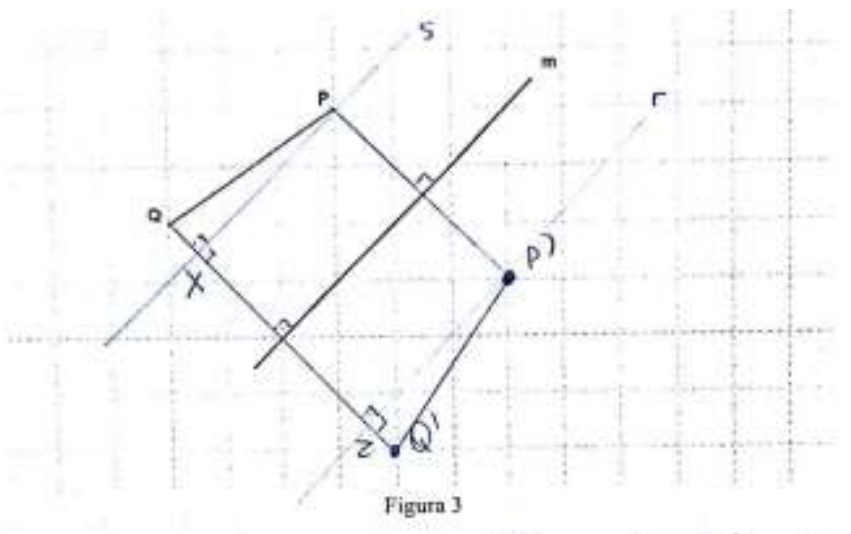

dejam se $r$, vespectivamente retas paralelar a $m$ pontos de $\overline{Q Q}$ que pertinam a se a $P_{\text {. }}$.

tringulos $P \times Q$ e $P^{\prime} Z Q^{\prime}$ são retângulos e $\lim$ catetos de merma medida*, potanto suas hipetenusas $\lambda \hat{m}$ a mesma medida, ou seza, $P Q=P^{\prime} Q^{\prime}$.

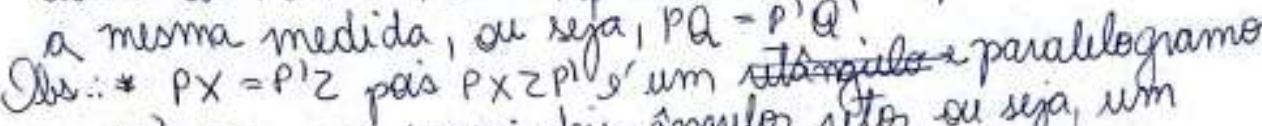

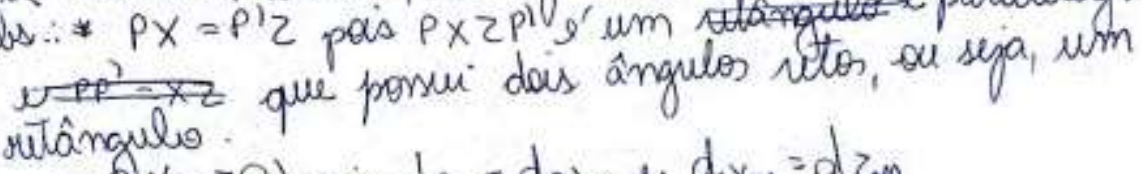

\& $Q X=Z Q^{\prime}$ pois $d_{Q_{m}}=d_{Q_{m}^{\prime}} v d_{X_{m}}=d z_{m}$

Figura 63: Resposta de M2 na Atividade 3 Fonte: Autor.

Note que, a tentativa de demonstração feita por M2 se restringe à figura, faltando ainda o caso em que $\overline{\mathrm{PQ}}$ é paralelo à reta $\mathrm{m}$.

Já M3 e M4 utilizaram a linguagem formal em suas respostas, com pouca articulação com a língua natural, como que mostrando os passos a serem seguidos. Isto é confirmado na solução de M4, a seguir:

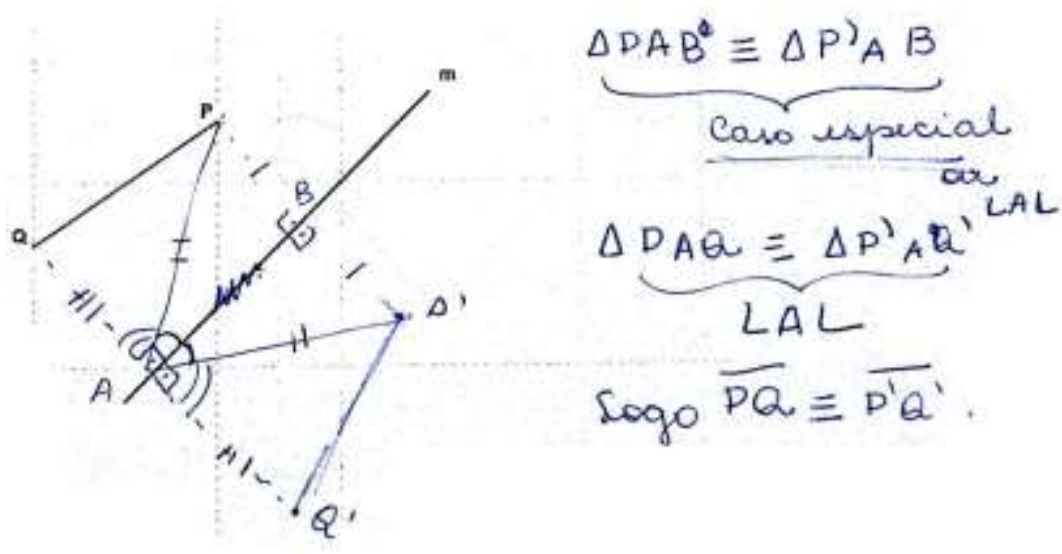

Figura 64: Resposta de M4 na Atividade 3

Fonte: Autor.

Além de ser notória a conversão de registros, percebemos que, por parte dos professores, houve a interpretação correta do enunciado, pois tiveram a preocupação de apresentar demonstrações. 
As representações de $\mathrm{M} 1$ e $\mathrm{M} 6$ se assemelham à algumas feitas pelos professores do Grupo I, pois refletiram o segmento $\overline{\mathrm{PQ}}$. Já M5, depois de refletir os pontos $\mathrm{P}$ e $\mathrm{Q}$ por $\mathrm{m}$, construiu os segmentos $\overline{\mathrm{PP}^{\prime}}$ e $\overline{\mathrm{QQ}^{\prime}}$. Abaixo estão as transcrições de suas respostas:

$\mathrm{M} 1$ : Seja $\mathrm{P}$ e $\mathrm{Q}$ dois pontos não pertencentes à reta $\mathrm{m} . .$. ?

M5: Demonstraria através da reflexão do segmento $P Q$ em relação a reta $m$ formando assim o segmento $P^{\prime} Q$ '.

M6: Demonstraria realizando a reflexão do segmento $P Q$ em relação a reta $m$.

Estes três professores não conseguiram observar outros elementos importantes em suas soluções, como os segmentos e a congruência de triângulos, o que acabou influenciando suas repostas.

\section{Grupo III (Licenciatura em Matemática)}

As produções dos alunos de Licenciatura estão, em sua maioria, associadas à linguagem simbólica para esta atividade. Dentre os dezenove alunos, apenas seis não apresentaram soluções em seus cadernos de respostas.

Dos alunos que utilizaram o software, L11 e L18 somente refletiram o segmento $\overline{\mathrm{PQ}}$ pela reta $\mathrm{m}$, mas em seus cadernos de respostas fizeram figuras diferentes, mostrando investigações maiores. Como exemplo, destacamos uma destas soluções a seguir:

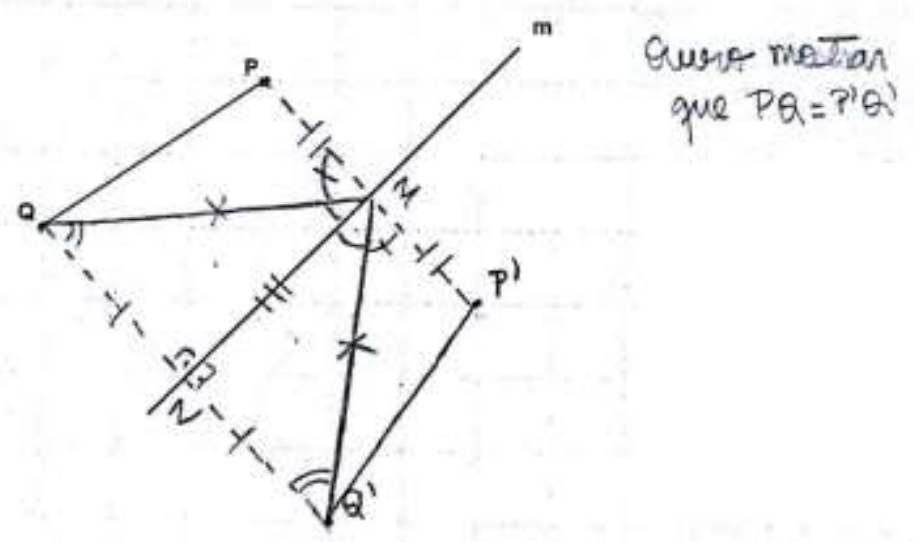

Figura 65: Solução de L11 na Atividade 3

Fonte: Autor. 
Os discentes, com exceção de L1, L2, L3, L12, L14 e L19 que não responderam à questão, revelaram a articulação entre as figuras feitas por eles e suas respectivas respostas escritas.

Nas respostas apresentadas houve referência à ângulos congruentes. A maior parte dos alunos encontrou triângulos congruentes em suas demonstrações, o que indica interpretação correta do enunciado. Mas L17 não demonstrou que os segmentos $\overline{\mathrm{PQ}}$ e $\overline{\mathrm{P}^{\prime} \mathrm{Q}^{\prime}}$ têm mesma medida, como podemos observar em sua resposta:

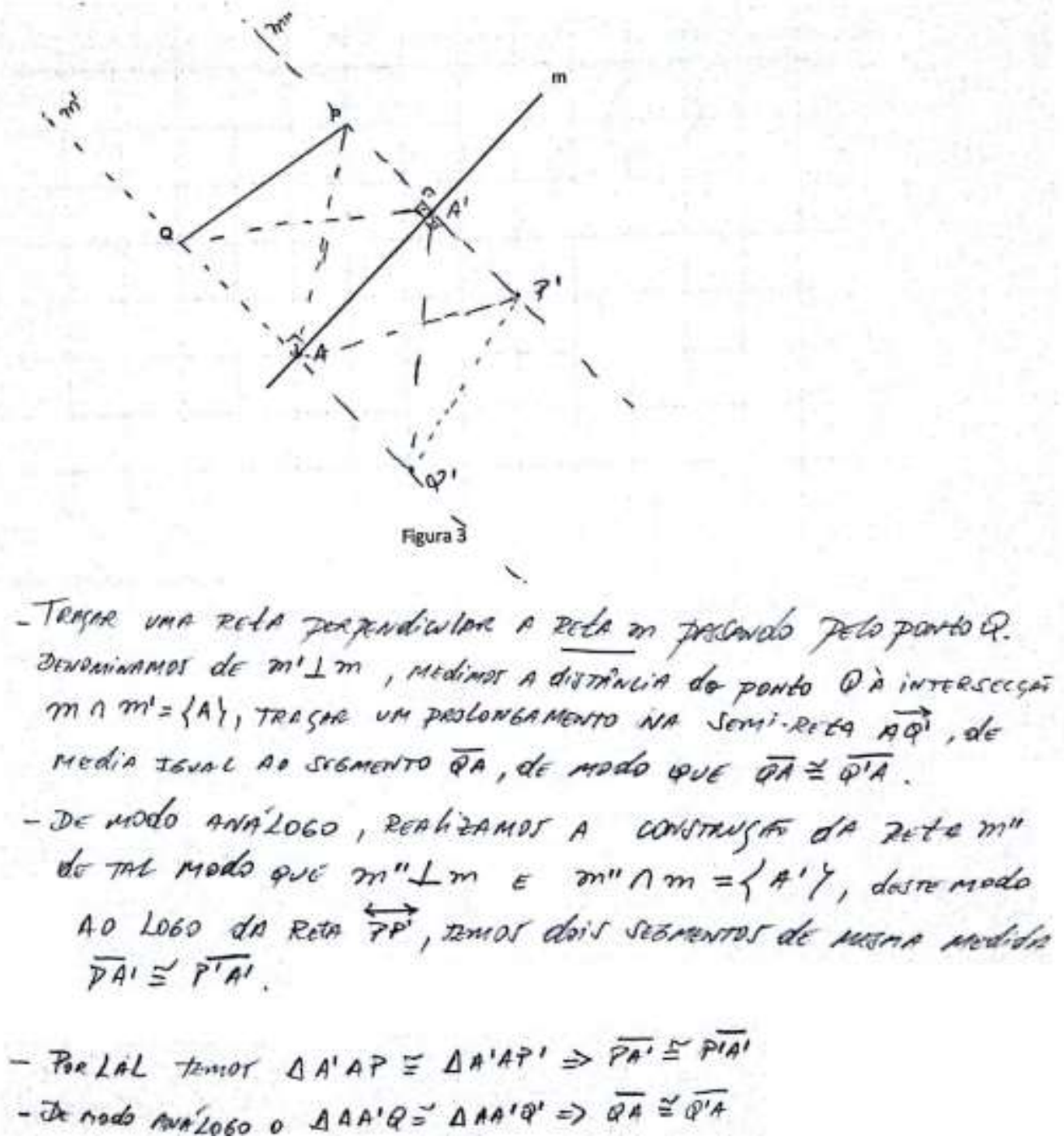

Figura 66: Solução de L17 na Atividade 3 Fonte: Autor.

Acima vemos que $\mathrm{L} 17$ não conclui que $\overline{\mathrm{PQ}}$ e $\overline{\mathrm{P}^{\prime} \mathrm{Q}^{\prime}}$ têm mesma medida, aparentando um equívoco na interpretação do enunciado. 
Os demais alunos visualizaram triângulos congruentes através dos tratamentos figurais semelhantes aos de L11 e L18 anteriormente citados (figuras 65 e 59, respectivamente).

\section{Considerações}

As respostas em língua natural observadas no Grupo I demonstram a subordinação da apreensão discursiva à perceptiva. Nota-se a influência da visualização nas respostas apresentadas. $O$ uso da língua natural também se destacou, o que é evidente segundo Duval (2012b), pois somente um dos professores respondeu à atividade utilizando a linguagem simbólica.

No Grupo II, as respostas mostram certa associação entre os tratamentos figurais e as representações discursivas usadas em suas respectivas demonstrações. Os professores que procuraram apresentar demonstrações formais foram os que reconheceram mais unidades figurais em suas soluções. Apesar disso, vimos na Figura 63 que um dos participantes considerou apenas um caso, onde $\overline{\mathrm{PQ}}$ não era paralelo à reta $\mathrm{m}$, o que pode, eventualmente, ser explicado pela subordinação da apreensão discursiva à perceptiva.

As modificações figurais foram amplamente usadas nas demonstrações pelos participantes do Grupo III. Devemos lembrar que alguns deles tiveram contato com outras isometrias, como translações e rotações, o que eventualmente, influenciou nas suas conclusões. Esta disciplina é ministrada aos estudantes no quinto semestre do curso de Licenciatura em Matemática. Por esse motivo os alunos articularam bem suas representações figurais com as discursivas, o que gerou, em sua maioria, demonstrações formais.

Percebemos nas respostas de alguns participantes que a atividade de demonstração só pode surgir se for a partir de um ponto de convergência de numerosas funções (DUVAL, 2012a, p.137). Isso implica a coordenação com outras apreensões, como a operatória por exemplo.

Outro fator que pode explicar os equívocos de alguns participantes é a utilização de registros multifuncionais. Duval (2013) afirma que sérias dificuldades são observadas nos tratamentos que envolvem registros plurifuncionais, como em demonstrações geométricas por meio de língua natural e a utilização heurística de figuras. 


\section{Apreensão Operatória}

\section{Grupo I (Oficina CAEM)}

Neste grupo os professores $\mathrm{O} 1$ e $\mathrm{O} 2$ realizaram mais modificações posicionais que os demais participantes, pois estes apenas refletiram 0 segmento dado pela reta $m$ (veja as figuras 56 e 57).

Vimos anteriormente que quatro professores não criaram outros segmentos em seus tratamentos figurais, dificultando, assim, a percepção de elementos essenciais para a demonstração formal da Atividade 3. Dessa forma, concluímos que $\mathrm{O} 1$ e $\mathrm{O} 2$ mostraram em suas respostas as apreensões operatórias de posição e mereológicas. Porém, não demonstraram de maneira satisfatória a atividade.

\section{Grupo II (Minicurso ENEM)}

Neste grupo, M1 conseguiu observar e construir poucos elementos em sua representação no caderno de respostas:

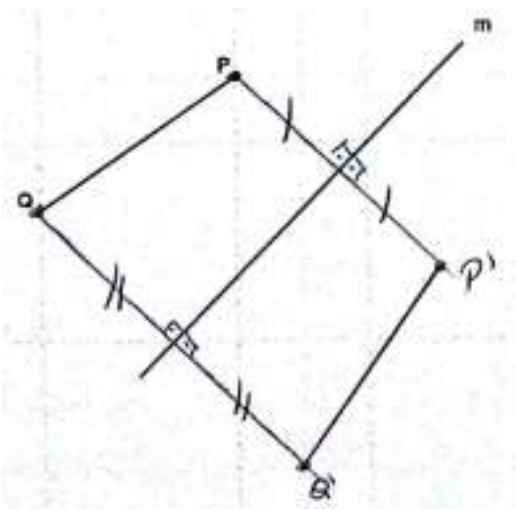

Figura 67: Representação figural de M1 na Atividade 3 Fonte: Autor.

Por sua vez, M5 fez apenas a reflexão de $\overline{\mathrm{PQ}}$, por m, obtendo $\overline{\mathrm{P}^{\prime} \mathrm{Q}^{\prime}}$ e mediu cada um dos segmentos através da ferramenta disponível no software.

O professor M6 fez sua resolução apenas no caderno de respostas para esta atividade. Sua resposta consistiu em refletir o segmento dado, não mostrando outros tratamentos figurais.

Nas respostas de M2 e M4, figuras 63 e 64 respectivamente, observamos a identificação de subfiguras, principalmente triângulos. Porém, M3 reconhece também em sua solução dois quadriláteros e relaciona suas áreas. 


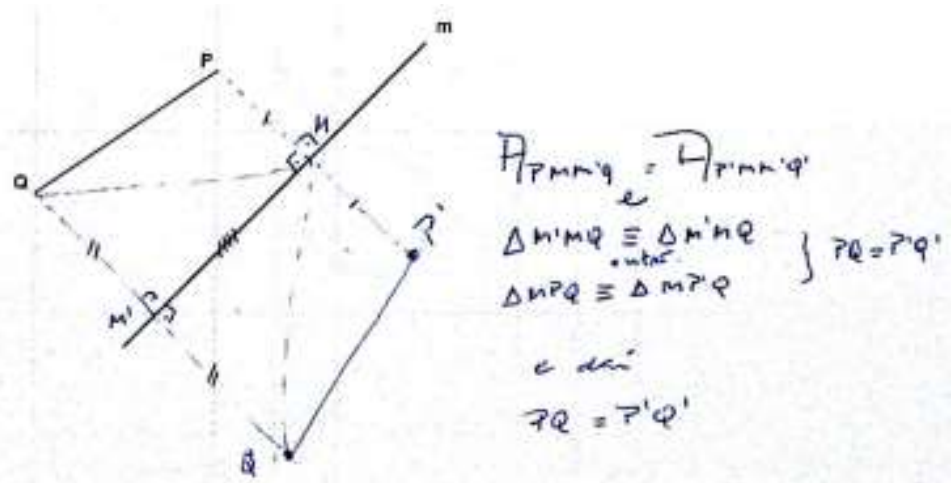

Figura 68: Representação figural de M3 na Atividade 3 Fonte: Autor.

\section{Grupo III (Licenciatura em Matemática)}

Os alunos L5, L8, L10, L11, L15, L16 e L17 apresentaram tratamentos figurais semelhantes ao que segue abaixo:

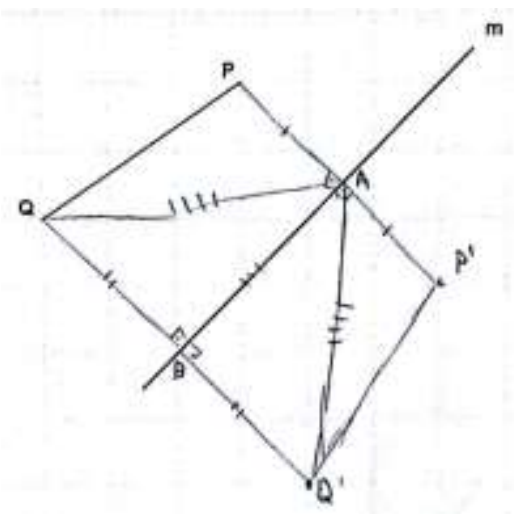

Figura 69: Representação figural de L5 na Atividade 3 Fonte: Autor.

Destes, somente L15 e L17 fizeram representações no GeoGebra. Apenas L15 refletiu o segmento dado, enquanto que L17 criou dois pontos, $\mathrm{K}_{4} \mathrm{e}$ $\mathrm{P}_{4}$ sobre o segmento $\overline{\mathrm{PQ}}$, o que os tornam móveis sobre $\overline{\mathrm{PQ}}$, aumentando $\mathrm{o}$ caráter investigativo da figura:
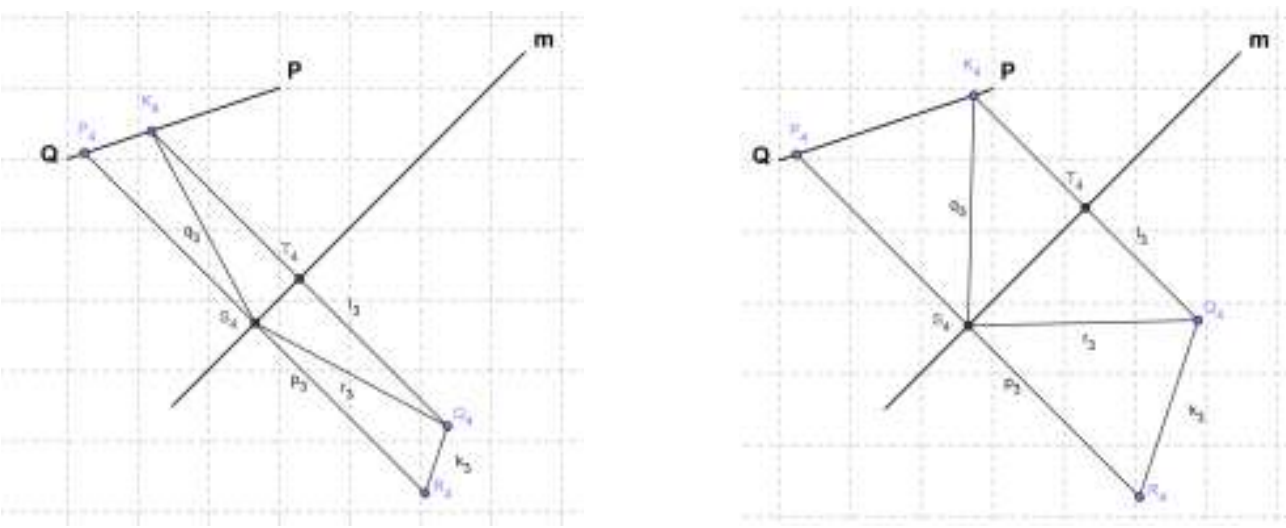

Figura 70: Representação figural de L17 na Atividade 3 Fonte: Autor. 
Os alunos L4, L7, L13 e L18 construíram duas diagonais do quadrilátero PP'Q'Q e, a partir disso, reconheceram a congruência de triângulos para suas demonstrações. Como exemplo, seguem as representações de L13:

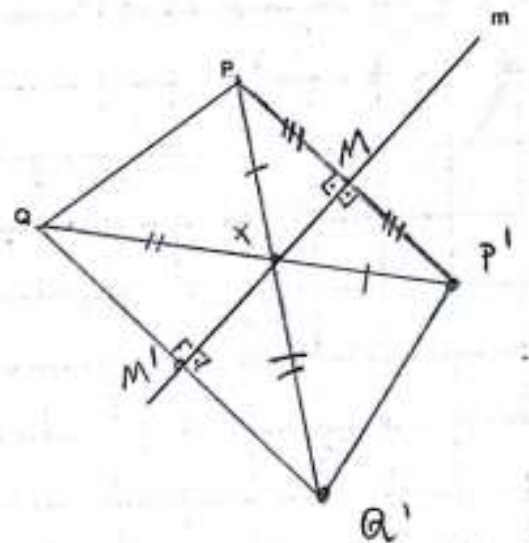

consudere oquadwila't, Fiends $P Q Q^{\prime} P^{\prime}$,

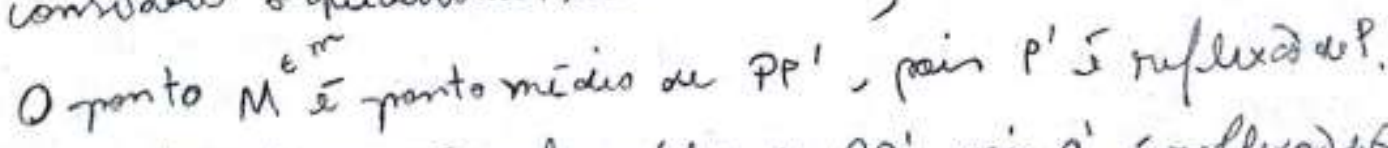

Q panto $M^{\prime}$ em é ponto mídeo de $Q Q^{\prime}$, pain $Q^{\prime}$ é ruflexardeQ arser, fermo que $\triangle \times P M \equiv \Delta \times \rho^{\prime} M$ for $L A L$ :

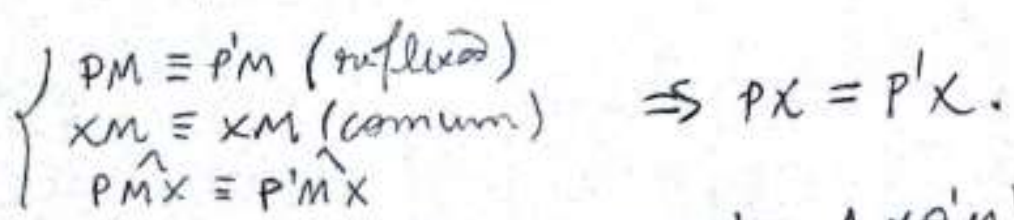
analogamenthe, $\triangle X Q M^{\prime} \equiv \triangle X Q^{\prime} M^{\prime} \Rightarrow G x=Q^{\prime} X$ Tome on triangulos $Q \times P$ e $P^{\prime} \times Q^{\prime}$, note que eb. sow conguentis por $\angle A L$

$$
\begin{cases}P X \equiv P^{\prime} X & \log 0, e^{\prime} \text { uma isome tura } \\ P \times Q^{\prime} Q^{\prime}\left(O P^{v}\right) & \operatorname{soin} P Q=P^{\prime} Q^{\prime} \\ Q_{1} X \equiv Q^{\prime} X & \end{cases}
$$

Figura 71: Solução de L13 na Atividade 3

$$
\text { Fonte: Autor. }
$$

Somente L9, neste grupo, tentou provar que as reflexões por retas são isometrias, através da observação das propriedades do quadrilátero PP'Q'Q, como mostra a figura seguinte: 


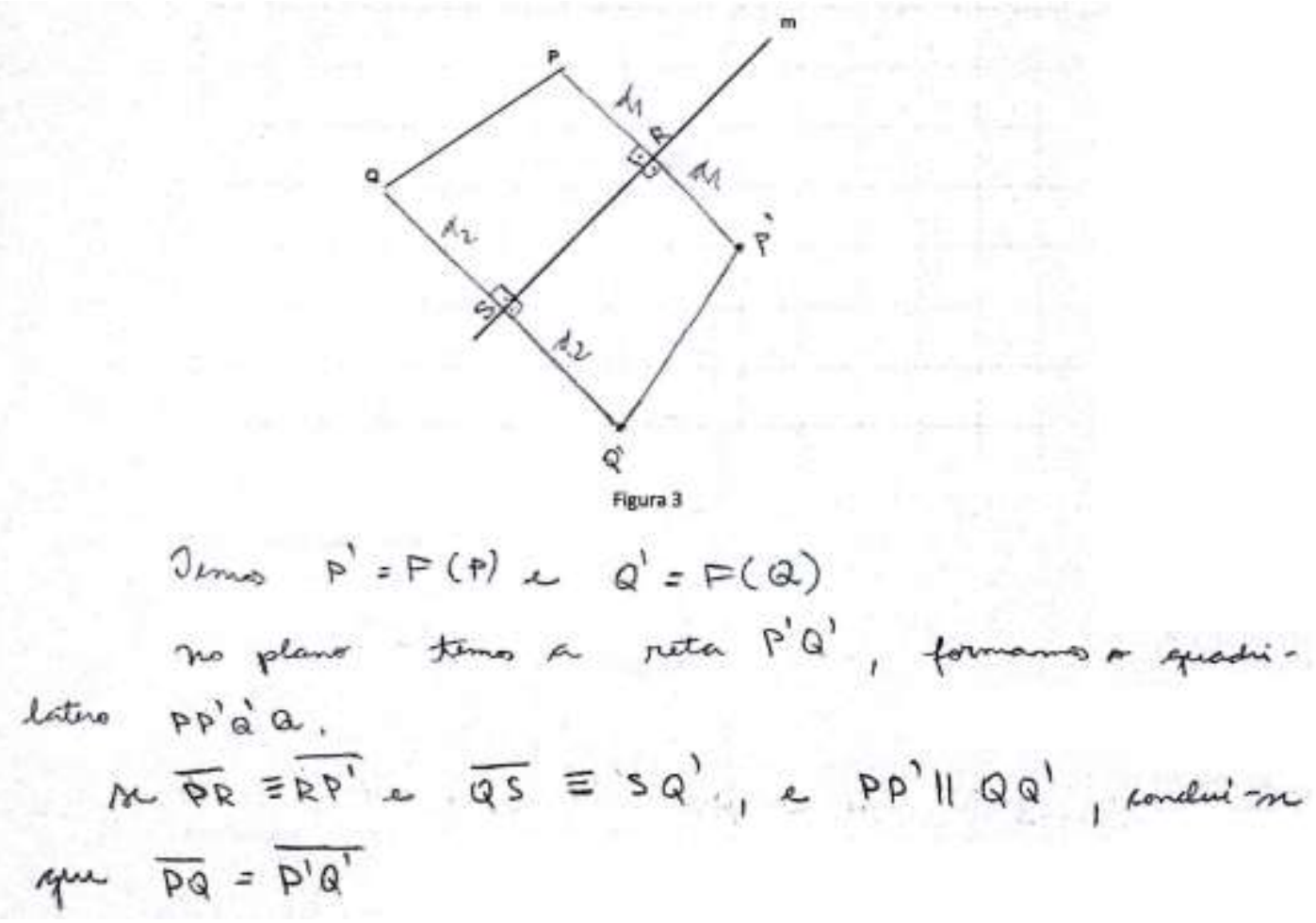

Figura 72: Solução de L9 na Atividade 3 Fonte: Autor.

O aluno L9, por meio da definição de reflexão por uma reta, identifica segmentos perpendiculares à reta $\mathrm{m}$ e afirma que estes são paralelos.

Os demais alunos deste grupo não evidenciaram representações discursivas ou figurais, na referida atividade, tanto nos cadernos de respostas como no GeoGebra.

\section{Considerações}

Os tratamentos figurais estão associados também à apreensão operatória. No caso das respostas feitas pelos professores do Grupo I foram em língua natural, mas não conseguiram observar propriedades auxiliares para suas demonstrações, mesmo com o software à disposição.

Todos os participantes do Grupo II realizaram algum tratamento figural, em sua maior parte, nos cadernos de respostas. Eles realizaram a Atividade 3 com o auxílio do GeoGebra. Durante o minicurso, todos efetuaram tratamentos primeiramente com o software, para depois escrever suas respostas. Mas alguns elementos, como ângulos e segmentos com mesma medida, foram destacados somente nas produções feitas nos cadernos de respostas. 
Nos grupos I e II percebemos como a apreensão operatória influencia em atividades de demonstração, pois os participantes que efetuaram tratamentos figurais, através de operações mereológicas, reconheceram mais unidades figurais, o que auxiliou suas representações discursivas, em alguns aspectos.

Os tratamentos realizados pelos estudantes de Licenciatura em Matemática mostram que a identificação de unidades figurais auxilia nas representações discursivas, especialmente, em atividades que envolvem demonstrações. Dessa forma, a possibilidade ou não de realizar tratamentos nessas representações tem consequências diretas no que diz respeito às apreensões das figuras ao resolver problemas de Geometria (MORAN, 2015, p. 58). Nesse sentido, os professores do Grupo I reconheceram poucas unidades figurais, como congruência de ângulos ou triângulos, ocasionando dificuldades em apresentar demonstrações formais nessa atividade.

Alguns problemas envolvendo demonstrações, em Geometria, necessitam da articulação entre as figuras feitas e as representações discursivas. Duval esclarece que há mecanismos que podem inibir a resolução de problemas (DUVAL, 2012, p.125). Se compararmos os grupos I e III de nossa pesquisa, comprovamos a fala de Duval, sendo que um desses fatores de inibição é o não reconhecimento de unidades figurais.

\section{Apreensão Sequencial}

\section{Grupo I (Oficina CAEM)}

Somente $\mathrm{O} 1 \mathrm{fez}$ representações no software. Como visto na Figura 56b, é possível notar que 01 construiu os pontos de intersecção $L$ e $Q$. Com isso, consideramos correta sua representação. Porém, este professor não descreveu sua construção como esperado, pois não foi pedido no enunciado.

\section{Grupo II (Minicurso ENEM)}

As produções no GeoGebra foram em maior número neste grupo. Apenas M5 fez uma construção robusta e M6 não fez representações no software. Já M1, M3 e M4 construíram os pontos $P$ e $Q$ possibilitando suas movimentações. No entanto, não mantiveram as propriedades da reflexão por reta, como vemos na figura a seguir: 


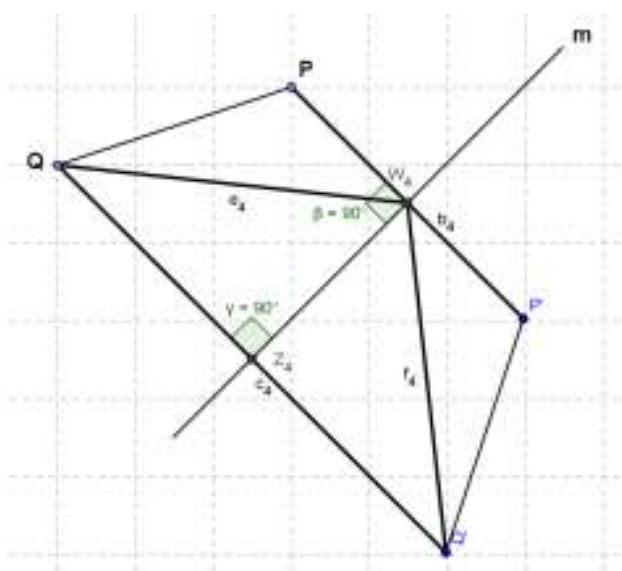

a

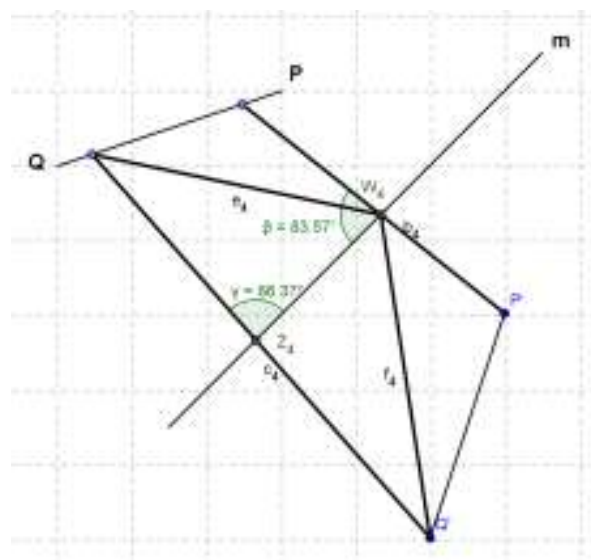

b

Figura 73: Construção de M3 no GeoGebra Fonte: Autor.

\section{Grupo III (Licenciatura em Matemática)}

Os alunos L7, L13 e L14 fizeram construções semelhantes às da Figura 73. Já $L 2, L 11, L 15$ e $L 18$, apenas refletiram $\overline{\mathrm{PQ}}$. $\mathrm{O}$ aluno $\mathrm{L} 4$ fez construções diferentes dos demais alunos, como visto na Figura 62, porém ao movimentarmos a sua representação, percebemos que $\overline{\mathrm{PQ}} \mathrm{e} \overline{\mathrm{W}_{4} \mathrm{~V}_{4}}$ não possuem a mesma medida, o que evidencia que sua construção não é robusta, como podemos verificar a seguir:

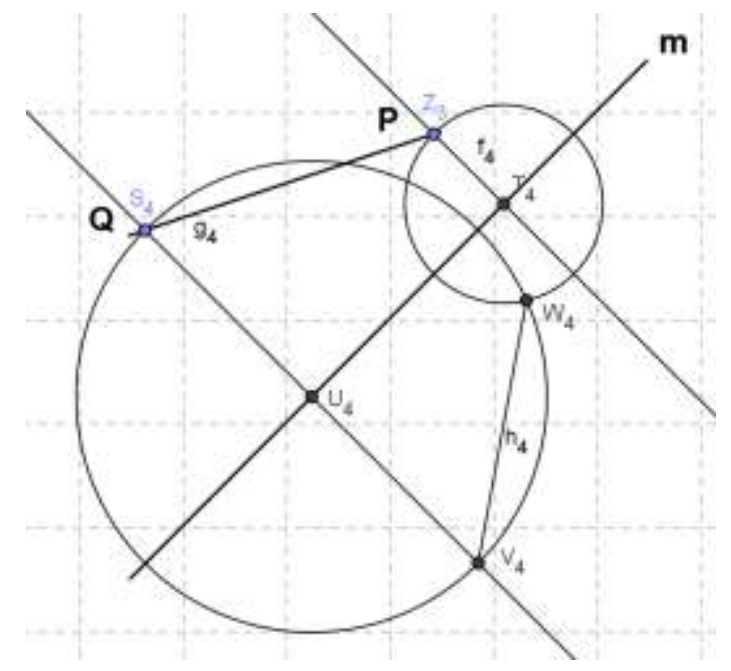

Figura 74: Construção de L4 na Atividade 3 Fonte: Autor.

Dentre os alunos, apenas L17 procurou descrever suas construções no caderno de respostas, como visto na Figura 66. 


\section{Considerações}

Percebemos que as construções no software foram em maior número nos grupos II e III. Devido ao enunciado não explicitar a descrição das construções, todos os participantes, com exceção de L17, não se preocuparam em realizálas.

As construções no GeoGebra, em sua maioria, não foram robustas. Constatamos isso por meio de movimentações que fizemos nos arquivos que os participantes nos entregaram. Duval esclarece que nas atividades envolvendo construções, a apreensão perceptiva pode servir de parâmetro para considerar a resolução certa ou não (DUVAL, 2012a). Note que essa consideração serve tanto para quem realiza a atividade, quanto para quem vai corrigi-la.

\section{Atividade 4}

\section{Comentários sobre a atividade}

Esta atividade consistia em observar o número de intersecções resultantes entre a reflexão de uma circunferência por uma reta $\mathrm{m}$ e a própria reta $\mathrm{m}$ (veja a Parte 1 , do Anexo $\mathrm{C}$ ). Dessa forma, só há três casos possíveis: intersecção vazia com a reta $m$ (Figura 75a), uma intersecção (ponto A na Figura 75b) ou duas intersecções (pontos A e B na Figura 75c):

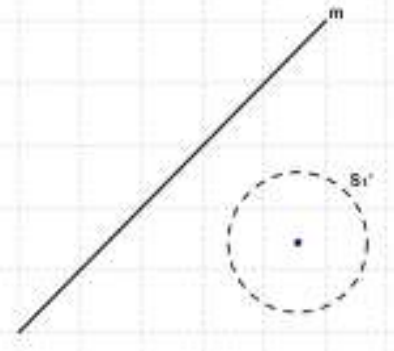

a

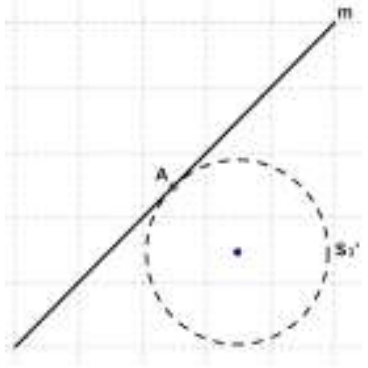

b

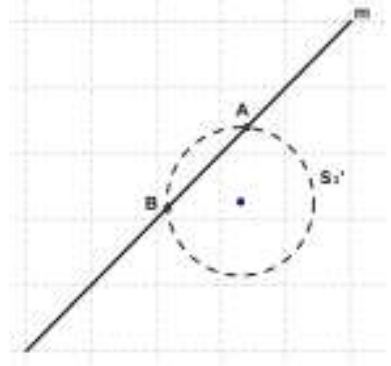

c

Figura 75: Intersecções de uma circunferência com uma reta. Fonte: Autor.

Nesta atividade não era solicitado qualquer tipo de demonstração em linguagem natural ou simbólica.

$\mathrm{Na}$ elaboração desta atividade, também procuramos seguir as características da Investigação Matemática, segundo os autores mencionados na Seção 4.2, deixando o problema em aberto, de modo que os participantes de todos os grupos investigassem possíveis caminhos para a suas respostas. 
Entendemos que fazem parte desta atividade os três primeiros momentos da Investigação Matemática. Explorar o problema com o auxílio do software, leva o participante a formular possíveis soluções e querer exibi-las. Além disso, surge o questionamento se todos os casos foram apresentados, conduzindo o participante a verificar se existem mais respostas.

Nos cadernos de respostas e no arquivo do GeoGebra disponibilizados na oficina do CAEM, era dada a reta $\mathrm{m}$. Já no minicurso do ENEM e para os alunos de licenciatura a reta $m$ não foi dada (veja a Parte 1 , do Anexo $C$ ). Entendemos que a segunda forma mencionada, quando a reta $m$ não é dada, é mais condizente com as características de atividades ligadas à Investigação Matemática proposta por Ponte, Brocardo e Oliveira (2003). No entanto, já adiantamos que as indagações dos participantes foram semelhantes em todos os grupos da pesquisa durante esta atividade, não havendo diferenças significativas entre as duas abordagens.

Espera-se, principalmente, a mobilização da apreensão perceptiva, devido à natureza da atividade. Quanto a apreensão discursiva, note que a interpretação correta do enunciado é primordial. É natural, para a resolução deste problema, que os participantes utilizem em suas representações a ferramenta de reflexão por reta, disponível no software.

\section{Apreensão Perceptiva}

\section{Grupo I (Oficina CAEM)}

Todos os professores deste grupo responderam em seus cadernos de respostas. Neles, apenas $\mathrm{O} 1$ e $\mathrm{O} 4$ não indicaram os pontos de intersecção entre as circunferências e a reta $\mathrm{m}$. Os demais professores utilizaram a notação usual para os pontos. Somente $\mathrm{O} 4$ destacou um valor para o raio de uma das circunferências em suas produções. Na figura a seguir, é perceptível o uso da malha quadriculada: 


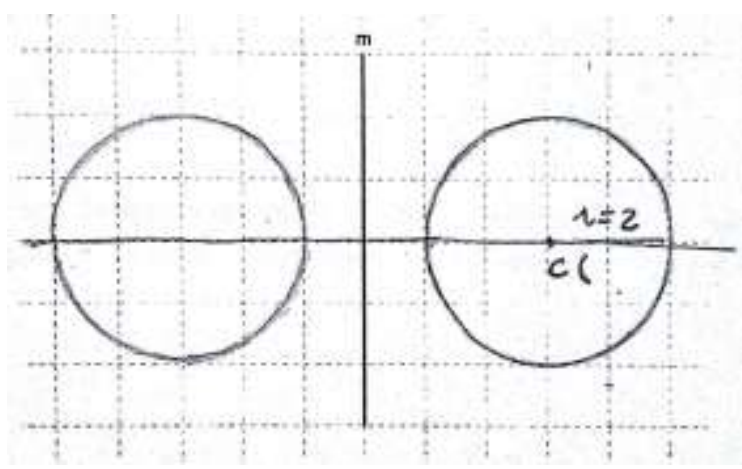

Figura 76: Representação figural de 04 na Atividade 4 Fonte: Autor.

Visivelmente, $\mathrm{O} 4$ quis escrever as coordenadas do centro de uma das circunferências, mas não concluiu seu raciocínio, inclusive para outras circunferências que fez.

Os professores, com exceção de O5, responderam também no GeoGebra e experimentaram primeiramente no software. Todos os participantes aplicaram a ferramenta de reflexão disponível. Posteriormente, em seus cadernos de respostas, apresentaram suas resoluções.

\section{Grupo II (Minicurso ENEM)}

De maneira semelhante ao grupo anterior, com exceção de M5 e M6, os professores fizeram suas produções nos cadernos de respostas também de maneira satisfatória. Em nenhuma das respostas a reta mediatriz estava na posição vertical ou horizontal, isso talvez tenha ocorrido porque, no exemplo usado pelo pesquisador (veja o Anexo $\mathrm{C}$ ), a mediatriz também estava inclinada. Neste grupo, todos os participantes responderam também no software. Três destes professores aplicaram estímulos visuais em suas figuras através da mudança de cores. Como exemplo, mostramos na solução de M4:

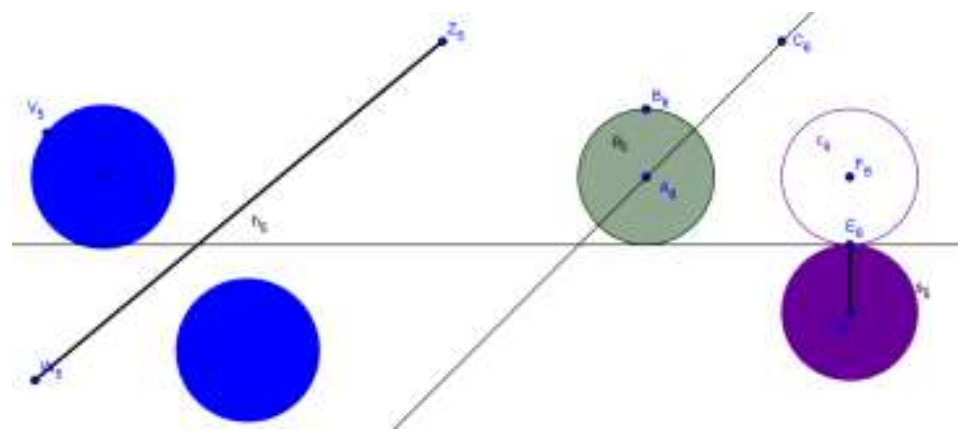

Figura 77: Representação figural de M4 na Atividade 4 Fonte: Autor. 
O professor M5, ao ler o enunciado e observar o caderno de respostas, teve a seguinte reação:

\author{
M5: É para fazer três representações? \\ Pesquisador: Quantas são possíveis? \\ M5: Ah, da mesma?
}

Aparentemente, para M5 era suficiente fazer uma figura. Ou seja, até aquele momento, ele estava considerando um único caso. Após alguns instantes, M5 apresentou de maneira correta os três casos no GeoGebra.

Neste grupo, apenas M2 identificou o centro das circunferências sem nomeá-los. Este professor foi o único do grupo que não apresentou todos os casos possíveis no caderno de respostas, faltando o caso em que as circunferências são tangentes à mediatriz, porém na resposta feita no GeoGebra, M2 apresentou todos os casos.

Nenhum dos professores indicou a nomenclatura usual para pontos, nem fez uso de medidas. Somente M3 nomeou cada uma das circunferências em suas produções.

\title{
Grupo III (Licenciatura em Matemática)
}

Os alunos L1, L3, L6, L12, L14 e L19 não responderam em seus cadernos de respostas. Destes, apenas $L 14$ utilizou o GeoGebra:

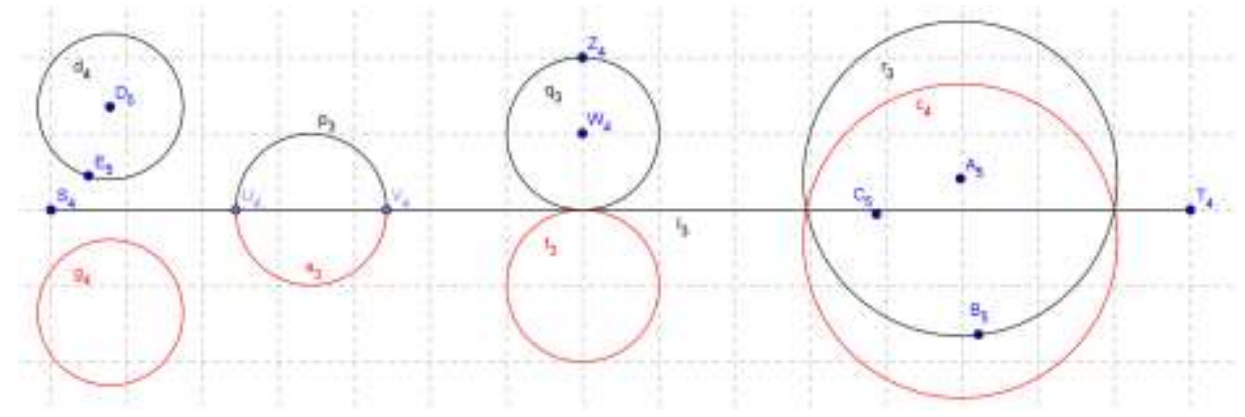

Figura 78: Representação figural de L14 na Atividade 4 Fonte: Autor.

Dos demais alunos, cinco apresentaram a reta de reflexão inclinada, enquanto que, em cinco outros cadernos as retas eram verticais e em dois horizontais. Percebemos que os alunos procuraram seguir o mesmo padrão de solução no software e no caderno de respostas. Em outras palavras, os alunos 
que construíram no GeoGebra a reta inclinada também procederam desta forma nos seus respectivos cadernos de respostas. O mesmo aconteceu para os que representaram retas na horizontal ou vertical.

O aluno L18 foi o único que representou os pontos de intersecção entre as circunferências e a reta com a nomenclatura usual. Outra singularidade foi a resposta de $\mathrm{L} 7$ que, tanto no software quanto no caderno de respostas, não apresentou um resultado satisfatório, como os demais alunos.

Com relação ao uso de medidas, apenas L9 fez menção de usá-las, como vemos abaixo, porém apenas na primeira construção:

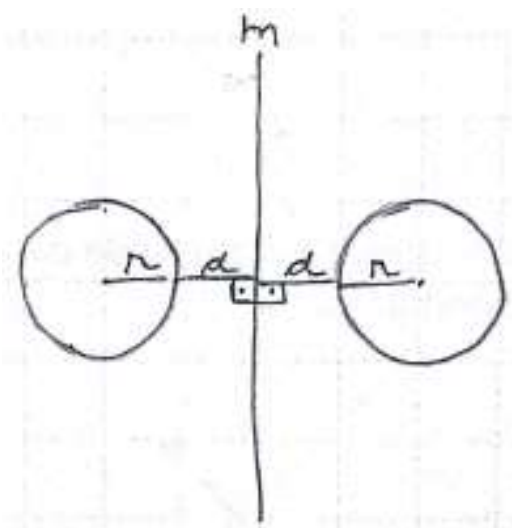

Figura 79: Representação figural de L9 na Atividade 4 Fonte: Autor.

\section{Considerações}

Antes dos participantes iniciarem a atividade, comentamos que as reflexões por retas preservam circunferências. Porém, nenhum deles perguntou como esse resultado poderia ser provado.

Os participantes demonstraram dificuldades na interpretação do enunciado. De início, não sabiam ao certo como devia ser respondida a atividade e consideraram, em sua maioria, apenas o caso em que a reta é secante às circunferências. Consequentemente, levou um certo tempo para apresentarem, por completo, suas repostas.

O fato de terem feito experimentações no GeoGebra, antes de escreverem suas respostas, mostra que o software auxiliou na investigação, caso contrário, os participantes o teriam ignorado. Concordamos com Medeiros (2012), quando afirma que o GeoGebra proporciona uma motivação para a exploração, pois seu uso permite a experimentação (MEDEIROS, 2012, p. 124). Outra iniciativa importante, e que ficou claro para os docentes, foi o modo como 
fizeram as reflexões em seus cadernos de respostas. Os professores refletiram o centro da circunferência primeiramente e, depois de ver o raio da circunferência original, a traçaram.

No Grupo II houve posicionamentos em relação à atividade semelhantes aos do grupo anterior, pois buscaram realizar a atividade primeiramente no GeoGebra. As dificuldades que tiveram, na interpretação do enunciado, foram iguais. Este grupo demonstrou ter mais familiaridade com o software, porque os participantes criaram estímulos visuais através da mudança de cores de alguns objetos, algo que não ocorreu tanto nos outros grupos. Duval (2005) ressalta que os instrumentos podem auxiliar nossa maneira de ver uma figura, contribuindo para o raciocínio geométrico.

A maioria dos alunos no Grupo III não se preocupou em nomear pontos ou circunferências através da escrita usual. Como nos outros grupos pesquisados, essa ação indica também a apreensão perceptiva, uma vez que a maioria dos participantes responderam sem se preocupar com o rigor. Isso também mostra o quanto a percepção visual foi utilizada, por grande parte dos alunos e professores. Os alunos também demonstraram dificuldades no início da atividade, como os participantes dos demais grupos. Apesar de $L 4$ ter feito de maneira correta atividades anteriores, ele não reconheceu o caso em que há duas intersecções, já L9 e L10 não representaram o caso em que a circunferência é tangente à reta.

Alguns participantes, após manipularem o software, responderam de imediato o problema, isso pode ter explicação no fato do software estimular a visualização de alguns aspectos geométricos. Neste sentido, concordamos com Moran (2015), pois a autora afirma que alguns problemas de Geometria podem ser resolvidos de maneira mais fácil, dependendo do instrumento utilizado para a representação figural.

\section{Apreensão Discursiva}

\section{Grupo I (Oficina CAEM)}

Apesar de não ter sido requisitado qualquer demonstração formal ou resposta por escrito nesta atividade, alguns participantes fizeram representações em língua natural, em seus cadernos de respostas. 
Os professores $\mathrm{O} 4$ e $\mathrm{O} 5$ apenas escreveram ao lado de suas respectivas figuras as palavras: tangente, secante e distante da reta. Já as respostas em língua natural de $\mathrm{O} 2$ e $\mathrm{O} 3$ foram:

O2: reta m secante à circunferência; circunferência totalmente à esquerda ou direita; circunferência tangente à reta $\mathrm{m}$.

O3: distância infinita; secante; circunferência tangente à reta m.

Dois professores, 01 e 06, não fizeram qualquer representação em língua natural ou simbólica algébrica nesta atividade.

\section{Grupo II (Minicurso ENEM)}

Os professores deste grupo não fizeram representações em língua natural ou simbólica algébrica em suas folhas de respostas ou no software. Dessa forma não faremos considerações sobre este grupo, nesta atividade.

\section{Grupo III (Licenciatura em Matemática)}

Três alunos fizeram representações em língua natural ou simbólica algébrica durante esta atividade, somente nas folhas de respostas. O aluno L10 usou a linguagem formal. Considerou uma circunferência $S_{1}$ e sua reflexão pela

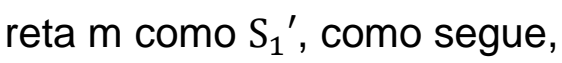

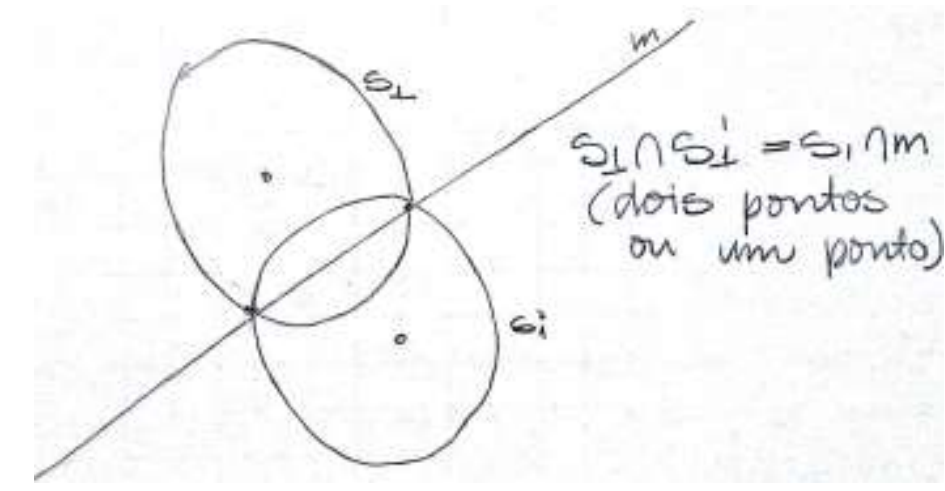

Figura 80: Representação discursiva de L10 na Atividade 4 Fonte: Autor.

Apesar da preocupação que L10 mostrou ao responder utilizando a linguagem simbólica algébrica, ele não considerou o caso em que a reta $m$ não intersecta a circunferência a ser refletida. 
O aluno $\mathrm{L} 13$ reconheceu todos os casos possíveis. Ao lado de cada figura escreveu em língua natural a quantidade de intersecções entre as circunferências e a reta $\mathrm{m}$. $\mathrm{O}$ caso em que o centro da circunferência pertence à reta, L13 reconheceu como sendo um caso particular, que gera dois pontos de intersecção com a reta dada.

A representação de $L 15$ foi semelhante ao dos professores participantes da Oficina do CAEM, usou apenas a língua natural, indicando o número de intersecções.

\section{Considerações}

A interpretação correta do enunciado é essencial para a realização de qualquer problema em Matemática. Com a Atividade 4, não foi diferente. Percebemos que os participantes dos três grupos tiveram certa dificuldade em apresentar suas representações de início, como mencionado na página 114. Moretti (2013) esclarece que alguns problemas em Geometria podem se tornar complexos devido a associação necessária entre as apreensões. Nesta atividade é possível perceber, por exemplo, a associação entre as apreensões perceptiva, discursiva e operatória.

Acreditamos que o enunciado também não estimulou a interação entre os tratamentos figural e a representação em língua natural ou simbólica algébrica, o que explica o número baixo de respostas escritas. Dessa forma, conclui-se que houve subordinação da apreensão discursiva à perceptiva.

\section{Apreensão Operatória}

\section{Grupo I (Oficina CAEM)}

Os tratamentos utilizados pelos professores foram semelhantes. No GeoGebra, aplicaram a ferramenta Reflexão por Retas para cada circunferência. Através da observação e do raciocínio dedutivo, reconheceram os casos possíveis.

\section{Grupo II (Minicurso ENEM)}

Os professores deste grupo aplicaram a ferramenta de reflexão disponibilizada pelo software. O participante M6 apresentou apenas o caso em 
que a reta é secante à circunferência e, em seu caderno de respostas, não fez representações para esta atividade, assim como M5.

\section{Grupo III (Licenciatura em Matemática)}

Apenas os alunos L11, L13, L14, L15, L17 e L18 fizeram representações no software para esta atividade, utilizando a ferramenta de reflexão do GeoGebra. Destes, o aluno L11 foi o único que apresentou tratamentos diferentes no caderno de respostas, em relação ao apresentado no GeoGebra. No caderno de respostas há três representações, enquanto que no software apenas uma, como segue:

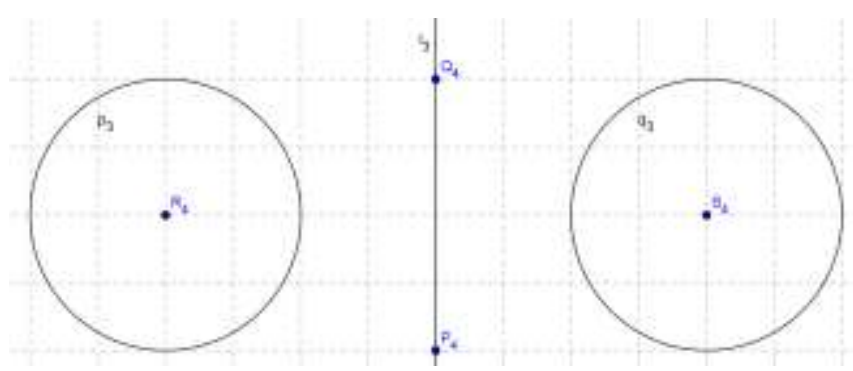

Figura 81: Representação figural de L11 na Atividade 4 Fonte: Autor.

É possível que L11 tenha movimentado a circunferência no software de modo a encontrar as soluções para o problema, o que explicaria ter feito apenas uma circunferência e sua reflexão pela reta $\mathrm{m}$, diferentemente dos outros alunos acima citados.

Os demais alunos, que fizeram representações em suas folhas de respostas, procederam de maneira semelhante aos demais participantes dos outros grupos.

\section{Considerações}

A apreensão operatória de posição é notória, uma vez que a modificação posicional de reflexão era suficiente para a realização da atividade. Considerando que a apreensão perceptiva se faz presente em grande parte das atividades em Geometria, percebemos o que Duval (1997, apud MORETTI, 2013, p. 293) chama de visualização, que é a conexão entre as apreensões perceptiva e operatória. 
A investigação foi estimulada através do software, pois todos os participantes recorreram a ele, antes de fazerem suas produções nos cadernos de respostas. A ferramenta de reflexão do GeoGebra foi utilizada pela maioria dos participantes, como era esperado.

De todos os participantes da pesquisa, apenas L11 parece ter usado o aspecto dinâmico que o software oferece, por ter apresentado um único par de circunferências em seu arquivo no GeoGebra, enquanto que os demais apresentaram três ou quatro pares de circunferências.

Acreditamos que o enunciado apresentado aos grupos II e III está mais condizente com as características de problemas propostos na Investigação Matemática, de acordo com os autores mencionados na Seção 4.2, pois permitiu maior autonomia dos participantes quando estes deveriam criar as retas e as circunferências com raios quaisquer.

\section{Apreensão Sequencial}

\section{Grupo I (Oficina CAEM)}

Os participantes deste grupo não descreveram suas construções, como era esperado. As representações foram semelhantes, e nenhum deles construiu de maneira correta o caso em que a circunferência tangencia a reta. Porém, deduziram este caso por meio da visualização de suas outras representações no software.

\section{Grupo II (Minicurso ENEM)}

Os professores, nesta atividade, não descreveram as construções, como era esperado. Somente M3 e M4 construíram de maneira correta suas representações em que a circunferências eram tangentes à reta. As demais construções foram semelhantes às do grupo anterior.

\section{Grupo III (Licenciatura em Matemática)}

As representações no software foram semelhantes às dos outros grupos. Os alunos não construíram de maneira correta o caso em que as circunferências são tangentes à reta. Como exemplo, observe que, na Figura 78, L14 não constrói o ponto de tangência entre as circunferências e a reta. 


\section{Comentários}

As representações, para o caso em que a circunferência tangenciava a reta, da maioria dos participantes foram construídas da seguinte forma: consideraram um ponto como centro de uma circunferência (Figura 82a) e um ponto qualquer sobre a reta de reflexão (Figura 82b). Em seguida, traçaram a circunferência (Figura 82c) e a refletiram, como segue (Figura 82d):

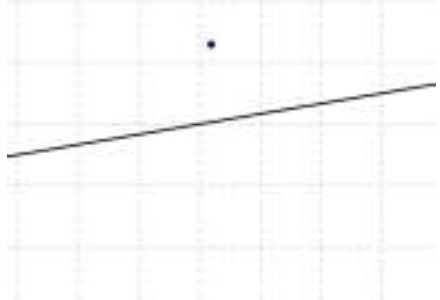

a

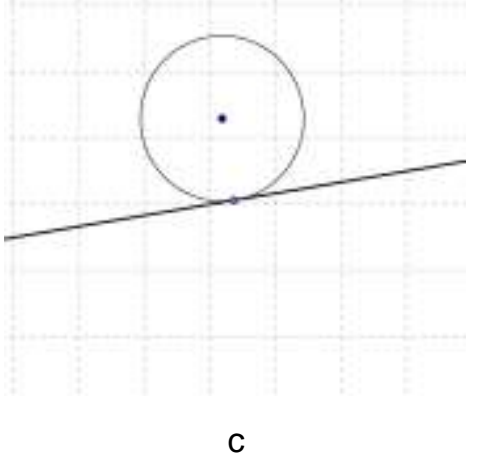

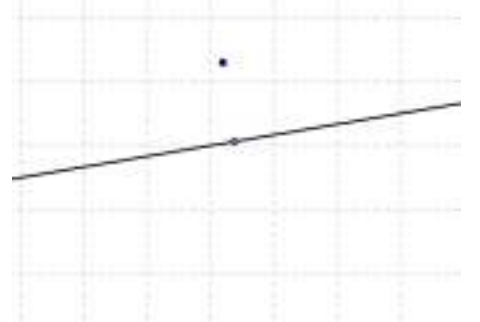

b

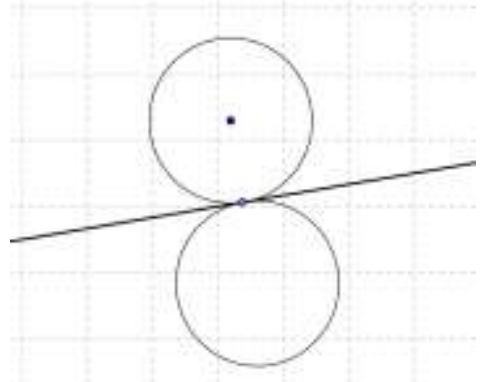

d

Figura 82: Circunferência tangente visualmente Fonte: Autor.

Visualmente, as circunferências tangenciam a reta. No entanto, basta movermos uma delas para percebermos que a construção pode apresentar mais um ponto de intersecção. Uma construção correta envolve, por exemplo, a reta perpendicular à mediatriz, o ponto de intersecção entre estas retas e o centro da circunferência sobre a reta perpendicular.

Como esperado, em nenhum dos grupos foi observado o detalhamento das construções e a maioria dos participantes fez suas representações baseando-se na apreensão perceptiva, principalmente para o caso em que as circunferências eram tangentes à reta. Segundo Duval (2012a), ao construirmos uma figura, a apreensão perceptiva serve de parâmetro para aceitarmos ou não a representação feita. Dessa forma, visualmente, pareceu aos participantes 
estarem corretas as suas representações, mas bastaria movimentá-las para perceber que não eram robustas.

\section{Atividade 5}

\section{Comentários sobre a atividade}

A Atividade 5 é composta dos itens a) e b) (veja a Parte 1 do Anexo C). No primeiro item, bastava usar a língua natural para mostrar todos os casos possíveis de intersecções entre duas circunferências: intersecção vazia; um ponto de intersecção; dois pontos de intersecção ou infinitos pontos de intersecção. Para este item, esperamos que os participantes reconheçam todas as possíveis respostas, uma vez que ela se assemelha à Atividade 4.

No item b) era necessário perceber que, sendo $S_{1}{ }^{\prime}$ a reflexão de $S_{1}$ pela reta $\mathrm{m}$, a intersecção de $\mathrm{S}_{1}{ }^{\prime}$ com $\mathrm{S}_{2}$ gera dois pontos $\mathrm{C}$ e $\mathrm{E}$, como na figura a seguir:

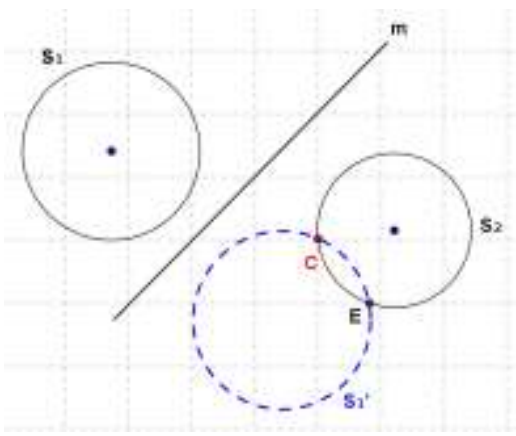

Figura 83: Ponto C e E na circunferência $S_{2}$ Fonte: Autor.

Por meio da reflexão do ponto $C$ por $m$, encontramos o ponto $A$ pertencente à circunferência $S_{1}$. Dessa forma já temos dois vértices do quadrado procurado, como segue:

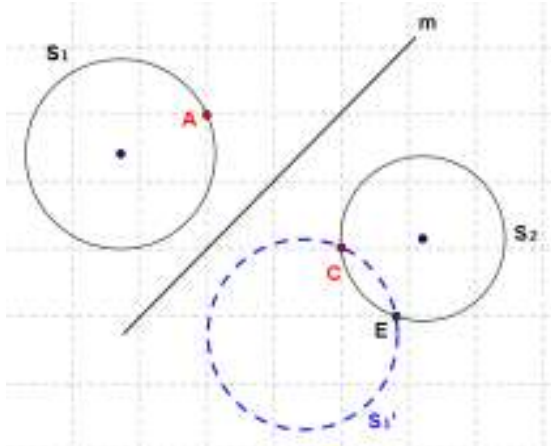

Figura 84: Ponto A na circunferência $S_{1}$ Fonte: Autor. 
Sendo $P$ a intersecção do segmento $\overline{\mathrm{AC}}$ com a reta $m$, os vértices $B$ e $D$ serão encontrados traçando-se uma circunferência $S_{3}$, com centro em $\mathrm{P}$ e raio PC:

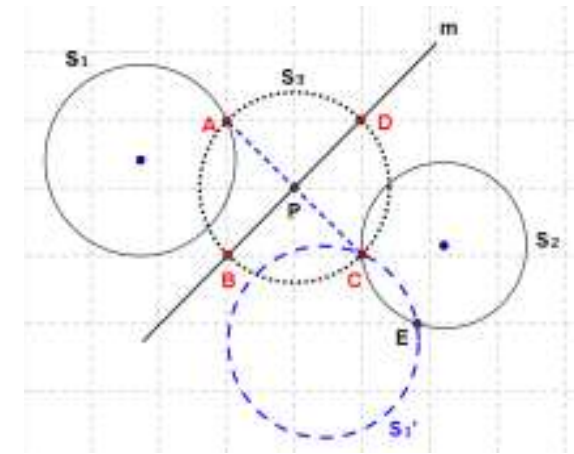

Figura 85: Pontos B e D em m Fonte: Autor.

Neste problema, deixamos de propósito duas soluções possíveis, apenas para facilitar a obtenção das possíveis respostas pelos participantes. A outra solução é análoga, trabalhando-se com o ponto $\mathrm{E}$.

O primeiro item abre caminho para as conjecturas no item seguinte. As tentativas no caderno de respostas ou no GeoGebra estimulam a investigação, gerando assim novos tratamentos no problema. No segundo item, pede-se para justificar as construções feitas, aprimorando a busca dos resultados encontrados. Dessa forma, conjecturas, testes e avaliações são requisitados nesta atividade.

Acreditamos que a observação da relação entre os itens a) e b) é relevante para a resolução completa da Atividade 5. Esperamos que sejam apresentadas, nos cadernos de repostas, as quatro possíveis soluções em representação discursiva e figural. Vale ressaltar que a mobilização das quatro apreensões é requisitada no problema como um todo.

No caderno de respostas sugerimos o roteiro (veja a Parte 1 do Anexo C): - Descrição da Construção, o participante deve descrever os passos da sua construção;

- Justificativa: por meio das propriedades de cada objeto construído, o participante deve justificar o porquê das construções serem válidas, em outras palavras, o porquê das construções fornecerem a resposta procurada; 
- Discussão: apresentar o número de soluções possíveis do problema. Note que, o fato deste roteiro estar presente no caderno de respostas já interfere na apreensão perceptiva.

Em problemas como este conseguimos notar como as apreensões operatória e discursiva estão subordinadas à apreensão perceptiva. Não é tão fácil perceber que a reflexão da circunferência $\mathrm{S}_{1}$ produzirá um dos vértices procurados. Este problema está associado ao olhar do inventor, segundo Moretti (2013). Note que, para resolver este problema, como outros em Geometria, se faz necessária a criação de segmentos, pontos de intersecção, circunferências e outros objetos. Sem a criação desses objetos, o problema se torna mais complicado.

Um outro caminho para a solução do problema é supô-lo resolvido. Então, a partir de um dos quadrados já formados, devemos encontrar propriedades ligadas aos objetos envolvidos no problema. No caso, perceber que as diagonais do quadrado formam entre si ângulos retos (Figura 86), e que isso pode ser associado à reflexão pela reta $\mathrm{m}$ :

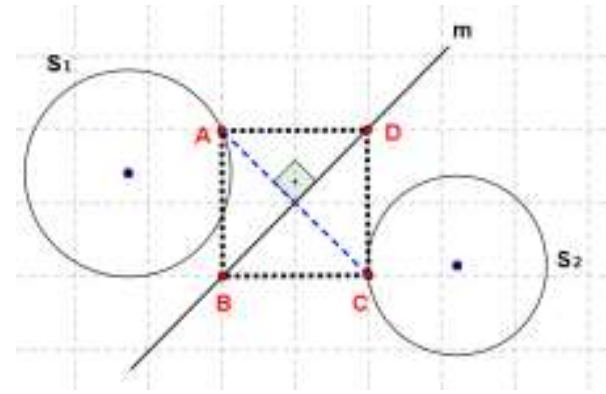

Figura 86: Supondo o problema resolvido Fonte: Autor.

Neste tipo de abordagem, ainda é necessário o olhar do inventor, pois criam-se elementos novos no problema.

A seguir, temos as produções dos participantes desta pesquisa e as respectivas análises.

\section{Apreensão Perceptiva}

\section{Grupo I (Oficina CAEM)}

Apenas 06 não respondeu ao primeiro item, sendo que as representações de 01 e 04 se destacaram. O professor 01 não mostrou o caso em que as circunferências são coincidentes. Já $\mathrm{O} 4$ apresentou duas vezes o caso em que 
há somente uma intersecção entre as circunferências, como observamos em sua resposta:

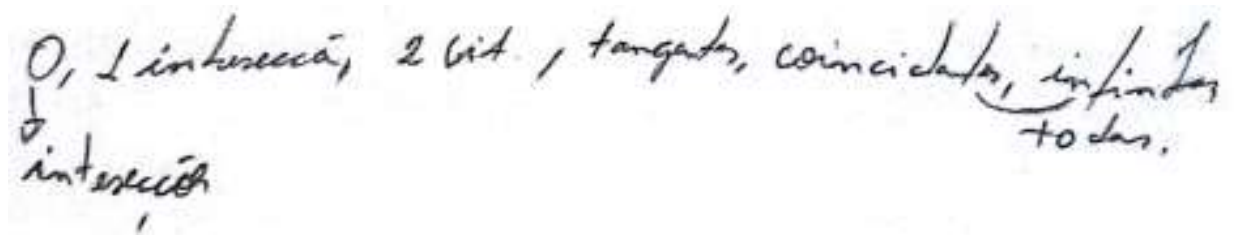

Figura 87: Solução de 04 sobre o número de intersecções

Fonte: Autor.

Os outros professores, para o primeiro item da Atividade 5, apresentaram respostas satisfatórias.

Com relação ao item b), os professores que fizeram representações no software foram $\mathrm{O} 2, \mathrm{O} 4$ e 06 . A resposta de $\mathrm{O} 2$ segue abaixo. Nela vemos que faltou apenas uma construção: a circunferência de centro em $R$ e raio RA. Este professor cogitou aplicar uma rotação no segmento $\overline{\mathrm{AC}}$, porém pediu auxílio ao pesquisador para a obtenção dos vértices $\mathrm{B}$ e $\mathrm{D}$. Percebe-se que $\mathrm{O} 2$ conseguiu extrair informações importantes de suas representações. Nesta atividade, O2 usou exclusivamente o GeoGebra e sua ferramenta de reflexão por reta.

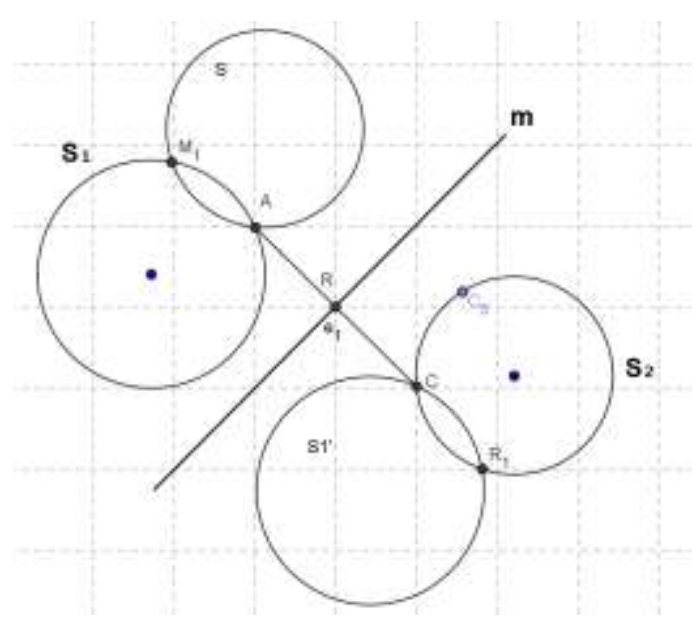

Figura 88: Representação figural de 02 no item 5 b) Fonte: Autor.

Por sua vez, O4 utilizou a ferramenta polígono em sua resposta, como segue: 


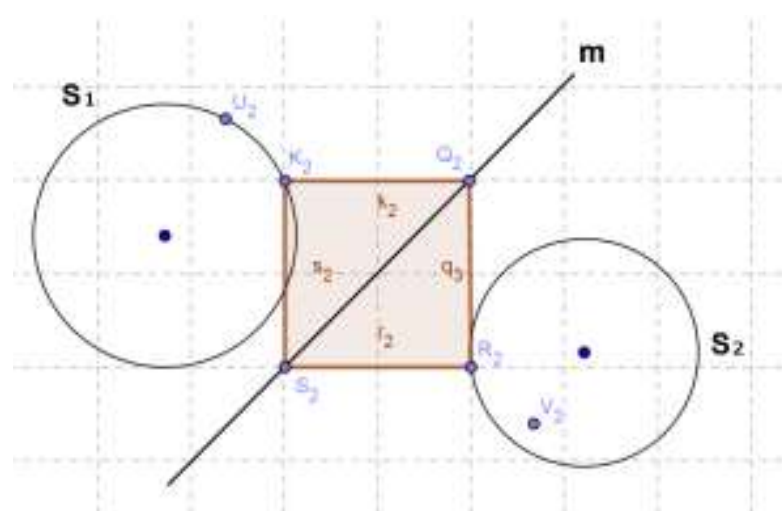

Figura 89: Representação figural de 04 no item 5 b) Fonte: Autor.

Note que O4 utilizou a malha quadriculada para a sua construção. Neste caso, vemos a apreensão perceptiva se impor sobre a discursiva mais uma vez. Para este professor foi suficiente a sua construção, não se atentando para uma outra possível solução.

A representação acima foi semelhante ao de $01 \mathrm{em}$ seu caderno de respostas:

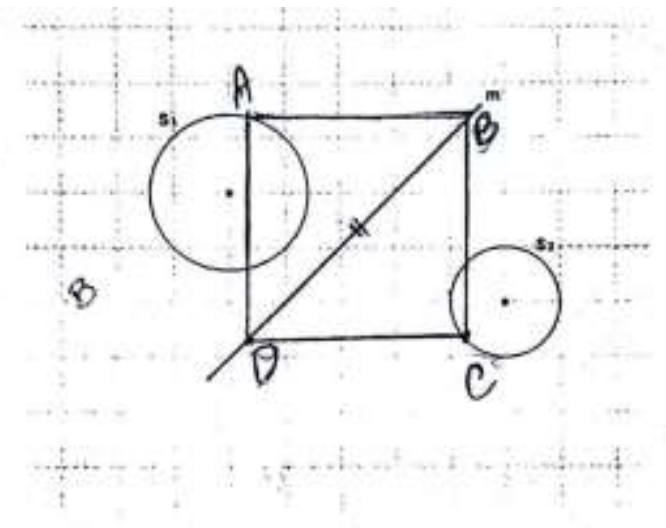

Figura 11

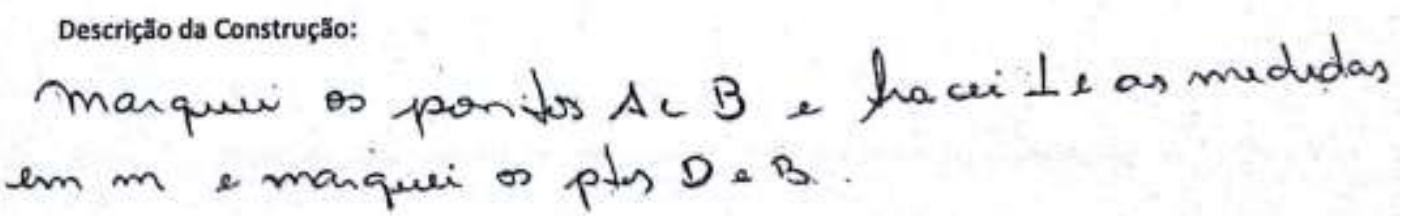

Figura 90: Representação figural de 01 no item 5 b) Fonte: Autor.

Novamente temos uma construção baseada na visualização e não na exploração das propriedades presentes nos objetos matemáticos envolvidos no problema.

O professor $\mathrm{O} 6$ começou a fazer suas construções no GeoGebra, de acordo com algumas reflexões e propriedades que reconheceu. Encontrou os 
vértices $A$ e $C$ (vértices $L_{1}$ e $L_{3}$, respectivamente, na Figura 91). No entanto, não avançou em sua resposta:

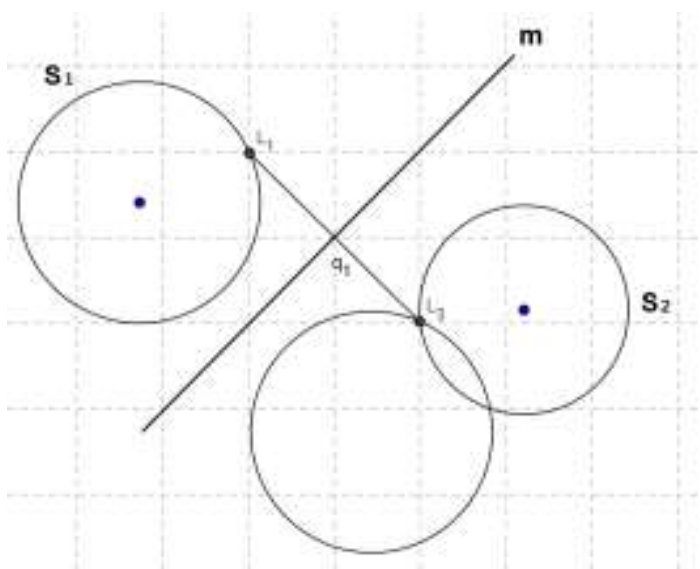

Figura 91: Representação figural de 06 na Atividade 5 Fonte: Autor.

Assim como O2, o professor 06 utilizou a ferramenta de reflexão disposta no software. Os demais professores não apresentaram construções nos cadernos de respostas, nem no GeoGebra.

\section{Grupo II (Minicurso ENEM)}

No primeiro item da atividade somente M1, M3 e M4 transcreveram suas respostas. O professor M1 apenas escreveu todos os casos possíveis. Já M3 e M4 também apresentaram tratamentos figurais associados às suas respostas:

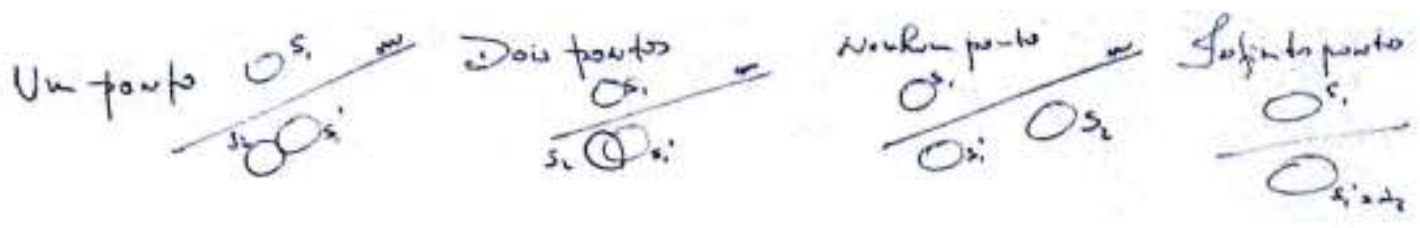

Figura 92: Resposta de M3 no item 5 a) Fonte: Autor.
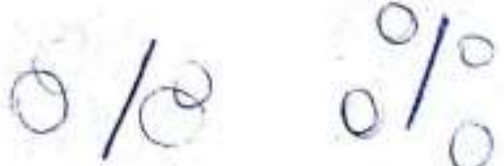

Pode ocoveres o

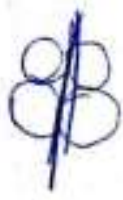

duas unterrecgês, nenhuma our uma.

Figura 93: Resposta de M4 no item 5 a) Fonte: Autor.

Na representação de M4 percebemos que não foi considerado o caso em que as circunferências são coincidentes. 
Os professores M3 e M4 utilizaram o tratamento figural para possivelmente identificar as soluções no primeiro item. Apesar de M3 ter utilizado o software em atividades anteriores, não quis utilizá-lo em sua investigação.

Somente M3 não fez representações no GeoGebra. Apesar de ter feito tratamentos no software, M5 não concluiu este item.

O professor M6 apresentou a mesma dificuldade que os professores $\mathrm{O} 2$ e O4, do grupo anterior (veja as figuras 88 e 89 , respectivamente), concluindo a atividade após o auxílio do pesquisador.

As construções destes professores foram semelhantes ao que apresentamos no início da seção, com a seguinte diferença: M2, M4 e M6 utilizaram a ferramenta polígono.

\section{Grupo III (Licenciatura em Matemática)}

No primeiro item, nenhum dos alunos efetuou tratamentos figurais. Os alunos L4, L10 e L18 responderam da seguinte forma:

L4: Dado a interpretação acima teremos dois pontos de intersecção.

L10: Zero, um (tangentes) ou dois.

L18: 2 intersecções.

Note que, estes alunos não apresentaram o caso em que há infinitos pontos de intersecção. Já os alunos L3, L5, L8, L11 e L16 perceberam todos os casos possíveis, porém não explicitaram as palavras infinitas intersecções, mas sim, que as circunferências são coincidentes.

Os alunos L2, L12, L15 e L17 apresentaram todos os casos através da língua natural, enquanto que $L 1, L 6, L 7, L 9, L 13, L 14$ e $L 19$ não fizeram qualquer tipo de representação em seus cadernos de respostas.

Em sua maioria, os participantes reconheceram as unidades figurais presentes no item b). Algumas propriedades do quadrado foram reconhecidas, como suas diagonais formarem ângulos retos. O aluno L15, por exemplo, identificou ângulos e lados congruentes, como vemos a seguir: 


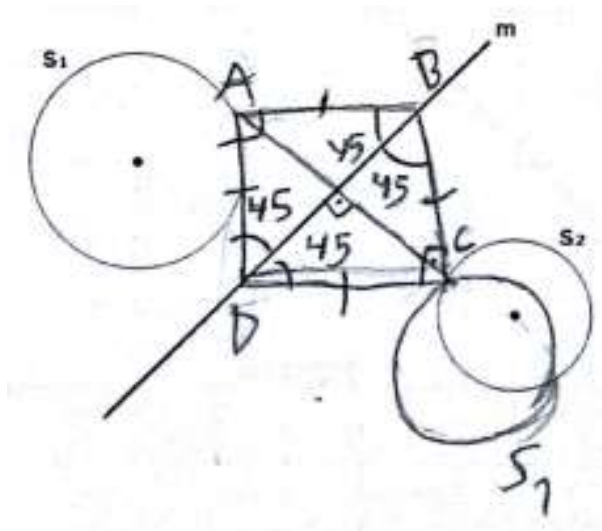

Figura 94: Representação figural de L15 no item 5 b) Fonte: Autor.

\section{Considerações}

Em todos os grupos houve, em relação ao item a), dificuldades no reconhecimento do número de intersecções quando este era infinito. Respostas imediatas foram percebidas nos relatos e nas representações dos participantes, quando estes identificaram uma ou duas intersecções entre as circunferências. A não consideração do caso em que há infinitas intersecções se observou no item b) em algumas respostas, como veremos na seção a seguir. Diante dessas respostas imediatas, Duval (2014 apud MORAN, 2015, p.141) aponta que o ensino de Geometria deve priorizar a maneira matemática de ver uma figura e não a maneira natural de vê-la. Ele ainda esclarece que ver uma figura é uma atividade cognitiva mais complexa do que o simples reconhecimento daquilo que uma imagem mostra (DUVAL, 2012a, p.118).

Nos grupos II e III, as representações figurais estiveram mais presentes nas produções dos participantes. Houve reconhecimento de unidades figurais, através da utilização da nomenclatura usual.

Todos os grupos utilizaram primeiramente o software para depois fazerem alguma representação no caderno de respostas (apenas o professor M3 preferiu trabalhar somente com o caderno de respostas, para esta atividade).

\section{Apreensão Discursiva}

\section{Grupo I (Oficina CAEM)}

Os professores não apresentaram nenhum tratamento figural associado às suas representações discursivas no primeiro item. O professor $\mathrm{O} 2$ foi o único que procurou responder usando linguagem simbólica, como segue: 


$$
\begin{aligned}
& \rightarrow 1 \text { se } S_{2} \text { c } S_{i} \text { formtrongertes } \\
& \rightarrow \text { nonhuma se } S_{2} \cap S^{\prime} I^{\prime}=\varnothing \text { infinitas se } S_{2 .} S_{i}^{\prime} \text { form corradete }
\end{aligned}
$$

Figura 95: Resposta de 02 no item 5 a)

$$
\text { Fonte: Autor. }
$$

O professor 01 não reconheceu o caso em que as circunferências são coincidentes e, dentre os outros professores, apenas $\mathrm{O} 6$ não fez representação discursiva.

No item b) o professor $\mathrm{O} 1$ apenas apresentou um caso particular (veja a Figura 90). Dessa forma não consideramos que ele interpretou de maneira correta o enunciado. Entendemos que a apreensão discursiva ficou novamente subordinada à perceptiva, pois a representação discursiva foi usada para descrever a representação figural, que era um caso particular.

Os outros professores interpretaram corretamente o enunciado, porém, como dito anteriormente, somente $\mathrm{O} 1, \mathrm{O} 2 \mathrm{e} \mathrm{O} 6$ responderam à questão. A seguir são apresentadas as produções de $\mathrm{O} 2$ e 06 :

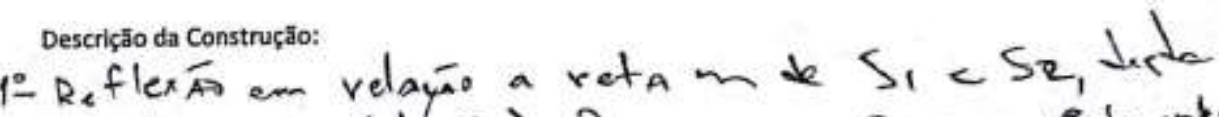

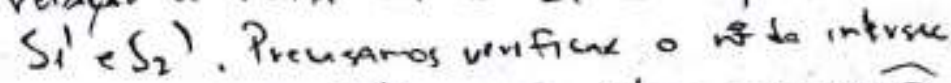
cösentre $S_{1} S_{2}^{\prime}$ ' $S_{2} S_{1}{ }^{\prime}$. Se houver intergecicas elas aparrceras vios 2 send planos 1 trafondo un segnento de reto wite elas, teren que a reto on sirámediatiz bosegnent- $\overline{A C}$ (onde $A$ e Csias.

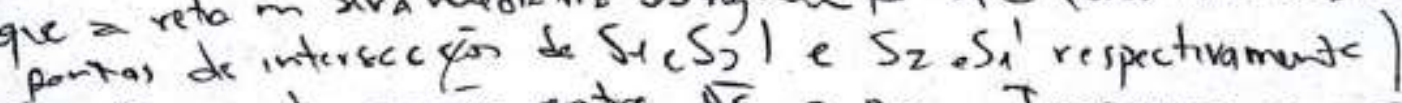

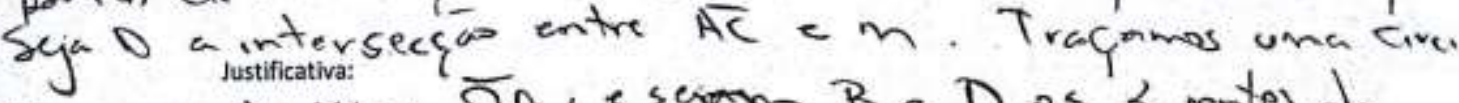
fivenar de raio $\sigma_{A}$, esegerm $B e D$ os 2 pontas de

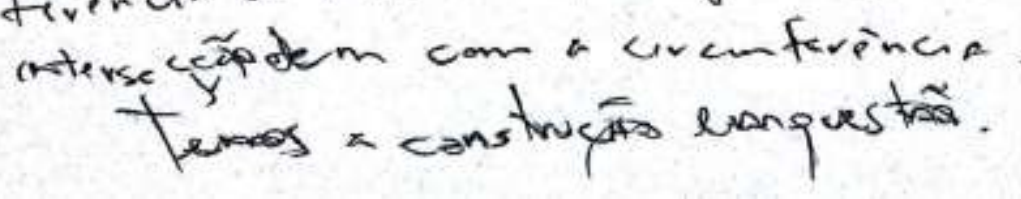

Figura 96: Resposta de 02 no item 5 b)

$$
\text { Fonte: Autor. }
$$


A construçāo é possivel devido a reflexāo dos circulos em relação a reta " $m$ i os pontos de interseçäa entre os circulos é usado para traggr uma das diagonas do quadrado o ponto médio desta diagonal cai exatamente en cima da reta "m" possibilitando assim tracar uma circunferêncra que vai ter o raia de medida iqual ao ponto médio desse dois pantos onde a reta " $m$ " sera' uma

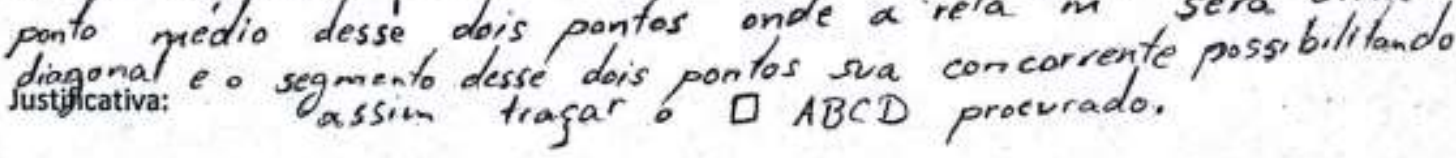

A construção de un quadrado dentro de uma circunteréncia e possivel desde que haya duas retas perpendiculares que passe pelo seu centro. Figura 97: Solução de 06 no item 5 b) Fonte: Autor.

Nenhum destes professores apresentou justificativa ou a discussão sobre o número de soluções do problema que, na verdade, vêm do item a) da atividade.

\section{Grupo II (Minicurso ENEM)}

Somente M1 e M4 responderam de maneira satisfatória o item a), apresentando todos os casos possíveis. Apenas M5 se confundiu ao interpretar o enunciado. Os professores M1, M3 e M4 fizeram suas representações em língua natural, como segue:

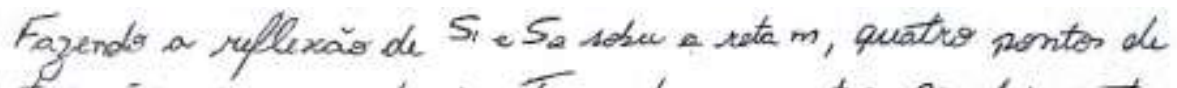

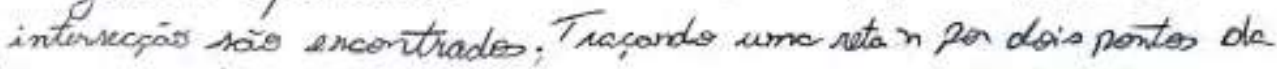
intersucspis opestor pele reta $m$, esta rete seré uma das diaganais do quadrode. A patra diagenal í reta m e o centwo do quadrado esté na interrecsás de reta $m$ com a reta $n$, com o compasso é possivel fogen uma curcu nferinoic

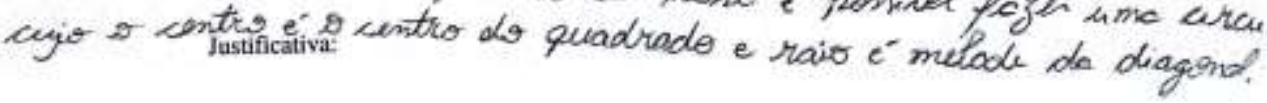

Figura 98: Resposta de M1 no item 5 b) 


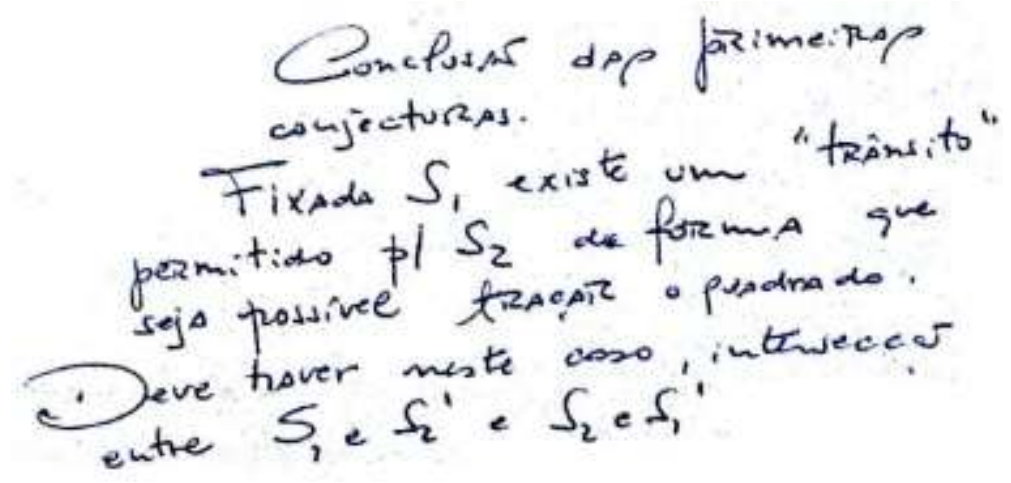

Figura 99: Resposta de M3 no item 5 b)

Fonte: Autor.

- Reflexão das duas curcunferincias.

- Sigando as duas untersecçors forma-se a diagonal, $\log o$ o ponto que toca a reta $m, e^{\prime} \theta$ centro da evicunferenac curcunserta a quadrado; - Unindo os 4 pontos formados, obtem-se a quadreado.

Figura 100: Resposta de M4 no item 5 b)

Fonte: Autor.

O professor M2 fez uma demonstração formal e no campo Discussão fez menção apenas do caso em que não há solução.

\section{Grupo III (Licenciatura em Matemática)}

Apenas L5 procurou responder usando linguagem simbólica no item a), como segue:

$$
\begin{aligned}
& \text { Vale omesmo que para } S_{A} \text { e } S_{B} \text { quisquer: }\left|S_{A} \cap S_{B}\right|=1 \text {, } \\
& \text { se forem tangantes; }\left|S_{A} \cap S_{B}\right|=2 \text {, se se intercepten e nive sade tangentes; }
\end{aligned}
$$

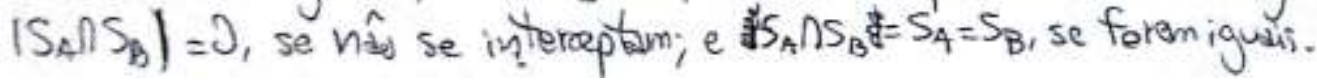

Figura 101: Resposta de L5 no item 5 a)

Fonte: Autor.

Para o primeiro item, dos alunos que responderam, nenhum recorreu à representação figural. Já no segundo item, o aluno L1 não interpretou corretamente o problema, como podemos perceber através de sua resposta a seguir: 

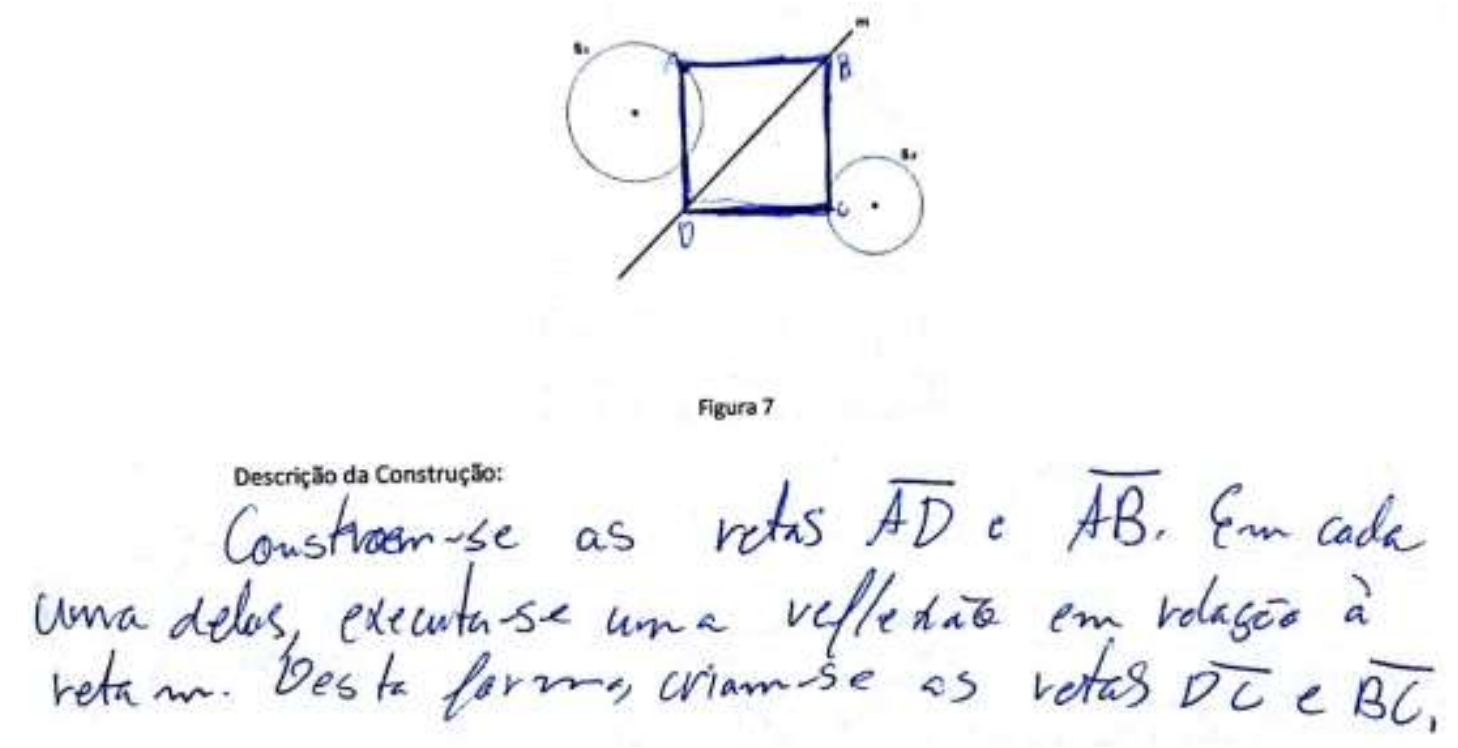

Figura 102: Solução de L1 no item 5 b)

Fonte: Autor.

A representação discursiva de L1 nos revela que o aluno considerou um caso particular associado à representação figural do caderno de respostas.

Os alunos L3, L8 e L11 foram os únicos que apresentaram de maneira completa suas respostas, com a descrição da construção, justificativa e discussão. Estes também apresentaram em linguagem natural ou simbólica suas respostas.

Já L4, L6, L7, L9, L14, L15 e L16 não apresentaram representações discursivas em seus cadernos de respostas. O aluno L12 usou apenas a língua natural na Descrição da Construção e no espaço destinado à Justificativa e Discussão não mostrou qualquer tipo de representação.

Os alunos, em sua maioria, fizeram uso da linguagem simbólica em suas representações, com exceção de L1 e L12. Destacam-se os alunos L17 e L18 que, em suas respostas, utilizaram as mesmas nomenclaturas formuladas pelo GeoGebra.

\section{Considerações}

Apesar do pouco uso da linguagem formal nos grupos I e II, houve interação entre os tratamentos figurais realizados e a representação discursiva em todos os grupos, devido ao amplo uso do software. Isso ficou mais evidente no Grupo III. Nestes casos, entendemos que houve também subordinação da apreensão perceptiva à discursiva. Para Duval, a compreensão desta teorização 
das figuras geométricas, na qual sua apreensão perceptiva deve estar subordinada a sua apreensão discursiva, constitui um dos vieses de acesso à demonstração (DUVAL, 2012a, p.133).

A maioria dos participantes interpretou corretamente o enunciado. No entanto, a ocorrência de respostas corretas ou com poucos erros foi pequena, em todos os grupos. Para Duval (2011), o controle das produções escritas parte do sujeito, sendo necessário um circuito de atividades cognitivas. Isso indica que alguns destes participantes não fez a articulação entre as apreensões. Segundo Moran (2015), os problemas de geometria exigem uma forma de raciocínio que depende, dentre outros fatores, de uma interpretação de enunciados e de figuras (MORAN, 2015, p.36). Duval (1997, apud MORETTI, 2013, p. 293) aponta ainda que a heurística e a demonstração são resultado da associação entre as apreensões operatória e discursiva.

\section{Apreensão Operatória}

\section{Grupo I (Oficina CAEM)}

Os professores 01, 02 e 06 foram os únicos que apresentaram algum tipo de tratamento figural, sendo que $\mathrm{O} 1$ realizou o tratamento figural apenas no caderno de respostas. Na Figura 90, percebemos praticamente uma apreensão sequencial, uma vez que o professor apenas construiu o quadrado na folha de respostas, o que envolve também a apreensão perceptiva.

Já $\mathrm{O} 2$ e $\mathrm{O} 6$ (veja as figuras 88 e 91 respectivamente) realizaram modificações posicionais de reflexão no GeoGebra. O professor O2 preferiu refletir as duas circunferências dadas e identificar as quatro intersecções, enquanto que $\mathrm{O} 6$ apenas refletiu $\mathrm{S}_{1}$ por $\mathrm{m}$ e evidenciou uma das intersecções.

\section{Grupo II (Minicurso ENEM)}

Os tratamentos realizados pelos participantes foram semelhantes. Os professores M1 e M4 refletiram as duas circunferências, enquanto que M2 e M6 apenas refletiram uma delas. Como exemplo, seguem as representações figurais feitos por M1 e M2: 


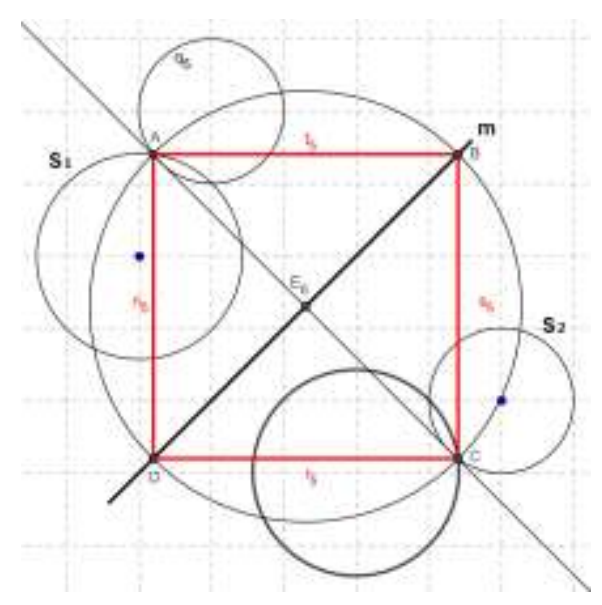

Figura 103: Representação figural de M1 no item 5 b) Fonte: Autor.

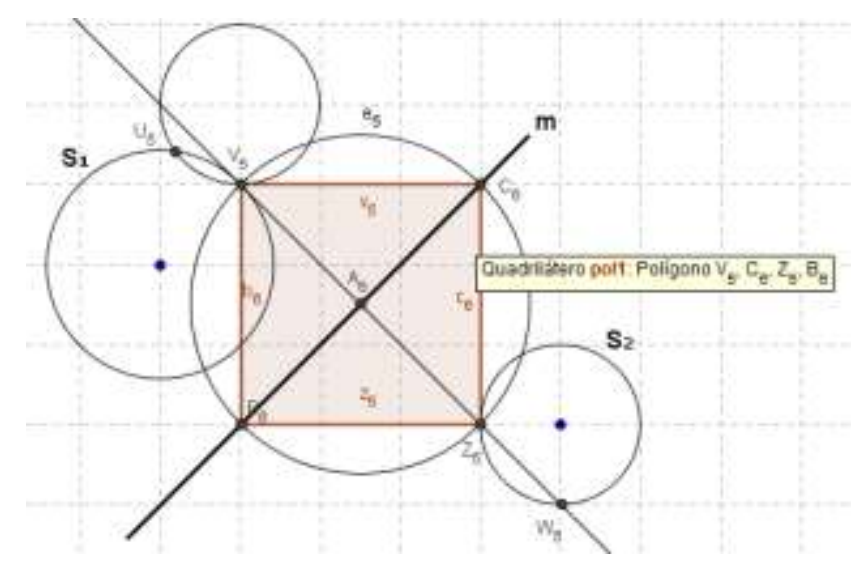

Figura 104: Representação figural de M2 no item 5 b) Fonte: Autor.

No item b), M3 e M4 fizeram representações nos cadernos de respostas, como segue:

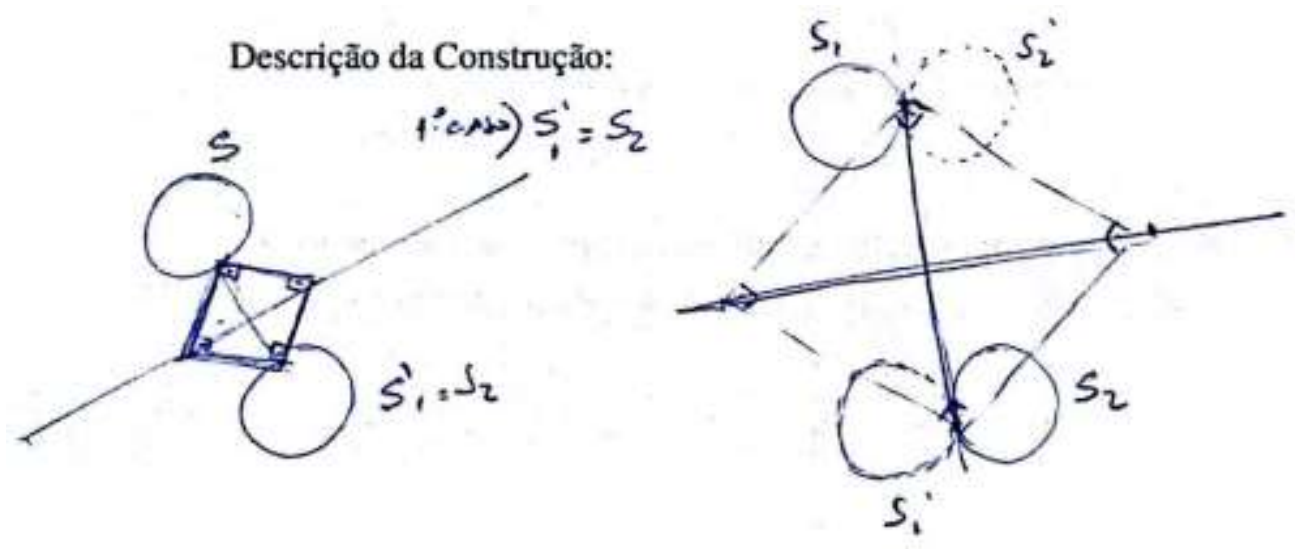

Figura 105: Representação figural de M3 no item 5 b) Fonte: Autor. 


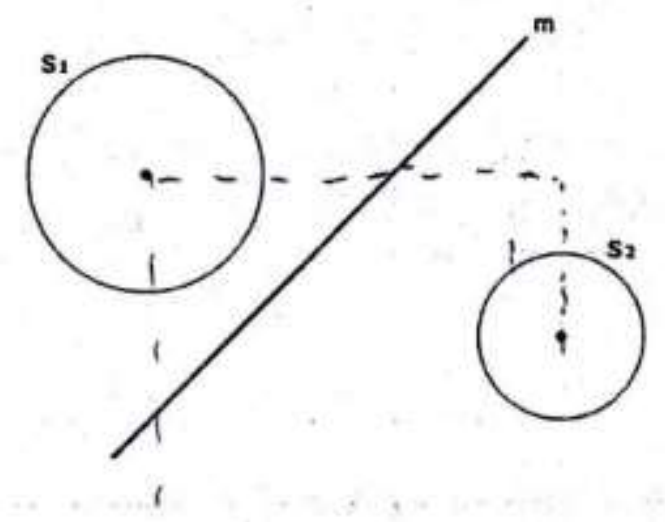

Figura 106: Representação figural de M4 no item 5 b) Fonte: Autor.

$\mathrm{Na}$ última resposta acima, vemos uma primeira tentativa do professor buscando uma relação entre os centros das circunferências dadas, indicando uma reação imediata. Logo em seguida, desistindo da ideia inicial de unir esses centros por algum segmento ou reta, começou a manipular o software na tentativa de resolver o problema.

O professor M5 começou a atividade tentando perceber alguma relação entre os centros das circunferências dadas, não obtendo sucesso:

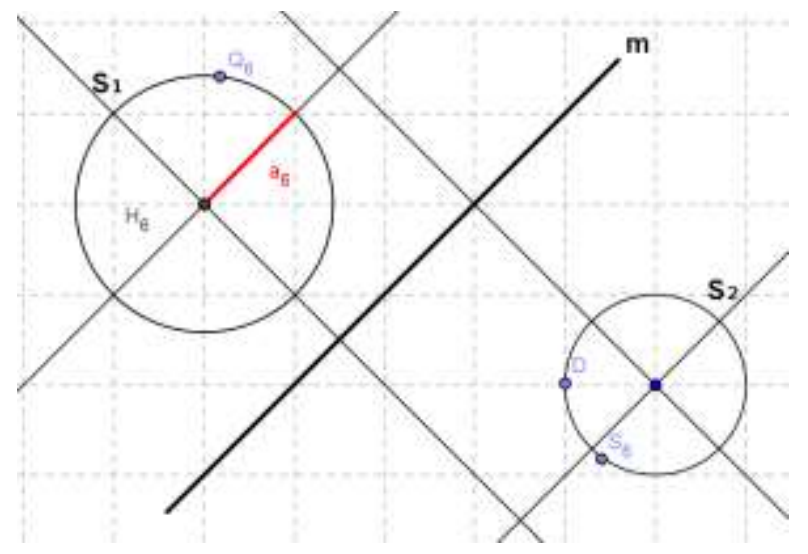

Figura 107: Representação figural de M5 no item 5 b) Fonte: Autor.

\section{Grupo III (Licenciatura em Matemática)}

O aluno L4 fez uma figura semelhante ao de M5 (Figura 107), tanto no GeoGebra como em seu caderno de respostas: 


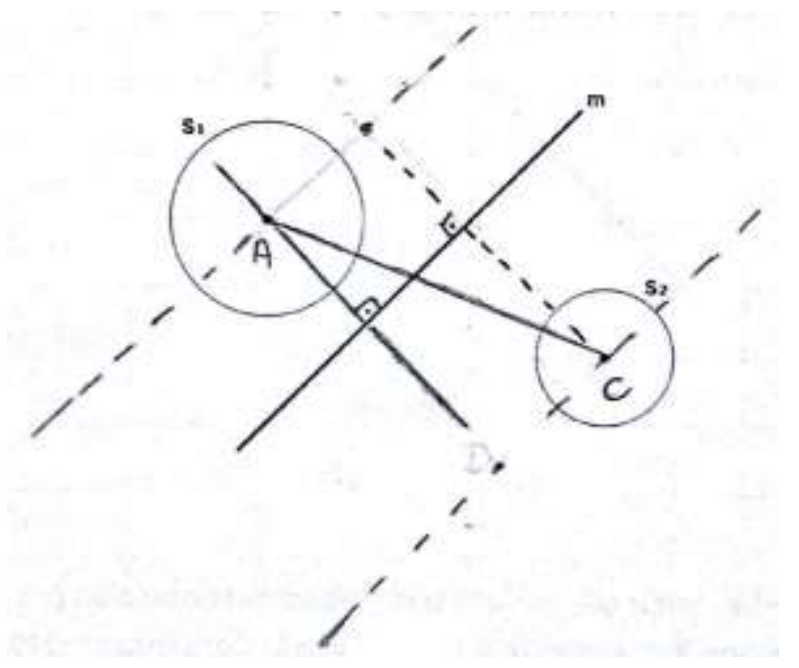

Figura 108: Solução de L4 no item 5 b) Fonte: Autor.

Os alunos L2, L8, L11, L15 e L16 refletiram apenas uma das circunferências em suas representações, mas no software apenas L2 apresentou a reflexão das duas circunferências. Já L9, L17, L18 e L19 realizaram as duas reflexões.

Vale ressaltar que L1, em seu caderno de respostas, mostrou uma modificação posicional de reflexão para os segmentos $\overline{\mathrm{AD}}$ e $\overline{\mathrm{AB}}$ (veja a Figura 102).

\section{Considerações}

Nos três grupos presenciamos a utilização primeiramente do software, com exceção de alguns participantes.

Houve interação entre modificações realizadas e o raciocínio dedutivo, sendo que as representações discursivas auxiliaram nessa percepção, por meio das unidades figurais que foram destacadas pelos participantes como pontos de intersecção entre circunferências, por exemplo.

No Grupo I, ocorreram poucas representações figurais e discursivas. Mesmo com poucas respostas produzidas, podemos perceber que os registros de representação permitem definir os fatores cognitivos que comandam a compreensão e a incompreensão na aprendizagem de matemática (DUVAL, 2011, p. 139). Nessa Atividade 5 imperaram as modificações posicionais de reflexão, o que foi permitido pela sua natureza. Modificações mereológicas homogêneas também foram evidenciadas pelos participantes, quando estes 
destacaram as duas diagonais do quadrado, o que influenciou em suas representações discursivas. Isso indica variação cognitiva, pois, segundo Moran (2015), as variações cognitivas são os tratamentos figurais que interagem com as representações discursivas.

\section{Apreensão Sequencial}

\section{Grupo I (Oficina CAEM)}

Apenas $\mathrm{O} 2$ e $\mathrm{O} 6$ procuraram descrever suas construções, no entanto, não as apresentaram de maneira correta, uma vez que suas respostas contêm imprecisões e ambiguidades nas construções dos objetos, como vimos nas figuras 96 e 97.

As construções no software, também destes dois professores, estavam corretas até onde conseguiram chegar, como mostramos nas figuras 88 e 91. Faltaram as construções de alguns objetos. Já os outros professores não descreveram suas construções e a solução de O4 (Figura 89) não é robusta, pois basta movimentarmos qualquer um dos vértices para deformarmos o quadrilátero, não mantendo mais as propriedades de um quadrado.

\section{Grupo II (Minicurso ENEM)}

Neste grupo apenas M1 e M4 fizeram alguma descrição de suas construções (veja as figuras 98 e 100), faltando descrever algumas unidades figurais como pontos, por exemplo. Neste grupo, M2 foi o único professor que descreveu passo a passo suas construções, como segue:

Deseriçào đa Construçào:

Reflita a circunf. $S_{2} \mathrm{em}$ ulacioo à veta $m$ dija $P$ uma das interseccaès das desese circunferincian $S_{1}$ e $S_{2}$ ?. Prace a perpendicular a $m$ pazando por $P$ u determine, QC (interstecdo desso perpendecular e $S_{2}$ ). deja $M$ o ponto médio de $A R$. Lrace a circunferéncia com antro em $M$ panando por $P$ dejam $A \angle B, D$ as interseccos dina

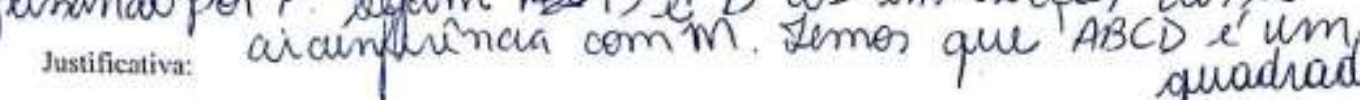

Figura 109: Descrição da construção feita por M2 na Atividade 5 b) Fonte: Autor.

Das representações feitas no GeoGebra, apenas as dos professores M1, M2 e M4 estavam corretas. A construção de M6 possui alguns pontos que foram 
criados sobre a malha quadriculada (ponto B na Figura 110a, por exemplo), quando os movimentamos, percebemos que o quadrilátero não fica com um dos vértices sobre $S_{1}$ (vértice A na Figura 110b), como segue:

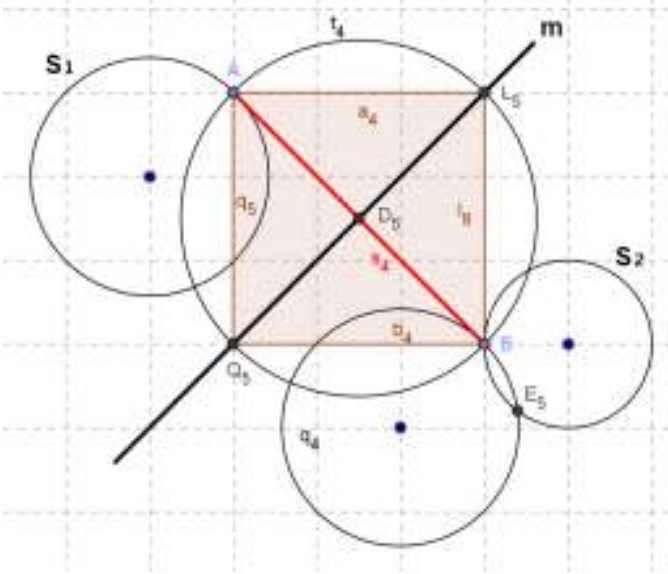

a

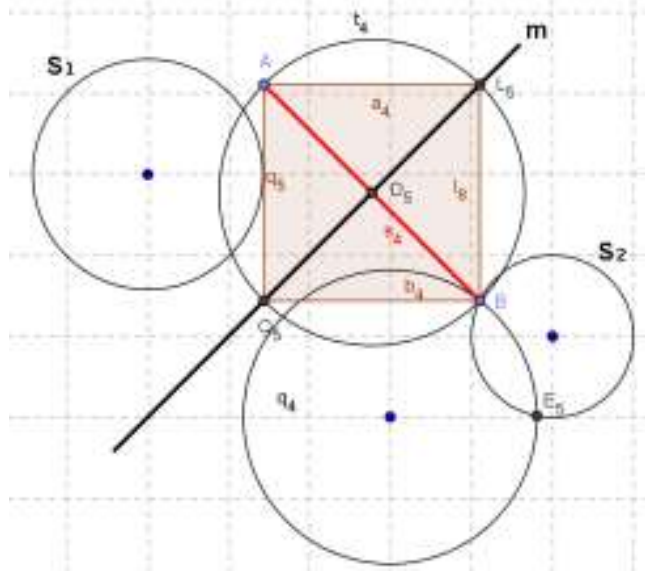

b

Figura 110: Construção de M6 na Atividade 5 b) Fonte: Autor.

\section{Grupo III (Licenciatura em Matemática)}

As descrições feitas por L3 e L8, figuras 111 e 112 respectivamente, foram as mais completas, tanto entre as respostas dos outros alunos, como em relação às dos outros participantes da pesquisa.
(A) $S_{i}=$ reflexiso de S. por $m$;
(B) $A \in S^{\prime} \cap S_{2}$, (C) $C$ reflexso de A por $n(c \in S)$;
(D) $E=\overparen{A C} \cap m$;
(E) $S_{3}=\operatorname{arconferencia}$ centro
E $C$ rio
$\overline{E A}(f)\{B, D\}=s_{3} \wedge \mathrm{m}$.

Figura 111: Descrição da construção feita por L3 Fonte: Autor.

\footnotetext{
Descriçäo da Construçẵo:

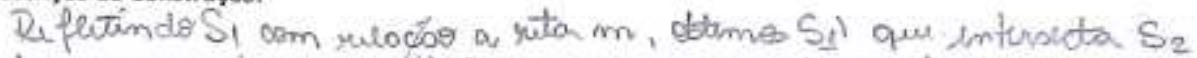
em dois pentes, que suram posibifidods pawa e ponte C. hoseg, excethender um dilis, teremes em $S_{1} 0$ pente $A$ que é a rufevar der $C$ excollids. Ansim temen $\overline{A C}$ divosenal de quidrade.

construi nds uma circumferencia $S_{3}$ com centio ra intursicōos a $\overline{A C}$ e a rata $m$ (ponte $m$ ) e raio $\overline{m C}$, encon tramos os pontos $B$ e D the intersecopo das reta m e de $S_{3}$. Absin tmos ABCD quodrado.
}

\section{Figura 112: Descrição da construção feita por L8 Fonte: Autor.}

As respostas de L2, L10, L11, L13 e L17 no caderno de respostas contêm alguns equívocos como, por exemplo, a falta da descrição de como obter a 
circunferência $S_{1}{ }^{\prime}$ que é simplesmente a reflexão de $S_{1}$ por $m$. Já os alunos $L 4$, L6, L7, L9 e L14, não descreveram suas construções nos cadernos de respostas, enquanto que os demais participantes deste grupo cometeram vários equívocos, tornando várias construções ambíguas.

Os alunos L2, L11, L17, L18 e L19 fizeram construções corretas no software. Já a representação de L15 foi semelhante à de M6 (Figura 110), enquanto que L4, L7, L13 e L14 não terminaram suas construções.

\section{Considerações}

O segundo item da Atividade 5 envolvia a descrição da construção, a sua justificativa e discussão de quantas soluções eram possíveis. As construções corretas feitas no GeoGebra apareceram em maior número nos grupos II e III.

Para Duval (2012a), formular as instruções para a construção de uma figura é diferente de demonstrar um resultado. Para ele, as instruções precisam ter três aspectos:

- Apenas uma instrução por frase, quando possível;

- Evitar ambiguidade em cada instrução;

- Definir um quadro de referência autônoma permitindo uma descrição de tudo o que é mostrado.

O terceiro aspecto mencionado por Duval, revela que as descrições devem, de certa forma, conduzir a construção e não o contrário.

Das descrições feitas pelos participantes, destacamos as apresentadas pelos alunos L3 e L8 (figuras 111 e 112 respectivamente), pois percebemos que elas estão mais próximas dos três aspectos mencionados por Duval.

\section{Atividade 6}

Alguns participantes do Grupo III conseguiram fazer parte da Atividade 6 (veja na Parte 1 do Anexo C).

Dividimos esta atividade em três itens, sendo o item c) o mesmo problema que apresentamos na introdução deste trabalho.

No item a) deve-se construir uma circunferência de centro no ponto $\mathrm{B}$ e tangente à reta $\mathrm{m}$ dada. Uma das construções possíveis, utilizando-se o GeoGebra, seria: construir uma reta $r$ perpendicular à $m$ e passando pelo ponto 
B (Figura 113a). Sendo o ponto $E$ a intersecção entre $r$ e $m$, basta construirmos uma circunferência com centro em B e raio BE (Figura 113b).

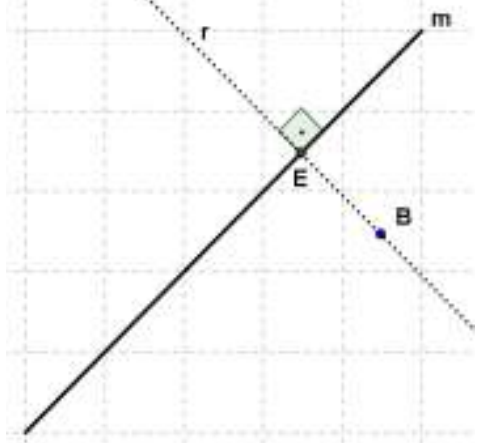

a

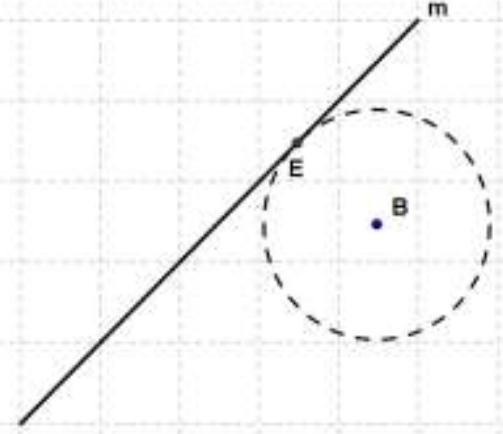

b

Figura 113: Circunferência tangente à reta $\mathrm{m}$ Fonte: Autor.

No item b) o participante deveria construir as retas tangentes a uma circunferência dada, com essas tangentes se intersectando em um ponto $A$, fora da circunferência. $O$ próprio software oferece uma ferramenta que faz essa construção. Caso o participante optasse por não utilizar essa ferramenta, ele deveria construir o ponto médio entre os pontos A e B (ponto M na Figura 114a); traçar uma circunferência com centro no ponto médio $\mathrm{M}$ e raio $\mathrm{MB}$. Os pontos $\mathrm{F}$ e H (Figura 114b), dados pelas intersecções entre as duas circunferências, são os pontos de tangência.

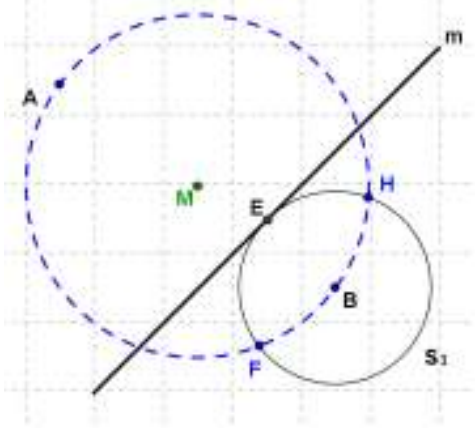

a

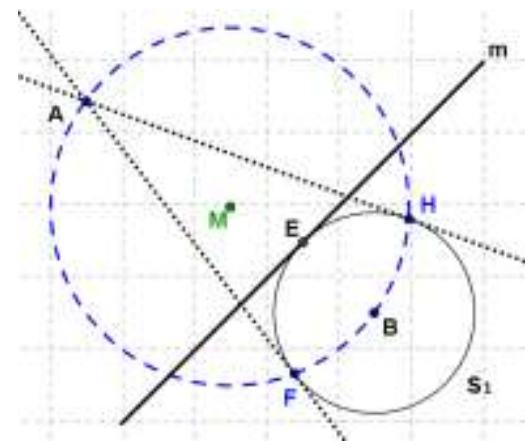

b

Figura 114: Construção de retas tangentes a uma circunferência Fonte: Autor.

O terceiro item da Atividade 6 envolvia, em sua resolução, as construções feitas nos dois itens anteriores. Sendo B' a reflexão do ponto $B$ pela reta $\overleftrightarrow{C D}$, construímos uma circunferência $S_{1}$ com centro em $B^{\prime}$ e tangente a $\overleftrightarrow{C D}$ no ponto E (Figura 115a). Sendo M o ponto médio entre os pontos A e B', construímos 
uma circunferência $S_{2}$ com centro em $M$ e raio $M B$ '. Sejam $F$ e $H$ as intersecções entre as circunferências $S_{1}$ e $S_{2}$. Sejam $X$ e $Y$ as intersecções de $\overleftrightarrow{\mathrm{CD}}$ com $\overleftrightarrow{\mathrm{AF}}$ e $\overleftrightarrow{\mathrm{AH}}$ (Figura 115b), respectivamente, tais que $C-X-Y-D$. O ponto $X$ é a solução do problema.

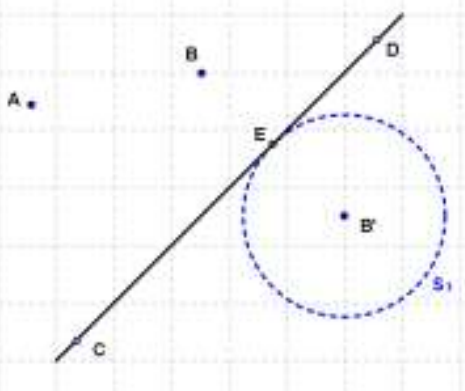

a

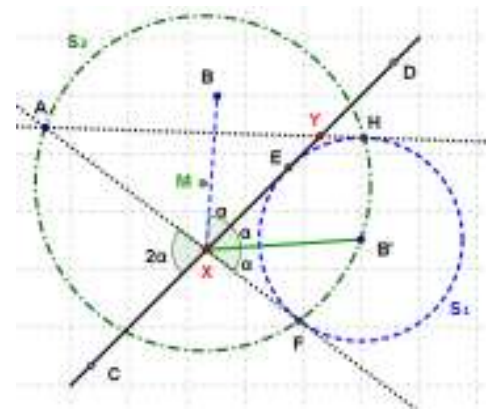

b

Figura 115: Resolução da Atividade 6 c) Fonte: Autor.

Note que, sendo $m(B \widehat{X} E)=\alpha$ e construindo os segmentos $\overline{\mathrm{BX}}$ e $\overline{\mathrm{B}^{\prime} \mathrm{X}}$, fica mais fácil de perceber que o ponto $X$ é a solução do problema. Por B' ser reflexão do ponto $B$, temos que $m(B \widehat{X} E)=m\left(B^{\prime} \widehat{X} E\right)=\alpha$. De $X$ ser ponto comum às retas $\overleftrightarrow{\mathrm{AF}}$ e $\overleftrightarrow{\mathrm{CD}}$ e de $\mathrm{F}$ e $E$ serem pontos de tangência entre e as retas $\overleftrightarrow{\mathrm{AF}}$ e $\overleftrightarrow{\mathrm{CD}}$ e $S_{1}$ respectivamente, temos $m(B \widehat{X} E)=m\left(B^{\widehat{X}} \widehat{X}\right)=m\left(B^{\prime} \widehat{X} F\right)=\alpha$. Fica fácil então concluir que $m(A \widehat{X} C)=2 \alpha$.

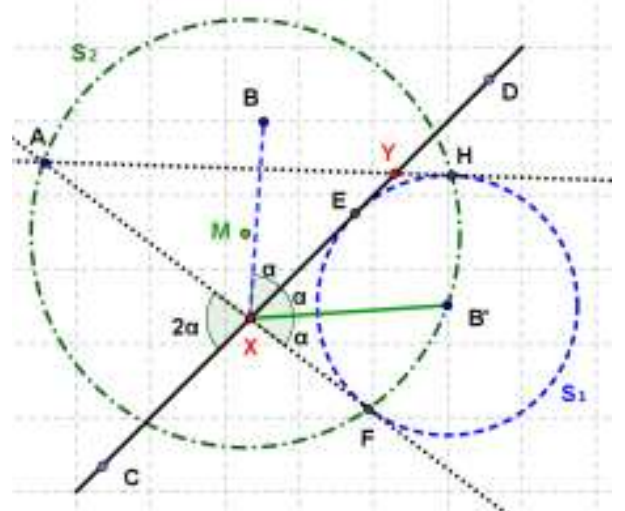

Figura 116: Resolução completa da Atividade 6 c) Fonte: Autor.

Perceber todas as unidades figurais envolvidas nesta atividade requer atenção e reconhecimento de algumas das propriedades das retas tangentes. As apreensões perceptiva e operatória, devem ser mobilizadas pelos participantes, direcionando-os para a identificação dessas unidades figurais. 
Esperamos que os dois primeiros itens da Atividade 6 auxiliem nessa identificação. Além disso, acreditamos que a ferramenta de reflexão por reta do software seja utilizada pelos participantes somente no terceiro item.

Esta atividade, assim como a Atividade 5, contempla todos os momentos que atividades ligadas à Investigação Matemática devem ter. Em um problema como este é importante fazer tentativas e conjecturar. Porém, se olharmos cada item separadamente, somente o último continua contemplando todos os momentos da Investigação Matemática.

A seguir, apresentamos as respostas feitas por alguns alunos do Grupo III, referentes à Atividade 6 .

\section{Apreensão Perceptiva}

\section{Grupo III (Licenciatura em Matemática)}

Reações imediatas foram observadas nas respostas de alguns alunos, principalmente nos cadernos de respostas. No primeiro item da atividade, L16 e L18 apenas esboçaram uma reta perpendicular à reta $m$ e uma circunferência de centro em B, sem se preocuparem com a precisão em suas representações.

As representações de L2, L8, L11, L13 e L15 apresentaram unidades figurais destacadas, como o ponto de tangência entre a circunferência e a reta. A nomenclatura usual foi utilizada por eles.

Já no item b), apenas L1 fez uma representação figural baseada em sua visualização, como podemos perceber em sua resposta abaixo:

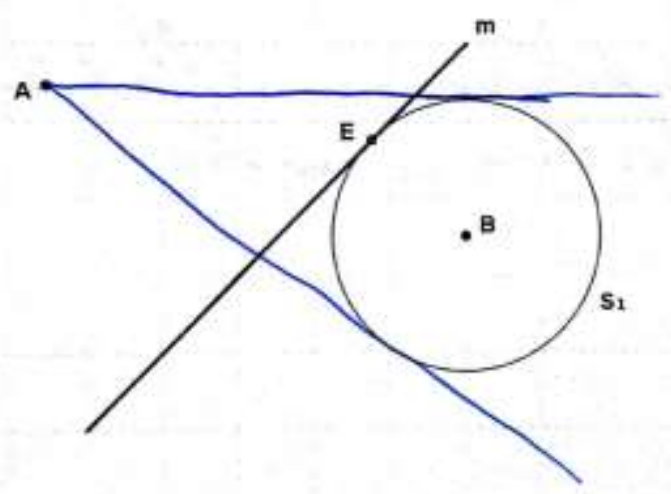

Figura 117: Representação figural de L1 no item 6 b) Fonte: Autor. 
Note que não há qualquer referência aos pontos de tangência ou às construções auxiliares para a obtenção das retas tangentes à $S_{1}$.

Dos demais alunos, apenas L11 respondeu no caderno de respostas destacando as unidades figurais e também no GeoGebra. O pesquisador, então, apresentou duas maneiras de construção nesse item: utilizando a ferramenta que o software disponibiliza e também a construção mostrada da Figura 114.

Apesar do item c) estar relacionado aos dois itens anteriores, a maioria dos alunos (L1, L11, L12, L13, L15 e L18), que fez alguma representação no caderno de respostas, apenas evidenciou os ângulos pedidos no enunciado, como na resposta de $L 15$, a seguir:

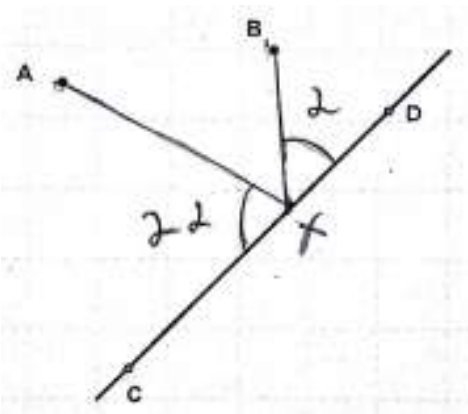

Figura 118: Representação figural de $L 15$ no item 6 c) Fonte: Autor.

O aluno L11 indicou as medidas dos ângulos o que, aparentemente, fez por meio da visualização com o auxílio da malha quadriculada, como segue:

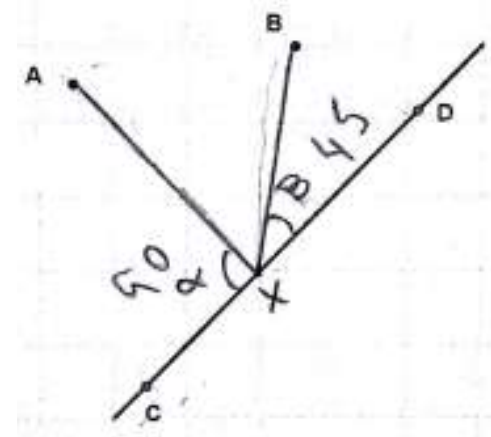

Figura 119: Representação figural de L11 no item 6 c) Fonte: Autor.

\section{Apreensão Discursiva}

Apenas um dos alunos procurou descrever suas construções nos dois primeiros itens, revelando, claramente a interação entre a representação figural e a representação discursiva, como vemos a seguir: 


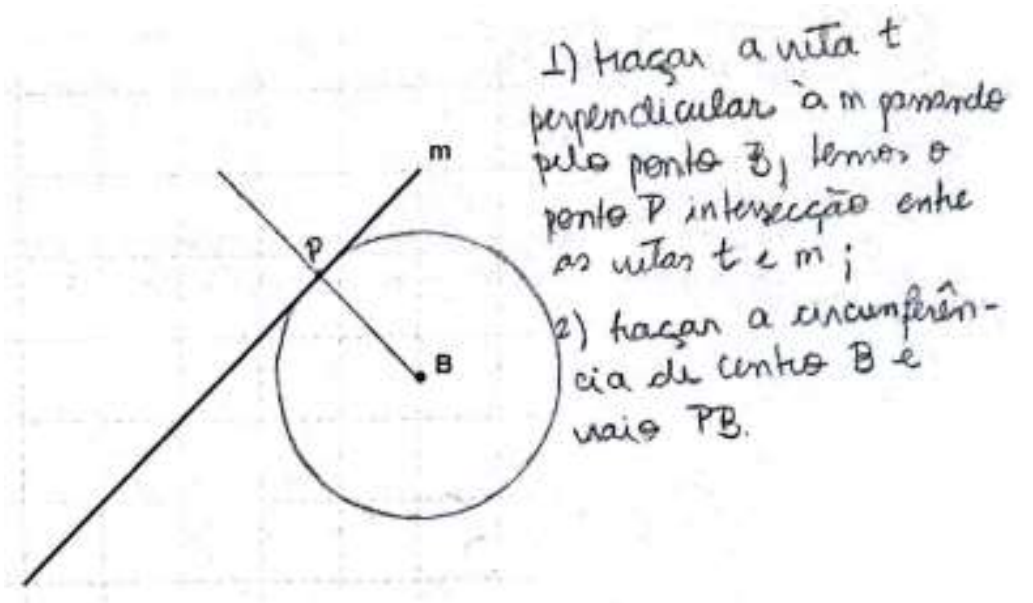

Figura 120: Resposta de L11 no item 6 a)

Fonte: Autor

No segundo item, este aluno também utilizou o caderno de respostas para fazer suas representações figurais. A figura a seguir nos revela, mais uma vez, a interação entre representação figural e discursiva, na resposta deste participante:

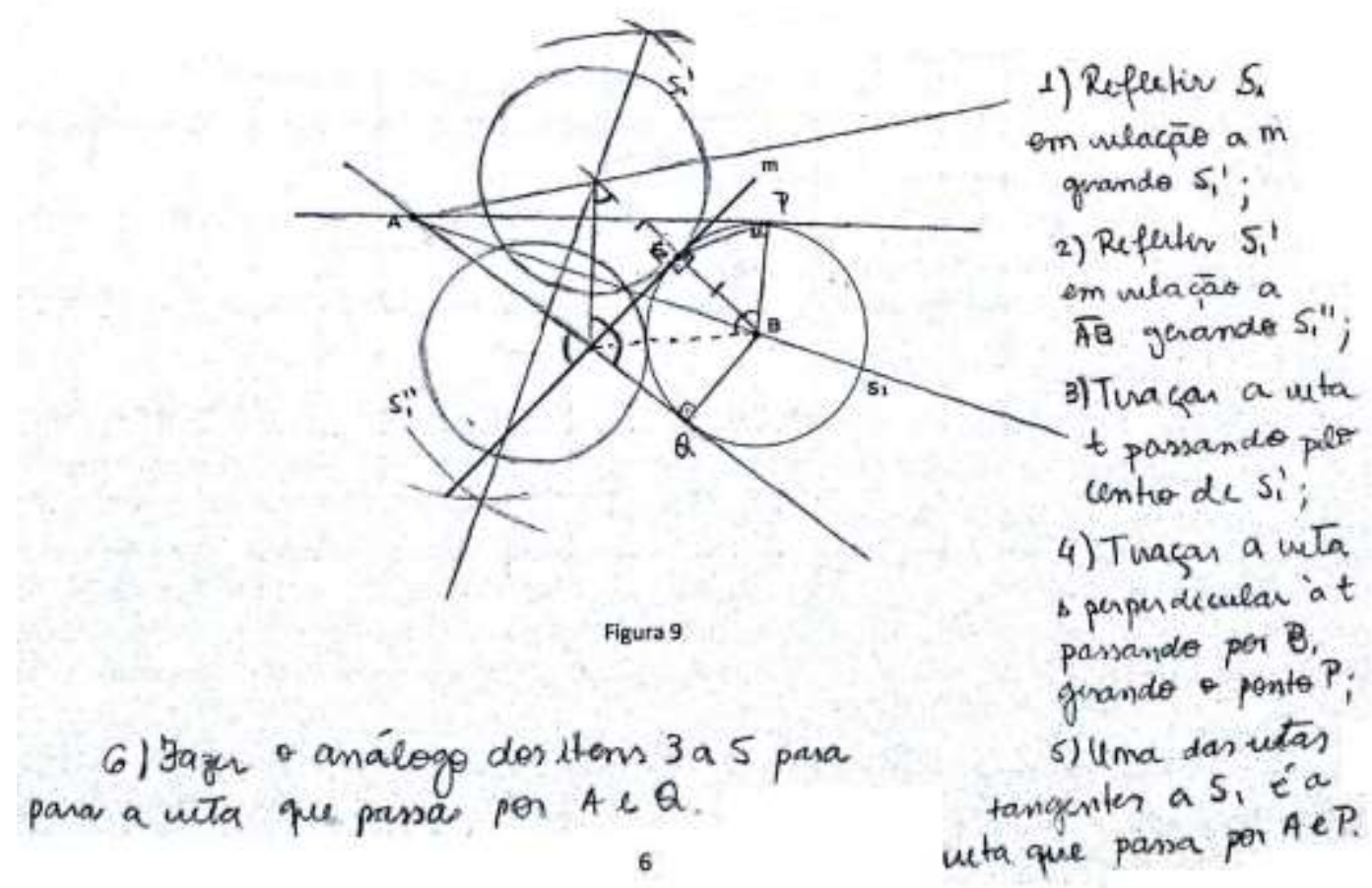

Figura 121: Resposta de L11 no item 6 b)

Fonte: Autor.

Percebe-se o uso da nomenclatura usual para pontos e retas e também a interpretação correta do enunciado. Apesar de seu rigor na construção de cada objeto matemático, percebemos que a apreensão discursiva ficou subordinada 
à perceptiva, uma vez que L11 construiu segmentos perpendiculares passando pelo ponto $\mathrm{B}$, mesmo sem a descrição correta de como encontrá-los.

\section{Apreensão Operatória}

No primeiro item, os alunos procuraram repetir as mesmas representações, feitas no software, em seus cadernos respostas. Os alunos L8, L11, L16 e L18 construíram retas perpendiculares em suas soluções, sendo que L8 e L16 o fizeram somente no caderno de respostas, enquanto que L11 e L18 usaram o GeoGebra. Já os alunos L2, L13, L15 e L19 refletiram o ponto B pela reta $\mathrm{m}$, utilizando efetivamente a reflexão por uma reta, como podemos observar na solução de $L 13$ a seguir:

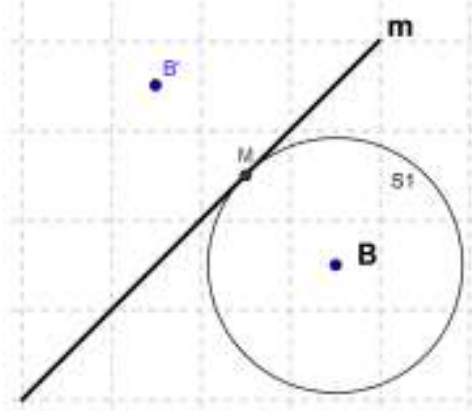

Figura 122: Representação figural de L13 no item 6 a) Fonte: Autor.

Note que uma das propriedades das reflexões por retas foi utilizada por estes quatro alunos na construção da circunferência tangente à reta $\mathrm{m}$. $\mathrm{Na}$ resposta de L13 acima, foi utilizado a ferramenta que cria o ponto médio entre dois pontos dados, no caso, B e B'. Os outros alunos criaram o segmento unindo o ponto $B$ e sua reflexão, tomando, por fim, a intersecção entre este segmento e a reta $\mathrm{m}$, como segue:

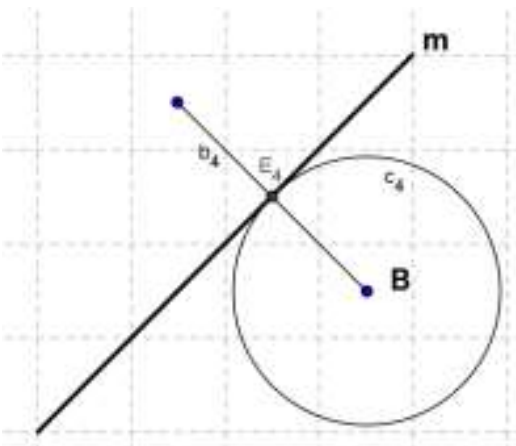

Figura 123: Representação figural de L2 no item 6 a) Fonte: Autor. 
Já no segundo item, somente L11 fez representações figurais. A realizada no software (Figura 124), é ligeiramente diferente do tratamento feito no seu caderno de respostas (Figura 121).

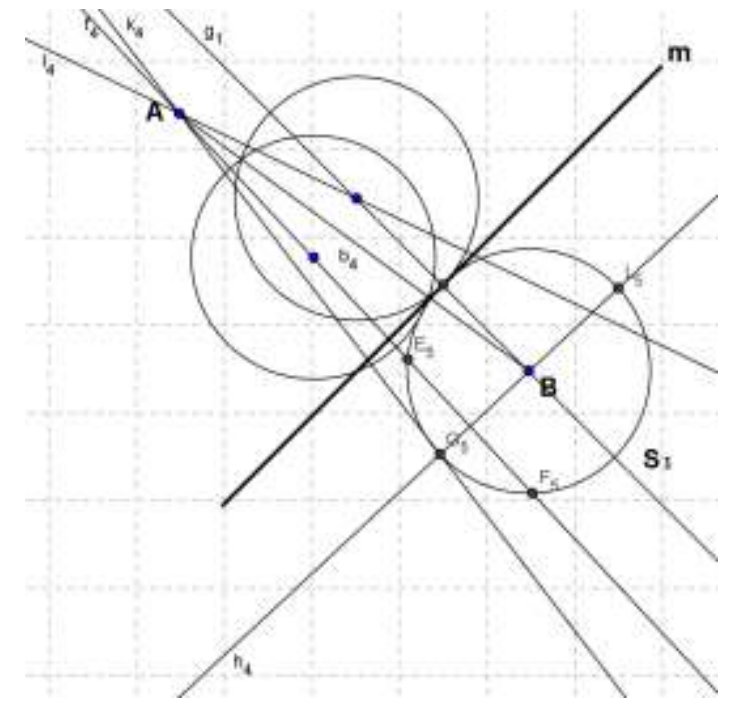

Figura 124: Representação figural de L11 no item 6 b) Fonte: Autor.

O aluno L11, por algum motivo, ocultou as retas $\mathrm{f}_{4}, \mathrm{~g}_{1}, \mathrm{~h}_{4}, \mathrm{I}_{4}$ e $\mathrm{k}_{4}$, o que ressalta o caráter investigativo que o software proporciona.

No último item desta atividade, L11, L15 e L18 apresentaram respostas somente no software. $\mathrm{O}$ tratamento feito por $\mathrm{L} 11$, revela que este aluno calculou alguns ângulos, chegando a uma boa aproximação através de suas construções, como vemos em sua solução:

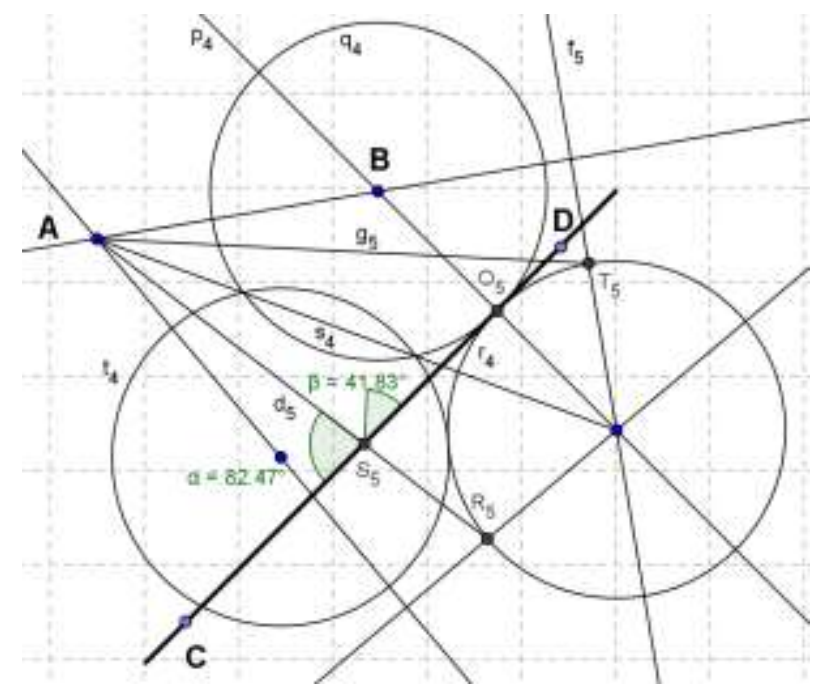

Figura 125: Representação figural de L11 no item 6 c) Fonte: Autor. 
Vale ressaltar que, por meio das marcações que o software produz para cada representação feito pelo usuário, é possível refazer a construção feita, o que auxilia na compreensão da solução realizada.

A representação figural apresentada por L15 mostra que este reproduziu construções semelhantes às feitas nos itens anteriores, utilizando as ferramentas que o software disponibiliza. Porém, não fez avanços na resolução, como podemos perceber na sua resposta a seguir:

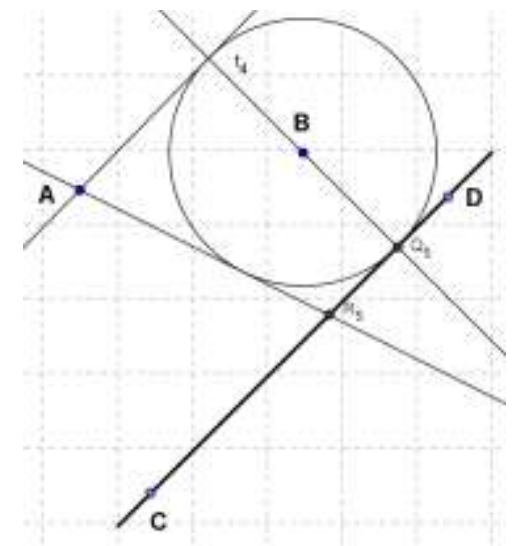

Figura 126: Resposta de L15 no GeoGebra no item 6 c) Fonte: Autor.

O aluno L18 apenas construiu algumas retas perpendiculares, porém, ocultou-as, não apresentando mais elementos em sua representação figural.

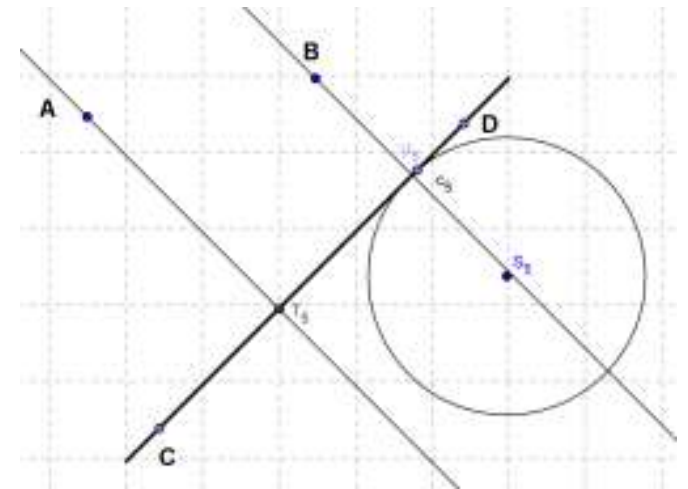

Figura 127: Resposta de L18 no GeoGebra no item 6 c) Fonte: Autor.

\section{Apreensão Sequencial}

Como mencionado anteriormente, somente L11 descreveu suas construções, nos dois primeiros itens desta atividade. No segundo item, veja a Figura 121, percebemos que na terceira etapa de sua construção, a reta não está bem descrita, pois só está mencionado um dos pontos pertencentes a ela. 
No primeiro item, das construções feitas no GeoGebra, somente a resposta de L19 estava incorreta. Quanto ao segundo item, feito somente por L11, é fácil perceber que suas construções também não estavam corretas (veja a Figura 124). Dentre as respostas apresentadas no último item, feitas por L11, L15 e L18, apenas a mostrada na Figura 125 está próxima da solução do problema. Nela é possível perceber que um dos erros na construção, por exemplo, foi L11 acreditar que os segmentos $g_{5}$ e $d_{5}$ eram tangentes a uma das circunferências nos pontos $T_{5}$ e $R_{5}$, respectivamente.

\section{Considerações}

Alguns alunos precisaram se ausentar, por esse motivo não apresentaram qualquer tipo de representação. Percebemos, dentre os alunos que realizaram a atividade, que houve pouco destaque para as unidades figurais através da nomenclatura usual de retas, segmentos e pontos.

Nota-se, principalmente no primeiro item, que algumas das propriedades das reflexões por retas foram bem utilizadas pelos participantes. Vimos também que, em algum momento, houve recorrência à medida de ângulos para, talvez, confirmar se estavam corretas as conjecturas.

Apenas na representação de um aluno houve interação entre a representação figural e a discursiva. Em nenhuma das respostas, itens a) e b), os alunos apresentaram demonstrações, pois o enunciado não as solicitava e, em muitas respostas, havia apenas representações figurais. Obviamente, estas representações não devem ser reconhecidas como demonstrações. Neste sentido, Duval (2012a, p. 135) nos diz que demonstrações não envolvem somente figuras, mas uma rede semântica de propriedades e objetos.

Já as modificações feitas através do software realçam a possibilidade de exploração que ele proporciona ao usuário, como vimos através das últimas três representações.

Para Duval (2012a), por meio formulação das instruções, o reconhecimento perceptivo indica se a construção está certa ou errada. Algumas representações dos alunos não foram baseadas nas descrições, mas sim em suas percepções. Por esse motivo, talvez, algumas construções estavam equivocadas. Além disso, o pouco tempo que os alunos tiveram para realizar a atividade influenciou, eventualmente, suas respostas. 


\section{Considerações Finais}

A sequência de atividades que tínhamos como proposta continha mais que seis problemas. As que apresentamos na seção anterior envolvem apenas a reflexão por uma única reta.

A sequência completa de atividades procurava trabalhar também com a composta de duas e três reflexões por retas, garantindo assim, a articulação entre essa e as demais isometrias do plano. Também há um pequeno exemplo de como pode ser introduzido o tema reflexões por retas no Ensino Fundamental e Médio, por meio de gráficos e as gravuras de M. C Escher (veja a Parte 2 do Anexo C).

Devido à natureza das atividades que procuramos utilizar em nossa pesquisa, não conseguimos aplicar a sequência completa em nenhum dos grupos que participaram da pesquisa. Verificamos, na prática, que o tempo para a realização das atividades se tornou o maior dos obstáculos para a implementação desta metodologia. Ponte, Brocardo e Oliveira (2003) comentam sobre as dificuldades envolvendo o tempo das tarefas, que outros professores sentiram ao trabalhar com Investigação Matemática, em sala de aula. Esses autores apontam o quanto é importante também o professor avaliar bem o tempo que é requisitado em atividades de investigação.

Procuramos, em cada atividade, contemplar alguns dos quatro momentos da Investigação Matemática. No entanto reconhecemos que nem todas as atividades eram abertas, como a metodologia sugere. Citamos a Atividade 4 como exemplo de atividade aberta, pois ela estimulou mais a investigação e a autonomia dos participantes.

Por conta dessa experiência que tivemos junto aos professores e alunos, acreditamos que a aplicação de atividades ligadas à Investigação Matemática deve estar mais presente em todos os níveis de ensino, em especial, nos cursos de formação de professores de Matemática.

Os comentários de alguns dos participantes desta pesquisa nos mostraram o quanto eles estavam entusiasmados com a proposta. No final do Minicurso no ENEM, os professores comentaram o desejo de que houvesse mais tempo para o minicurso. Isto revela 0 interesse e a receptividade que esses professores tiveram, diante das atividades propostas. 
Outra expectativa que tínhamos era que esta sequência de atividades incentivasse os professores e futuros professores a aplicar atividades investigativas em sala de aula. O professor $\mathrm{O} 2$ do Grupo I manifestou esse interesse ao fazer o seguinte comentário sobre a Atividade 5:

O2: Boa atividade para trabalhar na escola.

Com relação ao software notamos que, de fato, ele auxiliou os participantes da pesquisa. Dois comentários são pertinentes:

O3: É melhor fazer as atividades primeiro no GeoGebra para depois no papel.

L18: Vendo no GeoGebra os problemas ficam concretos.

Esses relatos nos mostram como é importante o uso do software na sala de aula, em particular, nas aulas de Geometria. Também revelam que, em parte, o uso do software foi satisfatório na resolução das atividades.

A utilização do GeoGebra, como mencionado anteriormente, auxilia na resolução dos problemas devido ao maior número de tratamentos figurais que ele proporciona realizar. Além disso, concordamos com Viana e Boiago, ao dizerem que o uso da malha quadriculada permite os tratamentos dos registros de representação semiótica e revelam processos cognitivos (VIANA; BOIAGO, 2015, p.164), pois auxiliou nas modificações figurais e, consequentemente, nas representações discursivas.

O GeoGebra se mostrou de grande importância nessa pesquisa também por conta das representações e recursos que ele oferece. Isso ajuda tanto os professores quanto os pesquisadores a perceberem qual percurso o aluno fez na resolução do problema. Neste sentido, a Teoria das Representações Semióticas, associada ao uso desse software, é de grande importância, pois até mesmo as representações que os alunos eventualmente deixaram ocultas, ajudam a entender o processo de resolução seguida por eles.

A teoria de Duval nos ajuda a entender que as apreensões perceptiva, discursiva, operatória e sequencial estão associadas e que, a todo momento, as mobilizamos quando estamos diante de problemas de Geometria, o que dificulta 
a distinção entre elas (DUVAL, 2012a), o autor ainda salienta que a distinção principalmente entre as três apreensões é fundamental para analisar a atividade geométrica e as dificuldades dos alunos (DUVAL, 2012a, p. 118). No caso das resoluções em nossa pesquisa, constatamos a influência, em algumas ocasiões, da apreensão perceptiva nas outras duas apreensões. Em certos problemas, a não identificação de unidades figurais, como segmentos e pontos de intersecção, prejudicou a resolução dos mesmos, como visto nas atividades 3,5 e 6 .

Duval (2011) salienta que para utilizarmos figuras na resolução de problemas, é necessário sabermos "vê-las" matematicamente, ou seja, observarmos as propriedades que elas contêm. Considerando os objetivos iniciais desta pesquisa, acreditamos que a sequência de atividades auxiliou na maneira de "ver" as figuras, pois contribuiu para a observação de desconstruções dimensionais e para a identificação de unidades figurais, ajudando na compreensão dos problemas 5 e 6.

Assim, acreditamos que nossa pesquisa respondeu positivamente aos nossos objetivos. No entanto, claramente, poderia ser mais aprofundado 0 estudo sobre o quanto as Representações Semióticas, associadas a atividades investigativas e ao GeoGebra, influenciam no ensino-aprendizagem. Por exemplo, poderia ser aplicada esta mesma sequência de atividades em outros grupos. Concluímos, dessa forma, que a Investigação Matemática deve estar mais presente nos cursos de formação docente, assim como o uso de softwares, não somente para o ensino das reflexões por retas, mas também para a melhor formação do professor e, consequentemente, a de seus futuros alunos. 


\section{Referências}

ALMOULOUD, S. A. Registros de representações semióticas e compreensão de conceitos geométricos. In: MACHADO, S. D. A. (Org.). Aprendizagem em Matemática: registros de representação semiótica. Campinas: Papirus, 2013.

ALVES, S.; GALVÃO, M. E. E. L. Um estudo geométrico das transformações elementares. São Paulo: IME-USP, 1996.

AMANCIO, R. A. 0 desenvolvimento do pensamento geométrico: trabalhando polígonos, especialmente quadriláteros. $2013.178 \mathrm{f}$. Dissertação (Mestrado Profissional em ensino de Ciências e Matemática) Ensino de Ciências e Matemática, Pontifícia Universidade Católica de Minas Gerais, Belo Horizonte, 2013.

ARAÚJO, P. V. Curso de Geometria. Lisboa: Gradiva, 1999.

BARROSO, M. M.; FRANCO, V. S. As diversas possibilidades de representações matemáticas: considerações sobre o seu uso no ensino e na aprendizagem. 2012. Disponível em:

<http://matematica.ulbra.br/ocs/index.php/ebrapem2012/xviebrapem/paper/view File/207/333>. Acesso em 08 Set. de 2015.

BOGDAN, R.C.; BIKLEN, S. K. Investigação qualitativa em educação. Porto: Porto Editora, 1994.

BORBA, M. C.; PENTEADO, M. G. Informática e Educação Matemática. São Paulo: Autêntica, 2007.

BRASIL. Ministério da Educação e do Desporto, Secretaria de Educação Fundamental. Parâmetros Curriculares Nacionais: Matemática $-3^{\circ}$ e $4^{\circ}$ ciclos. Brasília: MEC/SEF, 1998.

- Ministério da Educação e do Desporto. Parâmetros Curriculares Nacionais: Ensino Médio. Brasília: SEF, 2000.

. Ministério da Educação. Secretaria de Educação Básica. Orientações Curriculares para o Ensino Médio. Ciências da Natureza, Matemática e suas Tecnologias, v. 2. Brasília: MEC/SEB, 2006. 
. MEC. Guia de Livros Didáticos - PNLD 2008 - Matemática. Secretaria de Educação Básica, Brasília: Ministério da Educação, 2007.

. MEC. Catálogo do Programa Nacional do Livro para o Ensino Médio PNLEM 2009 - Matemática. Secretaria de Educação Básica, Fundo Nacional de Desenvolvimento da Educação. - Brasília: Ministério da Educação, 2008.

. MEC. Guia de Livros Didáticos - PNLD 2011 - Matemática. Secretaria de Educação Básica, Brasília: Ministério da Educação, 2010.

. MEC. Guia de livros didáticos - PNLD 2012 - Matemática: ensino médio. Secretaria de Educação Básica, Ministério da Educação Brasília, 2011.

. MEC. Guia de Livros Didáticos - PNLD 2014 - Matemática. Secretaria de Educação Básica, Brasília: Ministério da Educação, 2013.

. MEC. Guia de livros Didáticos - PNLD 2015 - Matemática: ensino médio - Ministério da Educação, Secretaria de Educação Básica, Brasília, 2014.

BURATTO, I. C. F. Representação semiótica no ensino da Geometria: uma alternativa metodológica na formação de professores. 2006. $143 \mathrm{f}$. Dissertação (Mestrado em Educação Científica e Tecnológica) - Centro de Educação Científica e Tecnológica, Universidade Federal de Santa Catarina, Florianópolis, 2006.

CARVALHO, A. M. P.; GIL-PEREZ, D. Formação de professores de ciências: tendências e inovações. São Paulo: Cortez, 2000.

CAVALCANTI, C. Diferentes formas de resolver problemas. In: SMOLE, Kátia Stocco; DINIZ, M. I. (Orgs.). Ler, escrever e resolver problemas: Habilidades básicas para aprender matemática. Porto Alegre: Artmed, 2001.

COUTINHO, C. Q. S; ALMOULOUD, S. A; SILVA, M. J. F da, O desenvolvimento do pensamento estatístico a partir do uso do geogebra: um estudo com professores de matemática. Revista Eletrônica de Educação Matemática, Florianópolis, v. 7, n. 2, p. 246-265, Dez. 2012. ISSN 1981-1322. Disponível em: $<$ https://periodicos.ufsc.br/index.php/revemat/article/view/19811322.2012v7n2p246>. Acesso em: 19 Mai. 2016. 
CURY, H. N. Concepções e crenças dos professores de matemática: pesquisas realizadas e significado dos termos utilizados. Bolema, Rio Claro, v. 12, n. 13, p. $29-43,1999$.

CYRINO, M. C. C. T.; BALDINI, L. A. F. O software geogebra na formação de professores de matemática, uma visão a partir de dissertações e tese. Revista Paranaense de Educação Matemática, Campo Mourão, PR, v. 1, n. 1, juldez. 2012. Disponível em:

<http://www.fecilcam.br/revista/index.php/rpem/article/viewFile/870/pdf_76>. Acesso em: 19 Mai. de 2016.

D'AMBROSIO, B. S. Como ensinar matemática hoje? Temas e Debates. SBEM, Brasília, Ano II, n. 2, p. 15-19, 1989. Disponível em: <http://www.academia.edu/1082177/Como_ensinar_matem\%C3\%A1tica_hoje> . Acesso em: 08 Set. 2015.

DAMM, R. F. Registros de representação. In: MACHADO, S. D. A. Educação Matemática: uma (nova) introdução, 3 ed. São Paulo: Educ, 2012.

DANTE, L. R. Didática da resolução de problemas de matemática: $1^{\text {a }}$ a $5^{\text {a }}$ series. 12. ed. São Paulo: Ática, 2000.

DUARTE, L. R. A utilização do software geogebra no ensino da distribuição normal de probabilidade: uma aproximação entre a geometria dinâmica e a educação estatística. 2010. 130 f. Dissertação (Mestrado em Ensino de Ciências e Matemática) - Pontifícia Universidade Católica, Belo Horizonte, 2010.

DUVAL, R. Les conditions cognitives de l'apprentissage de la géométrie: développement de la visualisation, différenciation des raisonnements et coordination de leurs fonctionnements. Annales de Didactique et Sciences Cognitives, v. 10, p. 5 - 53, IREM, Strasbourg, 2005.

DUVAL, R. Semiósis e pensamento humano: registro semióticos e aprendizagens intelectuais. Tradução de Lênio Fernandes Levy e Marisa Rosâni Abreu da Silveira. São Paulo: Editora Livraria da Física, 2009.

. Ver e ensinar matemática de outra forma: entrar no modo matemático de pensar: os registros de representações semióticas. Tânia M. M. Campos (Org.). v. 1. São Paulo: Proem: 2011. 
Abordagem cognitiva de problemas de geometria em termos de congruência. Approche cognitive des problèmes de geométrie en termes de congruence. Revista Eletrônica de Educação Matemática, Florianópolis, v. 7, n. 1, p. 118-138, 2012a. ISSN 1981-1322. Disponível em: $<$ https://periodicos.ufsc.br/index.php/revemat/article/view/19811322.2012v7n1p118>. Acesso em: 29 Set. 2016. Tradução Méricles Thadeu Moretti.

- Registros de representação semiótica e funcionamento cognitivo do pensamento. Registres de représentation sémiotique et fonctionnement cognitif de la pensée. Revista Eletrônica de Educação Matemática, Florianópolis, v. 7 , n. 2, p. 266-297, Dez. 2012b. ISSN 1981-1322. Disponível em: $<$ https://periodicos.ufsc.br/index.php/revemat/article/view/19811322.2012v7n2p266>. Acesso em: 08 Set. 2015. Tradução Méricles Thadeu Moretti.

. Registros de representações semióticas e funcionamento cognitivo da compreensão em Matemática. In: MACHADO, S. D. A. (Org.). Aprendizagem em Matemática: registros de representação semiótica. Campinas: Papirus, 2013.

EVANGELISTA, M. C. S. As transformações isométricas no GeoGebra com a motivação etnomatemática. In: 1 Conferência Latino Americana de GeoGebra. São Paulo, 2012. p. 125-149. Disponível em:

$<$ revistas.pucsp.br/index.php/lGISP/article/download/8876/6605>. Acesso em 29 Set de 2016.

FRANCO, M. C. L. G. Simetria. 2015. 147 f. Dissertação (Mestrado Profissional) - Universidade Estadual de Campinas, Instituto de Matemática, Estatística e Computação Científica, Campinas, 2015.

FROTA, M. C. R. Experiência matemática e investigação matemática.

Disponível em:

$<$ http://www.matematica.pucminas.br/Eventos/artigos/Maria_Clara_Frota.pdf>. Acesso em 08 Set. de 2015. 
GRAVINA, M. A. Geometria Dinâmica: uma nova abordagem para o ensino de Geometria. In: Anais do VII Simpósio Brasileiro de Informática na Educação. Belo Horizonte, 1996, p. 1-13.

Os ambientes de geometria dinâmica e o pensamento hipotético dedutivo. 2001. 277 f. Tese (Doutorado em Informática na Educação) Universidade Federal do Rio Grande do Sul, Porto Alegre: UFRGS, 2001.

KENSKI, V. M. Educação e novas tecnologias: o novo ritmo da informação. Campinas: Papirus, 2007.

LABORDE, C. Robust and soft constructions: two sides of the use of dynamics Geometry environments. In: PROCEEDINGS OF THE TENTH ASIAN TECHNOLOGY CONFERENCE IN MATHEMATICS - Korea National University of Education, Cheong-Ju, South Korea, p. 22-35, 2005. Disponível em: <http://epatcm.any2any.us/EP/EP2005/2005P279/fullpaper.pdf>. Acesso em: 14 Jan de 2017.

LAGE, M. A; FROTA, M. C. R. Explorar e comunicar ideias sobre isometrias. Revista Vidya, Santa Maria, v. 31, n. 2, p. 73-90, jun-dez. 2011. ISSN 0104270X. Disponível em:

<http://www.periodicos.unifra.br/index.php/VIDYA/article/view/293>. Acesso em: 29 Set de 2016.

LAMONATO, M; PASSOS, C. L. B. Discutindo resolução de problemas e exploração-investigação matemática: reflexões para o ensino de matemática. Revista Zetetiké, Campinas, v. 19, n. 36, p. 51-74, jun. 2011. Disponível em: <https://www.fe.unicamp.br/revistas/ged/zetetike/article/download/.../3316>. Acesso em: 08 Set. 2015.

LEDERGERBER-RUOFF, E. B. Isometrias e ornamentos do plano euclidiano. São Paulo, Atual, 1982.

LIMA, T. R. C. de; MIRANDA, D. F. de. Investigações matemáticas na sala de aula: relatos de uma experiência. Disponível em: <http://edumat.ouropreto.ifmg.edu.br/wp-content/uploads/sites/7/2014/10/ investigacos_matematicas_em_salas_de_aula_RE.pdf >. Acesso em 08 set. de 2015. 
MABUCHI, S. T. Transformações geométricas: a trajetória de um conteúdo ainda não incorporado às práticas escolares nem à formação de professores. 2000. 259 f. Dissertação (Mestrado em Educação Matemática) Pontifícia Universidade Católica, São Paulo, 2000.

MARTIN, G. E. Transformation geometry: an introduction to symmetry. New York, Springer, 1982.

MEDEIROS, F. M. Geometria dinâmica no ensino de transformações do plano: uma experiência com professores da Educação Básica. 2012. 172 f. Dissertação (Mestrado Profissional em Ensino de Matemática) - Ensino de Matemática, Universidade Federal do Rio Grande do Sul, Porto Alegre, 2012.

MOISE, E. E. Elementos de geometria superior. Tradução: Sergio Vargas Romero. México, D. F.: Companhia Editorial Continental, 1968.

MORAN, M. As apreensões em geometria: um estudo com professores da Educação Básica acerca de registros figurais. 2015. 250 p. Tese (Doutorado em Educação para a Ciência e a Matemática) - Universidade Estadual de Maringá, Maringá, 2015.

MORETTI, M. T. Semiosfera do olhar: um espaço possível para a aprendizagem da geometria. Revista de Ensino de Ciências e Matemática, Canoas, v. 15, n. 2, p. 289-303, Mai/Ago. 2013. ISSN 2178-7727. Disponível em: < http://www.periodicos.ulbra.br/index.php/acta/article/view/568 >. Acesso em: 29 Set de 2016.

NASCIMENTO, A. A. S. B. Relações entre os conhecimentos, as atitudes e a confiança dos alunos do curso de licenciatura em matemática em resolução de problemas geométricos. 2008. 202 f. Dissertação (Mestrado em Educação para a Ciência) - Universidade Estadual Paulista, Bauru, 2008.

OLIVEIRA, G. P. Estratégias didáticas em Educação Matemática: as tecnologias de informação e comunicação como mediadoras. In: Anais do IV Seminário Internacional de Pesquisa em Educação Matemática. Brasília: SBEM, 2009.

ONUCHIC, L. de la R. Ensino-aprendizagem de matemática através de resolução de problemas. In: BICUDO, M. A. V. (Org.). Pesquisa em Educação Matemática: concepções e perspectivas. São Paulo: Unesp, 1999. 
; ALLEVATO, N. S. G. Novas reflexões sobre o ensino-aprendizagem de matemática através da resolução de problemas. In: BICUDO, M. A. V.; BORBA, M. C. (Orgs.). Educação Matemática: pesquisa em movimento. São Paulo: Cortez, 2004.

ORTIGÃO, M. I. R. Currículo de matemática e perfil social do aluno. In: MARANHÃO, C. (Org.). Educação Matemática nos anos finais do ensino fundamental e no ensino médio: pesquisas e perspectivas. São Paulo: Musa, 2009.

PEREIRA, R. L. Interpretação de textos matemáticos: dificuldades na Resolução de problemas de geometria plana. 2010. 154 f. Dissertação (Mestrado em Educação em Ciências e Matemáticas) - Universidade Federal do Pará, Belém, 2010.

PINHEIRO, J. L.; BARRETO, M. C. A teoria dos registros de representação semiótica: contribuições para a formação matemática de professores em ambientes virtuais. Jun. 2013. Disponível em:

<http://evidosol.textolivre.org/papers/2013/upload/58.pdf>. Acesso em 08 Set. de 2015.

POLYA, G. A arte de resolver problemas: um novo aspecto do método matemático; tradução: Heitor Lisboa de Araújo. Rio de Janeiro: Interciência, 1995.

PONTE, J. P.; BROCARDO, J.; OLIVEIRA, H. Investigações Matemáticas na Sala de Aula. Coleção Tendências em Educação Matemática. Belo Horizonte: Autêntica. 2003a.

PONTE, J.P. Investigação sobre investigações matemáticas em Portugal. Revista Investigar em Educação, Lisboa, v. 2, Gráfica 2000, p. 93-169, 2003b.

POZO, J. I. (Org.). A solução de problemas: aprender a resolver, resolver para aprender. Porto Alegre: Artmed, 1998.

ROMANATTO, M. C. Resolução de problemas nas aulas de matemática. Revista Eletrônica de Educação, São Carlos, v. 6, n. 1, p. 299-311, mai. 2012. ISSN 1982-7199. Disponível em: 
<http://www.reveduc.ufscar.br/index.php/reveduc/article/viewFile/413/178>. Acesso em: 08 Set. de 2015.

SILVA, G. H. G. O software geogebra e o trabalho com atividades investigativas na formação de professores. In: Anais do XI Encontro Nacional de Educação Matemática: XI ENEM. Curitiba: SBEM, 2013. p. 1-9.

SOARES, L. H. Aprendizagem significativa na educação matemática: uma proposta para a aprendizagem de geometria básica. 2009. 141 f. Dissertação (Mestrado em Educação) - Universidade Federal da Paraíba, João Pessoa, 2009.

TEMPERA, T.; SERRAZINA, M. de L.; LOUREIRO, C. A Geometria na formação inicial de professores: contributos para a caracterização do conhecimento dos estudantes. Atas do I Encontro de Mestrados em Educação da Escola Superior de Educação de Lisboa. Lisboa: CIED, 2013. p. 109-118. Disponível em:

<http://repositorio.ipl.pt/bitstream/10400.21/2717/1/A\%20geometria\%20na\%20f orma\%C3\%A7\%C3\%A30\%20inicial\%20de\%20professores.pdf>. Acesso em: 29 Set de 2016.

TORREGROSA, G.; QUESADA, H. Coordinación de procesos cognitivos en Geometría. Revista Latinoamericana de Investigación en Matemática Educativa, v. 10, n. 2, p. 275-300, mai. 2007. ISSN: 1665-2436. Disponível em: <http://www.clame.org.mx/relime.htm>. Acesso em: 16 Jun. de 2016.

VIANA, O. A.; BOIAGO, C. E. P. Registros de representação semiótica em atividades de desenho geométrico no GeoGebra. Revista Eletrônica de Educação Matemática, Florianópolis, v. 10, n. 1, p. 162-182, Dez. 2012. ISSN 1981-1322. Disponível em:

<https://periodicos.ufsc.br/index.php/revemat/article/view/19811322.2015v10n1p162>. Acesso em: 29 Set. 2016.

YAGLOM, I. M. Geometric transformations, Random House, New Mathematical Library, Washington, D.C, 1962. 


\section{Anexo A}

Definição A1: Um subconjunto não vazio $\mathcal{G}$ das transformações do plano é um subgrupo de $\mathcal{F}$ se são satisfeitas as seguintes condições:

a) se $F, G \in \mathcal{G}$ então $G \circ F \in \mathcal{G}$;

b) se $F \in \mathcal{G}$ então $F^{-1} \in \mathcal{G}$.

Teorema A1: O conjunto de todas as isometrias do plano é um subgrupo de $\mathcal{F}$.

Demonstração: Seja $\mathcal{J}$ o conjunto de todas as isometrias, temos que $l d \in \mathcal{J}$, logo J é não vazio. Sejam $F, G \in \mathcal{J}$, e seja $P, Q$ pontos distintos do plano. Temos P' $Q$ ' $=P Q$ e $P^{\prime \prime} Q^{\prime \prime}=P^{\prime} Q^{\prime}$, com $P^{\prime}=F(P), Q^{\prime}=F(Q), P^{\prime \prime}=G\left(P^{\prime}\right), Q^{\prime \prime}=G\left(Q^{\prime}\right)$. Então temos: $\mathrm{P} " \mathrm{Q}$ " = $\mathrm{PQ}$, com $\mathrm{P} "=G(F(\mathrm{P}))=(G \circ F)(\mathrm{P})$ e $\mathrm{Q} "=G(F(\mathrm{Q}))=(G \circ F)(\mathrm{Q})$. Portanto, $(G \circ F) \in \mathcal{J}$.

Falta mostrar que $F^{-1} \in \mathcal{J}$. Suponha que $F(P)=\mathrm{P}^{\prime}$ e $F(\mathrm{Q})=\mathrm{Q}^{\prime}$. Como $F^{-1}$ é a inversa de $F$, então $F^{-1}\left(\mathrm{P}^{\prime}\right)=\mathrm{P}$ e $F^{-1}\left(\mathrm{Q}^{\prime}\right)=\mathrm{Q}$.

Como $F \in \mathcal{J}$ segue que $\mathrm{P}^{\prime} \mathrm{Q}^{\prime}=\mathrm{PQ}$, $\log$ o $\mathrm{PQ}=\mathrm{P}^{\prime} \mathrm{Q}^{\prime}$ e $F^{-1} \in \mathcal{J}$, terminando a prova.

Definição A2: Sejam $A, B$ e $C$ três pontos distintos do plano e colineares. Utilizaremos a notação $A-B-C$ para indicar que o ponto $B$ está entre os pontos A e $C$. Essa notação também nos ajuda a perceber o seguinte resultado:

$$
A-B-C \Leftrightarrow A B+B C=A C .
$$

Introduzimos essas considerações apenas para tratar da próxima proposição, que nos garante que qualquer isometria preserva a colinearidade de pontos.

Proposição A1: Se $F$ é uma isometria do plano, então $F$ preserva a colinearidade de pontos.

Demonstração: Seja $F$ uma isometria e A, B e C pontos distintos do plano, colineares, $F(A)=A^{\prime}, F(B)=B^{\prime}$ e $F(C)=C^{\prime}$. Sendo $A^{\prime} B^{\prime}=A B$; $B^{\prime} C^{\prime}=B C$ e $A^{\prime} C^{\prime}$ $=A C$ segue que como $A B+B C=A C$ então $A^{\prime} B^{\prime}+B^{\prime} C^{\prime}=A^{\prime} C^{\prime}$, 
isto é, $A-B-C$ implica em $A^{\prime}-B^{\prime}-C^{\prime}$.

Note que, pela desigualdade triangular, a soma de quaisquer dois lados de um triângulo é sempre maior que a medida do terceiro lado. Poderíamos ter então

$$
A B+B C>A C \text { então } A^{\prime} B^{\prime}+B^{\prime} C^{\prime}>A^{\prime} C^{\prime} \text {. }
$$

Mas se isso fosse verdade, teríamos que $A, B$ e $C$ formariam um triângulo. Contrariando a hipótese de A, B e C serem colineares. Dessa forma, as distâncias $A^{\prime} B^{\prime}=A B ; B^{\prime} C^{\prime}=B C$ e $A^{\prime} C^{\prime}=A C$ são mantidas. Portanto $F$ preserva a colinearidade de pontos.

Outro resultado importante, que se faz necessário observar, é que as isometrias preservam triângulos.

Proposição A2: Toda isometria preserva triângulos.

Demonstração: Considere três pontos A, B e C não colineares do plano. Sendo F uma isometria, os pontos $F(A)=A^{\prime}, F(B)=B^{\prime}$ e $F(C)=C^{\prime}$ são também não colineares. Suponha, por absurdo, que fossem colineares. Desse modo teríamos, por exemplo, A' - B' - C', o que nos leva a escrever A'B' + B'C' = A'C'. Porém, de $A, B$ e $C$ serem não colineares, temos pela desigualdade triangular que $A B+B C>A C$. Mas como $F$ é isometria, deveríamos ter $A C=A^{\prime} C^{\prime}$, o que seria absurdo. Portanto, a aplicação F preserva triângulos.

Corolário A1: Toda isometria preserva ângulos.

Demonstração: Sendo $\triangle \mathrm{ABC}$ um triângulo qualquer e $F$ um isometria, temos, pela Proposição $\mathrm{A} 2$, que $F(\triangle \mathrm{ABC})=\Delta \mathrm{A}^{\prime} \mathrm{B}^{\prime} \mathrm{C}^{\prime}$. Pelo critério LLL de congruência de triângulos, teremos $\triangle \mathrm{ABC} \cong \triangle \mathrm{A}^{\prime} \mathrm{B}^{\prime} \mathrm{C}^{\prime}$, logo, os ângulos do triângulo $\triangle \mathrm{ABC}$ são congruentes aos respectivos ângulos do triângulo $\Delta \mathrm{A}^{\prime} \mathrm{B}^{\prime} \mathrm{C}$ '.

Proposição A3: Se uma isometria do plano fixa dois pontos distintos de uma reta, então ela fixa ponto a ponto essa reta.

Demonstração: Seja $F$ uma isometria do plano. Considere A e B pontos distintos do plano tais que $F(A)=A, F(B)=B$. Queremos mostrar que $F(P)=P$, para todo $\mathrm{P} \in \overleftrightarrow{\mathrm{AB}}$. Considere $\mathrm{P} \in \overleftrightarrow{\mathrm{AB}}$ tal que $\mathrm{P} \neq \mathrm{A}$ e $\mathrm{P} \neq \mathrm{B}$. Seja $F(\mathrm{P})=\mathrm{P}^{\prime}$. Como $F$ 
preserva a colinearidade, pela Proposição $A 1$, temos que $P^{\prime} \in \overleftrightarrow{A B}$ e $A P^{\prime}=A P$, $\mathrm{BP}^{\prime}=\mathrm{BP}$. Logo, $\mathrm{P}^{\prime}=\mathrm{P}$, pois em $\overleftrightarrow{\mathrm{AB}}$ existem somente dois pontos cuja distância para A é AP: o ponto $P$ e um outro ponto na semirreta oposta de $\overrightarrow{A P}$. Mas conhecemos a distância $\mathrm{BP}$ ao ponto $\mathrm{B}$, então, o ponto $\mathrm{P}$ é único.

Vamos agora enunciar dois postulados e um famoso teorema da Geometria Plana que vão nos ajudar a demonstrar o Lema A1 a seguir.

Postulado A1: Postulado da Separação do Plano - Dados uma reta r em um plano, o conjunto de todos os pontos do plano que não estão em $r$ é a união de dois conjuntos convexos, chamados semi-planos, satisfazendo a seguinte condição: se um ponto $P$ pertence a um dos semi-planos e um ponto $Q$ pertence ao outro semi-plano, então $\overline{P Q}$ intersecta $r$.

Postulado A2: Postulado de Pasch - Sejam uma reta $r$ e um triângulo $A B C$ coplanares. Se $r$ intersecta $\overline{A B}$ em algum ponto diferente de $A$ e $B$, então $r$ intersecta também um dos outros dois lados do triângulo.

Teorema A2: Teorema da Barra Transversal-Sejam A, B, C e D quatros pontos no mesmo plano, tais que $D$ esteja no interior do $\Varangle B A C$, então $\overrightarrow{A D}$ intersecta $\overline{B C}$. Em um ponto $F$ tal que $B-F-C$.

A figura a seguir ilustra o teorema:

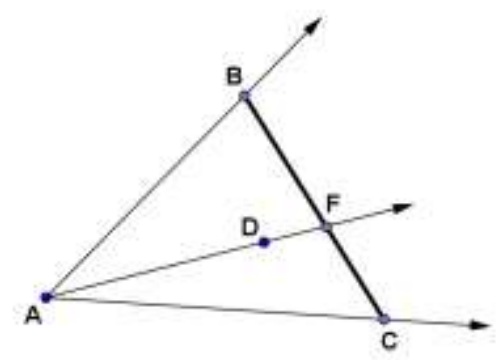

Figura 128: llustração do Teorema A2 Fonte: Autor.

Uma demonstração deste resultado pode ser vista em (MOISE, 1968, p. 100). 
Lema A1: Todo ponto $P$ do plano pertence a uma reta que intersecta o $\triangle A B C$ em dois pontos distintos.

Demonstração: Podemos considerar dois casos:

1ำ caso: $P$ é interno ao $\triangle \mathrm{ABC}$.

Pelo Teorema A2 e pelo fato de uma reta ser determinada por dois pontos distintos, é suficiente considerarmos uma reta passando por $\mathrm{P}$ e por qualquer um dos vértices do triângulo.

$2^{\circ}$ caso: $\mathrm{P}$ é externo ao $\triangle \mathrm{ABC}$.

Considere um ponto $\mathrm{D}$ interno ao $\triangle \mathrm{ABC}$. Segue do Postulado $\mathrm{A} 1$ que $\overleftrightarrow{\mathrm{PD}}$ intersecta um dos lados de $\triangle \mathrm{ABC}$. Como $\mathrm{P}$ e $\mathrm{D}$ são diferentes de $\mathrm{A}, \mathrm{B}$ e $\mathrm{C}$ por hipótese, segue do Postulado $\mathrm{A} 2$ que $\overleftrightarrow{\mathrm{PD}}$ intersecta $\triangle \mathrm{ABC}$ em dois pontos distintos.

Teorema A3: Se uma isometria do plano fixa três pontos não colineares, então ela é a transformação identidade.

Demonstração: Seja $F$ uma isometria do plano e $A, B, C$ três pontos não colineares e distintos do plano tais que $F(A)=A, F(B)=B$ e $F(C)=C$. Pela Proposição $A 3$, temos que $F$ fixa ponto a ponto cada uma das retas $\overleftrightarrow{\mathrm{AB}}, \overleftrightarrow{\mathrm{BC}}, \overleftrightarrow{\mathrm{CA}}$. Pelo Lema $A 1$, segue que $P$ pertence a uma reta que contêm dois pontos distintos fixos por $F$. Novamente pela proposição anterior temos: $F(\mathrm{P})=\mathrm{P}$ e como $P$ é arbitrário segue que $F=l d$.

Teorema A4: Sendo $F e G$ duas isometrias e $A, B$ e $C$ três pontos não colineares do plano, tais que $F(A)=G(A), F(B)=G(B)$ e $F(C)=G(C)$, então $F=G$.

Demonstração: Pelo Teorema $A 1$ vemos que $G^{-1} \circ F$ é uma isometria do plano, Mas, $\left(G^{-1} \circ F\right)(A)=G^{-1}(F(A))=G^{-1}(G(A))=\left(G^{-1} \circ G\right)(A)=I d(A)=A$.

Analogamente, $\left(G^{-1} \circ F\right)(B)=B$ e $\left(G^{-1} \circ F\right)(C)=C$. Segue do Teorema A3 que

$$
\left(G^{-1} \circ F\right)=I d \text {, ou seja, } F=G .
$$




\section{Anexo B}

\section{TERMO DE CONSENTIMENTO LIVRE E ESCLARECIDO}

Concordo em participar, como voluntário(a), da pesquisa intitulada Investigação Matemática em uma Disciplina de Geometria: reflexões por retas e GeoGebra, que tem como pesquisador responsável Herbert Wesley Azevedo, estudante do Instituto de Matemática e Estatística da Universidade de São Paulo, orientado pela Profa. Dra. Rosa Maria dos Santos Barreiro Chaves, que podem ser contatados pelos e-mails herbertwesley@hotmail.com e rosab@ime.usp.br ou pelo telefone (+55 11) 30916277.

O presente trabalho tem por objetivos:

- $\quad$ Estudar as concepções dos professores de Matemática a respeito do conceito de isometria, processos de prova e da própria matemática;

- Elaborar diretrizes para um curso de formação contínua para professores de Matemática a respeito dos temas estudados.

Minha participação consistirá em:

Ceder entrevistas, que poderão ser gravadas e transcritas para compor a dissertação de mestrado resultante da pesquisa;

Ceder material de sala de aula que possa ilustrar minha prática docente, tais como cadernos, fichas, listas de atividades, entre outros.

Compreendo que esse estudo possui finalidade de pesquisa, e que os dados obtidos serão divulgados seguindo as diretrizes éticas da pesquisa, assegurando, assim, minha privacidade. Sei que posso retirar meu consentimento quando eu quiser, e que não receberei nenhum pagamento por essa participação.

São Paulo, de de 2016.

Nome (legível):

Assinatura: 


\section{Anexo C}

\section{Parte 1}

Nome:

Semestre:

Definição 1: A reflexão em relação a uma reta $m$ é uma aplicação que associa a cada ponto $\mathrm{P}$ do plano, $\mathrm{P}$ não pertencente à $m$, o ponto $\mathrm{P}^{\prime}$, tal que $m$ é a reta mediatriz do segmento $\overline{\mathrm{PP}^{\prime}}$ e que fixa os pontos de $m$.

Exemplo:

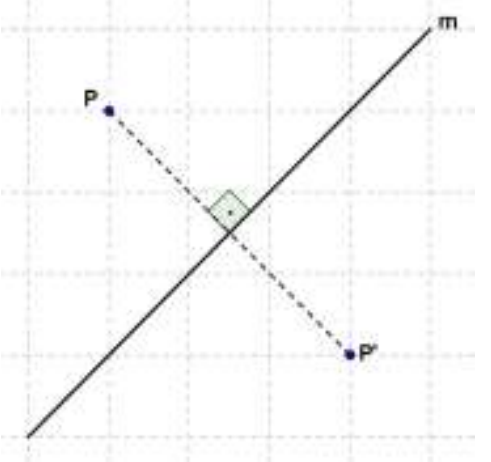

Figura 1

Atividade 1. Faça as reflexões dos pontos $A, B, C, D, E, F$ e G em relação à reta $\mathrm{m}$, conforme figura abaixo:

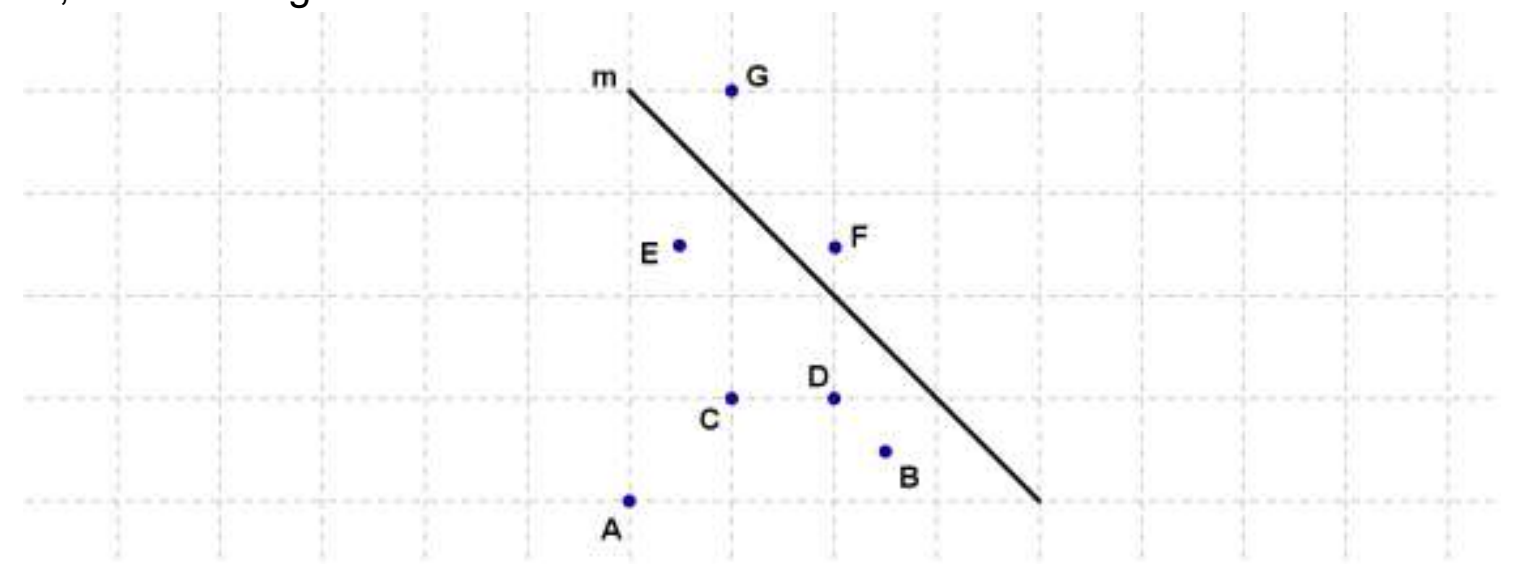

Figura 2 
Definição 2: Sejam $A, B$ e $C$ três pontos colineares distintos. Diremos que $o$ ponto $C$ está entre os pontos $A$ e $B$ se for satisfeita a seguinte condição: $A C+$ $C B=A B$. Usualmente esta relação é indicada por $A-C-B$.

Atividade 2. É razoável supor que, em todas as reflexões em relação a retas, as distâncias entre dois pontos dados e as de suas respectivas imagens são preservadas? Vale o mesmo para a relação de "estar entre"? Justifique.

Definição 3: Seja $F$ uma transformação do plano. $F$ é uma isometria se, para dois pontos distintos $P$ e $Q$ do plano com $P^{\prime}=F(P)$ e $Q^{\prime}=F(Q)$, tivermos $P Q=$ $P^{\prime} Q$ ', ou seja, a distância de $P$ à $Q$ é igual à distância de $P$ ' à $Q$ '.

Atividade 3. Dada uma reta $m$ no plano, prove que a reflexão por $m$ é uma isometria. Utilize o quadro abaixo para sua demonstração. (Proposição 1)

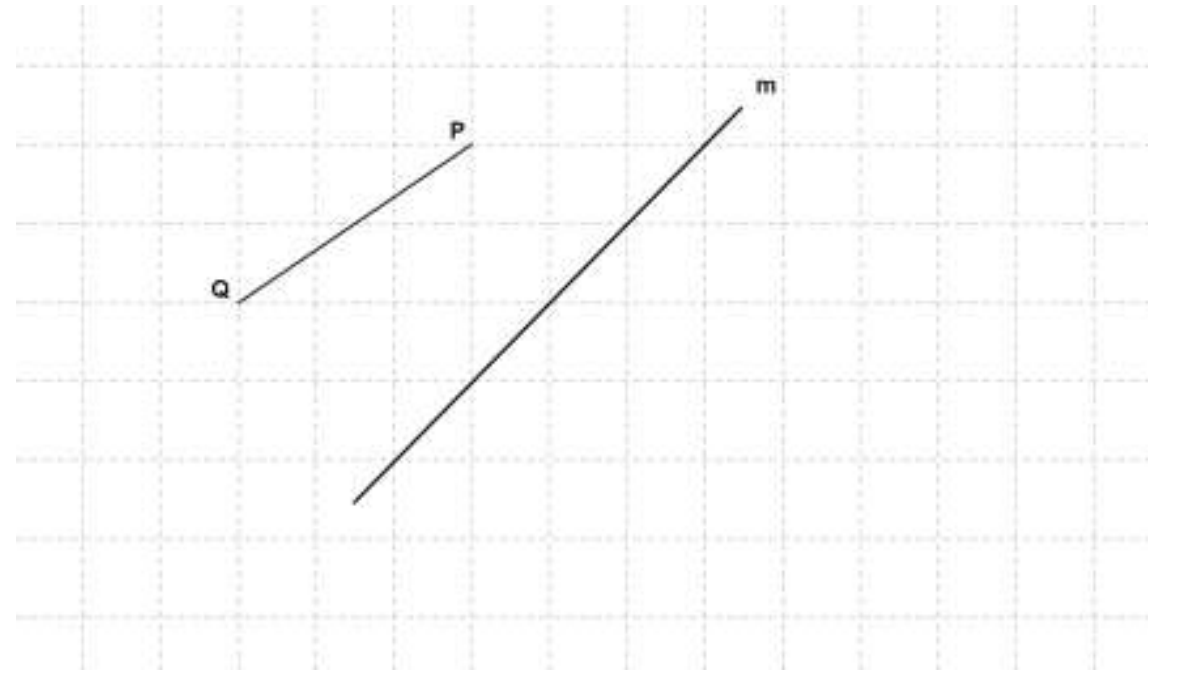

Figura 3 
Atividade 4. Apresente possíveis reflexões de uma circunferência (de raio qualquer) em relação à uma reta $m$ dada.

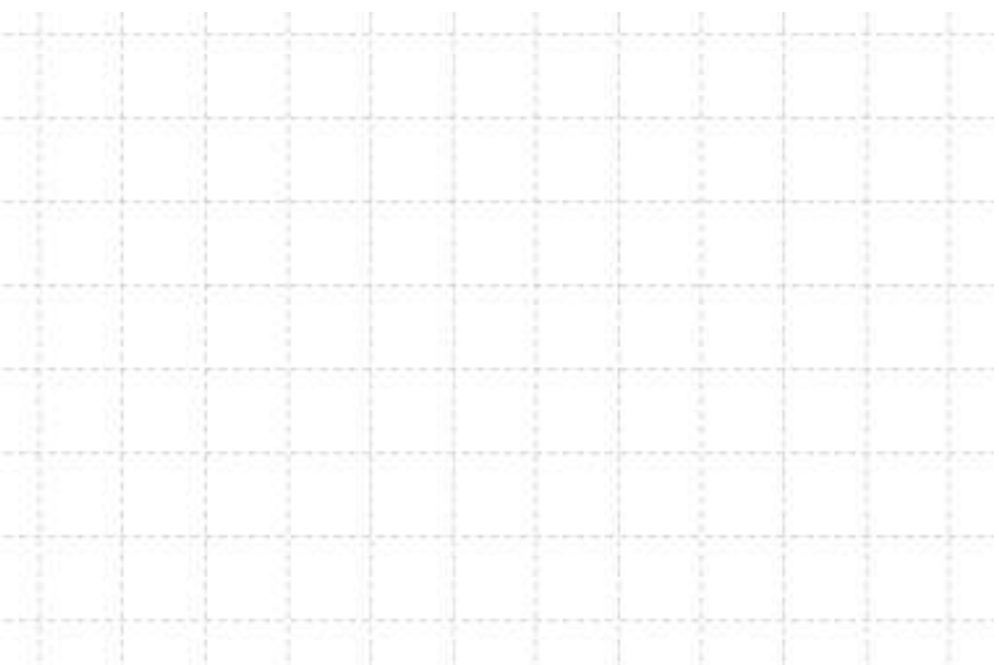

Figura 4

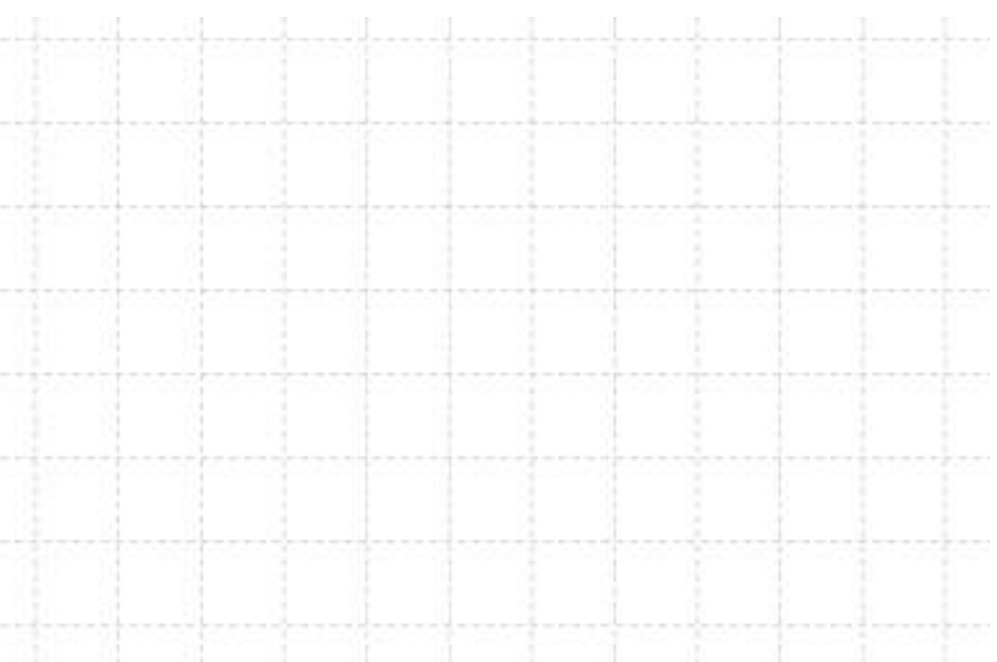

Figura 5

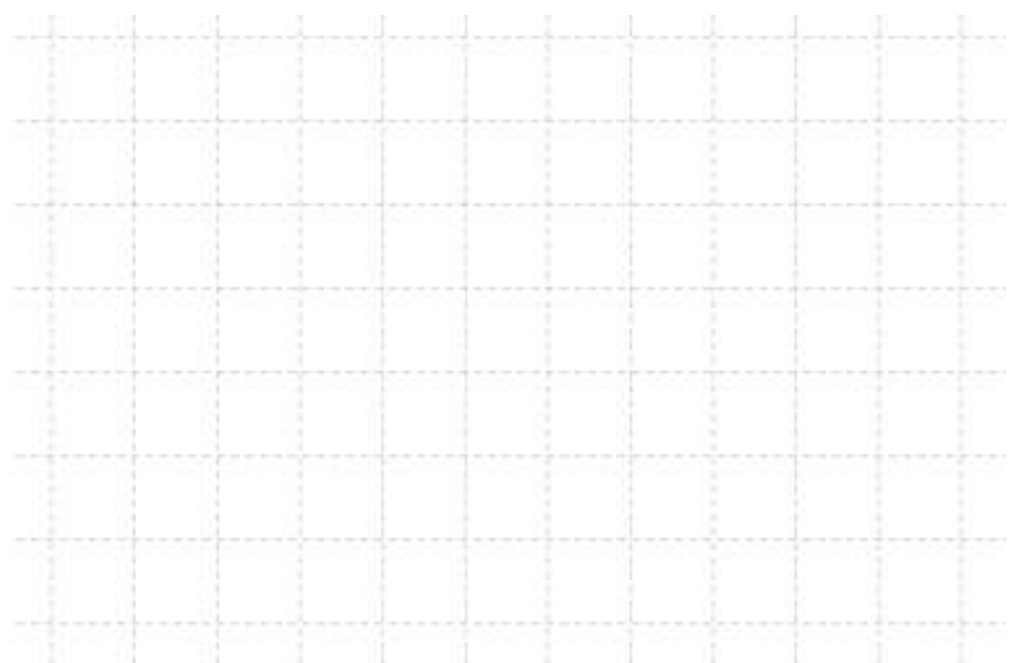

Figura 6 
Atividade 5. Para resolver o problema apresentado no item b), considere o resultado do item a) a seguir:

a) Sejam $S_{1}$ e $S_{2}$ duas circunferências em semi-planos opostos de uma reta $m$. Considere $S_{1}$ ' a reflexão de $S_{1}$ pela reflexão em relação à $m$. $O$ que podemos dizer sobre o número de intersecções entre $\mathrm{S}_{2}$ e $\mathrm{S}_{1}$ '?

b) Sejam $S_{1}$ e $S_{2}$ duas circunferências em semi-planos opostos de uma reta $m$. Construir um quadrado $A B C D$ que tenha dois vértices opostos $B$ e $D$ em $m$, o vértice $A$ em $S_{1}$ e o vértice $C$ em $S_{2}$.

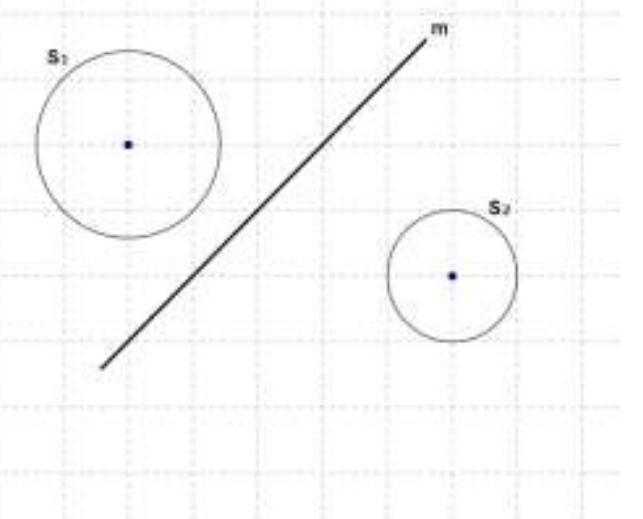

Figura 7

Descrição da Construção:

Justificativa:

Discussão: 
Atividade 6. Para resolver o problema apresentado no item c), considere as construções dos itens a) e b), a seguir:

a) Dada uma reta $m$ e um ponto B não pertencente à $m$, construir uma circunferência com centro em $B$ e tangente à reta $m$.

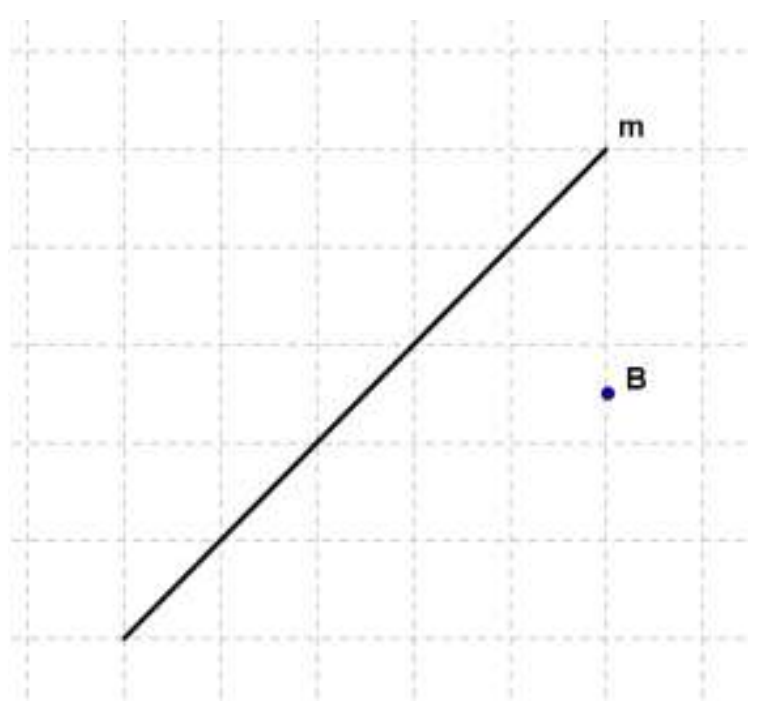

Figura 8

b) Sejam A e B dois pontos, cada um em um semi-plano determinado por uma reta $m$. Seja $S_{1}$ a circunferência de centro em $\mathrm{B}$ e tangente à $m$ no ponto $\mathrm{E}$. Construa as retas tangentes a $S_{1}$ e que passam por $A$.

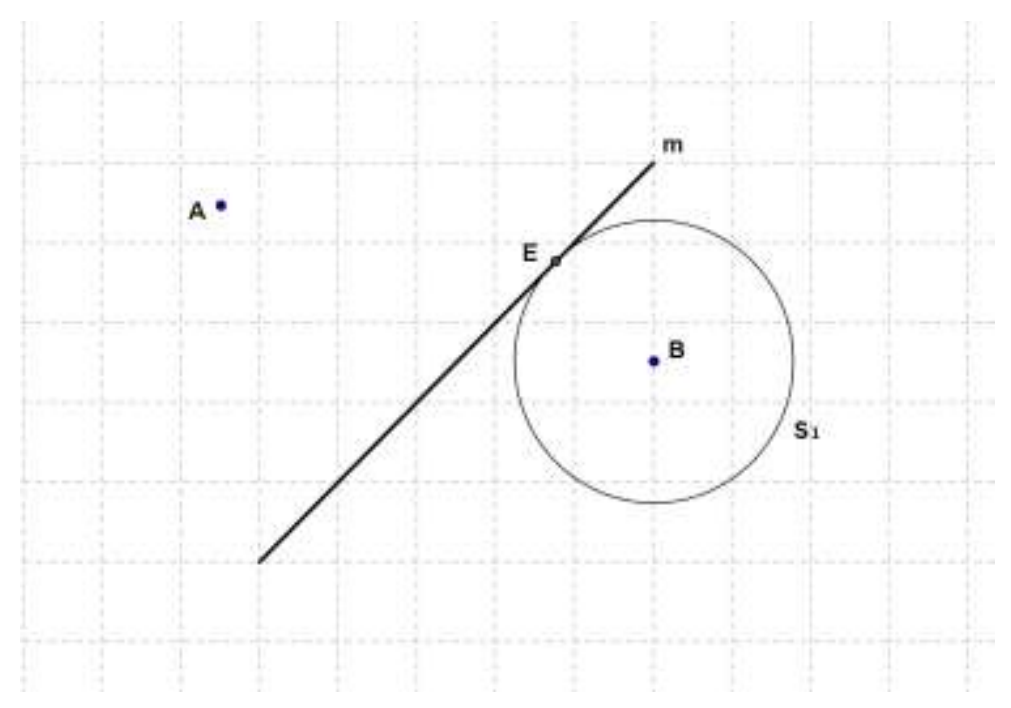

Figura 9 
c) Com o auxílio dos itens anteriores resolva: dados dois pontos distintos $\mathrm{A}$ e $\mathrm{B}$ em um mesmo lado de uma reta $\overleftrightarrow{\mathrm{CD}}$, encontrar um ponto $X \in \overleftrightarrow{\mathrm{CD}}$, de modo que a medida de $A \widehat{X} C$ seja o dobro da medida de $B \widehat{X} \mathrm{D}$.

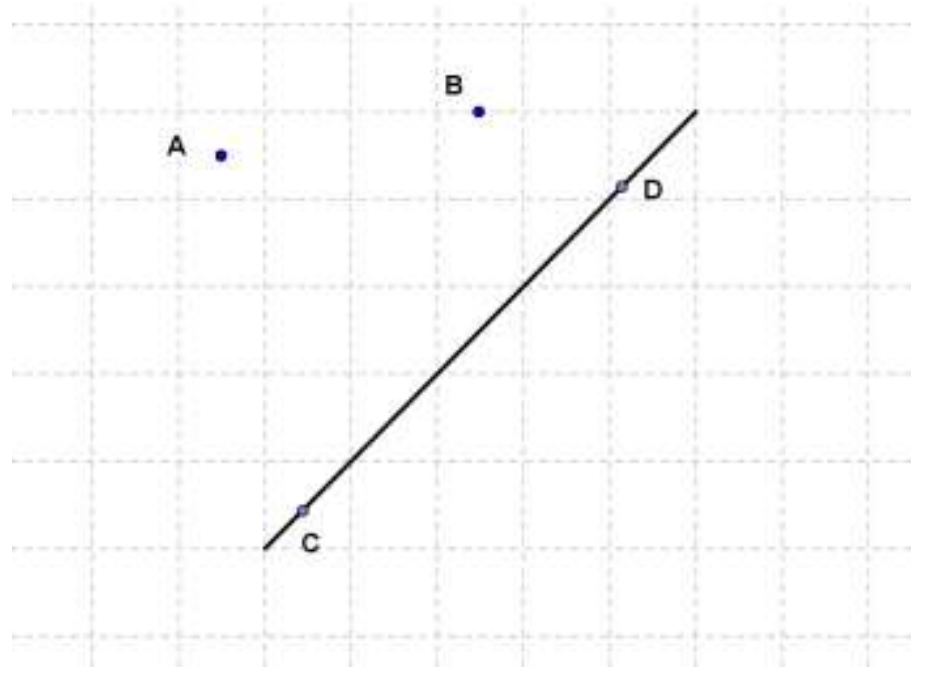

Figura 10

Descrição da Construção:

Justificativa:

Discussão: 


\section{Parte 2}

Atividade 1. Faça a reflexão composta do ponto $P$, começando pela reta $r$ e depois pela reta $\mathrm{s}$, sendo $\mathrm{r} / / \mathrm{s}$. (Teorema 1)

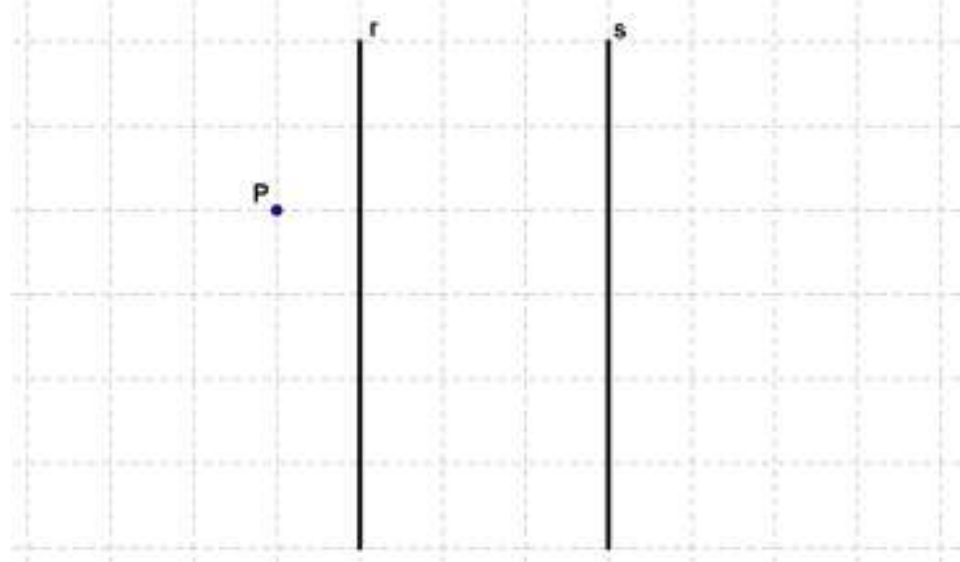

Figura 1

Atividade 2. Faça o mesmo processo para o segmento $\overline{\mathrm{PQ}}$ abaixo, novamente com r//s. (Teorema 1 )

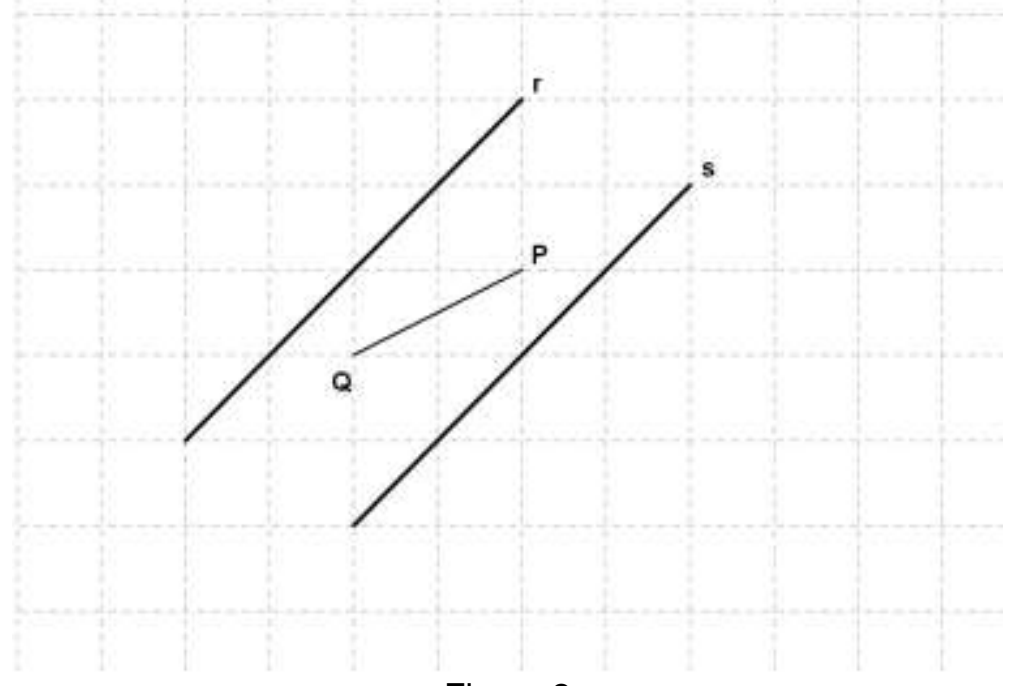

Figura 2

Para indicar a reflexão em relação a uma reta $r$, vamos adotar a seguinte notação: $R_{r}$. Ou seja, quando escrevemos $R_{r}(A)=A^{\prime}$ significa que $A^{\prime}$ é a imagem de $A$ pela reflexão em relação à reta $r$. Assim, por exemplo, na atividade 1 acima foi feito:

$$
\begin{aligned}
& R_{r}(P)=P^{\prime} \\
& R_{s}\left(P^{\prime}\right)=P^{\prime \prime}
\end{aligned}
$$

Este último resultado pode ainda ser resumido da seguinte forma: $R_{s} \circ R_{r}(P)=$ $P^{\prime \prime}$ 
Atividade 3. A composta das duas reflexões acima, em relação a duas retas paralelas, é igual a qual outra transformação do plano? (Teorema 1)

Atividade 4. Enuncie o resultado para a composta das reflexões $R_{s} \circ R_{r}$, sendo re s retas paralelas. (Teorema 1 )

Atividade 5. Faça a reflexão composta do segmento $\overline{\mathrm{PQ}}$, começando pela reta $r$ e depois pela reta s, no caso, com as retas r e s perpendiculares. (Corolário 1)

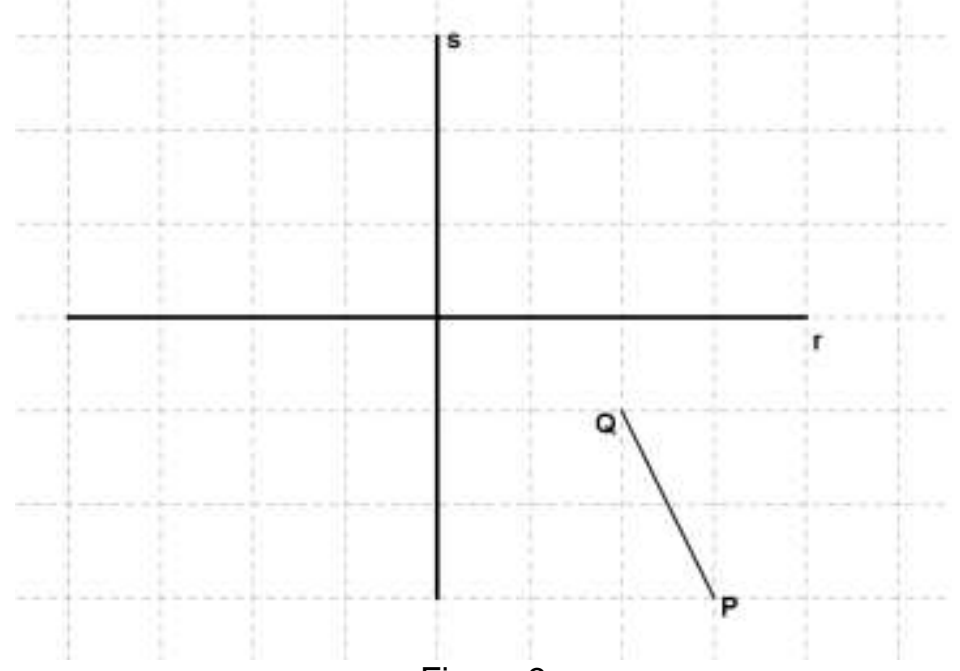

Figura 3

Atividade 6. A composta das duas reflexões acima é igual a qual outra transformação do plano? (Corolário 1) 
Atividade 7. Faça a reflexão composta $R_{s} \circ R_{r}(P)$ no quadro abaixo, com as retas $r$ e s concorrentes. Neste caso, a composta $R_{s} \circ R_{r}$ é igual a qual outra transformação do plano? (Teorema 3)

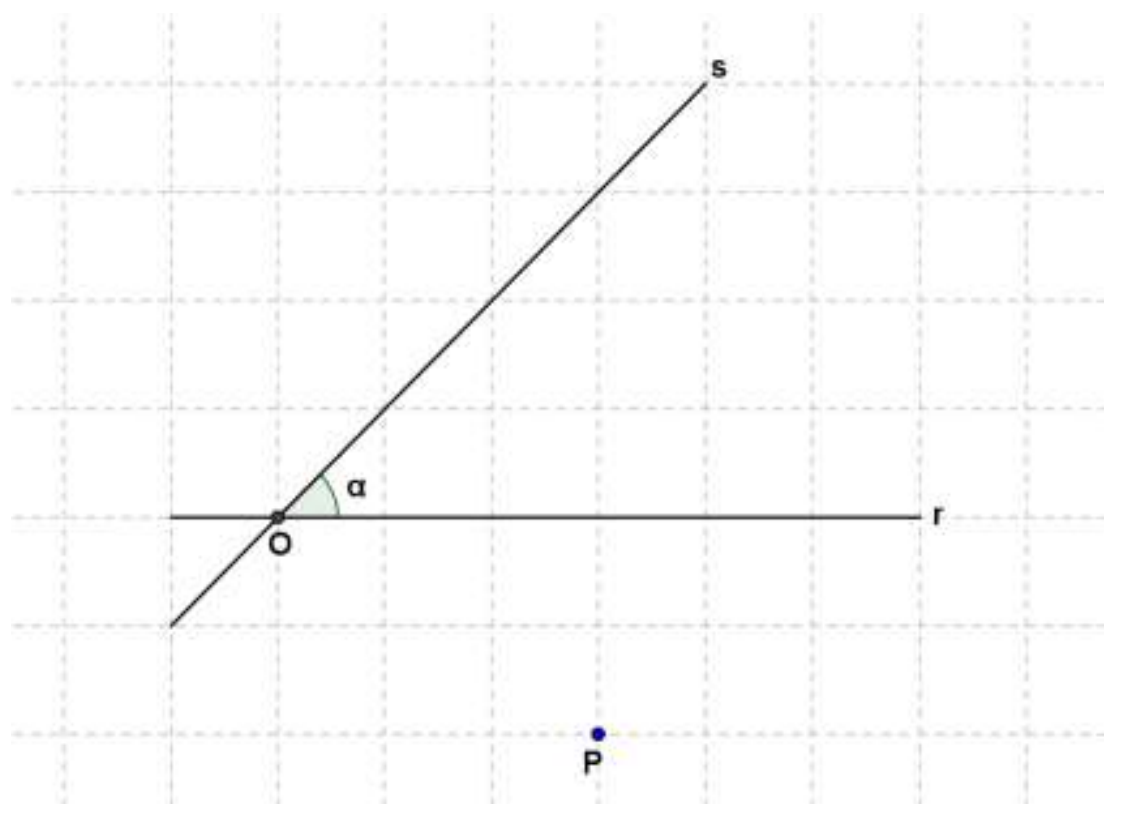

Figura 4

Atividade 8. A composta das reflexões $R_{t} \circ R_{s} \circ R_{r}$ é igual a alguma transformação geométrica? (Definição 12)

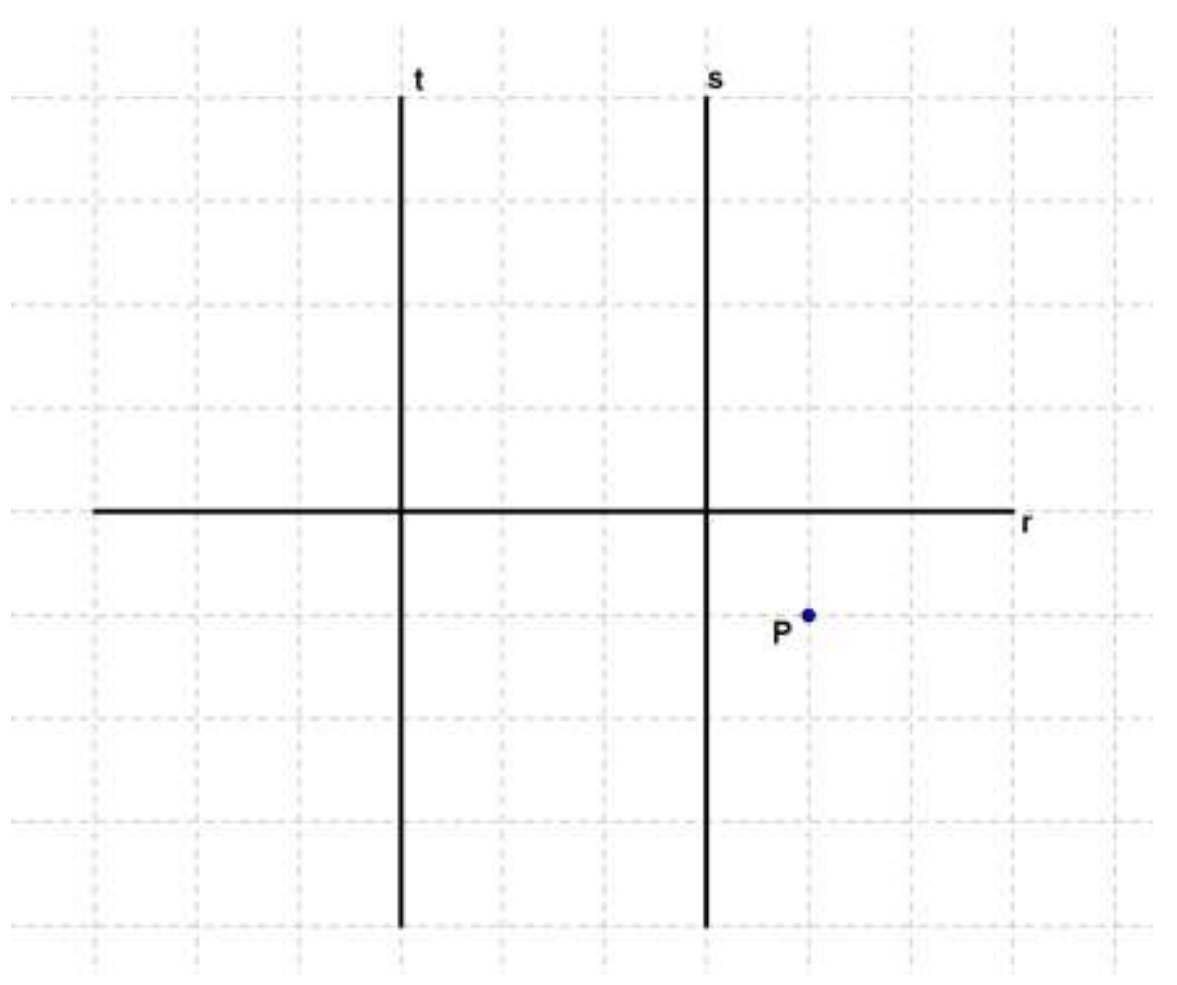

Figura 5 
Atividade 9. $\mathrm{Na}$ atividade anterior identifique se existem postos fixos ou retas fixas.

Atividade 10: A composta das reflexões $\mathrm{R}_{t} \circ \mathrm{R}_{s} \circ \mathrm{R}_{\mathrm{r}}$, onde $r$, s e $t$ são três retas concorrentes, resulta em qual transformação do plano? (Teorema 4 e Proposição 4)

Figura 6

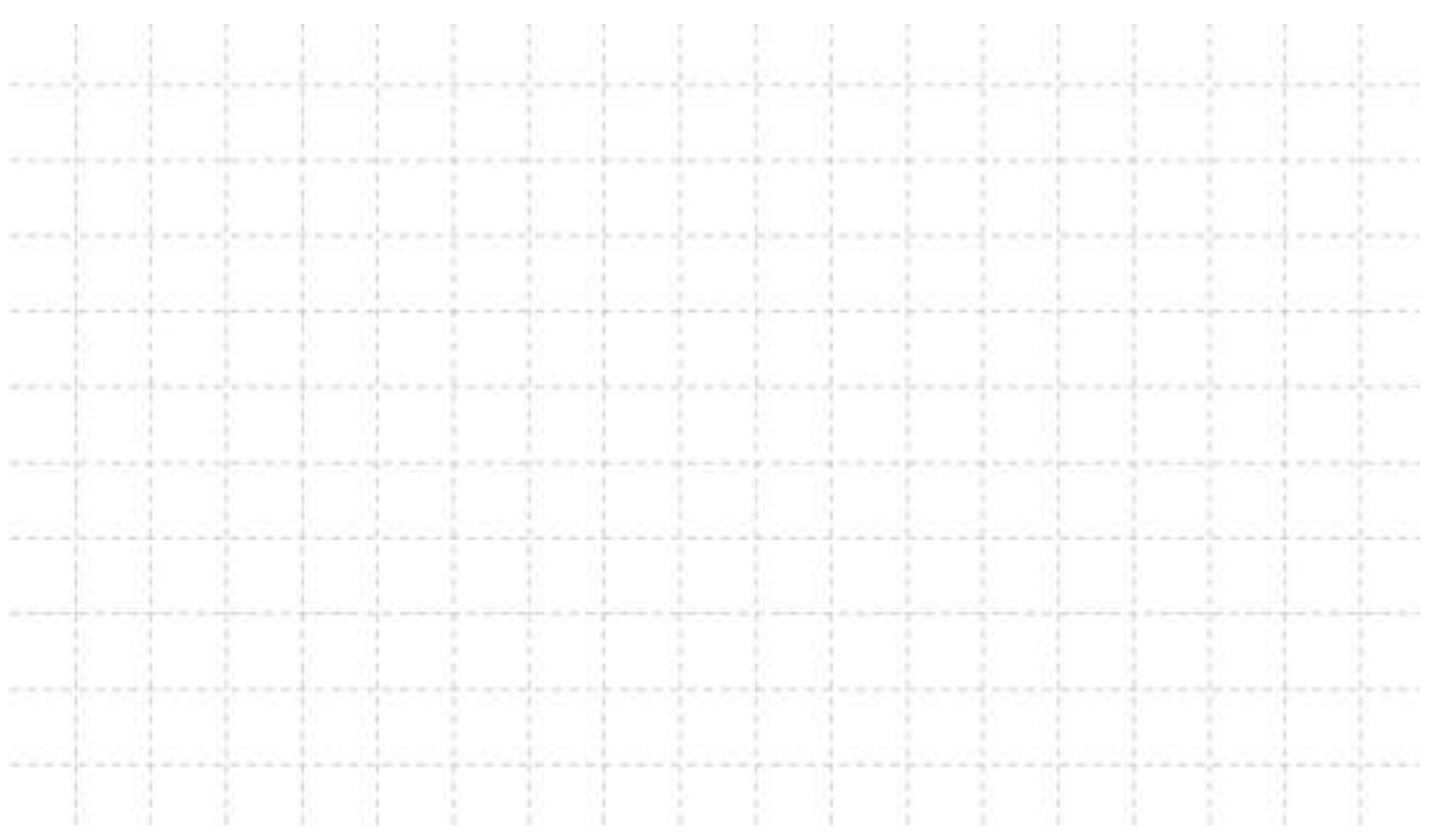

Figura 7 
Definição 1: Uma reta $r$ do plano é chamada de eixo de simetria de uma figura $F$ se a reflexão de $F$ por $r$ deixa essa figura invariante, isto é, $R_{r}(F)=F$.

Atividade 11. Identifique dentre as gravuras de M. C. Escher abaixo qual possui eixos de simetria.

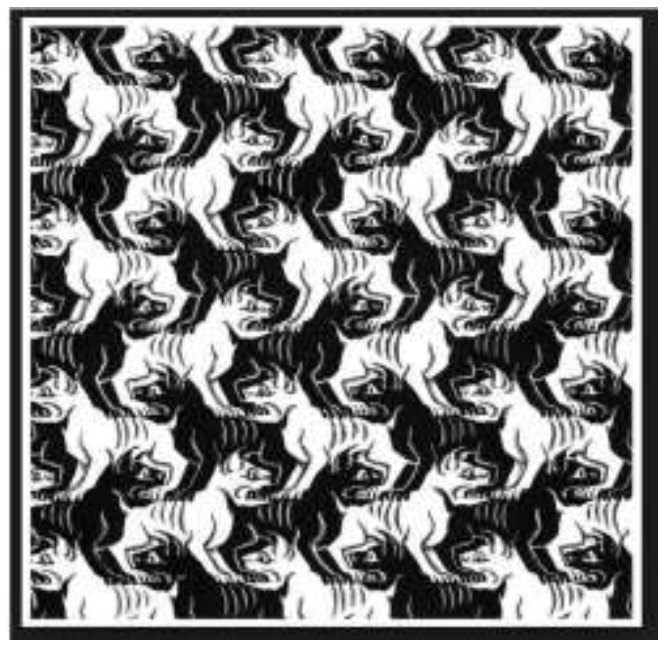

Figura 8

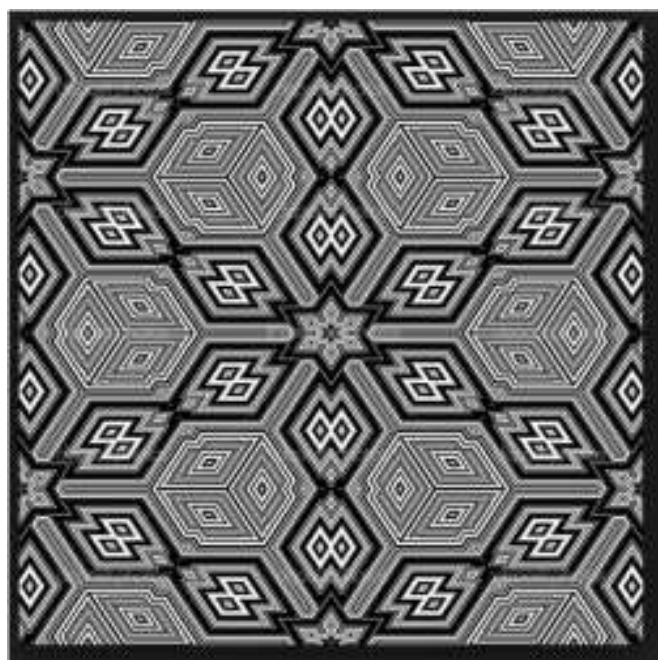

Figura 10

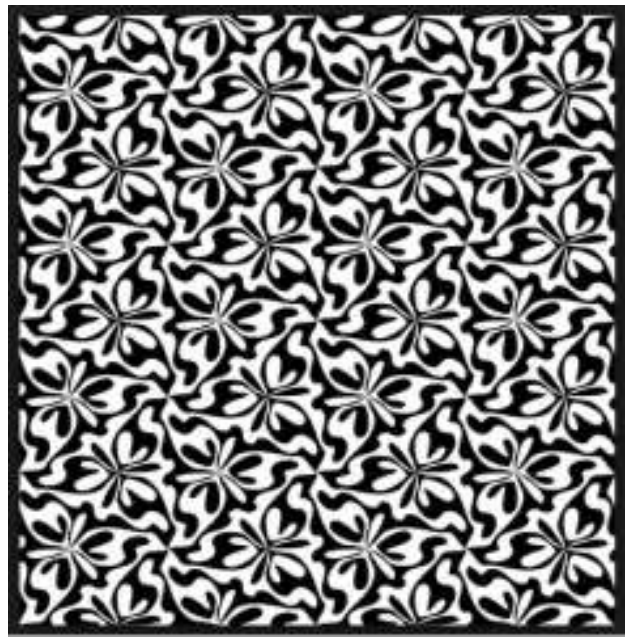

Figura 9

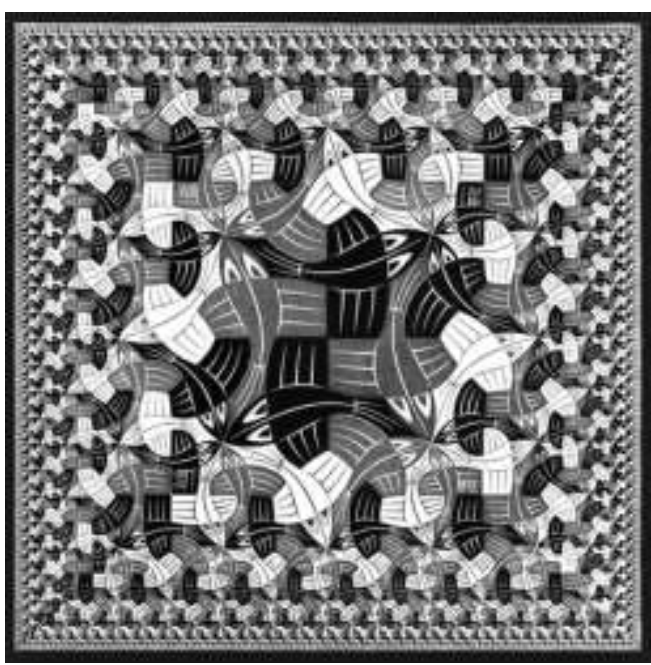

Figura 11 
Atividade 12. Na gravura abaixo existe alguma figura mínima que, se refletirmos algumas vezes, conseguimos reproduzir a gravura original? Em caso afirmativo, identifique-a

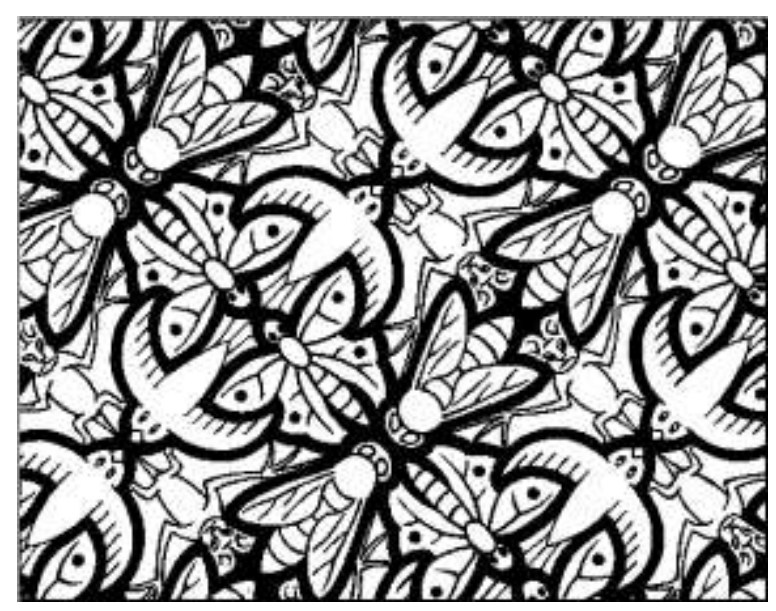

Figura 12

Fonte: https://artnme.wordpress.com/2007/04/24/mc-escher/

Atividade 13. Obtemos o gráfico da função $g(x)=\sqrt{x}$ através da reflexão do gráfico da função $f(x)=x^{2}$ por uma reta, $\operatorname{com} x \geq 0$. Desenhe essa reta no mesmo plano cartesiano abaixo e obtenha a sua equação.

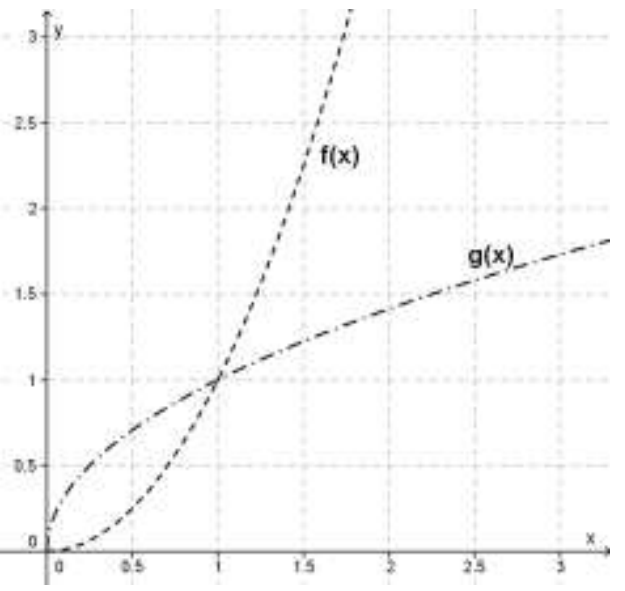

Figura 13 